Fachbereich 08 - Biologie und Chemie - der Justus-Liebig-Universität Gießen

Institut für Tierphysiologie

\title{
Hypoxie-induzierte Freisetzung reaktiver Sauerstoffspezies (ROS) in isoliert perfundierten und ventilierten Mauslungen
}

Inaugural-Dissertation zur Erlangung des Doktorgrades der Naturwissenschaften (Dr. rer. nat.)

Angefertigt im Lungenzentrum der Universität Gießen (University of Giessen Lung Center, UGLC) Medizinische Klinik II/V, 35392 Gießen

Vorgelegt von Rolf Ulrich Schäfer aus Bühl 


\section{Erstgutachter:}

Prof. Dr. rer. nat. Wolfgang Clauss

Justus-Liebig-Universität Gießen

Institut für Tierphysiologie

Wartweg 95

35392 Gießen

Zweitgutachter:

Prof. Dr. rer. nat. Norbert Weißmann

Lungenzentrum der Universität Gießen (University of Giessen Lung

Center, UGLC)

Medizinische Klinik II/V

Klinikstr. 36

35392 Gießen

Tag der Prüfung: 23. 11. 2007 


\section{Für meine Familie}

\section{Im Andenken an Manfred Schäfer}




\section{Teile dieser Doktorarbeit wurden veröffentlicht in:}

Weissmann, N., Kuzkaya, N., Fuchs, B., Tiyerili, V., Schäfer, R. U., Schütte, H., Ghofrani, H. A., Schermuly, R. T., Schudt, C., Sydykov, A., Egemnazarow, B., Seeger, W., and Grimminger, F., 2005, Detection of reactive oxygen species in isolated, perfused lungs by electron spin resonance spectroscopy, Respir Res 6(1):86.

Weissmann, N., Zeller, S., Schäfer, R. U., Turowski, C., Ay, M., Quanz, K., Ghofrani, H. A., Schermuly, R. T., Fink, L., Seeger, W., and Grimminger, F., 2006, Impact of mitochondria and NADPH oxidases on acute and sustained hypoxic pulmonary vasoconstriction, Am J Respir Cell Mol Biol 34(4):505-13.

\section{Abstracts}

Schäfer, R. U.; Schermuly, R. T.; Ghofrani, H. A.; Seeger, W.; Harrison, D. G.; Grimminger, F.; Weißmann, N., 2007, Hypoxie-induzierte Freisetzung reaktiver Sauerstoffspezies (ROS) in isoliert perfundierten und ventilierten Mauslungen. Pneumologie; Heft 01, 61.

Schäfer, R. U.; Schermuly, R. T.; Ghofrani, H. A.; Seeger, W.; Harrison, D. G.; Grimminger, F.; Weißmann, N., 2007, Hypoxie-induced formation of reactive oxygen species (ROS) in isolated perfused and ventilated mouse lungs. Free Radical Biology and Medicine; 41, Suppl. 1.

Schäfer R.U., Schermuly R.T., Ghofrani, H.A., Seeger, W., Grimminger, F., Weißmann, N. 2006, Hypoxie-induzierte Freisetzung reaktiver Sauerstoffspezies (ROS) in isoliert perfundierten und ventilierten Mauslungen. Pneumologie; Heft S1, 60.

Rolf U. Schäfer, Ralph T. Schermuly, Hossein A. Ghofrani, Werner Seeger, Friedrich Grimminger and Norbert Weissmann, 2005, Hypoxia-induced formation of reactive oxygen species (ROS) in isolated perfused and ventilated mouse lungs. Free Radical Biology and Medicine; 39, Suppl. 1.

Schäfer R.U., Schermuly R.T., Ghofrani, H.A., Seeger, W., Grimminger, F., Weißmann, N. 2005, Etablierung einer Technik zur Quantifizierung von Superoxid an isoliert perfundierten Mauslungen mittels Elektronenspinresonanz-Spektroskopie. Pneumologie; Heft 1, 59.

\section{Vorträge und Poster}

März 2006:

$4^{\text {th }}$ Lung Science \& International Consensus Conference of the European Respiratory Society (ERS), Taormina

September 2006: $\quad 16^{\text {th }}$ Annual Congress of the European Respiratory Society (ERS), München

\section{Preise und Auszeichnungen}

Best-Poster-Presentation, $4^{\text {th }}$ Lung Science \& International Consensus Conference of the European Respiratory Society (ERS), Taormina 


\section{Inhaltsverzeichnis}

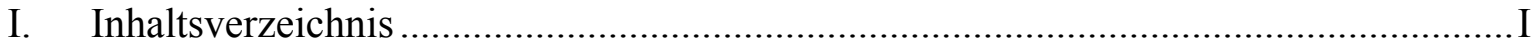

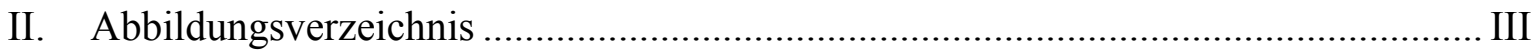

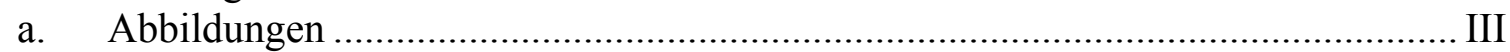

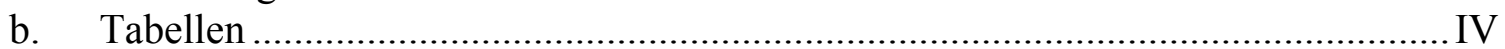

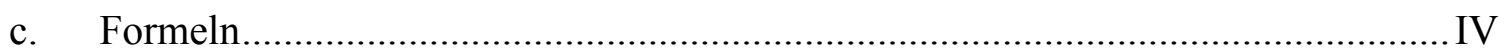

III. Abkürzungsverzeichnis ........................................................................... VI

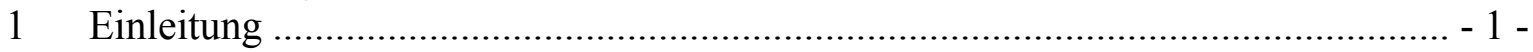

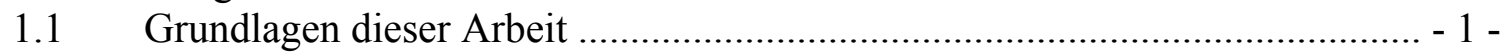

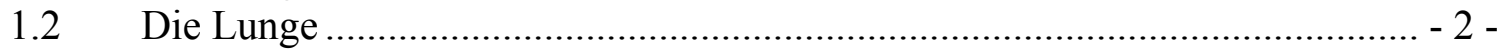

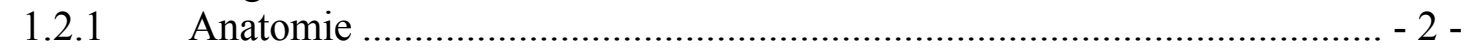

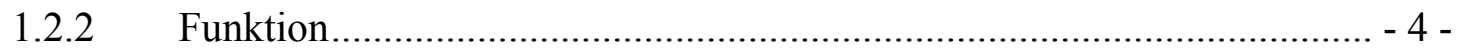

1.2.3 Hypoxische pulmonale Vasokonstriktion................................................ - 6 -

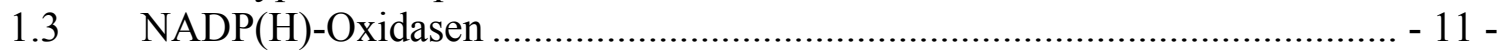

1.3.1 Aufbau und Funktion........................................................................ - 12 -

1.4 Reaktive Sauerstoffspezies .................................................................. - 16 -

1.5 Elektronenspinresonanz Spektroskopie .................................................... - 19 -

1.5.1 Physikalische Grundlagen ............................................................. - 20 -

1.5.1.1 Elektronenspin im äußeren Magnetfeld.......................................... - 20 -

1.5.1.2 Hyperfeinwechselwirkung ............................................................. 23 -

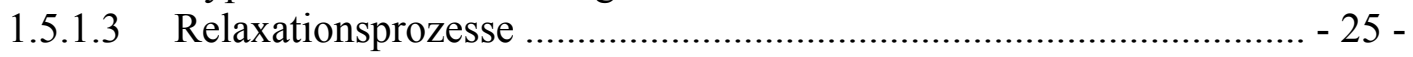

1.5.2 Apparative Grundlagen................................................................... - 26 -

1.5.2.1 Magnetsystem .................................................................................. 26 - 26 -

1.5.2.2 Mikrowellenbrücke................................................................. - 27 -

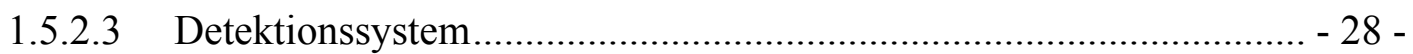

1.5.3 Spin-Labels und Spin-Traps .......................................................... - 29 -

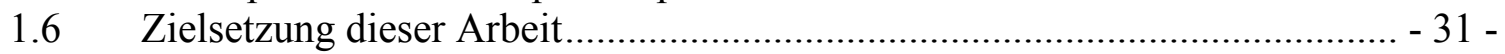

2 Material und Methoden .................................................................................. 32 -

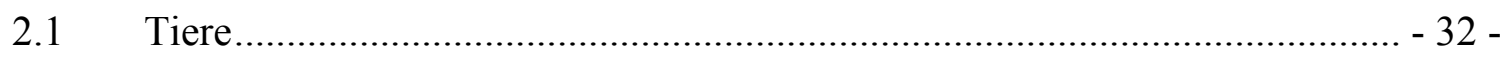

2.1.1 Wildtyp- und transgene Mäuse ....................................................... - 32 -

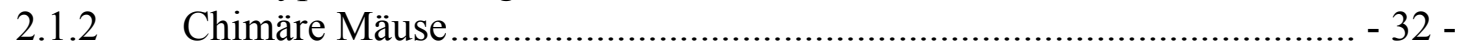

2.1.2.1 Knochenmarkstransplantation ........................................................ 33 -

2.1.2.1.1 Spendertiere ............................................................... 33 -

2.1.2.1.2 Empfängertiere .................................................................. - 34 -

2.1.2.2 Genotypisierung der chimären Mäuse ................................................. - 34 -

2.2 Isoliert perfundierte und ventilierte Mauslunge ......................................... - 37 -

2.2.1 Kalibrierung des Systems ............................................................ -37 -

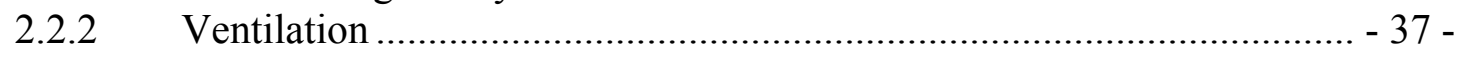

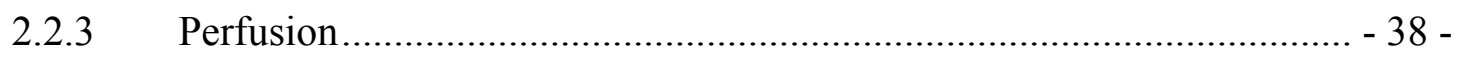

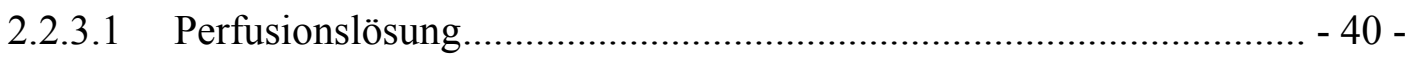

2.2.4 Präparation der Mäuse ................................................................. - 40 -

2.3 Elektronenspinresonanz Spektroskopie ................................................. - 42 -

2.3.1 Ansatz des Spin-Probes .................................................................... - 42 -

2.3.2 Einstellungen des Elektronenspinresonanz Spektroskops...................... - 42 -

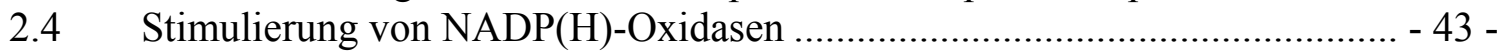

2.5 Quantifizierung von Superoxid ................................................................ 43 -

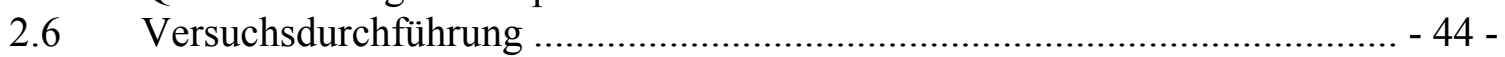

2.6.1 Messung der normoxischen Superoxid-Freisetzung............................... - 44 -

2.6.2 Messung der akut-hypoxischen Superoxid-Freisetzung ......................... - 45 -

2.6.3 Messung der Superoxid-Freisetzung nach chronischer Hypoxie ........... - 46 - 


\begin{tabular}{|c|c|c|}
\hline \multicolumn{2}{|c|}{2.6 .4} & Quantifizierung der Superoxidproduktion... \\
\hline 2. & $7 \quad$ Statis & 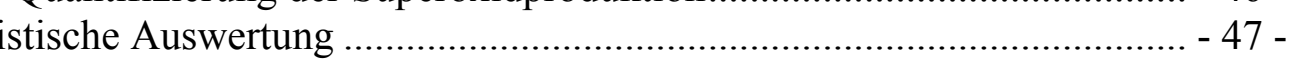 \\
\hline \multicolumn{3}{|c|}{ 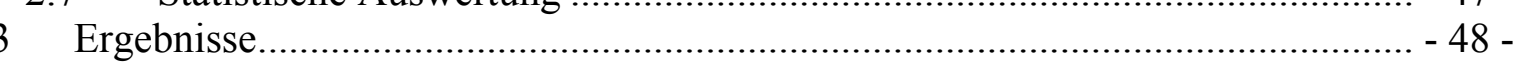 } \\
\hline 3. & \multicolumn{2}{|c|}{ Gewicht........ } \\
\hline 3. & \multicolumn{2}{|c|}{ Hämatokrit.... } \\
\hline 3. & \multicolumn{2}{|r|}{ Genotypisierung der chimären Mäuse } \\
\hline 3. & \multicolumn{2}{|r|}{ Pulmonalarterieller Druck } \\
\hline \multicolumn{3}{|c|}{ 3.4.1 Pulmonalarterieller Dru } \\
\hline \multicolumn{2}{|r|}{ 3.4.1.1 } & 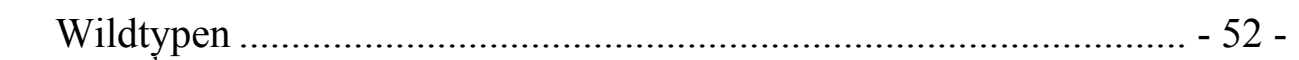 \\
\hline \multicolumn{2}{|r|}{3.4 .12} & 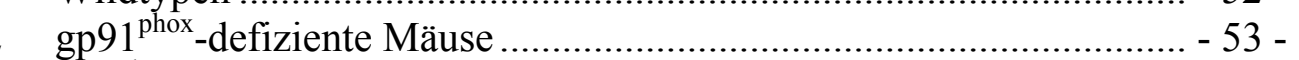 \\
\hline \multicolumn{2}{|r|}{3413} & p4 $7^{\text {phox }}$-defiziente Mäuse ....................... \\
\hline \multicolumn{2}{|r|}{ 3.4.1.4 } & 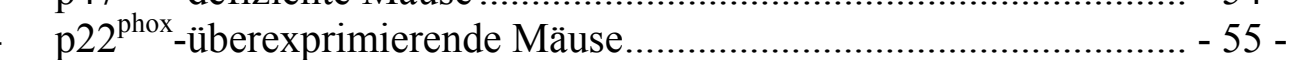 \\
\hline \multicolumn{2}{|r|}{3.4 .1 .5} & Chimäre Mäuse \\
\hline \multicolumn{2}{|r|}{3.4 .1 .6} & 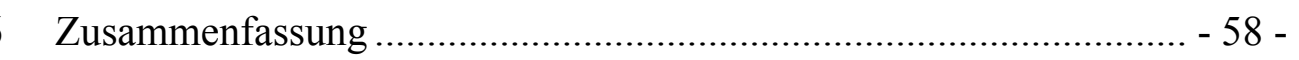 \\
\hline \multicolumn{2}{|r|}{3.4 .2} & Pulmonalarterieller Druck in akuter Hypoxie ............... \\
\hline & 3.4.2.1 & Wildtypen \\
\hline & 3.4 .2 .2 & 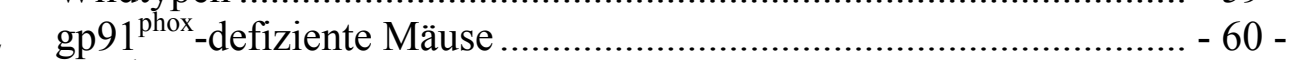 \\
\hline & 3423 & p4 $7^{\text {phox }}$-defiziente Mäuse \\
\hline & 3.4 .2 .4 & p22 $2^{\text {phox }}$-überexprimierende Mäuse \\
\hline & 3.4.2.5 & 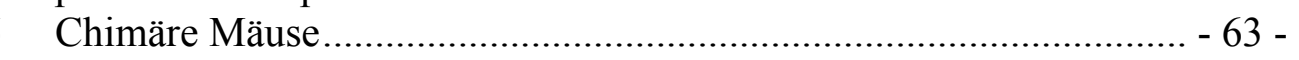 \\
\hline & 3.4.2.6 & 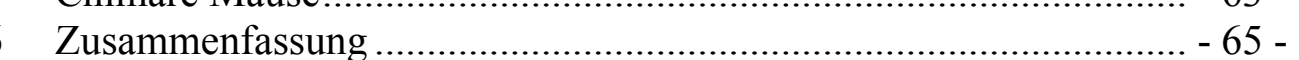 \\
\hline & .4 .3 & Pulmonalarterieller Druck nach chronischer Hypoxie ............................. - 66 - \\
\hline & 3.4.3.1 & Wildtypen \\
\hline & 3.4.3.2 & 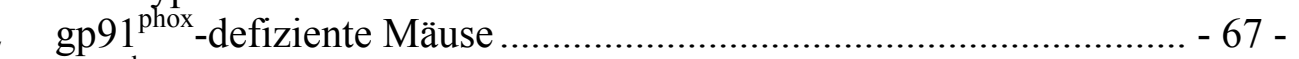 \\
\hline & 3.4.3.3 & 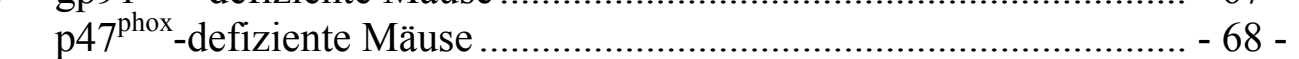 \\
\hline & 3.4.3.4 & p22 $2^{\text {phox }}$-überexprimierende Mäuse \\
\hline & 3.4.3.5 & Zusammenfassung \\
\hline 3. & $5 \quad$ Intra & 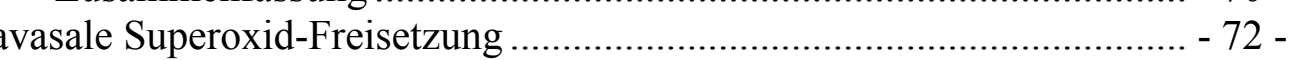 \\
\hline & 3.5 .1 & 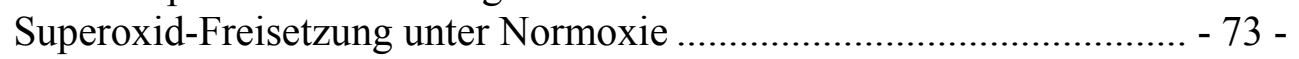 \\
\hline & 3.5 .2 & Superoxid-Freisetzung in chimären Mäusen unter Normoxie................. - 73 - \\
\hline & 3.5 .3 & 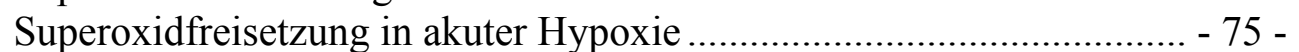 \\
\hline & 3.5 .4 & Superoxid-Freisetzung chimärer Mäuse in akuter Hypoxie .................... - 76 - \\
\hline & 3.5 .5 & Superoxid-Freisetzung nach chronischer Hypoxie.................................. - 77 - \\
\hline & Diskussio & on \\
\hline 4. & $1 \quad$ Meth & hoden \\
\hline & 4.1 .1 & Isoliert perfundierte und ventilierte Mauslunge ……………….......... -80 - \\
\hline & 4.1 .2 & Elektronenspinresonanz Spektroskopie ...................................... - 81 - \\
\hline 4. & 2 Phys & siologie \\
\hline & 4.2 .1 & Gewicht und Hämatokrit ............................................... - 83 - \\
\hline & 4.2 .2 & Normoxische ROS-Produktion und PAP ……........................... - 84 - \\
\hline & 4.2 .3 & Akut hypoxische ROS-Produktion und HPV …............................ - 87 - \\
\hline & 4.2 .4 & ROS-Produktion und PAP nach chronischer Hypoxie ............................ - 89 - \\
\hline & 4.2 .5 & Phorbol-Myristat-Acetat stimulierte ROS-Produktion und PAP............. - 91 - \\
\hline & 4.2 .6 & Entkopplung endothelialer NO-Synthasen .................................... - 92 - \\
\hline 4. & $3 \quad$ Ausb & blick \\
\hline & 4.3 .1 & ROS-Produktion in chronisch obstruktiven Lungenerkrankungen ......... - 93 - \\
\hline & 4.3 .2 & ROS-Produktion nach Ischämie und Reperfusion (I/R) ....................... - 94 - \\
\hline & $4 \quad$ Fazit & $\mathrm{t}$ \\
\hline 5 & Zusamme & enfassung ..... \\
\hline 6 & Abstract... & ............ $-99-$ \\
\hline & Anhang .. & …........ $100-$ \\
\hline
\end{tabular}




\begin{tabular}{|c|c|}
\hline 7.1 & 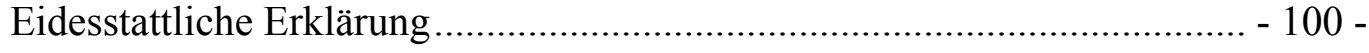 \\
\hline 7.2 & 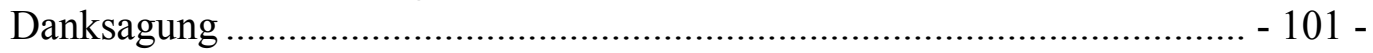 \\
\hline
\end{tabular}

\section{Abbildungsverzeichnis}

\section{a. Abbildungen}

Abbildung 1-1 Frontalansicht der humanen Lunge ........................................................ - 2 Abbildung 1-2: Topographie der Atemwege ................................................................. - 3 Abbildung 1-3: Terminale Endverzweigung mit zu- und abführenden Blutgefäßen ....... - 5 Abbildung 1-4: Effekt der hypoxischen pulmonalen Vasokonstriktion (HPV) ............... - 7 Abbildung 1-5: Schematische Darstellung der pathophysiologischen Einflüsse bei der Entstehung pulmonaler Hypertonie ..................................................................... 8 Abbildung 1-6: Schematischer Aufbau der Gefäßwand ............................................... - 9 Abbildung 1-7: Schematische Darstellung der aktiven NADP(H)-Oxidase ................... - 14 Abbildung 1-8: Elektronentransport der aktivierten NADP(H)-Oxidase........................ - 16 Abbildung 1-9: Entstehung von Radikalen ........................................................... - 18 Abbildung 1-10: Zelluläre Interaktionen reaktiver Sauerstoffspezies........................... - 19 Abbildung 1-11: Das magnetische Moment $\mu_{\mathrm{S}}$ des Elektrons im äußeren Magnetfeld $\vec{B}_{z} \ldots$ 21 -

Abbildung 1-12: Zeeman-Aufspaltung der Energien $E$ der beiden Spinzustände $m_{s}$ im

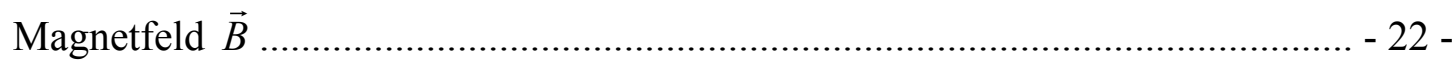
Abbildung 1-13: Spin-Energieniveaus und ESR-Übergänge für den Fall $S=1 / 2, I=1$. - 24 Abbildung 1-14: ERS-Spektrum von Hydroxy-3-carboxy-2,2,5,5tetramethylpyrrolidin. $\mathrm{HCl}$ bei einer isotropen Hyperfeinkopplung a. ................... - 25 Abbildung 1-15: rechteckiger Hohlraumresonator................................................... - 27 Abbildung 1-16: Zusammenhang zwischen Absorptions- und ESR-Signal .................. - 28 -

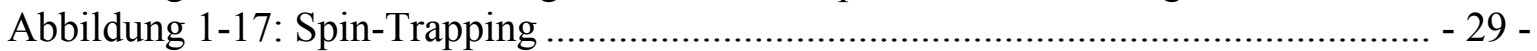

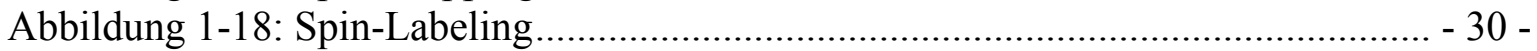
Abbildung 2-1: Schema der isoliert perfundierten und ventilierten Lunge................... - 39 Abbildung 2-2: Versuchsablauf Normoxie..................................................................... 45 -

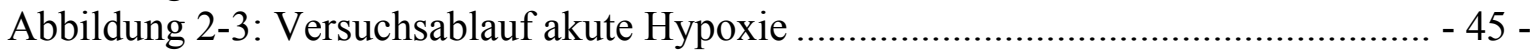
Abbildung 2-4: Versuchsablauf chronische Hypoxie.................................................... - 46 Abbildung 2-5: Versuchsablauf für die Quantifizierung der ${ }^{\circ} \mathrm{O}_{2}{ }^{-}$-Produktion ............... - 47 Abbildung 3-1: Elektrophoretische Auftrennung der amplifizierten DNA................... - 51 Abbildung 3-2: Pulmonalarterieller Druck in Mauslungen des Wildtyps (C57Bl/6J) ... - 53 Abbildung 3-3: Pulmonalarterieller Druck in gp91 ${ }^{\text {phox }}$-defizienten Mauslungen .......... - 54 Abbildung 3-4: Pulmonalarterieller Druck in p47 $7^{\text {phox }}$-defizienten Mauslungen ............ - 55 Abbildung 3-5: Pulmonalarterieller Druck in p22 $2^{\text {phox }}$-überexprimierenden Mauslungen.- 56

Abbildung 3-6: Pulmonalarterieller Druck in Wildtyplungen mit gp91/- Granulozyten - 57 Abbildung 3-7: Pulmonalarterieller Druck in gp91 ${ }^{-/}$Mauslungen mit Wildtyp-

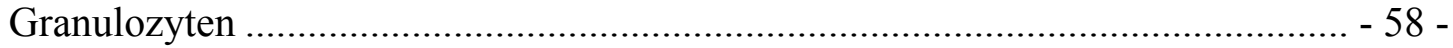
Abbildung 3-8: Hypoxische pulmonale Vasokonstriktion in Lungen des Wildtyps...... - 60 Abbildung 3-9: Hypoxische pulmonale Vasokonstriktion in gp91 ${ }^{\text {phox }}$-defizienten Mauslungen 
Abbildung 3-10: Hypoxische pulmonale Vasokonstriktion in $\mathrm{p} 47^{\text {phox }}$-defizienten Mauslungen $-62-$

Abbildung 3-11: Hypoxische pulmonale Vasokonstriktion in $\mathrm{p} 22^{\text {phox }}$-überexprimierenden Mauslungen $63-$

Abbildung 3-12: Hypoxische pulmonale Vasokonstriktion in Mäusen des Wildtyps nach Transplantation von Knochenmark aus gp91 ${ }^{\text {phox }}$-defizienten Tieren ... $-64-$ Abbildung 3-13: Hypoxische pulmonale Vasokonstriktion in gp91 ${ }^{\text {phox }}$-defizienten Mäusen nach Transplantation von Knochenmark aus Wildtypen... $-65-$

Abbildung 3-14: Pulmonalarterieller Druck in Wildtypen nach chronisch hypoxischer Exposition $-67-$

Abbildung 3-15: Pulmonalarterieller Druck in gp91 ${ }^{\text {phox }}$-defizienten Mäusen nach chronischer Hypoxie:

Abbildung 3-16: Pulmonalarterieller Druck in p47 $7^{\text {phox }}$-defizienten Mauslungen nach chronisch hypoxischer Exposition. $-68-$ Abbildung 3-17: Pulmonalarterieller Druck in p22 $2^{\text {phox }}$-überexprimierenden Mauslungen nach chronisch hypoxischer Exposition... $-70-$ Abbildung 3-18: Darstellung des ESR-Signals im zeitlichen Versuchsverlauf ............. - 72 Abbildung 3-19: Normoxische Superoxid-Freisetzung in Mauslungen......................... - 73 Abbildung 3-20: Superoxid-Freisetzung aus Lungen chimärer Mäuse.......................... - 74 Abbildung 3-21: Superoxid-Freisetzung aus Mauslungen in akuter Hypoxie ................ - 75 Abbildung 3-22: Superoxid-Freisetzung aus Lungen chimärer Mäuse in akuter Hypoxie....77 -

Abbildung 3-23: Superoxid-Freisetzung aus Mauslungen nach 21 Tagen Hypoxie...... - 78 -

\section{b. Tabellen}

Tabelle 1-1: Partialdrücke der Atemgase in den Lungenkapillaren und Alveolen: ......... - 5 Tabelle 1-2: Übersicht der phagozytierenden Zellen in Blut und Gewebe: ................... - 12 Tabelle 1-3: Einteilung der Untereinheiten von NADP(H)-Oxidasen .......................... - 15 Tabelle 2-1: Sequenzen der eingesetzten Primer...................................................... - 35 Tabelle 2-2: Einstellungen für die Polymerase-Kettenreaktion .................................... - 36 Tabelle 2-3: Zusammensetzung der zur Ventilation eingesetzten Gasgemische ........... - 38 Tabelle 2-4: Einstellungen des ESR-Spektroskops für die CP-H Messung ................... - 43 Tabelle 3-1. Gewichte von Wildtypen und genetisch veränderten Mäusen .................... - 48 Tabelle 3-2: Gewichte der chimären Mäuse.............................................................. - 49 Tabelle 3-3. Hämatokrit von Wildtyp und genetisch veränderten Mäusen.................... - 50 Tabelle 3-4: Hämatokrit der chimären Mäuse ................................................................ - 50 Tabelle 3-5: Übersicht der gemessenen Werte für den pulmonalarteriellen Druck ....... - 58 Tabelle 3-6: Übersicht des $\triangle$ PAPs als Ausdruck der HPV ......................................... - 66 Tabelle 3-7: Übersicht der PAPs nach chronisch hypoxischer Exposition ..................... - 71 -

\section{c. Formeln}

Formel 1-1: Reduktion von NADP ${ }^{+}$in Gegenwart eines Substrats (Redox-Reaktion) . - 15 -

Formel 1-2: Fenton-Reaktion........................................................................... - 17 -

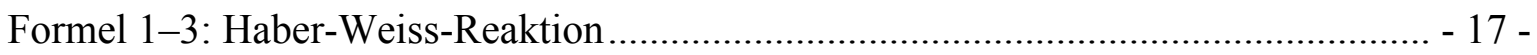

Formel 1-4: Zusammenhang von Spin $\vec{S}$ und magnetischem Moment $\mu_{S} \ldots \ldots \ldots \ldots \ldots \ldots . . . .20-$

Formel 1-5: Energie des magnetischen Moments $\mu_{S}$ in einem Magnetfeld $\vec{B}$........... -21 - 
Formel 1-6: Resonanzbedingung für den Übergang zwischen den Energieniveaus zweier

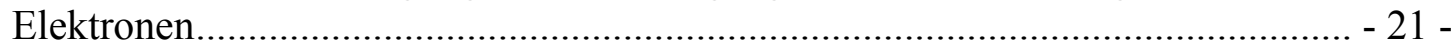

Formel 1-7: Magnetische Induktion einer Substanz in einem äußeren Magnetfeld ...... - 22 -

Formel 1-8: isotrope Hyperfeinkopplung $a_{i}$ eines Kerns i........................................... - 23 -

Formel 1-9: Aufspaltung der Spin-Energieniveaus ................................................. - 23 -

Formel 1-10: Hyperfeinwechselwirkung eines freien Elektrons mit mehreren Kernen i mit

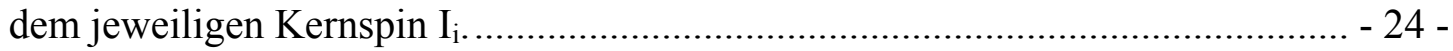

Formel 1-11: Definition der Spin-Gitter-Relaxationszeit ......................................... - 26 -

Formel 1-12: Definition der Spin-Spin-Relaxationszeit .............................................. - 26 - 


\section{Abkürzungsverzeichnis}

\begin{tabular}{|c|c|c|c|}
\hline $\mathrm{A} / \mathrm{D}$ & Analog/Digital & NADP(H) & Nikotinamid-Adenin- \\
\hline${ }^{\circ} \mathrm{C}$ & Grad Celsius & & Dinukleotid-Phosphat \\
\hline$\mu \mathrm{m}$ & Mikrometer & $\mathrm{NO}^{\bullet}$ & Stickoxid \\
\hline${ }^{\circ} \mathrm{O}_{2}^{-}$ & Superoxid & $\mathrm{O}_{2}$ & Sauerstoff \\
\hline${ }^{1} \mathrm{O}_{2}$ & Singlet Sauerstoff & $\mathrm{OCl}^{-}$ & Hypochlorit Ion \\
\hline $\mathrm{Bp}$ & Basenpaare & $\mathrm{OH}^{\bullet}$ & Hydroxyl Radikal \\
\hline bzw. & beziehungsweise & $\mathrm{ONOO}^{-}$ & Peroxynitrit \\
\hline $\begin{array}{l}\mathrm{ca} . \\
\mathrm{Ca}^{2+}\end{array}$ & $\begin{array}{l}\text { cirka } \\
\text { Kalzium }\end{array}$ & PAP & $\begin{array}{l}\text { engl:: pulmonary arterial } \\
\text { pressure, pulmonalarterieller }\end{array}$ \\
\hline $\mathrm{CaM}$ & Calmodulin & & Druck \\
\hline $\mathrm{CO}_{2}$ & Kohlenstoffdioxid & $\mathrm{PCO}_{2}$ & Kohlenstoffdioxidpartialdruck \\
\hline $\mathrm{dB}$ & dezi-bel & PCR & Polymerase Chain Reaktion, \\
\hline DNA & Desoxyribonukleinsäure & PEEP & positiver endexpiratorischer \\
\hline G & Gauss & & Druck \\
\hline $\mathrm{H}_{2} \mathrm{O}_{2}$ & Wasserstoffperoxid & $\mathrm{PH}$ & pulmonale Hypertonie \\
\hline $\mathrm{Hg}$ & Quecksilber & & (Lungenhochdruck) \\
\hline HPV & $\begin{array}{l}\text { hypoxische pulmonale } \\
\text { Vasokonstriktion }\end{array}$ & $\begin{array}{l}\text { Phox } \\
\text { PK }\end{array}$ & $\begin{array}{l}\text { phagozytäre Oxidase } \\
\text { Proteinkinase }\end{array}$ \\
\hline $\mathrm{K}^{+}$ & Kalium & $\mathrm{PK}-\mathrm{C}$ & Proteinkinase C \\
\hline $\mathrm{kD}$ & Kilo-Dalton & PMA & Phorbol-Myristat-Acetat \\
\hline $\mathrm{KO}$ & Knock-out; Deletion eines & $\mathrm{PO}_{2}$ & Sauerstoffpartialdruck \\
\hline $\begin{array}{l}\mathrm{kPa} \\
\mathrm{K}_{\mathrm{V}}\end{array}$ & $\begin{array}{l}\text { bestimmten Gens } \\
\text { Kilopascal } \\
\text { spannungsabhängige }\end{array}$ & RNS & $\begin{array}{l}\text { Reaktive Stickstoffspezies, } \\
\text { engl.: reactive nitroxide } \\
\text { species }\end{array}$ \\
\hline & Kaliumkanäle & $\mathrm{ROO}^{\bullet}$ & Peroxyl Radikal \\
\hline LVP & $\begin{array}{l}\text { engl.: left ventricular } \\
\text { pressure, linksventrikulärer } \\
\text { Druck }\end{array}$ & ROS & $\begin{array}{l}\text { engl.: reactive oxygen } \\
\text { species; Reaktive } \\
\text { Sauerstoffspezies }\end{array}$ \\
\hline $\mathrm{m}^{2}$ & Quadratmeter & sog. & so genannt \\
\hline $\mathrm{mG}$ & milli-Gauss & SR & sarkoplasmatisches \\
\hline $\mathrm{mm}$ & Millimeter & & Retikulum \\
\hline $\mathrm{ms}$ & Millisekunde & u. a. & unter anderem \\
\hline $\mathrm{N}_{2}$ & Stickstoff & USA & $\begin{array}{l}\text { United States of America, } \\
\text { Vereinigte Staten von }\end{array}$ \\
\hline $\mathrm{NAD}(\mathrm{H})$ & $\begin{array}{l}\text { Nikotinamid-Adenin- } \\
\text { Dinukleotid }\end{array}$ & z.B. & $\begin{array}{l}\text { Amerika } \\
\text { zum Beispiel }\end{array}$ \\
\hline
\end{tabular}




\section{Einleitung}

\subsection{Grundlagen dieser Arbeit}

Die Lunge ist das Gasaustauschorgan bei allen höheren landlebenden Tieren. Über die Atembewegung wird sauerstoffreiche Luft aus dem externen Milieu in die Lunge eingebracht, wo in den respiratorischen Abschnitten, also den respiratorischen Bronchiolen und Alveolarsäckchen, der Austausch der Atemgase mit den im Blut der feinen Kapillaren, die die respiratorischen Einheiten umgeben, gelösten Gase stattfindet. Eine Besonderheit des Lungenkreislaufes ist die Adaptation des Blutflusses in der Lunge an die in dem Organ vorzufindenden Ventilationsverhältnisse. Dies geschieht über den Mechanismus der hypoxischen pulmonalen Vasokonstriktion, kurz HPV. Durch Konstriktion präkapillärer Gefäße in Regionen niedrigen alveolären Sauerstoffpartialdrucks $\left(\mathrm{PO}_{2}\right)$ sorgt dieser Mechanismus dafür, dass überwiegend Bereiche mit hohem alveolärem Sauerstoffpartialdruck mit Blut versorgt werden. Somit wird eine unphysiologische Perfusion hypoxischer oder gar anoxischer Bereiche umgangen und der Blutfluss den regionalen Ventilationsverhältnissen angeglichen. Ulf von Euler und Göran Liljestrand beschrieben den Vorgang erstmals in den 50er Jahren (von Euler and Liljestrand, 1946) und seitdem ist die hypoxische pulmonale Vasokonstriktion Gegenstand zahlreicher wissenschaftlicher Untersuchungen (Sham, 2002; Sylvester et al., 1985; Sylvester and McGowan, 1978; Waypa and Schumacker, 2005; Weissmann et al., 2004; Weissmann et al., 2001a; Weissmann et al., 2006b). Trotz aller Anstrengungen, die auf die Aufklärung der Mechanismen, die zur HPV beitragen, verwendet wurden und werden, sind die genauen zellulären, biochemischen und physiologischen Vorgänge nach wie vor unklar und heftig umstritten. $\mathrm{Zu}$ den Streitpunkten gehört unter anderem die Frage, ob und wo in der Lunge bzw. den zuführenden Blutgefäßen ein Sauerstoffsensor, ähnlich dem Glomus caroticus, lokalisiert ist und auf welche Art und Weise das Signal übertragen wird, welches letztendlich zur Konstriktion präkapillärer Gefäße führt (Jones et al., 2000; Lopez-Barneo et al., 2004; Waypa et al., 2001). Mehrere Arbeitsgruppen postulierten, dass reaktive Sauerstoffspezies (ROS) als Signalmoleküle in die Prozesse, die letztendlich zur HPV führen, eingebunden sind (Archer et al., 1993; Bonnet et al., 2006; Hool et al., 2005; Kelley et al., 2006; Waypa et al., 2002; Weissmann et al., 2005; Weissmann et al., 2006b; Weissmann et al., 2006d). Neben der HPV als Antwort auf einen akuten Abfall des Sauerstoffpartialdruckes in den Lungenalveolen ist insbesondere im klinischen Alltag ein weiteres, ausschließlich die Lunge betreffendes Phänomen, von Bedeutung. Dabei handelt es sich um die durch chronische Hypoxie ausgelöste Krankheit Lungenhochdruck, auch pulmonale Hypertonie (PH) genannt. Diese Krankheit entsteht durch die Verdickung der Gefäßmedia in den blutzuführenden Gefäßen der Lunge unter chronischer Hypoxie. In diesen sog. Remodelingprozess sollen ebenfalls ROS als Mediatoren involviert sein (Brennan et al., 2003; Fresquet et al., 2006; Jeffery and Morrell, 2002; Liu et al., 2006). Allerdings ist noch umstritten, welche Rolle den ROS sowohl für die Entwicklung der PH als auch für die physiologische Anpassung des Blutflusses vermittels der HPV zukommt, denn nach wie vor streitet sich die wissenschaftliche Fachwelt über den Punkt, ob es unter Hypoxie zu einer vermehrten Produktion von ROS kommt oder eine Verminderung der ROS-Freisetzung zu den auslösenden Faktoren der HPV und PH zählt (Rojas et al., 2006; Sham, 2002; Sylvester, 2001; Weir and Archer, 2006; Weissmann et al., 2001a). 


\subsection{Die Lunge}

Die Lunge liegt im oberen Bereich des Körpers in der Brusthöhle. Der Raum wird vom knöchern-muskulären Thorax und vom Zwerchfell begrenzt. Durch eine in der Medianebene stehende Bindegewebsplatte, dem Mediastinum, wird die Brusthöhle in eine linke und rechte Hälfte geteilt, in denen die jeweiligen Lungenflügel liegen. Das Organ wird topographisch in obere und untere Atemwege eingeteilt. Die oberen Atemwege werden durch Nasenhöhle, Schlund und Kehlkopf gebildet, die unteren Atemwege bestehen aus Luftröhre und den Lungen (Abbildung 1-2). Nach funktionellen Gesichtpunkten wird das Organ in luftleitende (Nasenhöhle, Luftröhre, Bronchien und Bronchiolen) und respiratorische Abschnitte (Bronchioli respiratorii, Alveolen) gegliedert.

\subsubsection{Anatomie}

Gemäß der Gliederung der Pleurahöhle durch das Mediastinum ist die Lunge in einen linken und rechten Flügel geteilt (Abbildung 1-1). Beide Lungenflügel werden vom Lungenfell (Pleura visceralis) überzogen. Diese dünne bindegewebige Schicht trennt die Berührungsflächen der Lungenlappen, vermindert den Reibungswiderstand bei der Atembewegung der Lunge und schützt sie vor Verletzungen. Zwischen der Pleura visceralis und der dem Thorax innen anliegenden Membran (Pleura) besteht der Pleuralspalt. Der Zwischenraum ist mit Flüssigkeit gefüllt, so dass die Lunge passiv den Atembewegungen des Thorax folgt.

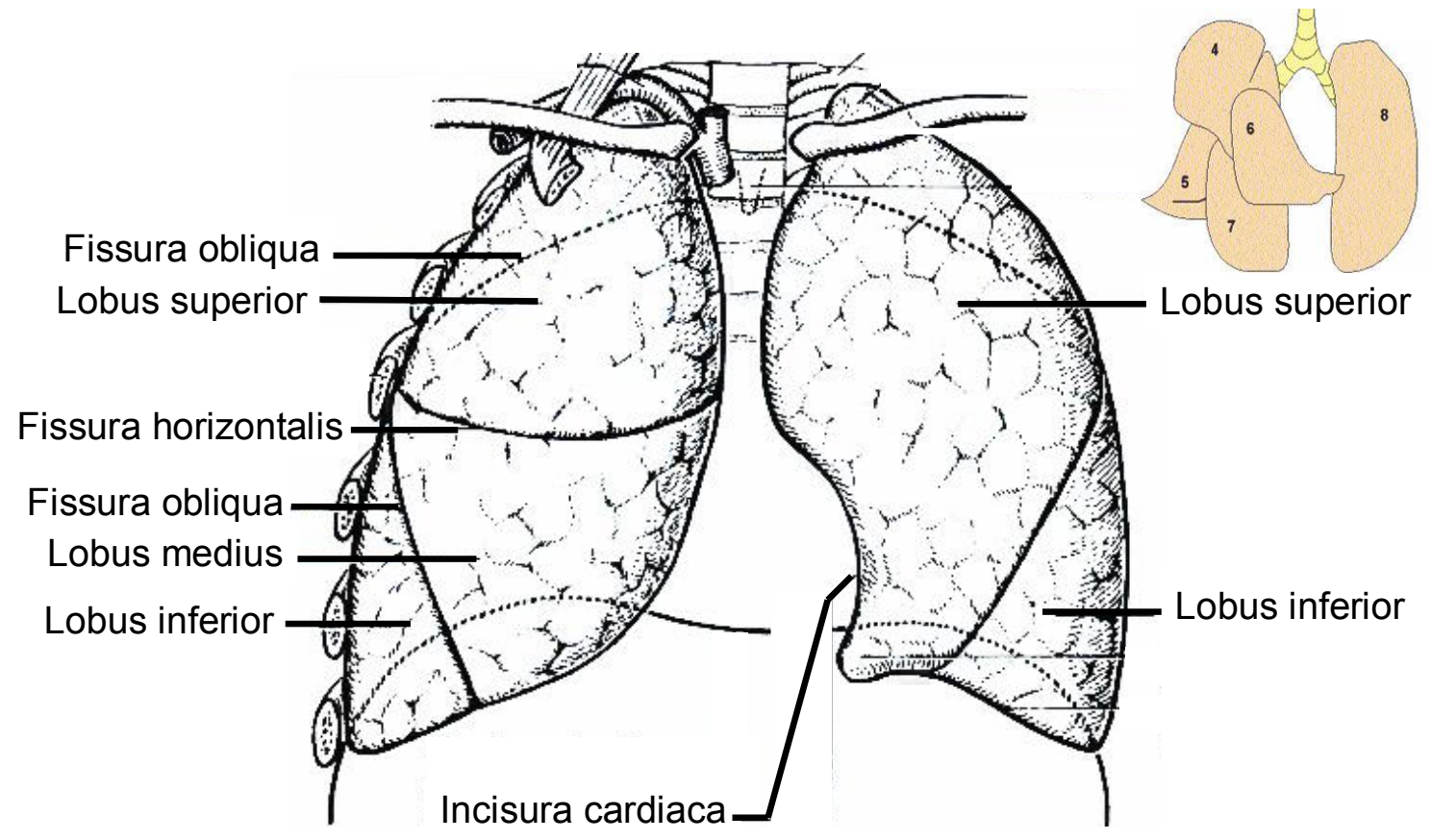

\section{Abbildung 1-1 Frontalansicht der humanen Lunge}

Die zwei Lungenflügel des Menschen sind in Lungenlappen gegliedert. Deren Anzahl ist für den rechten (3) und linken (2) Lungenflügel unterschiedlich. Die Zeichnung zeigt zudem die Fissuren, die die einzelnen Lappen voneinander trennen (nach Bertolini R., Hrsg, Systematische Anatomie des Menschen, 5. Auflage, 1995, verändert). Im Einschub rechts oben ist die Aufteilung der Mauslunge schematisch dargestellt. Das Schema zeigt die Gliederung des rechten Lungenflügels in Ober-, Mittel- und Unterlappen sowie den Herzlappen (4 - 7), der linke Lungenflügel ist nicht unterteilt (8). 
Die Lungenflügel gliedern sich in verschiedene Lappen. Die Anzahl der Lungenlappen beim Menschen ist unterschiedlich für die linke und rechte Lunge und unterscheidet sich grundsätzlich von der Unterteilung bei der Maus. Die linke humane Lunge besteht aus Ober- und Unterlappen (Lobus superior und Lobus inferior), die durch die Fissura obliqua getrennt werden. Charakteristisch für den linken Lungenflügel ist die Incisura cardiaca am Lobus superior, einer Eindellung die durch die nach links verschobene Lage des Herzens hervorgerufen wird. Die rechte Lunge besteht aus drei Lappen, Lobus superior, Lobus inferior und dem dazwischen liegenden Lobus medius (Abbildung 1-1). Die Lappen sind durch Fissuren voneinander getrennt. Der Oberlappen wird durch die Fissura obliqua vom Unterlappen getrennt, die Fissura horizontalis trennt Oberlappen und Lobus medius. Die Mauslunge hingegen zeigt eine andere Aufteilung für die unterschiedlichen Lungenflügel. Der rechte Flügel des Organs besteht aus insgesamt vier Lappen: dem Oberlappen mit einem dahinter liegenden Lappen, Herzlappen und Zwerchfelllappen. Der linke Lungenflügel ist bei der Maus nicht weiter unterteilt (Einschub in Abbildung 1-1).

In der Lunge werden neben anatomischen Merkmalen auch topographische Aspekte definiert (Abbildung 1-2). So werden obere und untere Atemwege unterschieden. Die oberen Atemwege werden aus Nasenhöhle, Schlund und Kehlkopf gebildet. Der Bereich ist mit respiratorischem Epithel ausgekleidet, das - entgegen des Namens - nicht zum Gasaustausch beiträgt, denn dieser Abschnitt hat keine respiratorische Funktion, dient aber der Luftzufuhr in die respiratorischen Bereiche der Lunge. In den oberen Atemwegen wird die eingeatmete Luft erwärmt, befeuchtet und gereinigt, so dass sie nahezu körperwarm und frei von größeren Fremdpartikeln zu den respiratorischen Abschnitten der unteren Atemwege gelangt.

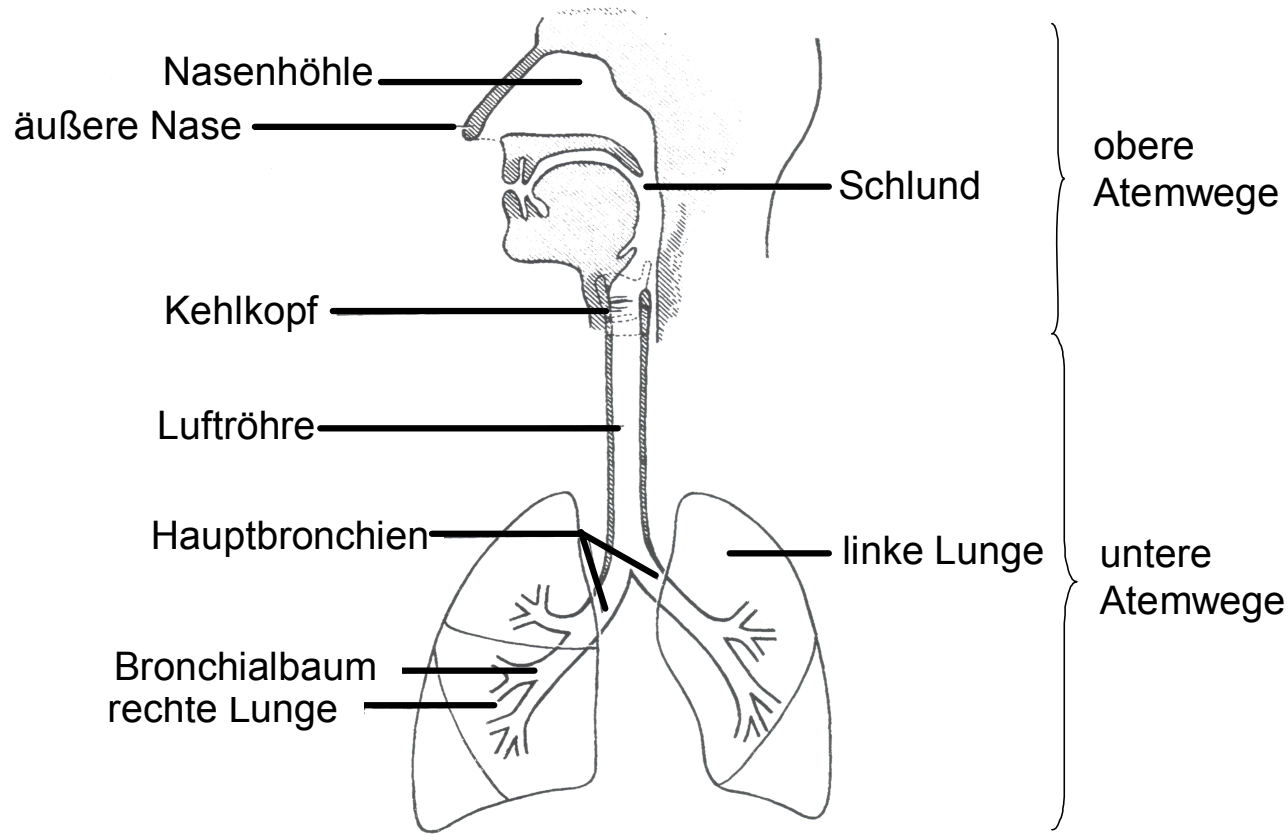

\section{Abbildung 1-2: Topographie der Atemwege}

Die Lunge gliedert sich in obere und untere Atemwege. Die oberen Atemwege werden aus Nasenhöhle, Schlund und Kehlkopf gebildet, die unteren setzen sich aus Luftröhre und den Lungen zusammen. Nach Bertolini R., Hrsg, Systematische Anatomie des Menschen, 5. Auflage, 1995, verändert. 
Die unteren Atemwege bestehen aus Luftröhre und den Bronchien bis hin zu den terminalen Verzweigungen der Alveolarsäckchen. Dieser untere Teil der Atemwege ist funktionell zweigeteilt. Die oberen Abschnitte, Luftröhre, Bronchien und Bronchiolen bis hin $\mathrm{zu}$ den Bronchioli terminalis dienen weiterhin der Luftleitung, wohingegen die untersten Abschnitte, Bronchioli respiratorii und die Sacculi aleveolarii, die respiratorisch aktive Region der Lunge darstellen. Im nachfolgenden Abschnitt 1.2.2 wird genauer auf die respiratorische Funktion eingegangen.

\subsubsection{Funktion}

Neben der Hauptfunktion als Organ der äußeren Atmung hat die Lunge viele weitere Aufgaben. Die Atemluft enthält neben den Atemgasen auch Fremdpartikel und schädliche Mikroorganismen, die durch die Inspiration in die Lunge eingebracht werden. Größere Partikel werden im Nasen-Rachen-Raum aus der Atemluft gefiltert, so dass sie die respiratorischen Abschnitte der Lunge nicht erreichen. Kleinere Partikel gelangen in die Atemwege und werden dort entweder durch den Schleim des Flimmerepithels gebunden und abtransportiert oder von alveolären Makrophagen unschädlich gemacht. In den oberen Atemwegen befinden sich zudem Zellen zur spezifischen Immunabwehr, hauptsächlich Lymphozyten und Plasmazellen. Plasma- und Epithelzellen sezernieren in den oberen Atemwegen Immunglobuline (Ig), v. a. IgA, deren genaue Funktion allerdings nicht bekannt ist (Klinke and Silbernagl, 2003). Zudem ist die Lunge ein Reservoir für zirkulierende Leukozyten, die ebenfalls der spezifischen Immunabwehr dienen. Insgesamt sind bis $\mathrm{zu}^{1 / 3} 3$ der gesamten Leukozytenpopulation in der Lunge lokalisiert (Klinke and Silbernagl, 2003).

Der Gasaustausch erfolgt nicht im gesamten Volumen der Lunge, sondern beschränkt sich auf den Alveolarraum, der von den letzten sieben Verzweigungsgenerationen der Bronchiolen gebildet wird. Nur diese Verzweigungen vom Bronchiolus respiratorius bis zum Sacchus alveolaris tragen Alveolen (Abbildung 1-3). Durch die hohe Anzahl an Alveolen in einer humanen Lunge (ca. 30 Mio.) vergrößert sich die respiratorische Oberfläche trotz des geringen Durchmessers von 200 - $300 \mu \mathrm{m}$ einzelner Alveolen auf bis zu $90 \mathrm{~m}^{2}$. Damit ist die gesamte respiratorische Oberfläche ca. 50-mal so groß wie die äußere Körperoberfläche. Das Volumen des Alveolarraumes beträgt beim Menschen ca. $3000 \mathrm{ml}$ und ist bedeutend größer als das durch die oberen Atemwege gebildete anatomische Totraumvolumen, das etwa $150 \mathrm{ml}$ beträgt. Da das Atemzugvolumen dreimal so groß ist wie das anatomische Totraumvolumen, gelangen $2 / 3$ der Frischluft eines Atemzuges in den Alveolarraum. Trotz der Volumenunterschiede zwischen anatomischem Totraum und Alveolarraum gelangt die Frischluft eines Atemzuges nicht völlig zu den respiratorisch aktiven Oberflächen. In den respiratorischen Bereichen wird die Atemluft durch rein passive Diffusionsprozesse ausgetauscht und mit Sauerstoff angereichert.

Wie Abbildung 1-3 zeigt, werden die Endverzweigungen des Bronchialbaumes von einem dichten Kapillarnetz umgeben. Da auch der Gasaustausch zwischen Alveolarluft und dem Blut passiv durch Diffusion erfolgt, wird durch die Anordnung von Blutgefäßen und Alveolen der Austausch von Gasen vereinfacht. Zudem haben sowohl die blutführenden Kapillaren als auch die luftgefüllten Alveolen sehr dünne Wände, so dass die Diffusionsstrecke vom Alveolarraum bis ins Blut der Kapillaren auf ca. $1 \mu \mathrm{m}$ minimiert wird. 


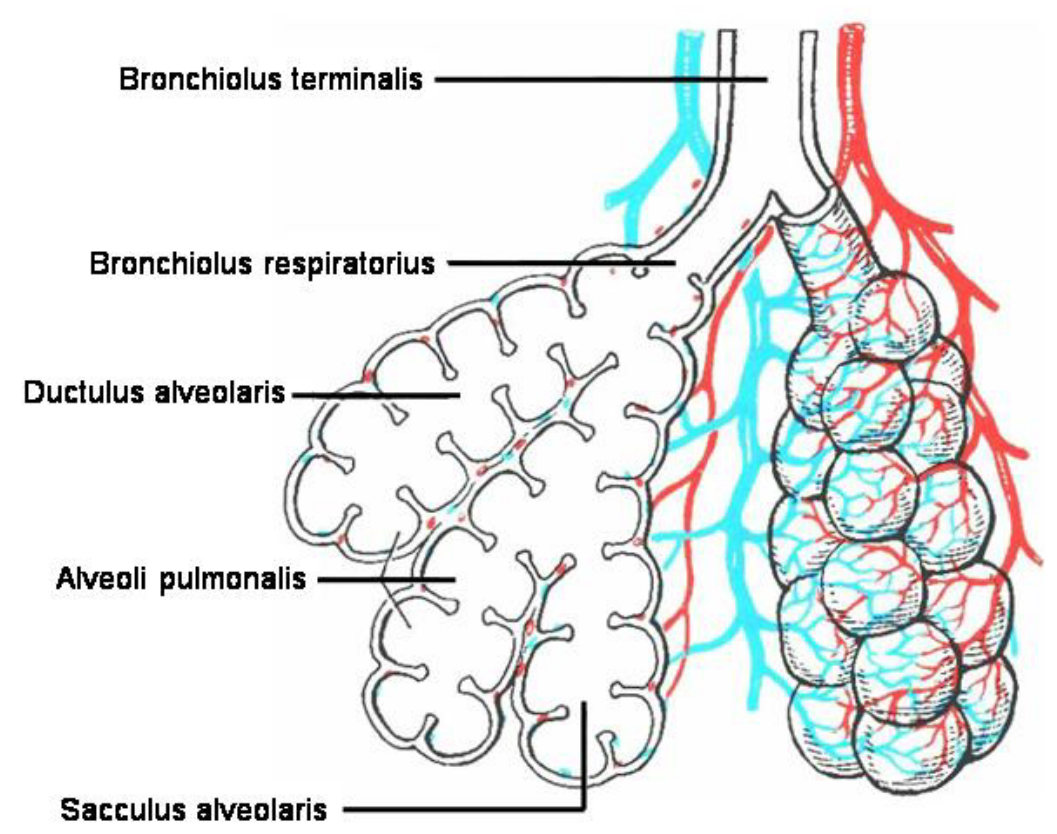

\section{Abbildung 1-3: Terminale Endverzweigung mit zu- und abführenden Blutgefäßen}

Die Oberfläche der respiratorisch aktiven Bereiche der Lunge ist mit blasigen Ausstülpungen übersät (Alveolen). Die Alveolen vergrößern die Oberfläche und sorgen für eine Optimierung des Gasaustausches zwischen Blut und Alveolarraum. Durch die dünnen Wände der Kapillaren und der Alveolen werden die Diffusionsdistanzen verringert. Nach Bertolini R., Hrsg, Systematische Anatomie des Menschen, 5. Auflage, 1995.

Treibende Kraft für den Gasaustausch zwischen Kapillarblut und Alveolarluft sind Unterschiede in den jeweiligen Gaspartialdrücken (Tabelle 1-1). Der geringe Anteil an Kohlenstoffdioxid in der Luft kann medizinisch vernachlässigt werden. Stickstoff, Argon und andere in der atmosphärischen Luft vorkommenden Edelgase werden summarisch als „Stickstoff“ zusammengefasst, sind aber in der Tabelle nicht erfasst.

\section{Tabelle 1-1: Partialdrücke der Atemgase in den Lungenkapillaren und Alveolen:}

Durch Diffusion werden die Partialdrücke der Atemgase in den Lungenkapillaren und Alveolen angeglichen. Die unterschiedlichen Partialdrücke in verschiedenen Kompartimenten (Blut/Alveolarraum) sind die treibende Kraft für den alveolären Gasaustausch. Die Angaben des Partialdruckes atmosphärischer Luft beziehen sich auf einen Umgebungsdruck von $100 \mathrm{kPa}$ (Klinke und Silbernagl, 2003; verändert).

\begin{tabular}{|l|c|c|c|}
\hline \multicolumn{1}{|c|}{ Gas } & $\begin{array}{c}\text { Partialdrücke der Gase } \\
\text { atmosphärische Luft }[\mathbf{k P a}]\end{array}$ & $\begin{array}{c}\text { Alveolärer Partialdruck } \\
{[\mathbf{k P a}]}\end{array}$ & $\begin{array}{c}\text { Arterieller Partialdruck } \\
{[\mathbf{k P a}]}\end{array}$ \\
\hline \hline Sauerstoff $\left(\mathbf{O}_{\mathbf{2}}\right)$ & $\mathrm{P}_{\mathrm{O} 2}=19,6$ & $13,3 \triangleq 100 \mathrm{~mm} \mathrm{Hg}$ & $12,0 \bumpeq 90 \mathrm{~mm} \mathrm{Hg}$ \\
\hline $\begin{array}{l}\text { Kohlenstoffdioxid } \\
\left(\mathbf{C O}_{2}\right)\end{array}$ & $\mathrm{P}_{\mathrm{CO} 2}=0,0$ & $5,3 \triangleq 40 \mathrm{~mm} \mathrm{Hg}$ & $5,3 \triangleq 40 \mathrm{~mm} \mathrm{Hg}$ \\
\hline
\end{tabular}

Die Partialdrücke der im Blut der Lungenkapillaren gebundenen Gase ist in der normalen Lunge praktisch gleich den Partialdrücken der Gase in den Alveolen. Dennoch gibt es in der Lunge regionale Unterschiede für alveoläre und kapilläre Partialdrücke der Gase. Dies geht auf die Einwirkung der Schwerkraft in verschiedener Höhe der Lunge zurück (West et al., 1964, 1965). Teilt man die Lunge von oben nach unten in drei Zonen, eine Einteilung, die West und Mitarbeiter vornahmen, weshalb man auch von „West-Zonen“ spricht, erhält man für jede Zone ein anderes Verhältnis von Ventilation zu Perfusion. Durch die 
Schwerkraft, die auf die unteren Bereiche (Zone III) stärker wirkt als auf die oberen (Zonen I und II), ändert sich in diesen Abschnitten die Perfusion. Aber auch die alveoläre Ventilation ist schwerkraftabhängig. Dies erklärt sich daraus, dass die einzelnen Lungenabschnitte zusammenhängen und die oberen von den darunter liegenden gedehnt werden. Durch diese Vordehnung werden die Alveolarwände in den oberen Abschnitten versteift und die Alveolen schlechter ventiliert, wohingegen in den unteren Lungenbereichen eine Kompression stattfindet, wodurch die Alveolen stärker dehnbar sind.

\subsubsection{Hypoxische pulmonale Vasokonstriktion}

Im Körper gibt es zwei unabhängige Kreislaufsysteme, deren gemeinsamer Motor das Herz ist. Das Herz pumpt das Blut zum einen in den Körperkreislauf, der die Organe des Körpers mit Sauerstoff versorgt und zum anderen in den pulmonalen Kreislauf, in dem sauerstoffarmes Blut mit $\mathrm{O}_{2}$ angereichert wird. Im systemischen Kreislauf herrscht ein diastolischer Druck von 100 bis $130 \mathrm{~mm} \mathrm{Hg}$, weshalb man in diesem Fall auch von einem Hochdrucksystem spricht. Dem gegenüber steht der sog. kleine Kreislauf der Lunge, ein Niederdrucksystem mit einem pulmonalarteriellen Druck (PAP) von ca. $20 \mathrm{~mm} \mathrm{Hg}$. Abgesehen von den vorherrschenden Drücken in den beiden Kreisläufen gibt es weitere Unterschiede. Der systemische Kreislauf bringt sauerstoffreiches Blut zu den Geweben und Erfolgsorganen des Körpers, in denen der Gasaustausch stattfindet. Sauerstoff diffundiert aus dem Blut in die verbrauchenden Gewebe und Kohlenstoffdioxid aus den Geweben wird im Blut angereichert. Im pulmonalen Kreislauf wird sauerstoffarmes Blut durch die Pulmonalarterie in die Lunge geleitet, um dort mit Sauerstoff angereichert zu werden. Ein wichtiger Unterschied zwischen den beiden Kreisläufen besteht in der Reaktion auf Hypoxie. Werden Gewebe bzw. Organe im systemischen Kreislauf hypoxisch, d. h. der Sauerstoffpartialdruck sinkt, entspannen sich die Wände der zuführenden Gefäße, um eine bessere Versorgung des Erfolgsorgans zu gewährleisten. Ein Beispiel für systemische Vasodilatation unter Hypoxie ist die Renalarterie, die den Nieren Blut zuführt (Li et al., 2002; Sanders et al., 2002; Zou and Cowley, 2003). Anders und einzigartig verhalten sich die Gefäße in der Lunge. Auf alveoläre Hypoxie reagieren die Pulmonalarterien und kleinen Widerstandsgefäße der Lunge mit Kontraktion der glatten Muskelzellen, woraufhin sich das Lumen der Gefäße verengt. Dieser Prozess wird hypoxische pulmonale Vasokonstriktion, kurz HPV, genannt (Abbildung 1-4).

Obwohl die HPV schon Ende des 19. Jahrhunderts entdeckt wurde (Bradford and Dean, 1894), geht die Beschreibung dieses Mechanismus auf Ulf von Euler und dessen Mitarbeiter Göran Liljestrand im Jahr 1946 zurück (von Euler and Liljestrand, 1946). Deswegen wird der Prozess der HPV auch als „,von-Euler-Liljestrand-Mechanismus“ bezeichnet. Bei Untersuchungen des pulmonalarteriellen Kreislaufes in Katzen fanden von Euler und Liljestrand heraus, dass in Ventilationsphasen mit geringer Sauerstoffkonzentration - in den Versuchen wurde eine $\mathrm{O}_{2}$-Konzentration von $10 \%$ gewählt - der pulmonalarterielle Druck ansteigt. Der Anstieg des Druckes war reversibel und kehrte in Ventilationsphasen mit Raumluft wieder auf den Basiswert zurück. Weitergehende Untersuchungen von Eulers und Liljestrands zeigten, dass der Druckanstieg auf die Kontraktion der Pulmonalarterie zurückzuführen ist. Dennoch ist die HPV nach heutiger Ansicht nicht einzig auf die Pulmonalarterie beschränkt, vielmehr tragen insbesondere präkapilläre Gefäße zur Anpassung des Blutstroms an die vorherrschenden Ventilationsverhältnisse bei (Jeffery and Morrell, 2002). 
Die hypoxische pulmonale Vasokonstriktion ist ein natürlich vorkommender Prozess, der ausnahmslos in der Lunge zu finden ist. Durch den Mechanismus wird die Perfusion der Lunge den regionalen Ventilationsverhältnissen angepasst und somit der pulmonale Gasaustausch optimiert (Weissmann et al., 2004; Weissmann et al., 1995). Das in die Lunge fließende Blut wird in gut ventilierte Areale geleitet, indem sich die Blutgefäße in schlecht oder nicht ventilierten Bereichen der Lunge kontrahieren. Somit wird eine unphysiologische Blutversorgung hypoxischer oder anoxischer Areale in der Lunge umgangen.

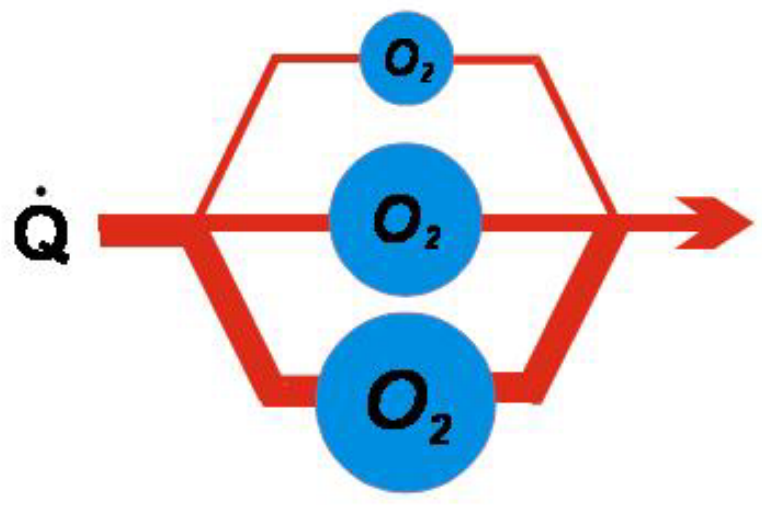

Abbildung 1-4: Effekt der hypoxischen pulmonalen Vasokonstriktion (HPV)

Das Schema zeigt den Einfluss der HPV auf den Blutfluss (Q) in der Lunge. Durch Konstriktion der Gefäße (dünne rote Linie) in Regionen niedrigen Sauerstoffpartialdruckes (kleiner blauer Kreis, oberer Teil der Darstellung) wird Blut in Regionen hohen Sauerstoffpartialdruckes (großer blauer Kreis) dirigiert (dicke rote Linie, im unteren Teil der Darstellung).

Die Reaktion der Gefäße auf akute Hypoxie verläuft in zwei Phasen, in denen jeweils unterschiedliche zelluläre Kompartimente aktiviert werden (Jin et al., 1992; Weissmann et al., 1995). Die erste Phase wird gemeinhin als Akutantwort auf die hypoxische Ventilation angesehen und ist prinzipiell unabhängig vom Endothel (Jin et al., 1992). Sie ist durch einen sehr schnellen Anstieg des pulmonalarteriellen Druckes gekennzeichnet, allerdings kehrt der Druck innerhalb von ca. 10 min. wieder auf ein niedrigeres Niveau zurück, jedoch ohne den Basiswert zu erreichen. Anhand von Knock-Out Mäusen konnten Weißmann und Mitarbeiter zeigen, dass die initiale Phase der akut hypoxischen Antwort auf die Aktivierung nicht-phagozytärer NADP(H)-Oxidasen zurückzuführen ist, die reaktive Sauerstoffspezies (engl. reactive oxygen species, ROS) als Mediatoren freisetzen (Schumacker, 2003; Weissmann et al., 2006d). Die zweite Phase der akuten Antwort tritt bei verlängerter Hypoxie auf, ist abhängig vom Endothel (Jin et al., 1992; Yuan et al., 2006; Yuan et al., 1990) und durch einen langsamen Anstieg des pulmonalarteriellen Druckes charakterisiert. Verantwortlich für die Steigerung des PAP sind insbesondere die Mitochondrien, bei denen anhaltende Hypoxie möglicherweise zu einem Leck in der Elektronentransportkette führt, woraufhin wiederum ROS freigesetzt werden (Schumacker, 2003; Waypa and Schumacker, 2002, 2006; Weissmann et al., 2006d).

Neben den physiologischen Anpassungen unter akuter alveolärer Hypoxie führt chronische generalisierte Hypoxie zu pathophysiologischen Modifikationen der Lungenstrombahn. Unter chronischer Hypoxie setzt vaskuläres Remodeling ein: glatte Muskelzellen der medialen Schicht der Gefäßwand proliferieren und Fibroblasten wandern aus der Adventitia in die Media ein (Rose et al., 2002; Stenmark et al., 2006; Stenmark et al., 2002). Die zunehmende Muskularisierung der Gefäßwand setzt sich bis in die kleinen Widerstandsgefäße der Lunge fort und das Resultat von Proliferation und Migration ist die 
Verdickung der Gefäßmedia in diesen Gefäßen (Humbert et al., 2004; Jeffery and Morrell, 2002). Das vaskuläre Remodeling unter chronischer Hypoxie ruft diverse Symptome hervor: Hypertrophie des rechten Ventrikels des Herzens, Anstieg im pulmonalarteriellen Druck und Reduktion des Herz-Zeit-Volumens. Zusammen genommen sind das erste Anzeichen von Lungenhochdruck (Pulmonale Hypertonie, PH), einer zwar seltenen, aber aufgrund der diffusen Symptomatik oftmals tödlichen Krankheit (Peacock, 1999). Einen Überblick der unter chronischer Hypoxie ablaufenden zellulären Prozesse die zu vaskulärem Remodeling führen gibt Abbildung 1-5.

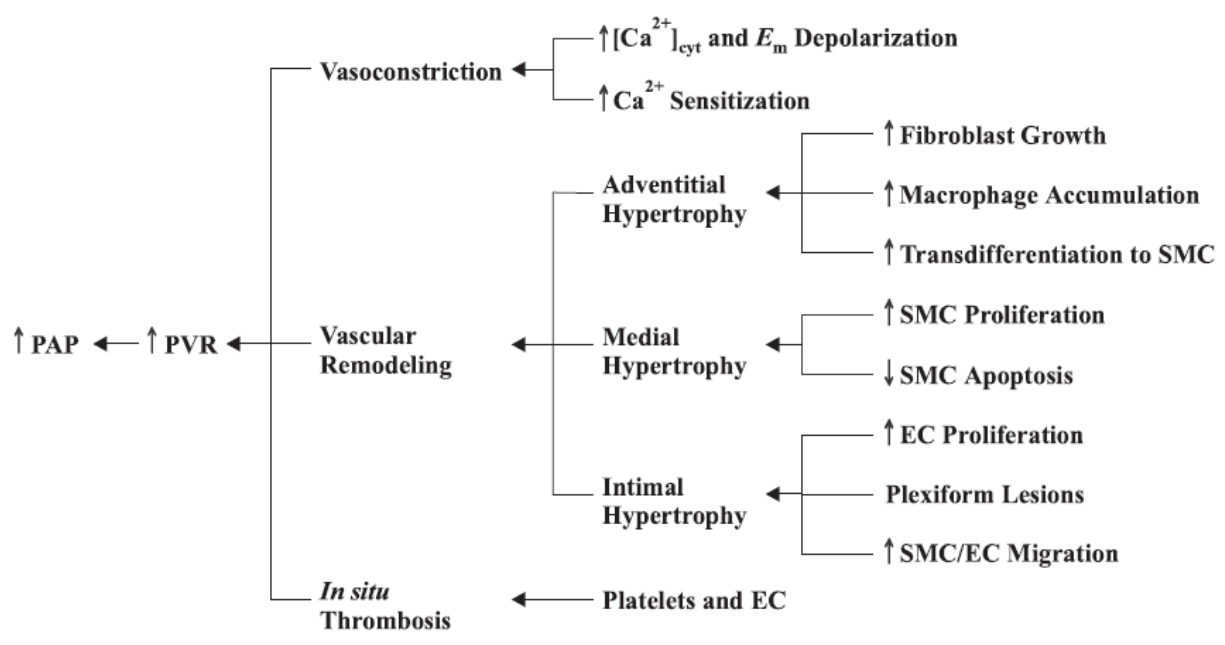

\section{Abbildung 1-5: Schematische Darstellung der pathophysiologischen Einflüsse bei der Entstehung pulmonaler Hypertonie}

$\mathrm{PVR}=$ pulmonary vascular resistance $\mathrm{PAP}=$ pulmonary artery pressure $; \mathrm{EM}=$ membrane potential; $\mathrm{SMC}=$ pulmonary smooth muscle cell; $\mathrm{EC}=$ pulmonary arterial endothelial cell (Mandegar et al., 2004).

Obwohl das Phänomen der Anpassung von Perfusion an die Ventilation schon seit über 50 Jahren bekannt ist, sind die grundlegenden molekularen, physiologischen und zellulären Prozesse, die letztendlich zur HPV führen, weitgehend ungeklärt. Einzig bezüglich der Effektorzellen herrscht Konsens zwischen den Arbeitsgruppen, die sich mit der Entstehung der HPV beschäftigen. Als einzige Zellen in der Gefäßwand sind glatte Muskelzellen befähigt $\mathrm{zu}$ kontrahieren und werden deshalb als Erfolgszelle für die hypoxische pulmonale Vasokonstriktion angesehen (Madden et al., 2000; Michelakis et al., 2004; Moudgil et al., 2005).

Die Kontraktion aller Muskelfasern in Warmblütern ist kalziumabhängig. Aber die Vorgänge, die zur Kontraktion der glatten Muskelzelle führen, unterscheiden sich von den zur Kontraktion führenden in der quergestreiften Muskulatur. Im inaktiven glatten Muskel liegt die Konzentration an sarkoplasmatischem $\mathrm{Ca}^{2+}$ unter $10^{-7} \mathrm{~mol} / \mathrm{l}$ und die Aktinfilamente des Muskels sind von dem Protein Caldesmon bedeckt. Durch das Protein werden die Bindungsstellen für den Myosinkopf blockiert, so dass keine Kontraktion stattfinden kann. Wird die Membran der glatten Muskelzelle depolarisiert, wird $\mathrm{Ca}^{2+}$ aus dem sarkoplasmatischen Retikulum (SR) freigesetzt und bildet mit Calmodulin (CaM) einen Komplex (Ca/CaM-Komplex). Der $\mathrm{Ca} / \mathrm{CaM}-$ Komplex wiederum aktiviert Proteinkinasen, die die Proteine Calponin, Caldesmon und die leichten Myosinketten des Myosinkopfes phosphorylieren. Durch die Phosphorylierung von Caldesmon löst sich das Protein vom Aktinfilament und gibt die Myosinbindungsstelle frei. Am Myosinfilament 
der Muskelfaser wird die leichte Kette des Myosinkopfes durch die $\mathrm{Ca} / \mathrm{CaM}$-vermittelte Aktivierung der Myosinleichtkettenkinase (Myosin Light Chain Kinase, MLCK) phosphoryliert. Nun können beide Filamente ineinander greifen und die Muskelzelle kontrahiert.

Unter Hypoxie wird die Zellmembran pulmonalarterieller glatter Muskelzellen durch die Inhibition spannungsabhängiger Kaliumkanäle $\left(\mathrm{K}_{\mathrm{V}}\right)$ depolarisiert. Durch die hypoxieinduzierte Hemmung der $\mathrm{K}_{\mathrm{V}}$, vor allem $\mathrm{K}_{\mathrm{V}} 1.5$ und $\mathrm{K}_{\mathrm{V}}$ 2.1, wird der Kaliumeflux aus der Zelle eingeschränkt und die Zellmembran depolarisiert. Infolgedessen werden spannungsabhängige Kalziumkanäle, vorrangig des L-Typs, aktiviert und Kalzium strömt aus dem extrazellulären Raum in die Zelle ein. Gleichzeitig wird Kalzium aus dem intrazellulären sarkoplasmatischen Retikulum freigesetzt. Dadurch wird die Zellmembran weiter depolarisiert, die oben beschriebenen Vorgänge werden induziert und die Zelle kontrahiert (Archer and Cowan, 1991; Cornfield et al., 1996; Hampl et al., 1995; Weir et al., 1994).

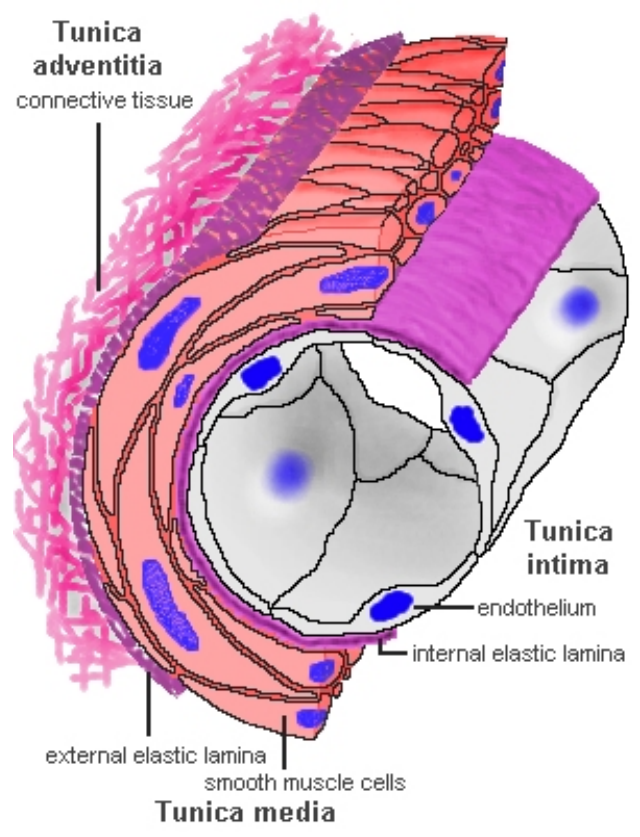

\section{Abbildung 1-6: Schematischer Aufbau der Gefäßwand}

Die Gefäßwand baut sich aus drei Schichten auf. Die innerste Schicht ist die Tunica intima, die aus Endothel und innerer elastischer Lamina besteht. Darauf folgt die Tunica media mit glatten Muskelzellen und äußerer elastischer Lamina. Die äußerste Begrenzung wird vom Bindegewebe gebildet (Tunica adventitia).

Neben dem beschriebenen Mechanismus der Inhibition spannungsabhängiger Kaliumkanäle, der die Kontraktion der glatten Muskelzelle auslöst, wird auch ein Mechanismus diskutiert, der unabhängig von $\mathrm{K}_{\mathrm{V}}$ ist. Die Kontraktion glatter Muskelzellen beruht nach dieser Theorie auf einem Kalziumeinstrom durch unselektive, kalziumpermeable Kationenkanäle, die entweder durch rezeptorvermittelte Antworten oder durch die Entleerung von Kalziumspeichern aktiviert werden (Albert and Large, 2006). Diese Kationenkanäle, die neben kalzium- auch natrium- und kaliumpermeabel sind, sind strukturell eng verwandt mit transienten Rezeptorpotentialkanälen (TRP) von Drosophila- 
Fliegen und werden bei Säugern in insgesamt sechs Unterfamilien gegliedert, nämlich canonische (TRPC), vanilloide (TRPV), polycystine (TRPP), ankyrine (TRPA), melastatine (TRPM) und mucolipine (TRPML) Kationenkanäle (Clapham et al., 2001). Die Funktion und Signaltransduktion vieler TRP-Kanäle ist noch nicht genau geklärt, von einigen ist allerdings bekannt, dass sie Aufgaben der Schmerzrezeption, Wärme- und Kältewahrnehmung übernehmen und die Signalübertragung über Diacylglycerol (DAG) oder Phosphatidyl-Inositol-Triphosphat $\left(\mathrm{PIP}_{3}\right)$ gesteuert wird (Clapham, 2003). In den letzten Jahren sind v. a. Kanäle des canonischen Typs (TRPC) in den Focus der aktuellen Diskussion um eine Beteilung bei der akut hypoxischen pulmonalen Vasokonstriktion und der Ausbildung der Mediahypertrophie in pulmonaler Hypertonie gelangt (Yao and Garland, 2005). Weißmann et al. zeigten in einer Studie, dass die akute HPV auf einem Einstrom von Kalzium durch den TRPC-6 Kanal gesteuert wird. Gleichzeitig konnte die Gruppe in ihrer Untersuchung nachweisen, dass der durch anhaltende Hypoxie ausgelöste kontinuierliche Anstieg des pulmonalarteriellen Druckes nicht von dem Einstrom von Kalziumionen durch diesen Kanal abhängig ist (Weissmann et al., 2006a). Nach einer Arbeit von Yu et al. sind TRPC-3 und TRPC-6 Kanäle ebenfalls für die Proliferation von pulmonalarteriellen glatten Muskelzellen verantwortlich und stehen somit in direktem Zusammenhang mit der in idiopathischer pulmonalarterieller Hypertonie auftretenden Mediahypertrophie (Yu et al., 2004).

Die Signaltransduktionskaskaden und die in die Kaskaden involvierten Schritte, die zur Kontraktion der glatten Muskelzellen führen, sind dagegen umstritten, ebenso wie die Frage nach den Sauerstoffsensoren, die in der Lage sind den $\mathrm{PO}_{2}$ im Gewebe zu „,messen“. Obwohl die glatten Muskelzellen der Gefäßwand weder in direktem Kontakt mit dem Blut noch mit dem Alveolarraum stehen (Abbildung 1-6), werden sie von einigen Arbeitsgruppen als Sauerstoffsensoren diskutiert (Lopez-Barneo et al., 2004; Michelakis et al., 1995; Weir et al., 2002; Wolin et al., 2005). Diese These wird zudem durch die Beobachtung gestützt, dass pulmonalarterielle glatte Muskelzellen und Schnitte von Pulmonalarterien als Reaktion auf Hypoxie kontrahieren, selbst wenn die endotheliale Zellschicht mechanisch entfernt wurde (Liu et al., 2003; Michelakis et al., 2004). Somit scheiden nach dieser Hypothese Endothelzellen als mögliche Sauerstoffsensoren aus. Andere Arbeitsgruppen konnten zudem zeigen, dass die HPV vom Sauerstoffpartialdruck $\left(\mathrm{PO}_{2}\right)$ im Blut unabhängig ist und allein durch den $\mathrm{PO}_{2}$ im Alveolarraum gesteuert wird. Weitere hypothetisch in Frage kommende Sauerstoffsensoren sind

$>$ Zytochrom P450, das unter Hypoxie oxidiert werden soll (Acker et al., 2006; Fleming et al., 2001; Kummer and Yamamoto, 2002; Porwol et al., 2001; Sylvester and McGowan, 1978),

$>$ NO-Synthasen, die durch Hypoxie inhibiert werden sollen (Archer et al., 1995; Dumitrascu et al., 2006; Landmesser et al., 2003; Weissmann et al., 2003b),

> Mitochondrien (Archer et al., 2006b; Archer et al., 2004; Michelakis et al., 2002; Michelakis et al., 2004; Waypa et al., 2001; Waypa and Schumacker, 2002; Zwicker et al., 1998)

$>$ phagozytäre und nicht-phagozytäre NADP(H)-Oxidasen (Babior, 2004; Brennan et al., 2003; Ellmark et al., 2005; Liu et al., 2006; Weissmann et al., 2006c).

Für alle oben angeführten Sauerstoffsensormechanismen für die akute und chronische Hypoxie werden reaktive Sauerstoffspezies als Signalmoleküle diskutiert (Chandel and Schumacker, 2000; Lassegue and Griendling, 2004; Moudgil et al., 2005; Schumacker, 2003; Touyz and Schiffrin, 2004; Ward et al., 2004b; Waypa and Schumacker, 2005; Weir et al., 2002; Wenger, 2006). Durch die ROS-Produktion soll das intrazelluläre RedoxPotential verändert und auf diese Weise das Signal weitergeleitet werden, das letztendlich 
durch Konformationsänderung der $\mathrm{K}_{\mathrm{V}}$ zur Kontraktion der glatten Muskelzellen unter Hypoxie führt (Gupte and Wolin, 2006; Kummer and Yamamoto, 2002; Lopez-Barneo et al., 2004; Waypa et al., 2001; Weir et al., 2002; Weissmann et al., 2003a; Wolin et al., 2005). Offen hingegen ist die Frage, welche Strukturen zur ROS-Produktion unter Hypoxie beitragen und ob es zu einer vermehrten oder verminderten Freisetzung der Radikale kommt (Aaronson, 2006; Aaronson et al., 2006; Rojas et al., 2006; Sham, 2002; Sylvester, 2001; Weissmann et al., 2006b).

\section{$1.3 \mathrm{NADP}(\mathrm{H})$-Oxidasen}

$\underline{\text { Nikotinamid-A }}$ denin-Dinukleotid-Phosphat (NADP(H))-Oxidasen wurden ursprünglich als ROS-produzierende Systeme phagozytierender Zellen (Tabelle 1-2) wie den polymorphkernigen neutrophilen Leukozyten und den mononukleären Phagozyten (Babior, 2002b; Babior et al., 2002) beschrieben. Diese Zellen des Immunsystems setzen als Antwort auf eingedrungene Fremdpartikel und Mikroorganismen eine große Menge an Sauerstoffradikalen frei, ein Vorgang, durch den der Sauerstoffverbrauch der Zelle um das hundertfache ansteigt und der deswegen ,respiratorischer Burst“ bzw. „oxidativer Burst" genannt wird (El-Benna et al., 2005). Das Hauptprodukt des respiratorischen Bursts ist Superoxid $\left({ }^{\circ} \mathrm{O}_{2}{ }^{-}\right)$, das durch die Ein-Elektronen-Reduktion aus molekularem Sauerstoff entsteht und das Vorläufermolekül einer Vielzahl weiterer reaktiver Sauerstoffspezies ist $\left(\mathrm{HOCl}, \mathrm{OH}^{-}, \mathrm{H}_{2} \mathrm{O}_{2}\right)$. In nicht-phagozytierenden Zellen, u. a. Endothelzellen (Bokoch and Knaus, 2003; Hohler et al., 2000; Li and Shah, 2002), Fibroblasten der Adventitia (Bengtsson et al., 2003; Brennan et al., 2003; Chamseddine and Miller, 2003) und glatten Muskelzellen (Ellmark et al., 2005; Griendling et al., 1997), setzen NADP(H)-Oxidasen reaktive Sauerstoffspezies als Signalmoleküle und zur Regulation des Zellstoffwechsels frei. Hier übernehmen die ROS wichtige Funktionen bezüglich des Zellzyklus, der Aktivität von Proteinkinasen und der Genexpression (Berasi et al., 2004; Frank et al., 2000; Martins Chaves et al., 2002; Potashkin and Meredith, 2006; Sauer et al., 2001; Yoshimoto et al., 2005). 
Tabelle 1-2: Übersicht der phagozytierenden Zellen in Blut und Gewebe:

Die Gesamtpopulation der phagozytierenden Zellen setzt sich aus polymorphkernigen Leukozyten im Blut und mononukleären Phagozyten in Blut und Geweben zusammen. Die Leukozytenpopulation wird aus neutrophilen, eosinophilen und basophilen Granulozyten gebildet. $\mathrm{Zu}$ den Phagozyten gehören Monozyten und Makrophagen, Lymphozyten bilden ein weiteres System der Immunabwehr (Klinke and Silbernagl, 2003).

\begin{tabular}{|c|c|c|c|}
\hline Zelltyp & $\begin{array}{l}\text { Anzahl/ } \\
\mu 1 \text { Blut }\end{array}$ & $\begin{array}{c}\% \text { der } \\
\text { Leukozyten }\end{array}$ & Funktion \\
\hline Leukozyten & $\begin{array}{l}5.000- \\
10.000\end{array}$ & & \\
\hline \multicolumn{4}{|l|}{ Granulozyten } \\
\hline Neutrophile & & $40-60$ & $\begin{array}{l}\text { Phagozytose und Lyse von Parasiten (Viren, Bakterien) } \\
\text { Freisetzung von Leukotrienen } \\
\text { Bildung von Lysozym, Laktoferrin, ROS }\end{array}$ \\
\hline Eosinophile & & $1-3$ & $\begin{array}{l}\text { Abwehr von parasitären Würmern } \\
\text { Synergie mit Mastzellen und basophilen Granulozyten }\end{array}$ \\
\hline Basophile & & $0-1$ & $\begin{array}{l}\text { Freisetzung von Histamin und Heparin } \\
\text { Abwehr einzelliger Mikroorganismen } \\
\text { Histaminabhängige Allergiesymptome } \\
\text { Freisetzung chemotaktischer Lockstoffe für } \\
\text { Eosinophile }\end{array}$ \\
\hline $\begin{array}{l}\text { Mononukleäre } \\
\text { Phagozyten } \\
\text { (Monozyten, } \\
\text { Makrophagen) }\end{array}$ & & $4-8$ & $\begin{array}{l}\text { Vorläuferzellen des mononukleären } \\
\text { Phagozytensystems (MPS) } \\
\text { MPS-Zellen: Phagozytose und Antigenpräsentation } \\
\text { Freisetzung von Proteasen, ROS, NO, Interleukine }\end{array}$ \\
\hline Lymphozyten & & $20-40$ & $\begin{array}{l}\text { B- und T-Lymphozyten } \\
\text { Humorale und zellvermittelte Immunität }\end{array}$ \\
\hline
\end{tabular}

\subsubsection{Aufbau und Funktion}

Nicht-phagozytäre NADP(H)-Oxidasen (Nox) sind prinzipiell in ihrer Struktur identisch oder homolog zu phagozytären NADP(H)-Oxidasen (Phox). Allerdings unterscheidet sich abhängig vom zellulären Ursprung die Nomenklatur für manche Untereinheiten. Auf die verschiedenen Bezeichnungen für homologe Strukturen wird bei der Beschreibung der Untereinheiten eingegangen.

Die aktive NADP(H)-Oxidase ist ein Multi-Protein-Komplex und setzt sich aus mindestens sechs Untereinheiten zusammen (Abbildung 1-7). Die erste Untereinheit ist das membrangebundene Glykoprotein gp9 ${ }^{\text {phox }}$ bzw. dessen Homolog Nox-2. Dieses Protein hat katalytische Funktion und beinhaltet die gesamte Redox-Maschinerie die nötig ist, um Elektronen von NADP(H) auf der zytoplasmatischen Seite über FAD und zwei Hämproteine auf molekularen Sauerstoff im extrazellulären oder intraphagosomalen Raum zu übertragen. Für Nox-2 wurden insgesamt sieben Isoformen beschrieben, die in unterschiedlichen Zelltypen vorkommen. Griendling und Mitarbeiter beschrieben 1997 als erste die in vaskulären glatten Muskelzellen vorkommende Isoform Nox-1 (Griendling et 
al., 1997). Diese Isoform soll u. a. auch an Signaltransduktionskaskaden beteiligt sein, die zu Hypertrophie und Zellproliferation führen (Arnold et al., 2001; Suh et al., 1999). Neben Nox-1 und Nox-2 wurde von Cheng et al. und Banfi et al. die dritte Nox-Isoform, Nox-3, beschrieben (Banfi et al., 2004; Cheng et al., 2001; Cheng et al., 2004). Nox-3 kommt überwiegend in fetalem Gewebe der Niere und Leber vor. Die vierte, von Cheng et al. und Shiose et al. beschriebene Isoform Nox-4 wurde ebenfalls in Nierengewebe identifiziert. Zudem wurde Nox-4 in kardialen Endothelzellen nachgewiesen (Cheng et al., 2001; Shiose et al., 2001). Die Funktion der von Banfi et al. beschriebenen fünften Isoform, Nox-5, ist zumindest für die Lungenphysiologie zurzeit noch nicht bekannt (Banfi et al., 2001; Cheng et al., 2001). Im Jahr 2003 konnten Brar und Mitarbeiter eine regulatorische Funktion für das Wachstum von Krebszellen für die Nox-5 Isoform nachweisen (Brar et al., 2003). Neben den angeführten Nox-Isoformen wurden zwei weitere Ausprägungen der gp91 ${ }^{\text {phox }}$ Untereinheit charakterisiert. Da sie eine zusätzliche Transmembrandomäne aufweisen, wurden diese Formen mit Duox-1 und Duox-2 bezeichnet, wobei sich der Name aus der Abkürzung für „Dual Oxidase“ zusammensetzt (Donko et al., 2005; Geiszt, 2006; Leto and Geiszt, 2006).

Die zweite membrangebundene Untereinheit aktiver NADP(H)-Oxidasen ist das nicht glykosylierte Protein p22 $2^{\text {phox }}$. Zusammen mit gp9 $1^{\text {phox }}$ bildet es einen stabilen Komplex, der Zytochrom $b_{558}$ genannt wird und zur Gruppe der Flavohämproteine gehört. p22 $2^{\text {phox }}$ besitzt an seinem C-Terminus eine Bindungsstelle für das regulatorische zytoplasmatische Protein $\mathrm{p} 47^{\text {phox }}$ und trägt damit wesentlich zur Bildung der aktiven NADP(H)-Oxidase bei. Zudem ist $\mathrm{p} 22^{\text {phox }}$ wichtig für die Regulation der katalytisch aktiven gp91 ${ }^{\text {phox }}$-Untereinheit.

Neben den beiden besprochenen integralen Membranproteinen sind an der Bildung aktiver NADP $(\mathrm{H})$-Oxidasen vier zytosolische Proteine beteiligt. Sie liegen normalerweise frei im Zytosol vor und komplexieren erst auf einen Stimulus, um dann als Tetramer an Zytochrom $b_{558} \mathrm{zu}$ binden. $\mathrm{Zu}$ den zytosolischen Untereinheiten gehört das regulatorisch aktive Adapterprotein $\mathrm{p} 47^{\text {phox }}$. In nicht aktiviertem Zustand ist dieses Protein so gefaltet, dass die Bindungsstellen für $\mathrm{p} 22^{\text {phox }}$ nicht zugänglich sind, $d$. h. es liegt in autoinhibitorischer Konformation vor. Nach Stimulierung entfaltet sich das Protein und bindet dann an $\mathrm{p}^{2} 2^{\text {phox }}$ des Zytochroms $\mathrm{b}_{558}$.

Ein weiteres NADP(H)-Oxidase spezifisches regulatorisches Protein ist $\mathrm{p} 67^{\text {phox }}$. Es bindet an aktiviertes $\mathrm{p} 47^{\text {phox }}$ und wird mit ihm zusammen zur Zellemembran translokiert. Zusammen mit der GTPase Rac aktiviert p6 $7^{\text {phox }}$ den NADP(H)-Oxidase Komplex. Die GTPase Rac ist bis zur Stimulation an das inhibitorische Protein RhoGDI im Zytosol gebunden. Nach Stimulation löst sich Rac von dem Inhibitor, bindet an der Zellmembran GTP und wird dadurch aktiviert. Wie bereits erwähnt, bindet es in der aktiven Form an die p6 $7^{\text {phox }}$-Untereinheit und ist somit unbedingt notwendig für die Aktivierung von NADP(H)-Oxidasen. 


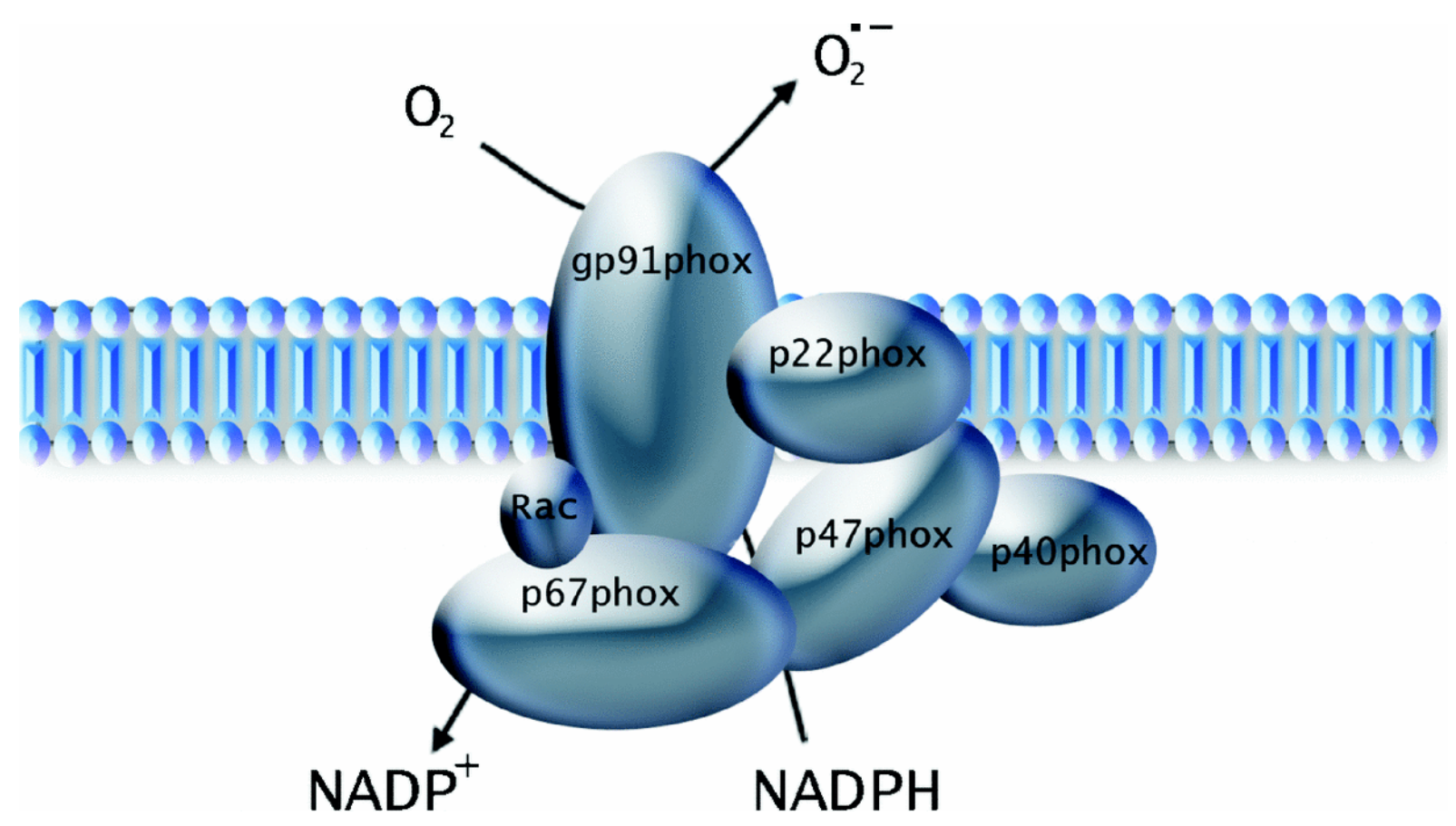

\section{Abbildung 1-7: Schematische Darstellung der aktiven NADP(H)-Oxidase}

Der aktive Komplex setzt sich aus den beiden membrangebundenen Proteinen gp91 $1^{\text {phox }}$ und $\mathrm{p} 22^{\text {phox }}$ zusammen. Hinzu kommt ein Tetramer aus zytosolischen Proteinen, das aus den Einheiten p6 $7^{\text {phox }}$, p40 $0^{\text {phox }}$ und der GTPase Rac sowie aus der p47 $7^{\text {phox }}$-Untereinheit besteht (nach www.clinsci.org/cs/109/0217/cs1090217f02.gif).

Das vierte und letzte Protein, das zur Bildung des Komplexes beiträgt, ist $\mathrm{p} 40^{\text {phox }}$. Das Protein funktioniert wie ein Adapter für die gp91 ${ }^{\text {phox }}$-Untereinheit und reguliert folglich ebenfalls die Aktivität der NADP(H)-Oxidase. Im Zytosol bindet $\mathrm{p} 40^{\text {phox }}$ fest an $\mathrm{p} 67^{\text {phox }}$, allerdings ohne dessen Bindungsfähigkeit für das $\mathrm{p} 47^{\text {phox }}$ Protein zu beeinträchtigen. Alle drei genannten Proteine formen im Zytosol einen trimeren Komplex, der als Ganzes zur Zellmembran wandert, wo die Interaktion von p67 $7^{\text {phox }}$ mit Rac stattfindet. Die homologen Proteine $\mathrm{zu}$ p $47^{\text {phox }}$ und $\mathrm{p} 67^{\text {phox }}$, die in nicht-phagozytären Zellen vorkommen, wurden gemäß ihrer organisierenden bzw. aktivierenden Funktion benannt. Das organisierende Protein $\mathrm{p} 47^{\text {phox }}$ trägt in nicht-phagozytären NADP(H)-Oxidasen den Namen NoxOrganizer, NoxO, und das aktivierende Protein $\mathrm{p} 67^{\text {phox }}$ wird, wenn es in nichtphagozytären Zellen exprimiert wird, Nox-Aktivator, NoxA, genannt. Eine Übersicht über die einzelnen Untereinheiten von NADP(H)-Oxidasen gibt auch Tabelle 1-3.

Die Funktion der NADP(H)-Oxidasen wird durch die Zelle bestimmt, die den Proteinkomplex exprimieren. In Phagozyten wird das von NADP $(\mathrm{H})$-Oxidasen produzierte Superoxid zur Bekämpfung von pathogenen Organismen eingesetzt. In allen anderen Zelltypen fungieren die durch die nicht-phagozytären NADP(H)-Oxidasen freigesetzten Radikale als intra- und interzelluläre Signalmoleküle. Auf die Rolle von ROS wird im nachfolgenden Abschnitt 1.4 genauer eingegangen.

Allen NADP(H)-Oxidasen gemein ist die Umwandlung von NADPH zu NADP ${ }^{+}+\mathrm{H}^{+}$ (Formel 1-1). Das bei dieser Reaktion freigesetzte Elektron wird durch die Redoxkette der NADP(H)-Oxidasen über verschiedene Zwischenschritte auf molekularen Sauerstoff übertragen, wodurch letztendlich das Superoxidradikal entsteht (Abbildung 1-8). 


\section{Tabelle 1-3: Einteilung der Untereinheiten von NADP(H)-Oxidasen}

Übersicht der in Phagozyten exprimierten Untereinheiten und deren Homologe in nichtphagozytären Zellen. Aufgeführt sind ebenfalls die Isoformen der homologen Proteine (Babior, 1999, 2000, 2002b, 2004; Babior et al., 2002; Bengtsson et al., 2003; Bokoch and Knaus, 2003; Cheng et al., 2001; Cheng and Lambeth, 2005; Donko et al., 2005; Geiszt, 2006; Geiszt and Leto, 2004; Lambeth, 2002, 2004; Lassegue and Clempus, 2003; Soccio et al., 2005; Sumimoto et al., 2005).

\begin{tabular}{|c|c|l|}
\hline Phagozyten & Homolog in Nicht-Phagozyten & \multicolumn{1}{|c|}{ Isoformen } \\
\hline \hline $\mathrm{gp} 91^{\text {phox }}$ & Nox-2 & $\begin{array}{l}\text { Nox-1; Nox-3; Nox-4; Nox-5; Duox-1; } \\
\text { Duox-2 }\end{array}$ \\
\hline $\mathrm{p} 22^{\text {phox }}$ & & \\
\hline $\mathrm{p} 47^{\text {phox }}$ & NoxO & NoxO-1; NoxO-2 \\
\hline $\mathrm{p} 67^{\text {phox }}$ & NoxA & \\
\hline $\mathrm{p} 40^{\text {phox }}$ & & \\
\hline Rac & & \\
\hline
\end{tabular}

Die Aktivierung des Komplexes kann auf zweierlei Weise erfolgen und verläuft in fünf Phasen. In der ersten Phase kann zum einen eine rezeptorvermittelte Antwort entstehen, nämlich wenn ein Agonist an einen Rezeptor in der Plasmamembran bindet. Zum anderen gibt es auch nicht-rezeptorvermittelte Antworten, wie sie bei künstlichen Stimuli, z. B. der Applikation von Phorbol-Myristat-Acetat (PMA), vorkommen. In beiden Fällen werden in der zweiten Phase Proteinkinasen aktiviert, darunter auch Proteinkinase C (PK-C), die diverse Komponenten von NADP(H)-Oxidasen phosphorylieren. Der wichtigste Schritt in dieser Phase ist die Phosphorylierung von $\mathrm{p} 47^{\text {phox }}$. Die übertragenen Phosphatgruppen sorgen für die Entfaltung der Untereinheit, so dass sie nicht länger in der autoinhibitorischen Konfiguration vorliegt. Die dritte Phase ist durch die Aktivierung von Phospholipase $\mathrm{A}_{2}$ charakterisiert, wodurch die Bildung von Arachidonic Acid begünstigt wird. Arachidonic Acid aktiviert nun wiederum die NADP(H)-Oxidase. Die vierte Phase dient dazu, die NADP(H)-Oxidase zu vervollständigen. Der trimere Komplex aus den zytosolischen Untereinheiten sowie die GTPase Rac wandern zur Zellmembran und verbinden sich mit Zytochrom $b_{558}$. In den letzten Phasen wird NADP(H) an die aktivierte Oxidase gebunden und zudem Protonenkanäle in einen aktivierten, geöffneten Zustand versetzt.

An der aktiven NADP(H)-Oxidase findet der Elektronentransport statt (Abbildung 1-8). In insgesamt neun Schritten werden Elektronen von NADP(H) auf molekularen Sauerstoff übertragen, wodurch Superoxid entsteht, das in einem abschließenden zehnten Schritt in Wasserstoffperoxid dismutiert werden kann. Am Anfang der Kette steht die Synthese von NADP(H), in Abbildung 1-8 mit „1“ gekennzeichnet. NADP(H) ist, genau wie das

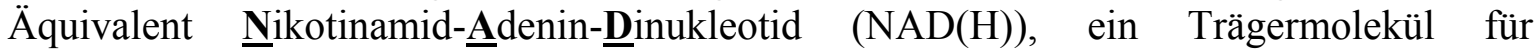
hochenergetische Elektronen. In einer typischen Oxidations-Reduktions-Reaktion gibt ein Substrat zwei Protonen $\left(\mathrm{H}^{+}\right)$und zwei Elektron $\left(\mathrm{H}^{-}\right)$ab. Ein $\mathrm{H}^{+}$und die zwei Elektronen werden von oxidiertem NADP ${ }^{+}$aufgenommen. $\mathrm{NADP}^{+}$wird also reduziert und es entsteht NADPH. Das zweite vom Substrat abgegebene $\mathrm{H}^{+}$gelangt in die Reaktionslösung und wird nicht an $\mathrm{NADP}^{+}$gebunden (Formel 1-1).

$$
N A D P^{+}+\text {Substrat }-H-H \stackrel{2 H-}{\longrightarrow} N A D P H+H^{+}+\text {Substrat }
$$


In den nächsten Schritten der Elektronentransportkette bindet NADPH an die Bindungsstelle der gp91 ${ }^{\text {phox }}$-Untereinheit (2) und gibt das Proton und zwei Elektronen ab, worauf es wieder von der Bindungsstelle abfällt (3). Im vierten Schritt erfolgt der Elektronentransfer von NADPH auf FAD (4), und FAD bindet an das innere der beiden Häm-Proteine im NADP(H)-Oxidase-Komplex (5). Vom inneren Häm werden die Elektronen an das äußere Häm weitergegeben (6) und von dort auf Sauerstoff übertragen (7). Molekularer Sauerstoff hat in der Zwischenzeit an die vorgesehene Bindungsstelle auf der äußeren Plasmamembran gebunden (8) und wird nach erfolgtem Elektronentransfer als Superoxidradikal entlassen (9). Als letzter Schritt kann ${ }^{\circ} \mathrm{O}_{2}{ }^{-}$in $\mathrm{H}_{2} \mathrm{O}_{2}$ umgewandelt werden.

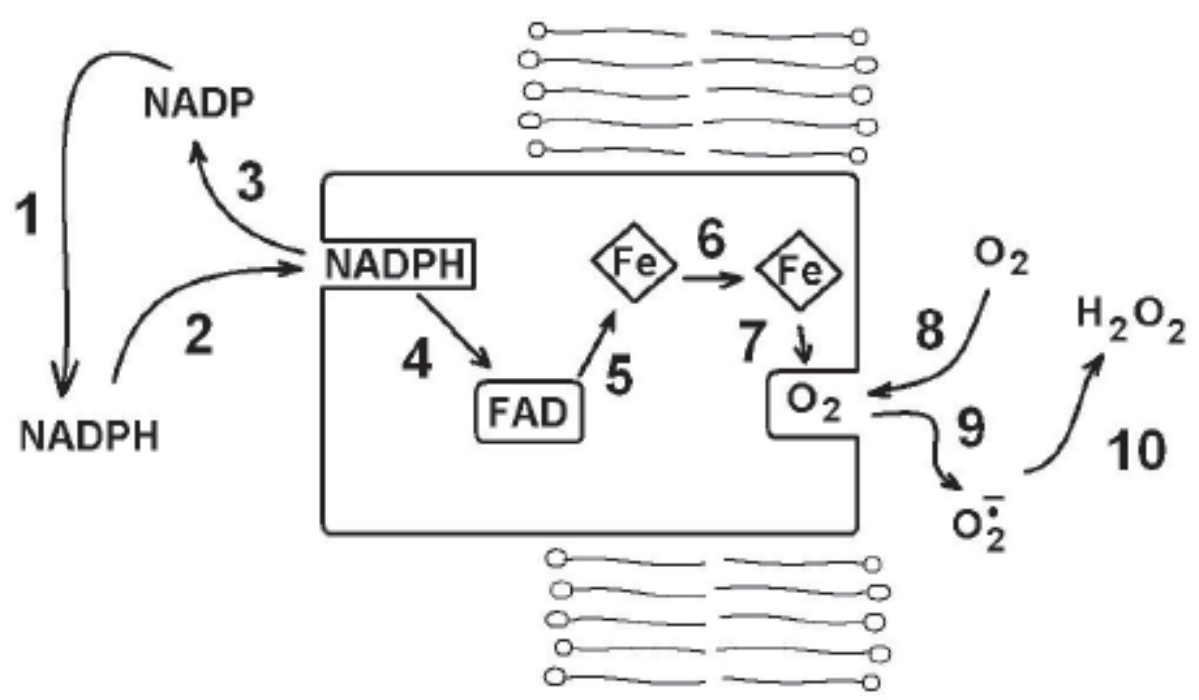

Abbildung 1-8: Elektronentransport der aktivierten NADP(H)-Oxidase

Die in der Graphik dargestellten Schritte $(1-10)$ sind im Text erklärt. (Decoursey and Ligeti, 2005).

\subsection{Reaktive Sauerstoffspezies}

Die Familie der reaktiven Sauerstoffspezies (ROS) umfasst sowohl Radikale als auch Nicht-Radikale. Das Superoxid-Anion $\left({ }^{\circ} \mathrm{O}_{2}{ }^{-}\right)$ist das biologisch relevanteste Radikal, da es das Vorläufermolekül anderer ROS ist. Zu den Radikalen werden weiterhin das HydroxylRadikal $\left(\mathrm{OH}^{\circ}\right)$ und das Peroxyl-Radikal $\left(\mathrm{ROO}^{\bullet}\right)$ gezählt. Zur Gruppe der Nicht-Radikale gehören das Wasserstoffperoxid-Molekül $\left(\mathrm{H}_{2} \mathrm{O}_{2}\right)$, Sauerstoff in der Singlet-Form $\left({ }^{1} \mathrm{O}_{2}\right)$, das Hypochlorit-Ion $\left(\mathrm{OCl}^{-}\right)$, sowie Stickoxid $\left(\mathrm{NO}^{\circ}\right)$ und Peroxynitrit $\left(\mathrm{ONOO}^{-}\right)$. Letztere Moleküle werden oftmals auch als RNS (reaktive Stickstoffspezies, engl.: reactive nitrogen species) zusammengefasst und zählen nur bedingt zur Familie der ROS.

Per Definition werden Atome bzw. Moleküle mit ungepaarten Elektronen als Radikale bezeichnet. Jedes Sauerstoffatom besitzt in seiner äußeren Schale zwei ungepaarte Elektronen und ist chemisch gesehen ein Diradikal, das sich in flüssiger Form in einem Magnetfeld ausrichtet. Diese Eigenschaft impliziert, dass für die vollständige Reduktion molekularen Sauerstoffs zu Wasser vier Elektronen benötigt werden. Die aufeinander folgende Reduktion von Sauerstoff durch jeweils ein Elektron führt zur Bildung von 
reaktiven Zwischenprodukten, die intra-, inter- und extrazellulär wirken können. Das Superoxid-Anion entsteht durch Ein-Elektronen-Reduktion aus molekularem Sauerstoff. Wird ein zweites Elektron übertragen, entsteht Peroxid, das durch Protonierung in Wasserstoffperoxid übergeht. Das hoch reaktive Hydroxyl-Radikal entsteht durch weitere Ein-Elektronen-Reduktion aus Wasserstoffperoxid, wie es bei der Fenton-Reaktion (Formel 1-2) der Fall ist. Das Wassermolekül, das durch den letzten Reduktionsschritt entsteht, ist das Endprodukt der Elektronentransportkette. Die im Text aufgeführten Schritte zur Entstehung von ROS sind in Abbildung 1-9 nochmals graphisch dargestellt. Sauerstoff in der Singlet-Form besitzt ein Elektron in der äußersten Schale, welches in einen höheren energetischen Zustand gebracht wurde. Es ist eine sehr kurzlebige aber hoch reaktive Form von molekularem Sauerstoff, die durch viele Mechanismen entstehen kann. Als Beispiel ist hier die Haber-Weiss-Reaktion (Formel 1-3) angeführt.

$$
\mathrm{Fe}^{2+}+\mathrm{H}_{2} \mathrm{O}_{2} \rightarrow \mathrm{Fe}^{3+}+{ }^{\bullet} \mathrm{OH}+\mathrm{OH}^{-}
$$

\section{Formel 1-2: Fenton-Reaktion}

Durch die Reaktion mit Wasserstoffperoxid wird Eisen $\left(\mathrm{Fe}^{2+}\right)$ oxidiert und geht in die $\mathrm{Fe}^{3+}$-Form über. Zudem entsteht ein Hydroxyl-Radikal $\left({ }^{\circ} \mathrm{OH}\right)$ und ein Hydroxyl-Anion $\left(\mathrm{OH}^{-}\right)$

$$
\mathrm{H}_{2} \mathrm{O}_{2}+{ }^{\bullet} \mathrm{O}_{2}^{-} \rightarrow \cdot \mathrm{OH}+\mathrm{OH}^{-}+{ }^{1} \mathrm{O}_{2}
$$

\section{Formel 1-3: Haber-Weiss-Reaktion}

Durch die Reaktion von Wasserstoffperoxid mit dem Superoxid-Anion entsteht Singlet-Sauerstoff. Weitere Produkte sind das Hydroxyl-Radikal und das Hydroxyl-Anion.

Reaktive Sauerstoffspezies können in unterschiedlichen Geweben und Zellen durch eine Vielzahl enzymatischer und nicht-enzymatischer Mechanismen entstehen. Die wichtigsten Systeme die zur ROS-Bildung beitragen, sind Xanthin-Oxidasen (Kuppusamy and Zweier, 1989; McNally et al., 2003; Spiekermann et al., 2003), NADP(H)-Oxidasen (Boldogh et al., 2005; Seno et al., 2001; Vejrazka et al., 2005; Weissmann et al., 2000), die mitochondriale Elektronentransportkette (Archer et al., 2006a; Brunelle et al., 2005; Liu et al., 2002; Weissmann et al., 2001a) und Zytochrom P450 (Fleming et al., 2001; Zhang et al., 2006). Andererseits entstehen reaktive Sauerstoffspezies auch durch die Autooxidation von Katecholaminen (Lopez-Barneo et al., 2006) und durch Entkopplung von NOSynthasen (Archer et al., 1995; Kuzkaya et al., 2005; Satoh et al., 2005; Sies and de Groot, 1992; Weissmann et al., 2001b; Wolin, 2000).

Seit der Entdeckung reaktiver Sauerstoffspezies in biologischen Systemen durch Commoner und Mitarbeiter im Jahr 1954 (Commoner et al., 1954) wurden ROS zunächst als schädliche aber unabdingbare Nebenprodukte des oxidativen Stoffwechsels angesehen. Begründet ist das in den freien ungepaarten Elektronen, durch die die Radikale hochreaktiv sind und sehr schnell mit Strukturen in der Zelle, z. B. DNA, Proteinen und Lipiden, interagieren (Irani, 2000; Kimura et al., 2005; Sies and de Groot, 1992; Wilborn et al., 1996). ROS in unphysiologisch hohen Konzentrationen führen zu oxidativem Stress, der durch die Akkumulation von ROS aufgrund erhöhter Radikalbildung und eingeschränktem Abbau durch intrinsische Antioxidationsmechanismen entsteht. Dann erkannte man die Notwendigkeit der ROS-Produktion für die Immunabwehr durch Granulozyten und Makrophagen, die vermittels des oxidativen Bursts große Mengen der Radikale freisetzen 
(Forman and Torres, 2001, 2002; Moslen, 1994). Diese antimikrobielle Funktion von ROS wird in Abschnitt 1.3 genauer behandelt.

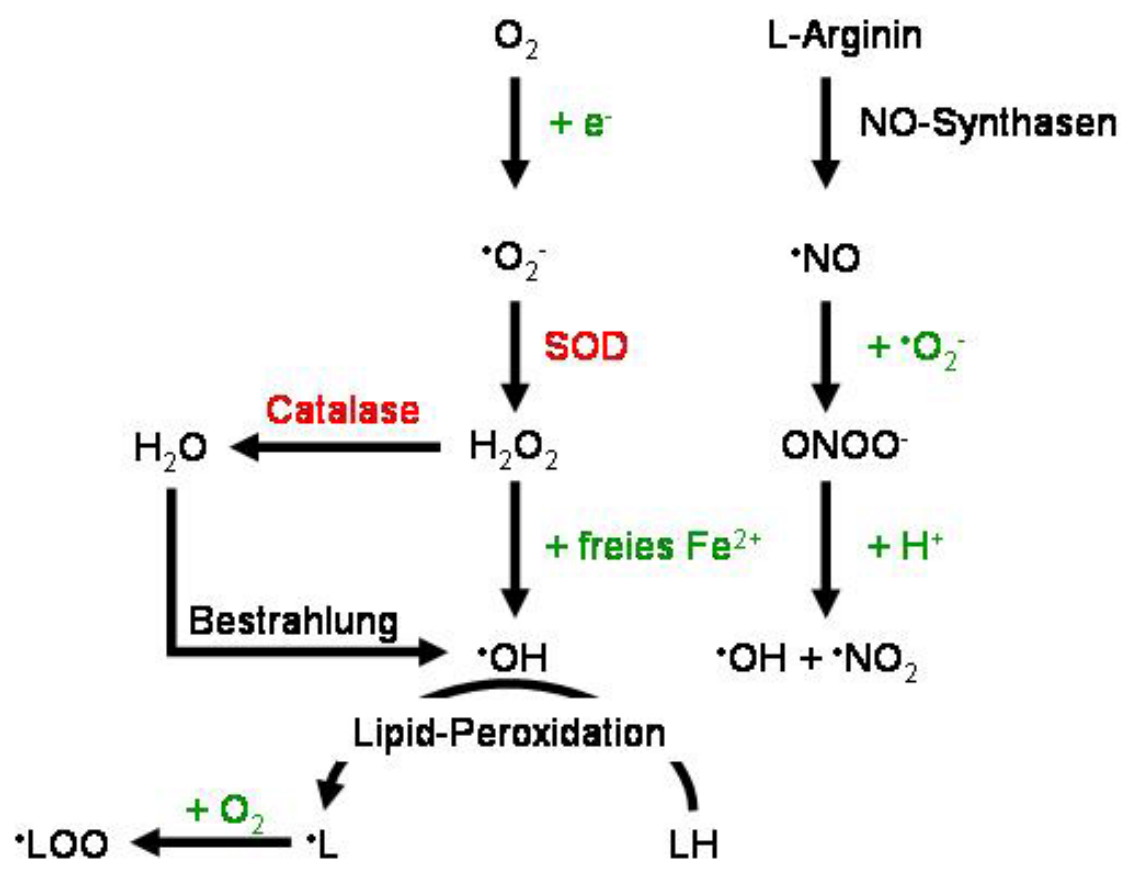

\section{Abbildung 1-9: Entstehung von Radikalen}

Durch Ein-Elektronen-Reduktion entsteht aus molekularem Sauerstoff das Superoxid-Anion. Es ist Vorläufermolekül für alle weiteren ROS. In rot sind die Enzyme Superoxiddismutase (SOD) und Catalase eingezeichnet, Moleküle und Atome, die zur Entstehung von ROS beitragen, sind in grün dargestellt. Weitere Erklärungen im Text. Nach H. Sies, verändert.

Wie im vorigen Abschnitt erwähnt, sind ROS in der Lage mit verschiedenen zellulären Komponenten $\mathrm{zu}$ interagieren. Auf DNA-Ebene induziert oxidativer Stress Konformationsänderungen und Veränderung der Basen, die die DNA-Moleküle aufbauen. Die Folgen dieser Modifikationen sind Brüche im DNA-Strang, Änderungen der Wasserstoffbrückenbindungen zwischen den Basen und dadurch Blockaden des Replikationsmechanismus. Insgesamt erhöht sich dadurch die Wahrscheinlichkeit für Mutationen (Abbildung 1-10 a). Werden Lipide durch die Reaktion mit reaktiven Sauerstoffspezies peroxidiert, vermindert sich die Effizienz von DNA-Polymerasen. Somit kann auch die ROS-induzierte Lipid-Peroxidation zu Mutationen führen, indem Fehler in der DNA nicht mehr repariert werden können (Abbildung 1-10 b). Als dritte Molekülgruppe werden Proteine von reaktiven Sauerstoffspezies beeinflusst. ROS können stress-induzierte Antworten von Genen und Proteinen modulieren und regulieren so Zellwachstum, Zelldifferenzierung, Apoptose und Nekrose. Ein weiterer Effekt der Reaktion von Proteinen mit ROS ist die Aktivierung von Zellproliferation und Signaltransduktion, was sich ebenfalls auf die vorgenannten zellulären Mechanismen auswirkt (Abbildung 1-10 c). 
a)

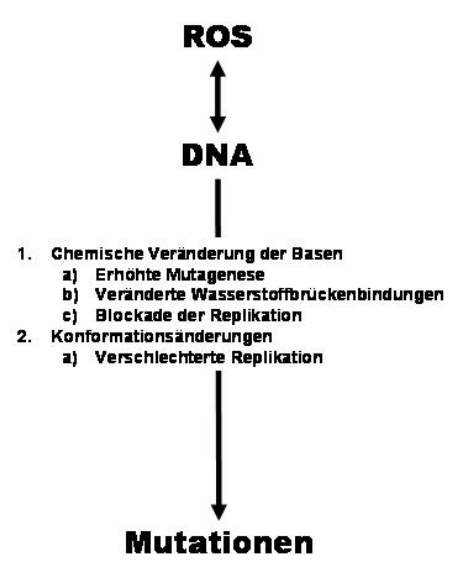

b)

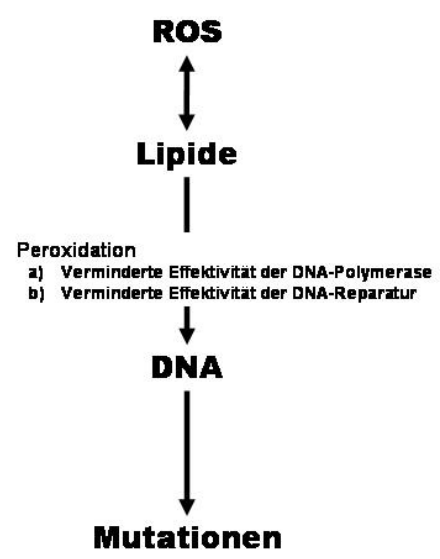

c)

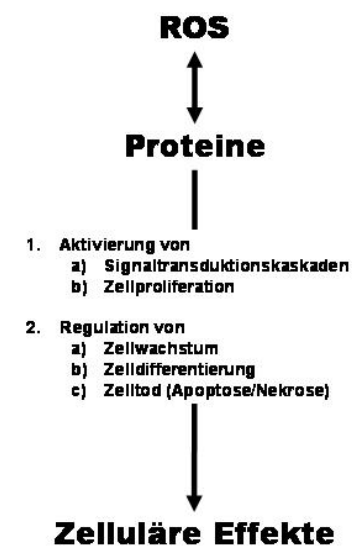

Abbildung 1-10: Zelluläre Interaktionen reaktiver Sauerstoffspezies

Die Folge der Interaktionen von ROS mit DNA (a), Lipiden (b) und Proteinen (c).

Im aktuellen Fokus steht die Rolle reaktiver Sauerstoffspezies als Signalmoleküle. Die vorgenannten Schädigungen der Zellintegrität beruhen auf Beobachtungen, bei denen ROS in unphysiologisch hohen Konzentrationen vorliegen. Unter diesen Umständen stehen die Radikale auch im Zusammenhang mit bestimmten Krankheiten, wie z. B. Atherosklerose (Harrison et al., 2003), Lungenfibrose (Manoury et al., 2005), Krebs (Mochizuki et al., 2006; Szanto et al., 2005), neurodegenerativen Erkrankungen (Potashkin and Meredith, 2006; Zekry et al., 2003) und Alterungsprozessen. Dennoch sind ROS nicht immer toxisch, sondern tragen vielmehr zu intra- und interzellulären Signal- und Regulationsprozessen bei. Diese Rolle für reaktive Sauerstoffspezies wurde zuerst in Bakterien entdeckt. So wurde gezeigt, dass das bakterielle Protein OxyR, das als Regulator der Transkription verschiedener $\mathrm{H}_{2} \mathrm{O}_{2}$-induzierten Gene wirkt, durch direkte Oxidation aktiviert wird (Christman et al., 1985; Storz et al., 1990). Pflanzen produzieren als Antwort auf eingedrungene Pathogene $\mathrm{H}_{2} \mathrm{O}_{2}$, so dass die betroffenen Zellen abstreben und somit die Ausbreitung des Pathogens verhindert wird. Als systemische Antwort auf die erhöhte $\mathrm{H}_{2} \mathrm{O}_{2}$-Konzentration wird die Transkription von Genen induziert, die wiederum die Immunabwehr der Pflanze an das Pathogen anpassen (Laloi et al., 2004).

Aber auch im humanen Organismus übernehmen ROS Aufgaben bei der Signaltransduktion. So werden wichtige Signalwege durch Sauerstoffradikale gesteuert, die regulierend auf Proteinkinasen und Proteinphosphatasen einwirken und dadurch die Phosphorylierung von Proteinen steuern (Cucoranu et al., 2005; Short et al., 2006). Die prominentesten und inzwischen am besten untersuchten Signalwege beziehen sich auf diejenigen, in denen NfאB oder TGF involviert sind und die durch MAP-Kinasen gesteuert werden (Nishiyama et al., 2004; Rhyu et al., 2005; Short et al., 2006).

\subsection{Elektronenspinresonanz Spektroskopie}

Die Messmethodik der Elektronenspinresonanz Spektroskopie, kurz ESR, beruht auf den physikalisch-chemischen Eigenschaften von Radikalen. Die Technik macht sich dabei die Aufspaltung der Energieniveaus eines Elektrons in einem äußeren Magnetfeld zunutze (Abbildung 1-12). Dieser Effekt wurde 1896 erstmals durch Pieter Zeeman beschrieben, der für die Entdeckung des nach ihm benannten Zeeman-Effekts 1902 den Nobelpreis 
erhielt. Wichtig für die zu beobachtenden Effekte sind die paramagnetischen Eigenschaften der zu messenden Proben, da nur diese, im Gegensatz zu diamagnetischen Stoffen, mit einem äußeren Magnetfeld wechselwirken und es unter diesen Bedingungen zu paramagnetischen Resonanzen kommt. Auf die Eigenschaften, die die Proben zur Messung mit ESR-Spektroskopie aufweisen müssen, wird in den folgenden Kapiteln eingegangen.

\subsubsection{Physikalische Grundlagen}

\subsubsection{Elektronenspin im äußeren Magnetfeld}

Elektronen besitzen neben ihrer Masse $m$ und der elektrischen Ladung $e$ auch einen Eigendrehimpuls, der als Spin $\vec{S}$ bezeichnet wird. Der Spin als Vektorgröße besitzt ein magnetisches Moment $\mu_{S}$, der aufgrund der negativen Ladung des Elektrons dem Spin entgegengesetzt ist. Quantenmechanisch ergibt sich der Zusammenhang von Spin und magnetischem Moment aus

$$
\mu_{S}=-g_{e} \mu_{B} \vec{S}, \text { mit } \mu_{B}=\frac{e h}{2 m c}
$$

\section{Formel 1-4: Zusammenhang von Spin $\vec{S}$ und magnetischem Moment $\mu_{S}$}

Die in der Gleichung verwendeten Variablen sind der dimensionslose g-Faktor des Elektrons, $\mathrm{g}_{\mathrm{e}}$, und $\mu_{\mathrm{B}}$, welche das Bohr'sche Magneton beschreibt. Letzteres setzt sich zusammen aus der elektrischen Ladung (e), dem Planck'schen Wirkungsquantum (h) und der Masse des Elektrons (m). c beschreibt die Lichtgeschwindigkeit (Mayer-Kuckuk, 1977).

Der g-Faktor (Landé-Faktor) für das freie Elektron gibt das Verhältnis von magnetischem Moment und Spindrehimpuls an. Für ein freies Elektron besitzt g den Wert 2,0023193 (Mayer-Kuckuk, 1977). Wird das freie Elektron nun in ein äußeres statisches Magnetfeld $\vec{B}_{z}$ eingebracht, wobei z für die Richtung des Magnetfelds steht, ergeben sich nach den Gesetzen der Quantenmechanik zwei Einstellmöglichkeiten für den Spin des Elektrons, parallel oder antiparallel zur z-Achse (Abbildung 1-11). Beide Einstellungen werden durch die magnetische Quantenzahl $m_{s}$ beschrieben und haben die Werte $\pm 1 / 2$.

Neben der angeführten Eigenbewegung, dem Elektronenspin, kommt in einem Magnetfeld eine weitere Bewegung hinzu. Der Elektronenspin $\vec{S}$ versucht durch eine Präzessionsbewegung um die Achse $\mathrm{z}$ des Magnetfelds der auf ihn wirkenden Kraft auszuweichen (Bartholome et al., 1980). Diese Bewegung entspricht der klassischen Kreiselbewegung und hat die Frequenz $\varpi_{0}=\gamma_{z}$ (Larmorfreqeunz). 


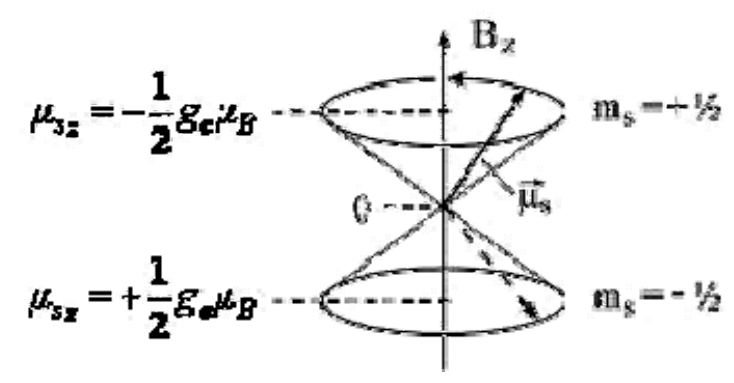

\section{Abbildung 1-11: Das magnetische Moment $\mu_{\mathrm{s}}$ des Elektrons im äußeren Magnetfeld $\vec{B}$}

Der Spin des Elektrons richtet sich entweder parallel oder antiparallel zur z-Richtung des Magnetfeldes aus. $g_{e}=$ Landé-Faktor, $\mu_{\mathrm{B}}=$ Bohr'sches Magneton, $\mathrm{m}_{\mathrm{s}}=$ magnetische Quantenzahl (Bartholome et al., 1980; Mayer-Kuckuk, 1977).

Nach den oben angeführten Gleichungen kann der Energiewert des Spins $S_{z}$ in Richtung des Magnetfeldes $\vec{B}_{z}$ definiert werden. Im Allgemeinen kann $m_{s}$ für einen beliebigen Spin $\vec{S}$ die Werte $-\mathrm{S},-\mathrm{S}+1, \ldots . \mathrm{S}-1, \mathrm{~S}$ annehmen. Die Energie des magnetischen Moments $\mu_{S}$ eines Elektrons mit einem Spin $\vec{S}=\frac{1}{2}$ im Magnetfeld $\vec{B}$ ergibt sich dann aus der Gleichung

$$
E_{1,2}=\mu_{S} B=g_{e} \mu_{B} m_{S}
$$

Formel 1-5: Energie des magnetischen Moments $\mu_{S}$ in einem Magnetfeld $\vec{B}$

Die Variable $m_{s}$ bezeichnet in dieser Gleichung die magnetische Quantenzahl, die die Werte $\pm 1 / 2$ annehmen kann (Bartholome et al., 1980).

Aus Formel 1-5 geht hervor, dass sich die Energie des Elektrons in zwei unterschiedliche Energieniveaus aufspaltet, wenn das Magnetfeld nur eine Komponente in z-Richtung aufweist. Die Energiewerte nach der Aufspaltung hängen vom äußeren Magnetfeld ab (Zeeman-Aufspaltung; Abbildung 1-12).

Im ESR werden die Übergänge zwischen den beiden Energiezuständen durch Einstrahlung elektromagnetischer Strahlung im Mikrowellenbereich senkrecht zur Richtung z des Magnetfeldes induziert. Es erfolgt eine Absorption dieser Strahlung, sobald die sog. Resonanzbedingung erfüllt ist:

$$
\Delta E=g_{e} \mu_{B} B \Delta m_{s}=h v
$$

\section{Formel 1-6: Resonanzbedingung für den Übergang zwischen den Energieniveaus zweier Elektronen}

Die Variable $h$ beschreibt das Planck'sche Wirkungsquantum und $v$ steht für die Frequenz der eingestrahlten elektromagnetischen Welle. 


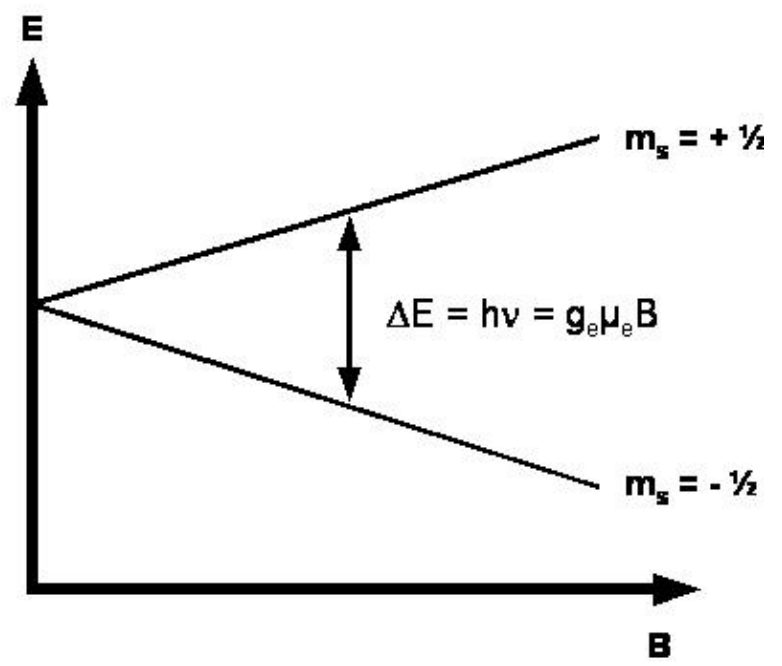

\section{Abbildung 1-12: Zeeman-Aufspaltung der Energien $E$ der beiden Spinzustände $m_{s}$ im Magnetfeld $\vec{B}$ \\ Das Energieniveau des Elektrons spaltet sich in einem Magnetfeld auf. Die Energiewerte der verschiedenen Energieniveaus sind vom äußeren Magnetfeld abhängig (Weil et al., 1994).}

Experimentell kann zum Erreichen des Resonanzzustandes die Frequenz der elektromagnetischen Welle verändert werden. Aus technischen Gründen ist in den meisten Spektroskopen allerdings ein anderes Verfahren verwirklicht. Danach wird nicht die Frequenz der Mikrowelle bis zur Resonanz verändert, vielmehr bleibt diese konstant und das Magnetfeld $B_{z}$ wird variiert.

Der Elektronenspin hängt eng mit der sog. magnetischen Suszeptibilität einer Substanz zusammen. Diese Variable spielt eine Rolle, sobald eine Probe in ein äußeres Magnetfeld gebracht wird. In der Probe baut sich eine magnetische Induktion auf, die durch Formel 17 beschrieben ist. Die in das Magnetfeld eingebrachten Substanzen teilen sich nun entsprechend ihrer magnetischen Suszeptibilität in diamagnetische, wenn $\chi_{m}<0$, und paramagnetische, wenn $\chi_{m}>0$. Da nur paramagnetische Substanzen auch ein Signal im ESR geben, wird die diamagnetische Komponente von Substanzen nicht näher betrachtet. Paramagnetische Materialien haben sehr kleine positive magnetische Momente, die untereinander nur sehr schwach wechselwirken und sich ohne Vorhandensein eines äußeren Magnetfeldes in alle Richtungen verstreuen. Werden diese Substanzen in ein äußeres Magnetfeld eingebracht, richten sich die magnetischen Momente parallel $\mathrm{zu}$ diesem aus.

$$
\vec{B}=\left(1+\chi_{m}\right) \mu_{0} \vec{H}
$$

\section{Formel 1-7: Magnetische Induktion einer Substanz in einem äußeren Magnetfeld}

$\vec{B}$ ist die magnetische Induktion, $\chi_{m}$ bezeichnet die magnetische Suszeptibilität und $\mu_{0}$ steht für die Induktionskonstante in einem Feld $\vec{H}$. 


\subsubsection{Hyperfeinwechselwirkung}

Neben den bereits angeführten Wechselwirkungen von Elektronenspin und äußerem Magnetfeld kommt es auch zur Kopplung des magnetischen Moments vom Elektronenspin mit dem Kernspin, wodurch sich eine weitere Aufspaltung des Spektrums ergibt. Diese Wechselwirkung wird Hyperfeinwechselwirkung genannt und tritt dann auf, wenn sich das ungepaarte Elektron in einem Orbital des Moleküls aufhält, in dem sich Kerne mit einem Kernspin $I \neq 0$ befinden. Die Hyperfeinwechselwirkung besteht aus isotropen und anisotropen Anteilen.

Die isotrope Hyperfeinkopplung $a_{i}$ eines Kerns $i$ ist direkt proportional zur Aufenthaltswahrscheinlichkeit $|\Psi(0)|^{2}$ des ungepaarten Elektrons am Ort des Kerns. Diese quantenmechanische Wechselwirkung wird auch als Fermi-Kontakt-Wechselwirkung bezeichnet und wie folgt definiert:

$$
a_{i}=(8 \pi / 3) g_{e} \mu_{B} g_{N i} \mu_{N i}|\Psi(0)|^{2}
$$

\section{Formel 1-8: isotrope Hyperfeinkopplung $a_{i}$ eines Kerns i}

$\mathrm{g}_{\mathrm{Ni}}$ ist der Kern $\mathrm{g}$-Faktor, $\mu_{\mathrm{Ni}}$ beschreibt das Magneton des Kerns.

Die Bedingung $|\Psi(0)|^{2} \neq 0$ ist für die Atom-Orbitale eines Moleküls nur für das s-Orbital gegeben. Daher führt die Spinpolarisation dazu, dass ein ungepaartes Elektron in einem pOrbital die Spinpaarung im energetisch tiefer liegenden, doppelt besetzten s-Orbital stört. Einfach gesagt, führt diese Störung zu einer geringeren Aufenthaltswahrscheinlichkeit des freien Elektrons im s-Orbital und dies führt wiederum $\mathrm{zu}$ der beschriebenen isotropen Hyperfeinkopplung. Als Beispiel für die isotrope Hyperfeinkopplung ist in Abbildung 1-13 die Aufspaltung eines Kerns mit einem Kernspin $I=1$ und einem Elektronenspin $S=1 / 2$ dargestellt. In diesem Fall spalten sich die Spin-Energieniveaus durch die isotrope Hyperfeinkopplung entsprechend

$$
E\left(m_{s}, m_{I}\right)=g_{e} \mu_{B} B m_{s}-g_{N} \mu_{N} B m_{I}+a m_{S} m_{I}
$$

\section{Formel 1-9: Aufspaltung der Spin-Energieniveaus}

Für den gegebenen Fall ist der Elektronenspin $\vec{S}=\frac{1}{2}$ und der Kernspin I $=1$. Die

Hyperfeinkopplungskonstante wird in der Gleichung als $a$ gegeben. $\mathrm{g}_{\mathrm{N}}$ bezeichnet den Kern-gFaktor, $\mu_{\mathrm{N}}$ ist das Kern-Magneton.

auf. Der zweite Term in Formel 1-9 beschreibt die Wechselwirkung des Kernspins mit dem Magnetfeld B und der dritte Term bezieht sich auf die Hyperfeinwechselwirkung. Im gegebenen Beispiel kann $\mathrm{m}_{\mathrm{I}}$ die Werte -I, -I + 1, ..... I annehmen. Abbildung 1-13 zeigt die Fälle für $m_{I}=-1,0$ und +1 . 


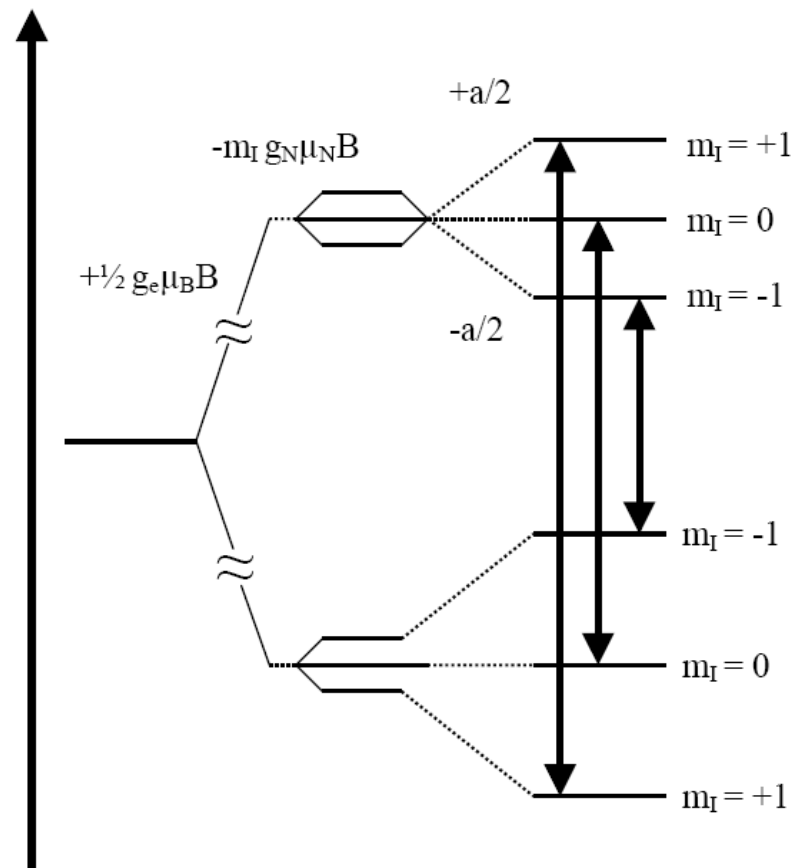

\section{Abbildung 1-13: Spin-Energieniveaus und ESR-Übergänge für den Fall $S=1 / 2, I=1$}

Für das in den Versuchen eingesetzte zyklische Hydroxylamin Hydroxy-3-carboxy2,2,5,5-tetramethylpyrrolidin ergeben sich drei Resonanzlinien (Abbildung 1-14), wobei der energetische Abstand zweier nebeneinander liegender Linien der jeweiligen Hyperfeinkopplungskonstanten a entspricht. Die Resonanzbedingungen der drei Übergänge ergeben sich aus

$$
\begin{gathered}
h v=\Delta E_{m_{I=-1}}=g_{e} \mu_{B} B-a \\
h v=\Delta E_{m I=0}=g_{e} \mu_{B} B \\
h v=\Delta E_{m I=+1}=g_{e} \mu_{B} B+a,
\end{gathered}
$$

wenn $\Delta m_{s}=1$ und $\Delta m_{I}=0$. Da die Feldstärken $\mathrm{B}_{\mathrm{mI}}$ in der normalen ESR-Spektroskopie verändert werden und die Frequenz $v$ konstant gehalten wird, ergeben sich die Resonanzfeldstärken $B_{m I=-1}, B_{m I=0}$ und $B_{m I=+1}$ aus

$$
\begin{gathered}
B_{m I=-1}=h v / g_{e} \mu_{B}+a / g_{e} \mu_{B} \\
B_{m_{I=0}}=h v / g_{e} \mu_{B} \text { und } \\
B_{m I=+1}=h v / g_{e} \mu_{B}-a / g_{e} \mu_{B} .
\end{gathered}
$$

Durch Wechselwirkungen des ungepaarten Elektrons freier Radikale mit mehreren Kernen $i$ und entsprechendem Kernspin $I_{i}$ ergeben sich weitere Aufspaltungen, die sich nach Formel 1-9 auflösen zu

$$
E\left(m_{s}, m_{I}\right)=g_{e} \mu_{B} B m_{s}-\sum_{i} g_{N i} m_{N i} B m_{I i}+\sum_{i} a_{i} m_{s} m_{I i}
$$

Formel 1-10: Hyperfeinwechselwirkung eines freien Elektrons mit mehreren Kernen i mit dem jeweiligen Kernspin $I_{i}$. 
Der anisotrope Anteil der Hyperfeinwechselwirkung besteht in der dipolaren Kopplung von Elektronen- und Kernspin. Da die Konstante in flüssiger Lösung, d. h. in Proben mit schneller rotatorischer Diffusion, nicht eingeht, wird sie an dieser Stelle nicht näher beschrieben.

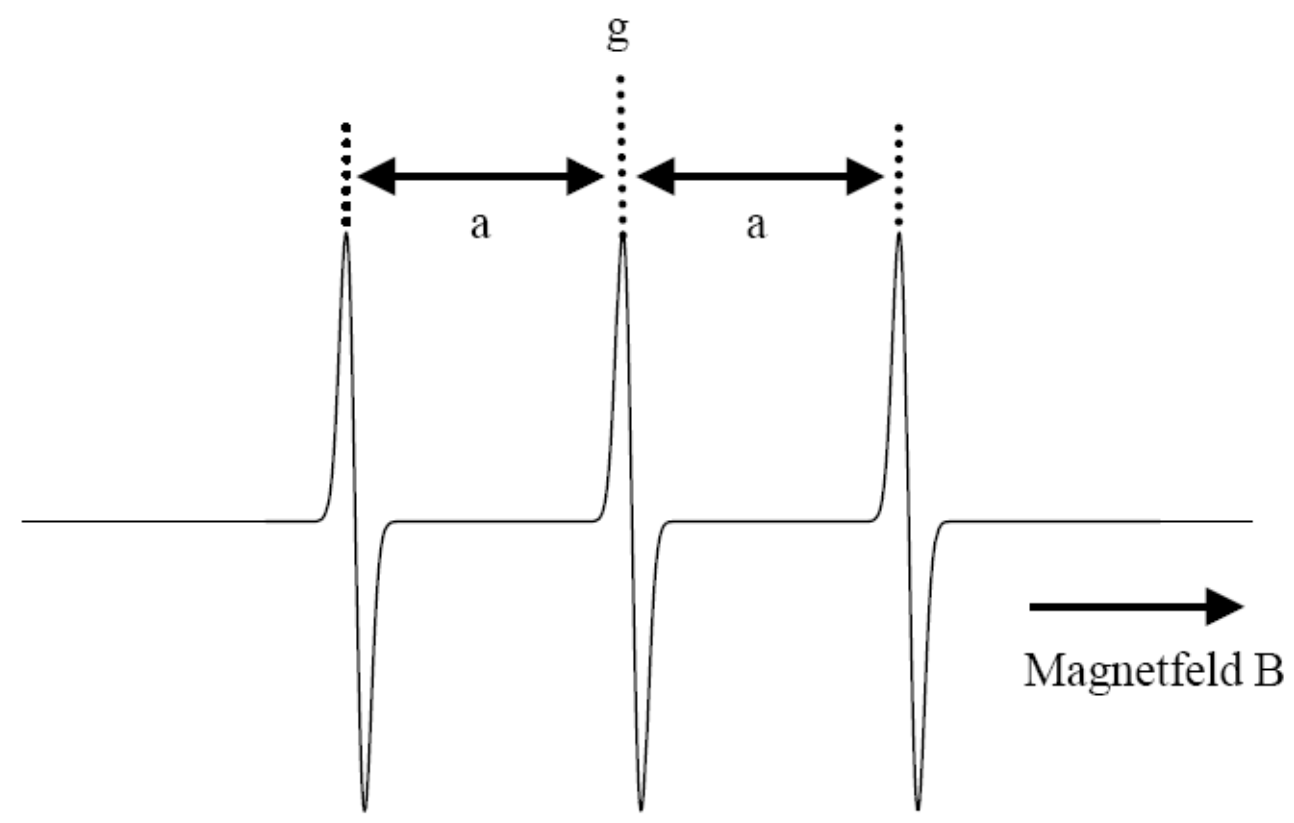

\section{Abbildung 1-14: ERS-Spektrum von Hydroxy-3-carboxy-2,2,5,5- tetramethylpyrrolidin.HCl bei einer isotropen Hyperfeinkopplung a.}

\subsubsection{Relaxationsprozesse}

Voraussetzung für die Beobachtung von Resonanzlinien ist, dass durch die eingestrahlte Mikrowelle die Resonanzbedingungen nach Formel 1-6 erfüllt werden und dass zwischen verschiedenen Energieniveaus der Unterschied in den Besetzungszahlen erhalten bleibt. Damit die letzte Bedingung erfüllt ist, werden in der ESR-Spektroskopie Mirkowellen geringer Intensität eingestrahlt. Die Nettoabsorption hängt dann nur noch von der Differenz der Energiezustände ab (Atherton, 1993; Scheffler and Stegmann, 1970).

Werden paramagnetische Substanzen einer starken Mikrowellenstrahlung ausgesetzt, sättigt sich das Spinsystem, d. h. die Energieabsorption geht gegen null und die Magnetisierung verschwindet. Wenn ein biologisches System aus seinem Gleichgewichtszustand gebracht wird, versucht es diesen durch einen als Relaxation bezeichneten Prozess wieder zu erreichen. Die Relaxation ist ein Mechanismus, der es dem Spinsystem ermöglicht, aus einem Zustand hoher Energie in einen Zustand geringer Energie zurückzukehren, also Energie an die Umgebung abzugeben, wodurch die fortlaufende Energieaufnahme gewährleistet wird. In der ESR-Spektroskopie sind zwei Formen der Energieübertragung möglich. Zum einen spielt die longitudinale Relaxation eine Rolle, bei der Energie an die Umgebung des Spins abgegeben wird. Da die Umgebung des Spins auch als Gitter bezeichnet wird, spricht mal auch von Spin-Gitter-Relaxation und die Zeit, die benötigt wird um von einem energiereichen in einen energieärmeren Zustand zurückzukehren wird als Spin-Gitter- oder longitudinale Relaxationszeit $\mathrm{T}_{1}$ bezeichnet. Die Definition der Spin-Gitter-Relaxation ist 


$$
\frac{d M_{z}}{d t}=-\frac{\left(M_{z}-M_{z, e}\right)}{T_{1}}
$$

\section{Formel 1-11: Definition der Spin-Gitter-Relaxationszeit}

Die Formel gibt die longitudinale Relaxationszeit an. $\mathrm{M}_{\mathrm{z}}$ beschreibt die Magnetisierung parallel zum statischen Feld $\mathrm{B}, \mathrm{T}_{1}$ seht für die longitudinale Relaxationszeit und der Index e steht für den Gleichgewichtszustand (IUPAC, 2006).

Neben der Spin-Gitter-Relaxationszeit spielt auch die Spin-Spin- oder transversale Relaxationszeit $\mathrm{T}_{2}$ für den Energietransfer eine Rolle (Atherton, 1993; Scheffler and Stegmann, 1970). Sie tritt dann auf, wenn Energie an andere Elektronen abgegeben wird und diese dadurch ein höheres Energieniveau erreichen. Die Spin-Spin-Relaxation führt zu einer zeitlichen Energischwankung und nicht zur Änderung der Energie im gesamten Spinsystem. Die Spin-Spin-Relaxationszeit ist wie folgt definiert:

$$
\frac{d M_{x}}{d t}=-\frac{\left(M_{x}\right)}{T_{2}}
$$

\section{Formel 1-12: Definition der Spin-Spin-Relaxationszeit}

Die Formel gibt die transversale Relaxationszeit an. $\mathrm{M}_{\mathrm{x}}$ beschreibt die Magnetisierung antiparallel zum statischen Feld $\mathrm{B}$ und $\mathrm{T}_{2}$ seht für die transversale Relaxationszeit (IUPAC, 2006).

\subsubsection{Apparative Grundlagen}

Das klassische ESR-Spektroskop besteht im Wesentlichen aus drei Bauteilen:

1. dem Elektromagneten zur Schaffung eines homogenen Magnetfeldes,

2. der Mikrowelleneinheit zur Erzeugung der Mikrowelle und Messung der Resonanzabsorption der Probe, die sich in einem Hohlraumresonator zwischen den Polen des Elektromagneten befindet,

3. dem Detektionssystem und der Magnetfeldmodulation zur Registrierung und Verarbeitung des Resonanzsignals (Spieß, 1998).

Für die Messung wird eine Probe in den Hohlraumresonator im Spalt zwischen den beiden Polschuhen des Elektromagneten eingeführt. Die Mikrowelleneinheit erzeugt eine elektromagnetische Welle, die senkrecht zum äußeren Magnetfeld steht. Im Resonanzfall wird Energie absorbiert und die dadurch bewirkte Änderung der Mikrowellenleistung durch eine Detektordiode registriert.

\subsubsection{Magnetsystem}

Wie bereits erwähnt, wird bei den meisten ESR-Spektroskopen aus technischen Gründen die Stärke des Magnetfeldes variiert, während die eingestrahlte Mikrowellenfrequenz konstant bleibt. Die Variation des magnetischen Feldes wird durch das Anlegen einer Sägezahnspannung an die Spulen des Elektromagneten erreicht. Bei dieser Feld-SweepMethode wird die Resonanzkurve als Funktion der magnetischen Flussdichte dargestellt. 


\subsubsection{Mikrowellenbrücke}

Als rauscharme und phasenstabile Mikrowellenquelle wird in älteren Geräten ein Reflexklystron in neueren Geräten, wie dem für die Versuche eingesetzten MS100, ein Halbleiterbauteil (Gunnoszillator) verwand. Er besteht aus einer Diode und einem Hohlraumresonator, der in Abhängigkeit von seiner Geometrie die Mikrowellenfrequenz, die von der Diode abgestrahlt werden muss, bestimmt.

Die Mikrowelle wird in einen Hohlleiter eingespeist und über einen so genannten Zirkulator ausschließlich in den Meßresonator (Cavity) geleitet, in dem sich die Probe befindet. Der Resonator dient zur Verstärkung und festen räumlichen Orientierung des Mikrowellenfeldes. Mikrowelle, die vom Resonator reflektiert wird, gelangt zurück zum Zirkulator und von dort zur Nachweisdiode. Der Resonator wird mittels eines variablen Kopplungselements (Iris) derart an den Hohlleiter angekoppelt, dass nur soviel Mikrowelle in den Hohlleiter zurück reflektiert wird, wie zur Vorbelastung der Diode benötigt wird. Ist für die Spins in der Probe die ESR-Resonanzbedingung erfüllt, so absorbieren sie Mikrowelle, was zu einer Änderung der vom Resonator reflektierten Mikrowellenleistung führt. Diese wird mit der Nachweisdiode gemessen.

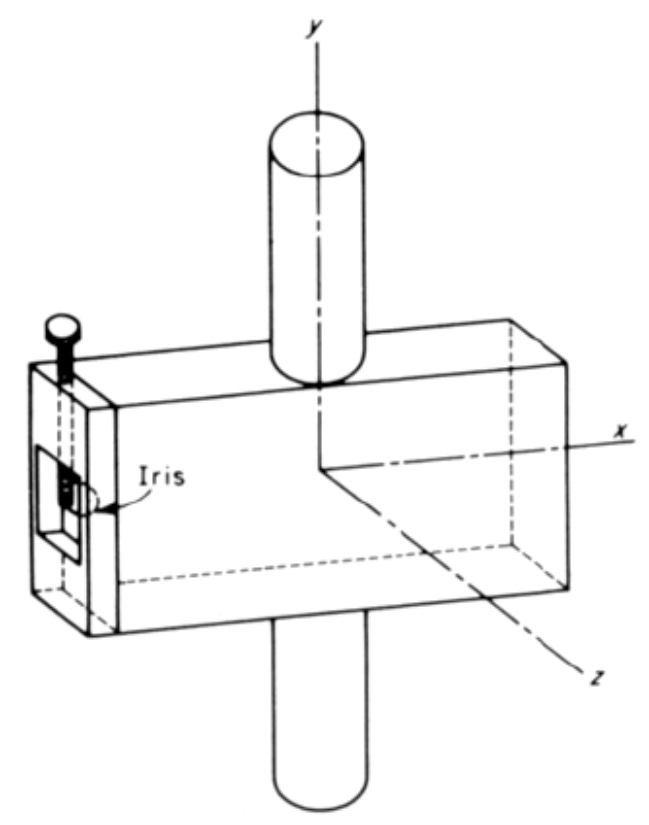

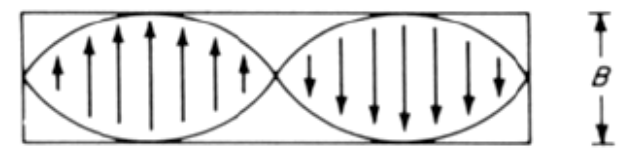

(b)

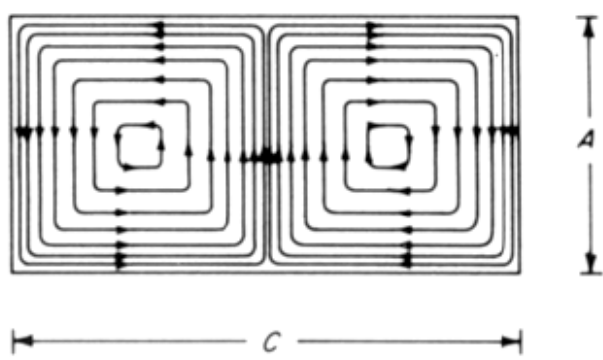

\section{Abbildung 1-15: rechteckiger Hohlraumresonator}

Auf der linken Seite der Darstellung ist der Probenraum mit Iris-Kopplung gezeigt. Rechts oben ist die elektrische Feldkomponente der Mikrowelle in x-z-Ebene dargestellt und darunter ist die magnetische Feldkomponente der Mikrowelle in der x-y-Ebene zu sehen. Das statische Magnetfeld ist parallel zur z-Achse.

Dem Hohlraumresonator kommt besondere Bedeutung zu (Abbildung 1-15). Er dient einmal zur Verstärkung des Mikrowellenfeldes am Ort der Probe. Zum anderen entsteht durch die stehende Welle im Resonator eine räumliche Trennung der Maxima von elektrischer und magnetischer Feldstärke der Mikrowelle. Da es sich bei ESR um magnetische Übergänge handelt - es ändert sich die magnetische Quantenzahl $m_{s}$ bzw. $m_{I}$

- wird die Probe an den Ort des Maximums der magnetischen Feldstärke der Mikrowelle gebracht. Proben, die sich im Bereich der elektrischen Feldstärke der Mikrowelle befinden, führen zu einer Verlustabsorption, die unabhängig vom Magnetfeld ist, und im Falle 
starker Absorption - z.B. flüssiges Wasser - eine Messung der ESR verhindert. Flüssige wässrige Proben werden daher in Flachzellen gemessen, die sorgfältig im Resonator positioniert werden, so dass sie sich in der Ebene des Maximums der magnetischen und des Minimums der elektrischen Feldstärke der Mikrowelle befinden.

\subsubsection{Detektionssystem}

Der am Detektor registrierte Strom ist mit der gleichen Frequenz wie das äußere Magnetfeld moduliert. Seine Amplitude ist proportional zur Änderung der Energieabsorption $\Delta \mathrm{S}$. Durch die Magnetfeldmodulation $\Delta \mathrm{B}$ erhält man als Signal die erste Ableitung des Absorptionssignals $\Delta \mathrm{S} / \Delta \mathrm{B}$, wenn die Modulationsamplitude im Verhältnis zur Linienbreite klein genug ist (Abbildung 1-16). Die Linienbreite ist als Abstand zwischen Maximum und Minimum des abgeleiteten Absorptionssignals definiert und abhängig von der Größe der Modulationsamplitude. Die Linienbreite nimmt bei Verkleinerung der Modulationsamplitude nicht weiter ab, aber bei optimaler Linienbreite ist die Amplitude des Signals am größten.

a)

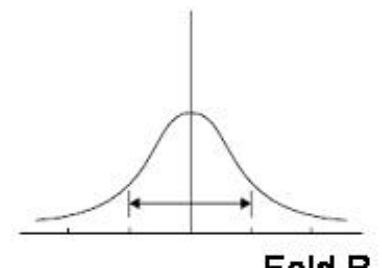

Feld B

b)

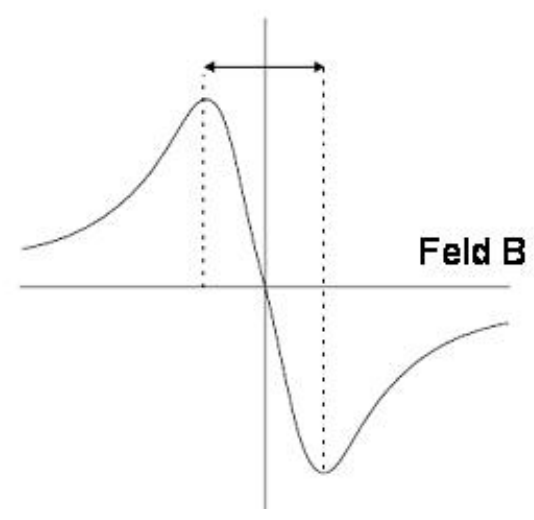

\section{Abbildung 1-16: Zusammenhang zwischen Absorptions- und ESR-Signal}

Der obere Teil der Abbildung (a) zeigt das Absorptionssignal. Im unteren Teil (b) ist die erste Ableitung des Absorptionssignals als ESR-Signal nach phasenempfindlicher Gleichrichtung dargestellt.

Ein Vorteil dieser differenzierten Resonanzkurve besteht in der besseren spektralen Auflösung, so dass Feinheiten im Kurvenverlauf besser sichtbar sind. Durch die Differenzierung ist eine Phasenverschiebung um $180^{\circ}$ zwischen Detektorsignal und Modulation am Maximum er Absorptionskurve $\mathrm{zu}$ berücksichtigen. Unterhalb des Absorptionsmaximums besteht Phasengleichheit, oberhalb des Absorptionsmaximums sind die beiden Signal in ihrer Phase entgegen gesetzt. 


\subsubsection{Spin-Labels und Spin-Traps}

Für die Bestimmung freier Radikale gibt es drei verschiedene Möglichkeiten unter Einsatz der ESR-Spektroskopie. Die erste ist die direkte Bestimmung. Dabei wird das aus einer Reaktion mit einem Elektron hervorgehende Radikal ohne eine weitere Zweitreaktion direkt gemessen. Diese Methode wirft aber im Falle der Quantifizierung von Superoxid einige Probleme auf. So ist die Halbwertszeit des Superoxidanions mit ungefähr $1 \mathrm{~ms}$ extrem kurz und die Konzentration des Radikals im Gleichgewichtszustand ist sehr niedrig $(\sim 1 \mathrm{nM})$. Das Hauptproblem besteht allerdings darin, dass Superoxid bei Raumtemperatur kein Spektrum in der ESR-Spektroskopie gibt (Dikalov, 2005). Daraus folgt, dass zumindest das Superoxidradikal nicht direkt aus biologischen Proben gemessen werden kann. Aus diesem Grund wurden Methoden zur indirekten Bestimmung von Radikalen etabliert.

Die ältere der beiden indirekten Nachweismethoden ist das sog. „Spin-Trapping“ (IUPAC, 2006). Das bedeutet, dass in einer Reaktionslösung ein kurzlebiges Radikal mit einer diamagnetischen Komponente in der Lösung reagiert und dadurch ein langlebigeres Radikal gebildet wird. Dieses Produkt akkumuliert in der Lösung, bis es schließlich eine Konzentration erreicht, bei der es möglich ist, das Radikal mittels ESR-Spektroskopie zu identifizieren (IUPAC, 2006). Die Reaktion ist üblicherweise eine Addition, bei der die diamagnetische Komponente als „Spin-Trap“ und das langlebigere Endprodukt als „SpinAddukt" bezeichnet wird. Typische Spin-Traps sind z. B. C-nitroso-Komponenten und Nitrone, an die sich das reaktive Radikal schnell bindet und so Nitryl-Radikale bildet. Die gebräuchlichsten Spin-Traps sind 5,5-Dimethyl-1-pyrroline-N-Oxide (DMPO) oder 2-Ethoxycarbonyl-2-methyl-3,4-dihydro-2H-pyrrole-1-oxid (EMPO) (Dikalov, 2005; Dikalov et al., 2005). Als Beispiel ist in Abbildung 1-17 die Reaktion von DMPO mit ${ }^{\circ} \mathrm{O}_{2}^{-}$ dargestellt.

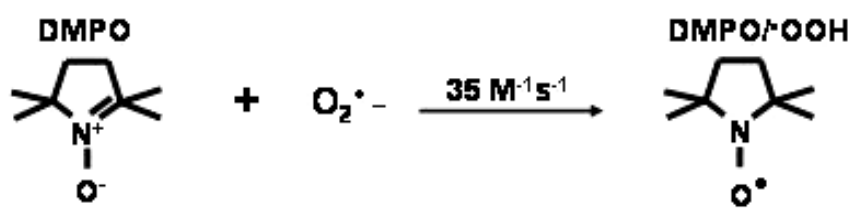

\section{Abbildung 1-17: Spin-Trapping}

Der diamagnetische Spin-Trap DMPO reagiert mit ${ }^{\bullet} \mathrm{O}_{2}^{-}$zum Spin-Addukt DMPO/OOOH. Die Geschwindigkeitskonstante für diese Reaktion ist $35 \mathrm{M}^{-1} \mathrm{~s}^{-1}$.

Aber auch diese Methode hat Nachteile. So ist die Reaktionsgeschwindigkeit sehr langsam und wird deshalb durch intrinsische Antioxidantien beeinflusst. Zudem können sich Hydroxyl-Radikal-Addukte oder Hydroxylamine bilden, von denen letztere kein Spektrum bei der Analyse mit ESR ergeben (Dikalov, 2005).

Aufgrund der angeführten Nachteile wurde eine weitere Technik zum Nachweis von Radikalen entwickelt. Es handelt sich hierbei um das sog. „Spin-Labeling“ (IUPAC, 2006). Ein Spin-Label ist eine paramagnetische Substanz, typischerweise ein Nitryl-Radikal oder, wie im Falle dieser Arbeit, ein zyklisches Hydroxylamin, das an ein Molekül bindet und dann mittels ESR analysiert werden kann (IUPAC, 2006). Wenn eine paramagnetische Komponente, die sich nicht-kovalent an das Radikal bindet auf diese Weise eingesetzt wird, wird diese paramagnetische Substanz auch als „Spin-Probe“ bezeichnet (IUPAC, 2006). Für die Quantifizierung von Superoxid sind die zyklischen Hydroxylamine am besten geeignet (Dikalov, 2005; Dikalov et al., 1997d; Fink et al., 2000), da die 
Geschwindigkeitskonstante ca. 100x höher liegt als bei einer Reaktion mit Spin-Traps und es den Spin-Probes deshalb möglich ist, mit intrinsischen Antioxidationsmechanismen zu konkurrieren (Dikalov, 2005). Zudem hat das Endprodukt der Reaktion, ein stabiles Nitroxid, eine sehr viel längere Halbwertszeit verglichen mit dem aus Spin-Traps gebildeten Spin-Addukt. Demnach erlaubt die Verwendung zyklischer Hydroxylamine die quantitative Bestimmung von Superoxid mit erhöhter Sensibilität, d. h. dass auch geringe Konzentrationen des Superoxidanions nachgewiesen werden können (Dikalov, 2005). Abbildung 1-18 zeigt als Beispiel für das Spin-Labeling die Reaktion von 1-Hydroxy-3carboxy-2,2,5,5-tetramethylpyrrolidin. $\mathrm{HCl}(\mathrm{CP}-\mathrm{H})$ mit Superoxid.

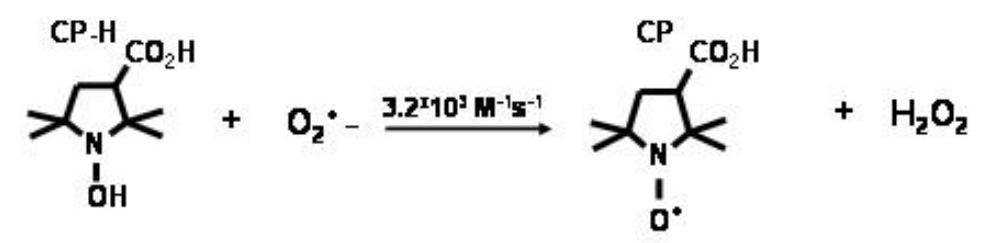

\footnotetext{
Abbildung 1-18: Spin-Labeling

Der paramagnetische Spin-Probe $\mathrm{CP}-\mathrm{H}$ reagiert mit ${ }^{\bullet} \mathrm{O}_{2}{ }^{-} \mathrm{zu} \quad \mathrm{CP}^{\bullet}$ und $\mathrm{H}_{2} \mathrm{O}_{2}$. Die Geschwindigkeitskonstante für diese Reaktion ist $3,2 \times 10^{3} \mathrm{M}^{-1} \mathrm{~s}^{-1}$.
} 


\subsection{Zielsetzung dieser Arbeit}

Die der vorliegenden Dissertation zugrunde liegende Hypothese besagt, dass sich unter Hypoxie vermehrt reaktive Sauerstoffspezies (ROS) bilden und die Quelle der ROSProduktion NADP(H)-Oxidasen sind.

Den Hintergrund dieser Arbeit bilden die (patho-)physiologischen Veränderungen der Lungenstrombahn unter akuter und chronischer Hypoxie. Unter akuter Hypoxie kontrahieren präkapilläre Gefäße der Lunge und passen so die Perfusion an die vorherrschenden Ventilationsverhältnisse in der Lunge an. Diese physiologische Anpassung wird hypoxische pulmonale Vasokonstriktion genannt. Verlängert sich aber die hypoxische Phase und wird zu einem chronischen Zustand, verdickt sich durch Proliferation und Migration von glatten Muskelzellen und Fibroblasten die mediale Schicht der Gefäßwand, ein Prozess der gemeinhin als vaskuläres Remodeling bezeichnet wird. Als Folge davon erhöht sich der pulmonalarterielle Druck, was ein typisches Anzeichen für die Krankheit pulmonale Hypertonie (PH) ist. Pulmonale Hypertonie führt in der Folge zu einer Überlastung des rechten Herzens, die Muskelschicht des rechten Ventrikels verdickt sich und in der Folge sterben Patienten, die an PH erkrankt sind, an Rechtsherzversagen. Sowohl unter akuter als auch in chronischer Hypoxie sollen reaktive Sauerstoffspezies in die Signaltransduktionskaskaden, die zu den vaskulären Veränderungen führen, eine Rolle spielen (Sham, 2002). Fraglich ist jedoch, ob unter den vorgenannten Bedingungen vermehrt oder vermindert ROS freigesetzt werden. Als Hauptquellen der normoxischen, akut und chronisch hypoxischen ROS-Produktion wurden NADP(H)-Oxidasen phagozytären und nicht-phagozytären Ursprungs untersucht (Brennan et al., 2003; Castier et al., 2005; Cave et al., 2005; Liu et al., 2006; Weissmann et al., 2000; Weissmann et al., 2006d). Die ROS-Produktion wurde in isoliert perfundierten und ventilierten Mauslungen mittels Elektronenspinresonanz-Spektroskopie analysiert. Um die Rolle von NADP(H)Oxidasen zu klären, wurden genetisch veränderte Mäuse verwendet, bei denen entweder die gp91 ${ }^{\text {phox }}$ oder $\mathrm{p} 47^{\text {phox }}$-Untereinheit von NADP(H)-Oxidasen deletiert war oder solche Tiere, die die p22 $2^{\text {phox }}$-Untereinheit dieses Komplexes überexprimieren. 


\section{Material und Methoden}

\subsection{Tiere}

Die Versuche wurden randomisiert an männlichen Mäusen unternommen. Das Alter der Tiere betrug acht bis zwölf Wochen, das Gewicht lag zwischen 22 bis 35 Gramm. Alle in den Versuchen verwendeten Tiere wurden nach entsprechender Genehmigung durch das Regierungspräsidium Gießen zu den Experimenten herangezogen. Die Tiere bekamen Wasser und Futter ad libitum, die Versorgung und Pflege erfolgte durch die Tierpfleger und eine Tierärztin in der Tierhaltung der medizinischen Klinik I und II der Justus-LiebigUniversität Gießen.

\subsubsection{Wildtyp- und transgene Mäuse}

Für die Kontrollen wurden aus Inzucht gewonnene Mäuse des Stammes C57Bl/6J verwendet, die von den Jackson Laboratorien (The Jackson Laboratories, Bar Habor, Maine, USA) gezüchtet und geliefert wurden.

Um den Einfluss von NADP(H)-Oxidasen auf die ROS-Produktion zu untersuchen, wurden ebenfalls Experimente mit genveränderten Tieren durchgeführt. Zwei Varianten mit einer Deletion (Knock-Out, KO) von NADP(H)-Oxidase Untereinheiten und eine Variante, die eine bestimmte NADP(H)-Oxidase Untereinheit überexprimiert, wurden verwendet. Beide Knock-Out Typen basieren auf dem genetischen Hintergrund des Stammes C57B1/6J. Mäuse des Typs C57B1/6.129S6-Cybb $b^{\text {tmlDin } / J}$ (Synonym: gp91 ${ }^{\text {phox-/- }}$ oder $\mathrm{Cybb}$ ) haben eine Deletion der NADP(H)-Oxidase Untereinheit gp91 ${ }^{\text {phox }}$ und wurden ebenfalls von den Jackson Laboratorien (The Jackson Laboratories) gezüchtet und geliefert. Des Weiteren wurden Mäuse mit einem Knock-Out der $\mathrm{p} 47^{\text {phox }}$-Untereinheit von NADP(H)-Oxidasen (p47 $7^{\text {phox-l- }}$ ) in den Versuchen eingesetzt. Diese Mäuse wurden im Rahmen einer Kooperation von Dr. Li Ding und Dr. Stephen M. Holland (Labor für klinische infektiöse Krankheiten, National Intitutes of Health, Bethesda, Maryland, USA) bereitgestellt und in den Laboratorien von Charles River (Charles River Deutschland, Sulzfeld, Deutschland) gezüchtet und aufgezogen. Ein dritter Typus genveränderter Mäuse überexprimiert die p22 $2^{\text {phox }}$-Untereinheit von NADP(H)-Oxidasen (p22 $\left.2^{\text {phox+/T }}\right)$. Diese Mäuse wurden freundlicherweise von Dr. David G. Harrison von der Emory Universität (Emory University, School of Medicine, Atlana, USA) zur Verfügung gestellt und im zentralen Tierlabor der Justus-Liebig-Universität Gießen gezüchtet und aufgezogen.

\subsubsection{Chimäre Mäuse}

Neben den kommerziell erhältlichen, im vorigen Abschnitt beschriebenen Wildtyp und transgenen Tieren, wurden im Labor zudem chimäre Mäuse mit dem Ziel generiert, die ROS-Produktion aus phagozytären von der aus nicht-phagozytären NADP(H)-Oxidasen unterscheiden zu können. Dazu wurden Mäuse des Wildtyps C57Bl/6J und Mäuse mit einem Knock-Out der gp91 ${ }^{\text {phox }}$-Untereinheit von NADP(H)-Oxidasen einer Knochenmarkstransplantation unterzogen. 


\subsubsection{Knochenmarkstransplantation}

Insgesamt werden drei unterschiedliche Ausformungen des Knochenmarks nach ihrer Farbe unterschieden. Die Einteilung erfolgt in rotes, gelbes und weißes Knochenmark. Für die Knochenmarkstransplantation ist insbesondere das rote Knochenmark von Interesse, da in diesem Teil die Hämatopoese abläuft. Rotes Knochenmark ist in den flachen Knochen, wie z. B. dem Brustbein, sowie den langen Knochen der Extremitäten lokalisiert. Durch Bestrahlung werden die Hämatozytoblasten, also die Stammzellen aller Blutvorläuferzellen, zerstört und somit werden keine Blutzellen (Erythrozyten, Leukozyten, Thrombozyten, Lymphozyten und Monozyten) mehr gebildet.

\subsection{Spendertiere}

Für die Knochenmarksspende wurden Wildtypen des Stammes C57Bl/6J (The Jackson Laboratories) und die gp91 ${ }^{\text {phox }}$ Knock-Out Variante C57B1/6.129S6-Cybb $b^{\text {th } 1 D i n} / \mathrm{J}$ (The Jackson Laboratories) verwendet. Die Spendertiere waren vier Wochen alt und das Gewicht betrug zwischen 20 bis 22 Gramm. Die Knochenmarkstransplantation wurde in Zusammenarbeit mit Herrn Dr. Robert Voswinckel durchgeführt.

Zur Präparation der Stammzellen aus dem Knochenmark wurde RPMI 1640 Medium (PAN Biotech GmbH, Aidenbach, Deutschland), dem eine Mischung aus Penicillin und Streptomycin (PAN Biotech) bis zu einer Konzentration von 1\% und fötales Kälberserum (PAA Labortechnik, Pasching, Österreich), ebenfalls in einer Konzentration von 1\%, zugegeben wurde, verwendet. Im Folgenden wird dieses Medium als Nährmedium bezeichnet.

Den Tieren wurde zuerst intraperitoneal 2500 U/kg Körpergewicht Heparin (Ratiopharm $\mathrm{GmbH}$, Ulm, Deutschland) injiziert. Dann wurden sie unter dem Abzug (Thulab GmbH, Langgöns/Dornholzhausen, Deutschland) in ein Glasgefäß (Schütt Labortechnik GmbH, Göttingen, Deutschland) gesetzt, in dem sich ein mit Isofluran (Baxter S.A., Baxter Deutschland $\mathrm{GmbH}$, Unterschleißheim, Deutschland) getränkter Wattebausch befand. Die narkotisierten Tiere wurden dann durch Genickbruch getötet. Dann wurden sie in Rückenlage auf einer Korkplatte fixiert und das Fell mit 70\%igem Alkohol befeuchtet. Von distal wurde rechts und links des Anus ein Schnitt gesetzt und die Hinterbeine aus der Hüftgelenkspfanne entfernt. Die Pfoten wurden am Tarsusgelenk abgetrennt und die verbleibende Haut vom Oberschenkel aus nach unten abgezogen. Dann wurden die Beine in ein PP-Röhrchen (Greiner Bio-One GmbH, Frickenhausen, Deutschland) mit $30 \mathrm{ml}$ eiskaltem Nährmedium überführt.

An der Sterilbank (HeraSafe, Heraeus Instruments GmbH, Hanau, Deutschland) wurden zunächst die Muskeln und den Beinen anhaftendes Gewebe mit einem Skalpell (Feather Safety Razor Co, Ltd.) grob entfernt. Feinere Fasern wurden mit steriler Gaze (Fuhrmann Verbandstoffe $\mathrm{GmbH}$, Munch, Deutschland) abgezupft, bis Tibia und Femur freigelegt waren. Danach wurden die Gelenke von den verbleibenden Knochen vorsichtig abgetrennt. Zum Herausspülen des Knochenmarks wurde eine Nadel der Stärke 21G (BD Microlance, Becton Dickinson GmbH, Heidelberg, Deutschland) verwendet, die auf eine mit Nährmedium gefüllte $5 \mathrm{ml}$ Spritze (B. Braun Melsungen AG, Melsungen, Deutschland) aufgesetzt war. Das Nährmedium und die herausgespülten Knochenmarkszellen wurden in einem auf Eis stehenden PP-Röhrchen (Greiner Bio-One) aufgefangen. Die Zellen wurden dann bei $4^{\circ} \mathrm{C}$ für fünf Minuten bei $400 \mathrm{~g}$ zentrifugiert (Rotina 46R, Andreas Hettich $\mathrm{GmbH}$ \& Co KG, Tuttlingen, Deutschland). Nach Zentrifugation wurde der Überstand verworfen und das Pellet in $1 \mathrm{ml}$ Nährmedium bis zum Erhalt einer Einzelzellsuspension resuspendiert. Die Zellsuspension wurde dann durch ein $100 \mu \mathrm{m}$ Nylon Zellsieb (BD Falcon, BD Biosciences Discovery Labware, Bedford, MA, USA) in ein neues PP- 
Röhrchen (Greiner Bio-One) überführt und das Zellsieb (BD Falcon) anschließend mit $1 \mathrm{ml}$ Nährmedium gespült. Nach diesem Schritt wurde die gefilterte Suspension erneut bei $4^{\circ} \mathrm{C}$ für $5 \mathrm{~min}$. bei $400 \mathrm{~g}$ zentrifugiert, der erhaltene Überstand verworfen und das Zellpellet für $3 \mathrm{~min}$. auf Eis gekühlt. Zur Lyse der Erythrozyten wurde $1 \mathrm{ml}$ eiskaltes steriles Wasser $\mathrm{zu}$ dem Pellet gegeben und drei- bis fünfmal sanft resuspendiert. Nach 30 Sekunden wurden der Suspension $10 \mathrm{ml}$ eiskaltes Nährmedium zugegeben. Durch einen $40 \mu \mathrm{m}$ Nylon Zellsieb (BD Falcon) wurde die erhaltene Suspension in ein neues PP-Röhrchen (Greiner Bio-One) überführt und anschließend $5 \mathrm{~min}$. bei $4^{\circ} \mathrm{C}$ und $400 \mathrm{~g}$ zentrifugiert. Der daraus erhaltene Überstand wurde wiederum verworfen und das Pellet in $1 \mathrm{ml}$ Nährmedium resuspendiert. Zur Bestimmung der Zellzahl wurden aus der erhaltenen Suspension $10 \mu \mathrm{l}$ abgenommen und mit Medium auf $1 \mathrm{ml}$ aufgefüllt. Daraus wurden $10 \mu 1$ in eine Neubauer Zählkammer (L-Optik, Berlin, Deutschland) gegeben und nach der Zählung die Zellzahl der Ausgangssuspension auf 20-50 x 10 $0^{6}$ Zellen $/ \mathrm{ml}$ eingestellt.

\subsection{Empfängertiere}

Mäuse, die Empfänger der Knochenmarkszellen waren, wurden 2 bis 8 Stunden vor der Transplantation bestrahlt. Dazu wurden sie einer Kobalt-Strahlenquelle mit einer Strahlungsintensität von 11 Gray (1100 rad) ausgesetzt, was einer Strahlungsdosis von 0,6 Gray pro Minute entspricht. Die Bestrahlung fand in Zusammenarbeit mit Herrn Dr. Schalch im Strahlenzentrum der Universität Gießen statt.

Nach der Bestrahlung wurden die Tiere bis zur Transplantation in sterilen Käfigen und steriler Umgebung im Tierstall des Labors gehalten und versorgt. Vor der Transplantation wurden die Mäuse in den Käfigen unter eine Infrarot-Wärmelampe gestellt um die periphäre Durchblutung zu verbessern. Nach ca. 10 Minuten erfolgte die Injektion von $100 \mu \mathrm{l}$ der Knochenmarkszellsuspension in die Schwanzvene der Mäuse. Zur Injektion wurden $1 \mathrm{ml}$ Spritzen (B. Braun Melsungen AG) mit aufgesetzten 24G Nadeln (BD Microlance) verwendet.

\subsubsection{Genotypisierung der chimären Mäuse}

Um die chimäre Rekonstitution der knochenmarkstransplantierten Tiere zu verifizieren, wurde eine Polymerase-Kettenreaktion (engl.: polymerase chain reaction; PCR) mit genomischer DNA aus Blut- und Endothelzellen durchgeführt.

\section{a) Isolation genomischer DNA aus Vollblut}

Den Mäusen wurde sechs Wochen nach erfolgter Knochenmarkstransplantation $100 \mu 1$ Blut aus der Schwanzvene entnommen und in heparinisierte Mikrokapillaren (Clinitubes, Radiometer A/S, Kopenhagen, Dänemark) abgefüllt. Direkt nach der Entnahme wurde das Blut in 1,5 ml Reaktionsgefäße (Eppendorf-Netheler-Hinz GmbH, Hamburg, Deutschland) gegeben und, um die Koagulation zu verhindern, sofort mit $10 \mu 1$ einer 10 mM EDTALösung (Fluka Chemie GmbH, Buchs, Schweiz) vermischt. Bis zur Verwendung wurde das Blut-EDTA-Gemisch auf Eis aufbewahrt.

Für die Zelllyse wurden zwei Puffer angesetzt. Der erste Puffer, im Folgenden als Puffer A bezeichnet, wurde aus Saccharose (Sigma-Aldrich Chemie GmbH, Steinheim, Deutschland) in einer Konzentration von 0,32 M mit Tris-HCl (Carl Roth $\mathrm{GmbH} \&$ Co. $\mathrm{KG}$, Karlsruhe, Deutschland) bis zu einer Endkonzentration von $10 \mathrm{mM}(\mathrm{pH}=7,5)$ und $\mathrm{MgCl}_{2}$ (Sigma-Aldrich Chemie $\mathrm{GmbH}$ ) in einer Konzentration von $5 \mathrm{mM}$ hergestellt. Dann wurde Triton X-100 (Roche Diagnostic GmbH, Mannheim, Deutschland) bis zum Erreichen einer 1\%igen Lösung (v/v) zugegeben. Die Bestandteile des zweiten Lysepuffers 
(Puffer B) waren $\mathrm{KCl}$ (Sigma-Aldrich $\mathrm{GmbH}$ ) in einer Konzentration von $50 \mathrm{mM}, \mathrm{MgCl}_{2}$ (Sigma-Aldrich $\mathrm{GmbH}$ ) in einer Konzentration von 1,5 mM, $10 \mathrm{mM}$ Tris-HCl (Carl Roth $\mathrm{GmbH} \& \mathrm{Co} . \mathrm{KG}$ ) mit einem $\mathrm{pH}$ von 8,3 sowie $0,45 \% \mathrm{NP}-40$ (Qiagen $\mathrm{GmbH}$, Hilden, Deutschland) und 0,45\% Tween-20 (Carl Roth GmbH \& Co. KG). Diesem Gemisch wurden $100 \mu \mathrm{g} / \mathrm{ml}$ Proteinase K (Qiagen $\mathrm{GmbH}$ ) beigemengt.

Dem Blut-EDTA-Gemisch wurden $800 \mu$ von Lysepuffer A zugegeben und kräftig durchmischt. Die Suspension wurde dann für 15 Minuten mit $1300 \mathrm{~g}$ bei $4{ }^{\circ} \mathrm{C}$ zentrifugiert (Mikro 200R, Andreas Hettich GmbH \& Co KG, Tuttlingen, Deutschland) und der sich ergebende Überstand verworfen. Das Pellet mit der nukleären DNA wurde in $1 \mathrm{ml}$ von Puffer A resuspendiert. Nach diesem Schritt erfolgte eine erneute Zentrifugation mit den vorgenannten Einstellungen. Der sich aus der Zentrifugation ergebende Überstand wurde verworfen und das DNA-Pellet in $1 \mathrm{ml}$ Lysepuffer A resuspendiert und erneut zentrifugiert. Nachdem sich kein Hämoglobin mehr in der Lösung befand, wurde das DNA-Pellet nach der Zentrifugation in $100 \mu$ Lysepuffer B resuspendiert und bei $55^{\circ} \mathrm{C}$ inkubiert. Nach zwei Stunden wurde die Probe zur Inaktivierung der Proteinase K für 10 Minuten auf $97^{\circ} \mathrm{C}$ erhitzt und dann für die PCR-Reaktion eingesetzt.

b) Isolation genomischer DNA aus Endothelzellen

Die für die Analyse benötigten Endothelzellen wurden aus den absteigenden Aorten der Versuchstiere gewonnen. Dazu wurde ein Stück des Gefäßes herauspräpariert, aufgeschnitten und die innere endotheliale Zellschicht mit einem Skalpell (Feather Safety Razor Co, Ltd, Osaka, Japan) abgekratzt. Die daraus gewonnenen Zellen wurden zusammen mit $50 \mu 1$ von Lysepuffer B direkt in ein Reaktionsgefäß gegeben und für zwei Stunden bei $55^{\circ} \mathrm{C}$ inkubiert. Danach wurden die Proben zur Inaktivierung der Proteinase $\mathrm{K}$ für 10 Minuten auf $97^{\circ} \mathrm{C}$ erhitzt und anschließend in der PCR eingesetzt.

\section{c) Polymerase-Kettenreaktion und Gel-Elektrophorese}

Die aus Vollblut und Endothelzellen gewonnene genomische DNA wurde mit der Polymerase-Kettenreaktion amplifiziert. Dazu wurden die beiden Nox-2 spezifischen Primer oIMR0517 und oIMR0518 sowie der neomycin-resistente Primer oIMR0519 verwendet (alle von Metabion International AG, Martinsried, Deutschland). Die Sequenzen der jeweiligen Primer sind in Tabelle 2-1 zusammengefasst.

\section{Tabelle 2-1: Sequenzen der eingesetzten Primer}

Übersicht der Sequenzen und Eigenschaften von den zur Typisierung der chimären Mäuse eingesetzten Primern.

\begin{tabular}{|c|c|c|}
\hline Primer & Sequenz & Eigenschaft \\
\hline oIMR0517 & $\begin{array}{l}5^{\prime}-\mathrm{AAG} \text { AGA AAC TCC TCT GCT GTG } \\
\text { AA-3' }\end{array}$ & $\begin{array}{l}\text { Amplifiziert mit IMR518 } \\
240 \text { bp des Wildtyp-Allels }\end{array}$ \\
\hline oIMR0518 & $\begin{array}{l}5^{\prime}-\mathrm{CGC} \text { ACT GGA ACC CCT GAG AAA } \\
\text { GG - } 3^{\prime}\end{array}$ & Normaler Primer \\
\hline oIMR0519 & $\begin{array}{l}\text { 5'-GTT CTA ATT CCA TCA GAA GCT } \\
\text { TAT CG-3' }\end{array}$ & $\begin{array}{l}\text { Amplifiziert mit IMR518 } \\
195 \text { bp des Knock-Out } \\
\text { Allels }\end{array}$ \\
\hline
\end{tabular}


Die PCR wurde in einem Reaktionsvolumen von $25 \mu 1$ durchgeführt. Der Reaktionsansatz enthielt $200 \mu \mathrm{M}$ dNTP, $1,5 \mathrm{mM} \mathrm{MgCl}_{2}, 1 \mu \mathrm{M}$ eines 10-fach DNA-Polymerase-Puffer (alles Red-Taq, Sigma-Aldrich $\mathrm{GmbH}$ ), 2 Units der Taq-Polymerase (Invitrogen GmbH, Karlsruhe, Deutschland) und 0,4 $\mu \mathrm{M}$ jeden Primers. Nachdem die Komponenten zusammengebracht waren, wurde die PCR gestartet. Die Temperatur zur Denaturierung der DNA betrug $94^{\circ} \mathrm{C}$ und wurde initial für drei Minuten gehalten. Danach folgte ein 12 Zyklen umfassender Reaktionsverlauf, der mit einem Denaturierungsschritt begann. Dieser Schritt wurde bei $94^{\circ} \mathrm{C}$ durchgeführt und dauerte 20 Sekunden. Im Anschluss wurde die Temperatur auf $64^{\circ} \mathrm{C}$ abgesenkt, um die Anlagerung der Polymerase an die nun einzelsträngig vorliegende DNA zu gewährleisten. Diese Phase dauerte 30 Sekunden, wobei die Temperatur in jedem Zyklus um $0,5^{\circ} \mathrm{C}$ abgesenkt wurde. Die Verlängerung der DNA durch die Polymerase erfolgte bei $72^{\circ} \mathrm{C}$ für eine Zeitspanne von 35 Sekunden. Nachdem die ersten zwölf Zyklen durchlaufen waren, änderten sich die Einstellungen für den Schritt der Anlagerung. In den folgenden 25 Zyklen erfolgte die Anlagerung bei $58^{\circ} \mathrm{C}$ für eine Zeitspanne von 30 Sekunden, wobei die weiteren Parameter für die Denaturierung und Verlängerung der DNA nicht verändert wurden (Tabelle 2-2).

Tabelle 2-2: Einstellungen für die Polymerase-Kettenreaktion

Darstellung der PCR-Zyklen zur Amplifizierung der isolierten genomischen DNA mittels PCR.

\begin{tabular}{|c|c|c|c|l|}
\hline Schritt & & Temperatur & Zeitspanne & Bemerkungen \\
\hline \hline 1 & Denaturierung & $94^{\circ} \mathrm{C}$ & 3 Min & \\
\hline 2 & Denaturierung & $94^{\circ} \mathrm{C}$ & 20 Sekunden & \\
\hline 3 & Anlagerung & $64^{\circ} \mathrm{C}$ & 30 Sekunden & \\
\hline 4 & Verlängerung & $72^{\circ} \mathrm{C}$ & 35 Sekunden & Starte bei 2, 12 Wiederholungen \\
\hline 5 & Denaturierung & $94^{\circ} \mathrm{C}$ & 20 Sekunden & \\
\hline 6 & Anlagerung & $58^{\circ} \mathrm{C}$ & 30 Sekunden & \\
\hline 7 & Verlängerung & $72^{\circ} \mathrm{C}$ & 35 Sekunden & Starte bei 5, 25 Wiederholungen \\
\hline 8 & Ende & $10^{\circ} \mathrm{C}$ & & \\
\hline
\end{tabular}

Die Produkte der PCR wurden zur abschließenden Analyse durch eine Gel-Elektrophorese aufgetrennt. Dazu wurde ein 2\%iges DNA-Agarose Gel mit den Reaktionsansätzen, die aus der PCR erhalten wurden, beladen und nach dem Durchlauf mit $0,1 \mu \mathrm{g} / \mathrm{ml}$ Ethidiumbromid (Sigma-Aldrich Chemie $\mathrm{GmbH}$ ) gefärbt. Die Größe der erhaltenen DNAFragmente wurde mit den Größen des ebenfalls aufgetragenen Standardmarkers verglichen. 


\subsection{Isoliert perfundierte und ventilierte Mauslunge}

Die Auswirkungen von normoxischer, akut und chronisch hypoxischer Exposition auf die Hämodynamik der Mauslungen wurden am System der isoliert perfundierten und ventilierten Lunge (Hugo Sachs Elektronik-Harvard Apparatus GmbH, March-Hugstetten, Deutschland) analysiert. Es besteht im Wesentlichen aus zwei Einheiten, der Ventilation und der Perfusion, und ist in Abbildung 2-1 schematisch dargestellt.

\subsubsection{Kalibrierung des Systems}

Vor den Versuchen wurden die Eingangssignale für den pulmonalarteriellen und linksventrikulären Druck sowie für den Pleuraldruck durch eine Zwei-Punkt-Kalibrierung geeicht. Nach dem Einlesen des unteren und oberen Kalibrierpunkts errechnete die Software „Pulmodyn“ (Version 1.0.16.9, Ingenieursbüro Peter Kegler und Sigrid Guhr, Gross-Zimmern, Deutschland) automatisch die Auflösung in der jeweils physiologischen Einheit und den mit dieser Einstellung möglichen Messbereich in physiologischen Einheiten. Die Kalibrierung wird an dieser Stelle exemplarisch für den pulmonalarteriellen Druck beschrieben.

Der Druckaufnehmer zur Aufnahme des pulmonalarteriellen Druckes wurde zum Umgebungsdruck geöffnet, ein Brückenverstärker (Kal-84, Hugo Sachs ElektronikHarvard Apparatus $\mathrm{GmbH}$ ) angeschlossen und auf Null abgeglichen. Im Programm „Pulmodyn“" wurde für den Nullwert ein Wert von 2048 A/D Punkten eingestellt, was einer Spannung von 0 Volt entsprach. Nach Schließen des Fensters wurde der Null-Wert angezeigt und dem physikalischen Wert $(0 \mathrm{~mm} \mathrm{Hg})$ gleichgesetzt wurde.

Zur Eichung des oberen Kalibrierpunkts wurde mit dem angeschlossenen Kalibriergerät ein Druck von $20 \mathrm{~mm} \mathrm{Hg}$ auf den Druckaufnehmer gegeben, was einer durch die Software errechneten Spannung von $\geq 1 \mathrm{~V}$ entsprach. Nach beendeter Kalibrierung wurden die erhaltene Auflösung und der Messbereich angezeigt. Beide Werte wurden überprüft und notfalls neu eingestellt. Im Falle einer zu geringen Auflösung wurde am Verstärker die Verstärkung erhöht. Wenn der errechnete Messbereich zu klein war, wurde die Verstärkung reduziert.

\subsubsection{Ventilation}

Die Ventilation erfolgte in einem Überdrucksystem, in dem das Atemgas für die Inspiration aktiv in die Lunge gepumpt wird und die Exspiration passiv durch die Elastizität der Lunge stattfand. Aus Gasflaschen (Air Liquide Deutschland $\mathrm{GmbH}$, Ludwigshafen, Deutschland) wurde die Atemluft mit einem Druck von 0,8 bar über handelsübliche Gewebeschläuche einem Einzelrohrströmungsmesser (Aalborg Instruments, Orangeburg, New York, USA) zugeleitet und dort auf einen Fluss von 60 $\mathrm{ml} / \mathrm{min}$ eingestellt. Aus dem Einzelrohrströmungsmesser gelangte das Atemgas dann über gasdichte Schläuche (Tygon, Cole-Parmer Instruments Company, Vernon Hills, Illinois, USA) zu der Ventilationspumpe (MiniVent Typ 845, Hugo Sachs Elektronik-Harvard Apparatus $\mathrm{GmbH}$ ), die das Gas der Lunge zuführte. Am Inspirationsschenkel wurde gleichzeitig der Beatmungsdruck über einen Drucksensor (Hugo Sachs Elektronik-Harvard Apparatus $\mathrm{GmbH}$ ) abgenommen und digital aufgezeichnet. Am luftzuführenden Schlauch war vor dem Übergang in die Ventilationspumpe als Reservoir für die Atemluft ein $30 \mathrm{ml}$ fassendes, ebenfalls gasdichtes Schlauchstück (Tygon) angebracht. Über diese Anordnung 
wurde verhindert, dass Raumluft mit in die Ventilationspumpe gesogen wird. Die Exspiration erfolgte passiv durch die Eigenelastizität der Lunge. Am Exspirationsschenkel wurde ein Druckgefäß angebracht, über das ein positiver endexpiratorischer Druck (PEEP) von $3 \mathrm{~cm} \mathrm{H} \mathrm{H}_{2} \mathrm{O}$ eingestellt wurde. Dadurch wurde verhindert, dass die Alveolen der Lunge während der Präparation und im Versuchsverlauf kollabierten.

Die Mauslungen wurden während der Versuche mit 90 Atemzügen/min und einem Atemzugvolumen von $300 \mu \mathrm{l} /$ Atemzug, d. h. mit einem Atemminutenvolumen von $27 \mathrm{ml}$, ventiliert. Die Zusammensetzung der Atemgase variierte je nach durchzuführendem Versuch und ist in Tabelle 2-3 angegeben.

Tabelle 2-3: Zusammensetzung der zur Ventilation eingesetzten Gasgemische

Der Anteil an $\mathrm{O}_{2}$ wurde je nach Versuchszweck, d. h. Normoxie, akute oder chronische Hypoxie, variiert. Die Bemischung von $\mathrm{CO}_{2} \mathrm{zu}$ den Atemgasen war notwendig, um den $\mathrm{pH}-\mathrm{Wert}$ in den Lungen konstant zu halten.

\begin{tabular}{|c|c|c|c|}
\hline Beatmung & $\begin{array}{c}\text { Anteil Sauerstoff } \\
{[\%]}\end{array}$ & $\begin{array}{c}\text { Anteil } \\
\text { Kohlenstoffdioxid [\%] }\end{array}$ & Anteil Stickstoff \\
\hline \hline Normoxisch & 21,0 & 5,3 & Rest \\
\hline Akut hypoxisch & 1,0 & 5,3 & Rest \\
\hline $\begin{array}{c}\text { Chronisch } \\
\text { hypoxisch }\end{array}$ & 10,0 & 5,3 & Rest \\
\hline
\end{tabular}

\subsubsection{Perfusion}

Das Perfusionssystem (Hugo Sachs Elektronik-Harvard $\mathrm{GmbH}$ ) bestand aus doppelwandigen Gefäßen, die ein Kühlen bzw. Erwärmen der Perfusionslösung ermöglichten. Die Kühlung bzw. Erwärmung des Systems wurde über einen Frigomix (Frigomix-U, B. Braun Melsungen AG, Melsungen, Deutschland) mit aufgesetztem Thermomix (Thermomix-UB, B. Braun Melsungen AG) gewährleistet. Alle für die Perfusion verwendeten Schläuche waren gasdicht (Tygon), so dass die Diffusion von Gasen verhindert wurde, zudem wurden alle Metallteile, die direkten Kontakt mit dem Perfusat hatten, durch Äquivalente aus Plastik ersetzt. Die Perfusion wurde für die Versuche in einem geschlossenen, rezirkulierenden System durchgeführt (Abbildung 2-1). 


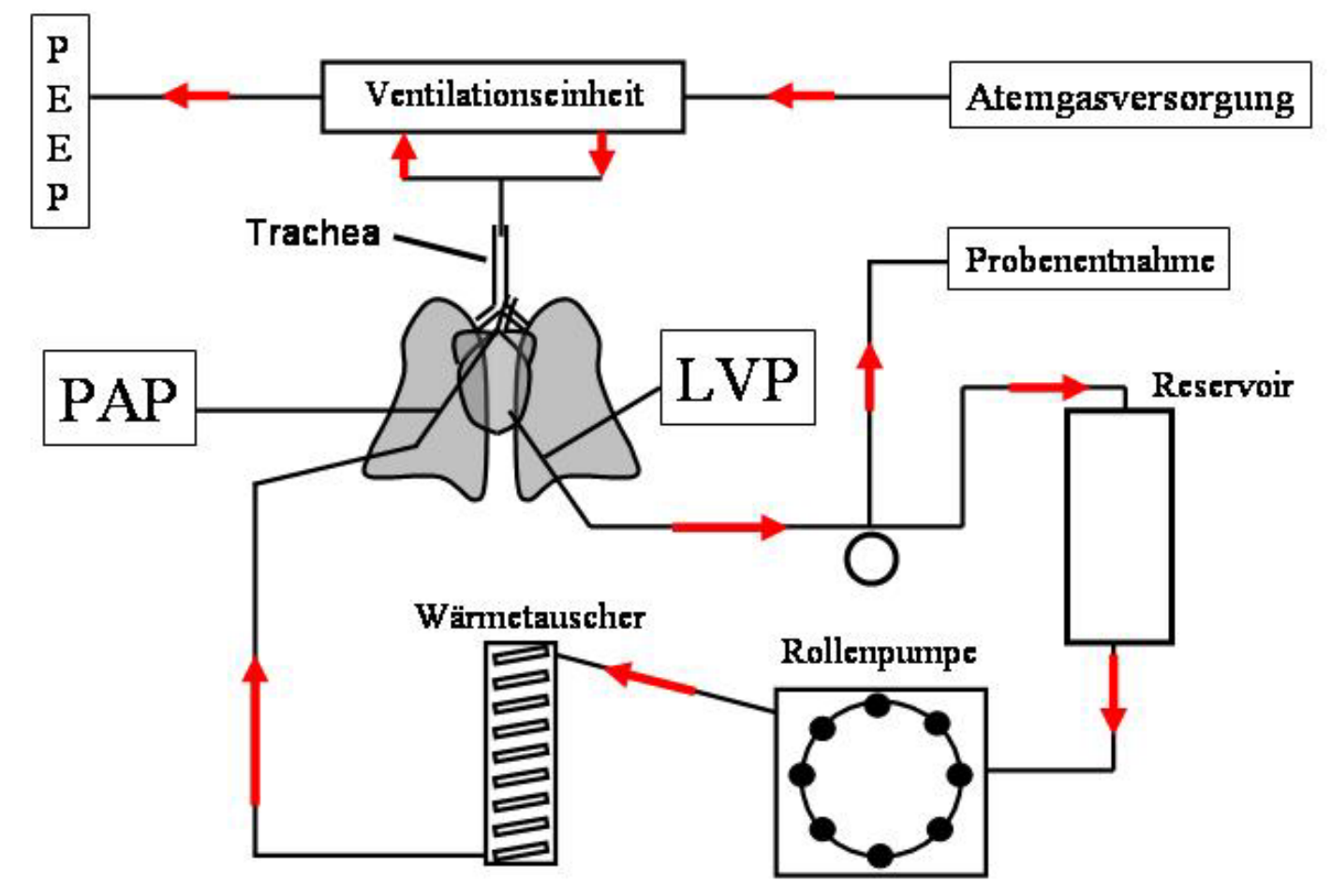

\section{Abbildung 2-1: Schema der isoliert perfundierten und ventilierten Lunge}

Im oberen Teil der Darstellung ist die Ventilationseinheit dargestellt. Die Lunge wird mittels einer Ventilationspumpe über die Trachea beatmet. Im unteren Teil der Abbildung ist die Perfusion der in grau eingefärbten Lunge dargestellt. Die Pfeile zeigen die Fliessrichtung des Perfusats im System an. Weitere Erläuterungen im Text. PAP = Pulmonalarterieller Druck; LVP = Linksventrikulärer Druck; $\mathrm{PEEP}=$ positiver endexpiratorischer Druck.

Aus einem Reservoir wurde das Perfusat mittels einer Rollenpumpe (Ismatech SA, Labortechnik-Analytik, Glattbrugg-Zürich, Schweiz) einem Wärmetauscher zugeleitet. Nach Durchfluss des Wärmetauschers gelangte die Perfusionslösung in eine Plastikkanüle, die während der Versuche in der Pulmonalarterie fixiert war. Vor dem Übergang in die Pulmonalarterie wurde über einen zweiten Schlauch der pulmonalarterielle Druck (PAP) abgegriffen und von einem Drucktransducer (Combitrans 1-fach, B. Braun Melsungen AG) gemessen. Nachdem das Perfusat die Lungengefäße durchströmt hatte, erreichte es den linken Ventrikel des Herzens, in dem eine weitere Plastikkanüle als Abfluss angebracht war. Auch hier wurde über einen zweiten Schlauch der linksventrikuläre Druck (LVP) abgegriffen und mittels eines weiteren Drucktransducers (Combitrans 1-fach, B. Braun Melsungen AG) gemessen. Sowohl PAP als auch LVP wurden über die Software „Pulmodyn“ während der Versuche kontinuierlich aufgezeichnet. In einer Entfernung von ca. $3 \mathrm{~cm}$ nach der linksventrikulären Kanüle befand sich ein kleiner Schlauch, von dem aus die Entnahme von Perfusat zu Zwecken der Analyse mittels ESR möglich war. Nachdem das Perfusat diese Stelle passiert hatte, wurde es in das Reservoir zurückgeleitet.

Vor Beginn der Versuche wurde das gesamte System auf $4^{\circ} \mathrm{C}$ gekühlt und mehrmals mit destilliertem Wasser (Aqua ad iniectabilia, Baxter S.A. Baxter Deutschland GmbH, Unterschleißheim, Deutschland) gespült. Direkt vor den Versuchen wurde das zum spülen verwendete Wasser aus dem System entfernt und durch Perfusat ersetzt. Anschließend wurden alle Schläuche luftblasenfrei mit Perfusat gefüllt und das gesamte System nochmals durchspült. Während der Versuche wurde die Apparatur derart gewärmt, dass in der Lunge eine konstante Temperatur von $37^{\circ} \mathrm{C}$ gegeben war. Der Fluss wurde über die 
Rollenpumpe auf einen konstanten Wert von $2 \mathrm{ml} / \mathrm{min}$ eingestellt und das Gesamtperfusatvolumen im rezirkulierenden System betrug $12 \mathrm{ml}$.

\subsubsection{Perfusionslösung}

Bei der Perfusionslösung handelte es sich um eine modifizierte Krebs-Henseleit-Lösung. Alle eingesetzten Chemikalien wurden in der höchst möglichen Reinheitsstufe (supra-pure oder ultra-pure) verwendet, um das Hintergrundrauschen während der ESR-Messungen möglichst gering zu halten. Das Perfusat wurde mit Wasser aus der Reinstwasseranlage (Milli-Q, Millipore GmbH, Schwalbach, Deutschland) hergestellt und bei $4^{\circ} \mathrm{C}$ für höchstens eine Woche aufbewahrt. Der Ansatz enthielt Natriumchlorid (Fluka Chemie $\mathrm{GmbH}$ ) in einer Konzentration von $120 \mathrm{mM}$, Kaliumdihydrogenphosphat (Merck KGaA, Darmstadt, Deutschland) in einer Konzentration von 1,1 mM und Kaliumchlorid (Fluka) in einer Konzentration von 4,3 mM. Zu diesem Ansatz wurden 20g/1 eines Chelators (Chelex 100 Resin, BioRad Laboratories, Hercules, Kalifornien, USA) gegeben und die Lösung vier Stunden bei Raumtemperatur durchmischt (Ret-Basic, IKA Labortechnik, Stauffen, Deutschland). Danach wurde die Lösung filtriert (Whatman, Schleicher \& Schuell GmbH, Dassel, Deutschland) und anschließend durch einen Sterilfilter (Steritop, Millipore) mit einer Porengröße von 0,22 $\mu \mathrm{m}$ gesaugt. Dem gefilterten Perfusat wurden dann Kalziumchlorid (Fluka) in einer Konzentration von 2,4 mM, Glukose (Fluka Chemie $\mathrm{GmbH}$ ) in einer Konzentration von $5 \mathrm{mM}$ und 50g/l Hydroxyethyl-Särke (HAES, SigmaAldrich Chemie $\mathrm{GmbH}$ ) unter rühren beigemengt. Das fertige Perfusat wurde in Flaschen zu $500 \mathrm{ml}$ abgefüllt und bis zur Verwendung bei $4^{\circ} \mathrm{C}$ aufbewahrt.

Vor Versuchsbeginn wurden $97,8 \mathrm{ml}$ des Perfusats abgefüllt und für eine Stunde im Wasserbad auf $38^{\circ} \mathrm{C}$ erwärmt. Dieser Schritt war notwendig, da sich in kalten Flüssigkeiten größere Gasmengen lösen, die durch Erwärmen der Flüssigkeit wieder in den gasförmigen Zustand übergehen und sich somit in den Perfusionsschläuchen Blasen bilden können. Das angewärmte Perfusat wurde dann mit normoxischen Gasgemisch (Air Liquide) für $5 \mathrm{~min}$. begast und anschließend 2,2 $\mathrm{ml}$ einer in Reinstwasser angesetzten 8,4 prozentigen Natrium-Bicarbonat (Fluka Chemie $\mathrm{GmbH}$ ) Lösung zugesetzt. Das Perfusat wurde danach weiter begast bis sich ein $\mathrm{pH}$-Wert zwischen 7,20 und 7,30 einstellte. Zur Bestimmung des pH-Wertes wurde das Perfusat in $1 \mathrm{ml}$ Spritzen (B. Braun Melsungen AG) aufgezogen und in ein ABL 500 (Radiometer A/S, Kopenhagen, Dänemark) gegeben. Nachdem der $\mathrm{pH}-$ Wert eingestellt war, wurde das Perfusat in gasdichte $50 \mathrm{ml}$ Perfusorspritzen (BD Perfusion) aufgezogen.

\subsubsection{Präparation der Mäuse}

Die Präparation der Tiere fand entweder unter Raumluft oder, im Falle von chronisch hypoxischen Mäusen, in einer hypoxischen Atmosphäre mit 10\% Sauerstoff statt. Die Tiere wurden vor der Präparation durch intraperitoneale Injektion einer lethalen Dosis von $80 \mathrm{mg} / \mathrm{kg}$ Pentobarbital (Narcoren, Merial AG, Hallbergmoss, Deutschland) betäubt, so dass sie von Beginn der Präparation an schmerzfrei waren und während der Präparation durch unterbinden der zentralen Blutversorgung verstarben. Nach der Narkose wurden 1000 U/kg Heparin (Ratiopharm GmbH, Ulm, Deutschland) in die Schwanzvene injiziert.

Die tief narkotisierten Tiere wurden zunächst intubiert. Dazu wurde das Fell von der Bauchmitte bis zur Mitte des Halses inzidiert und die Speicheldrüsen freigelegt. Diese wurden vorsichtig mit einer Pinzette zur Seite gelegt und der über der Trachea liegende Muskel durchtrennt, so dass die Luftröhre freigelegt war. Als nächstes wurde ein 
Bindfaden (Coats GmbH, Kenzingen, Deutschland) unter der Trachea durchgeführt und ein Knoten vorgelegt. Oberhalb des Knotens wurde die Trachea eingeschnitten und ein Tubus (Hugo Sachs Elektronik-Harvard) eingeführt, der vermittels des vorgelegten Fadens in der Trachea fixiert wurde. Die intubierte Maus wurde dann in die auf $4^{\circ} \mathrm{C}$ gekühlte Kammer des Perfusionssystems eingebracht und der tracheale Tubus mit der Beatmungspumpe verbunden. In diesem Stadium wurden normoxische Lungen weiterhin mit Raumluft, die Lungen chronisch hypoxischer Tiere mit einem Gasgemisch mit $10 \% \mathrm{O}_{2}$ ventiliert. Die Beatmungspumpe (Minivent, Typ 845) war auf ein Atemzugvolumen von $150 \mu$ pro Atemzug und 90 Atemzüge pro Minute eingestellt.

Die nun folgenden Schritte beschreiben die Katheterisierung der Pulmonalarterie und des linken Ventrikels. Dazu wurde zunächst der Bauchraum des Tieres eröffnet und die inneren Organe vorsichtig nach caudal hin verschoben, so dass das Diaphragma zugänglich war. Im nächsten Schritt wurde das Sternum fixiert und mit einer Pinzette das Zwerchfell vom Sternum aus nach ventral eingerissen. Durch den induzierten Pneumothorax fiel die Lunge in sich zusammen, so dass die weiteren Präparationsschritte ohne Verletzungsgefahr für das Organ durchgeführt werden konnten. Der auf $3 \mathrm{~cm} \mathrm{H}_{2} \mathrm{O}$ eingestellte PEEP verhinderte das Kollabieren der Alveolen und ermöglichte so eine schonende Ventilation der Lunge. Als nächstes wurde das Diaphragma entlang der äußeren Rippenbögen nach unten hin abgelöst und das Perikard sowie die Ligamente, die Herz und Lunge mit dem Thorax verbinden, durchtrennt. Im Anschluss wurde der Thorax mittig entlang des Sternums geöffnet, die Rippen aufgebogen, seitlich fixiert und so der HerzLungenkomplex freigelegt. Der am oberen Rand des Thorax lokalisierte Thymus wurde unter Sichtkontrolle (Leica MS5, Leica Microsystems, Wetzlar, Deutschland) bei einer 0,63-fachen Vergrößerung mit einer Pinzette entfernt und um die nun zugängliche Pulmonalarterie ein chirurgischer Faden (FSSB Chirurgische Nadeln GmbH, Jestetten, Deutschland) gelegt. Nun wurde zuerst der linke Ventrikel an der Herzspitze punktiert und dann der rechte Ventrikel eingeschnitten. Von dem aus dem rechten Ventrikel ausströmenden Blut wurden ca. $40 \mu \mathrm{l}$ in eine heparinisierte Kapillare (Hämatokritkapillare, Hirschmann Laborgeräte, Eberstadt, Deutschland) abgefüllt um später den Hämatokrit bestimmen zu können. Durch den Einschnitt im rechten Ventrikel wurde ein Plastikkatheter bis in die Pulmonalarterie geschoben und dort mit dem bereits vorgelegten Faden fixiert. Der Fluss des Perfusats war in diesem Stadium auf ein Minimum eingestellt, so dass die Lungengefäße nicht plötzlich überlastet wurden und sich die Gefahr der Ödembildung im Lungengewebe verringerte. Nachdem der Katheter in der Pulmonalarterie fixiert war, wurde zunächst die Beatmung von Raumluft auf das Flaschengasgemisch umgestellt. Das Gasgemisch enthielt neben den bereits beschriebenen Anteilen an Sauerstoff auch einen konstanten Prozentsatz von 5,3\% $\mathrm{CO}_{2}$. Die Umstellung auf das Gasgemisch wurde notwendig, da sich während der Versuche keine $\mathrm{O}_{2}$-verbrauchenden und $\mathrm{CO}_{2}$-abgebenden Organe mehr im Kreislauf befanden und somit auch kein $\mathrm{CO}_{2}$ für die Aufrechterhaltung des $\mathrm{pH}-$ Wertes im Perfusat produziert wurde und exogen zugeführt werden musste. Als nächstes wurde die untere Körperhälfte des Tieres abgetrennt und währenddessen öfters das Loch im linken Ventrikel geöffnet, so dass das über die Pulmonalarterie einfließende Perfusat abfließen und sich nicht über den linken Ventrikel, das linke Herzohr und die Lungengefäße zurückstauen konnte. Die Präparation wurde mit der Fixierung eines Plastikkatheters im linken Ventrikel abgeschlossen, über den das Perfusat zunächst in einen Abfallbehälter abgeführt wurde. Über die nächsten $20 \mathrm{~min}$. wurde die Ventilation, der Perfusatfluss und die Temperatur des Perfusionssystems langsam auf die für den Versuch benötigten Endwerte gebracht (s. Abschnitt 2.2.3). Nach Starten der digitalen Aufzeichnung (Pulmodyn) und eventuell notwendiger Korrekturen der Katheterpositionen wurde nun der Hämatokrit aus dem vorher abgenommenen Blut bestimmt. Dazu wurden die Hämatokritkapillaren für zwei Minuten zentrifugiert (Adams 
Autocrit Centrifuge, Clay Adams, Parsippany, New Jersey, USA) und der Hämatokrit mittels der in der Zentrifuge angebrachten Skala abgelesen.

\subsection{Elektronenspinresonanz Spektroskopie}

Da sich speziell das Superoxidanion aufgrund der kurzen Halbwertszeit ( 1Millisekunde) nicht direkt bestimmen lässt, wurde die Bestimmung der Radikalkonzentration mittels Elektronenspinresonanz Spektroskopie (ESR) nach Zugabe eines Spin-Probes in das Perfusionssystem durchgeführt. Als Spin-Probe wurde das zyklische Hydroxylamin 1Hydroxy-3-carboxy-2,2,5,5-tetramethylpyrrolidin- $\mathrm{HCl}$ (CP-H, L-Optik, Berlin, Deutschland) verwendet. Diese Komponente reagiert spezifisch mit Superoxid und Peroxynitrit. Durch die stöchiometrische Reaktion mit diesen Radikalen entsteht aus CP-H ein stabiles Produkt, das Spin-Addukt $\mathrm{CP}^{\bullet}$, das sich mit ESR-Spektroskopie einfach nachweisen lässt.

\subsubsection{Ansatz des Spin-Probes}

Der Ansatz der Spin-Probe Lösung erfolgte in einem $2 \mathrm{ml}$ Reaktionsgefäß (EppendorfNetheler-Hinz $\mathrm{GmbH}$ ) auf Eis. Für den Ansatz wurden die im Folgenden beschriebenen Lösungen verwendet. Zuerst wurde eine 0,9 prozentige NaCl-Lösung (Fluka Chemie $\mathrm{GmbH}$ ) mit Wasser aus der Reinstwasseranlage (Millipore $\mathrm{GmbH}$ ) angesetzt. Des Weiteren wurde eine $10 \mathrm{mM}$ Lösung von Diethylenetrimanine-Pentaacetic Acid (DTPA; Sigma-Aldrich Chemie $\mathrm{GmbH}$ ) benötigt. Dazu wurde DTPA in ca. $700 \mu 1$ einmolarer $\mathrm{NaOH}$ (Merck) unter schütteln gelöst und dann mit 0,9\%iger $\mathrm{NaCl}$ auf $10 \mathrm{ml}$ aufgefüllt. Von der $\mathrm{NaCl}$ Lösung wurden dann $1080 \mu \mathrm{l}$ in das auf Eis stehende Reaktionsgefäß pipettiert (Eppendorf-Netheler-Hinz $\mathrm{GmbH}$ ) und $120 \mu \mathrm{l}$ der $10 \mathrm{mM}$ DTPA-Lösung zugegeben. Dieser Ansatz wurde dann mit Stickstoff (Air Liquide) begast um die Autoxidation des Spin-Probes zu verringern. Zu der NaCl-DTPA-Mischung wurde unter fortlaufender Begasung $\mathrm{CP}-\mathrm{H}$, resultierend in einer Konzentration von 5 mM, gegeben.

\subsubsection{Einstellungen des Elektronenspinresonanz Spektroskops}

Die Bestimmung der ROS-Freisetzung wurde mit einem MiniScope MS 100 (Magnettech, Berlin-Adlershof, Deutschland) durchgeführt. Alle Parameter für die CP-H Messungen wurden über die zugehörige Software (MiniScopeControl, Version 2.4.1, CDmitri Vashkevich) auf folgende Werte eingestellt. Die Stärke des Magnetfelds betrug 3379,40 G und die Scan-Weite 58,52 G. Ein Messdurchlauf dauerte 15 Sekunden und wurde dreimal wiederholt, so dass eine Messung im Gesamten 45 Sekunden dauerte. Die Spektren der Einzelmessungen wurden dann gemittelt und gespeichert. Insgesamt wurden während eines Messdurchlaufs 4096 Messpunkte des Spektrums analysiert. Für die Messungen war der Tiefpassfilter inaktiv. Die Modulationsamplitude der Mikrowelle betrug $2000 \mathrm{mG}$ und die Mikrowellenleistung für die Analyse von CP-H $10 \mathrm{~dB}$. Das erhaltene Signal wurde um den Faktor 500 verstärkt, zudem wurde das Messsignal invertiert. Alle Parameter sind in Tabelle 2-4 nochmals zusammengefasst. Einstellung und Abgleich der Sensoren erfolgte automatisch, wobei die Anzeigen für die Abweichung des Diodenstroms, des Feldwertes vom Sollwert und die Regelabweichung der automatischen Frequenzregelung visuell 
kontrolliert wurden. Die Messung erfolgte nachdem die Mikrowellenleistung auf die jeweils zu messende Probe justiert war.

\section{Tabelle 2-4: Einstellungen des ESR-Spektroskops für die CP-H Messung}

Die Parameter wurden für die Messungen von CP-H über die Software MiniScopeControl eingestellt und für jede Einzelmessung beibehalten. Der Abgleich der Mikrowellenbrücke auf die jeweils zu messende Probe erfolgte vor jeder Messung automatisch.

\begin{tabular}{|l|l|c|}
\hline Parameter & \multicolumn{1}{|c|}{ Beschreibung } & Wert \\
\hline \hline B0-Field & Zentrum des Magnetfeldes & $3379,4 \mathrm{G}$ \\
\hline Sweep & Scan-Weite & $58,52 \mathrm{G}$ \\
\hline Sweep Time & Messzeit & 15 sek. \\
\hline Number & Anzahl Messdurchläufe & 3 \\
\hline Smooth & Tiefpassfilter & 0 sek. (inaktiv) \\
\hline Steps & Anzahl Messpunkte im Spektrum & 4096 \\
\hline Modulation & Modulationsamplitude & 10 dB \\
\hline MW atten & Mikrowellenleistung & 500 \\
\hline Gain & Verstärkung des Signals & 180 (Phase invertiert) \\
\hline Phase & $\begin{array}{l}\text { Phasenempfindliche } \\
\text { Verstärkers }\end{array}$ & Gleichrichtung \\
\hline
\end{tabular}

\subsection{Stimulierung von $\mathrm{NADP}(\mathrm{H})$-Oxidasen}

NADP(H)-Oxidasen wurden in den Versuchen durch Phorbol-12-Myristat-13-Acetat (PMA; Sigma-Aldrich Chemie $\mathrm{GmbH}$ ) stimuliert. Zunächst wurde eine $16 \mathrm{mM}$ PMA Stamm-Lösung angesetzt. Dazu wurden $10 \mathrm{mg}$ PMA in $1 \mathrm{ml}$ DMSO (Merck) gelöst. Diese Lösung wurde durch Zugabe von Perfusat auf eine Konzentration von $100 \mu \mathrm{M}$ eingestellt und dann $\mathrm{zu} 1 \mathrm{ml}$ in Reaktionsgefäßen aliquotiert. Die Aliquots wurden bis zur Verwendung bei $-20^{\circ} \mathrm{C}$ gelagert und direkt vor Gebrauch aufgetaut.

\subsection{Quantifizierung von Superoxid}

Die Freisetzung von Superoxid wurde in Parallelversuchen verifiziert und quantifiziert. Das Enzym Superoxiddismutase (SOD) katalysiert spezifisch die Umsetzung von Superoxid in $\mathrm{H}_{2} \mathrm{O}_{2}$. Der eingesetzte Spin-Probe $\mathrm{CP}-\mathrm{H}$ reagiert nicht mit $\mathrm{H}_{2} \mathrm{O}_{2}$, das selbst kein Signal im ESR-Spektroskop ergibt. Die Zugabe von SOD bewirkte also eine Abschwächung des Signals. Durch einen Vergleich der Versuche vor und nach SOD- 
Zugabe konnte so die Menge an freigesetztem Superoxid quantifiziert und zudem sichergestellt werden, dass es sich bei den analysierten Radikalen um ${ }^{\circ} \mathrm{O}_{2}{ }^{-}$handelte. Für diese Versuche wurde eine frisch aus Perfusat und Superoxiddismutase (Sigma-Aldrich Chemie $\mathrm{GmbH}$ ) hergestellte Lösung in das Reservoir des Perfusionssystems gegeben. Das Gesamtvolumen wurde auf $12 \mathrm{ml}$ eingestellt, die Konzentration an SOD betrug dann $150 \mathrm{U} / \mathrm{ml}$. Nach Ablauf einer Stunde wurden nochmals $150 \mathrm{U} / \mathrm{ml}$ SOD zugegeben. Damit konnte sichergestellt werden, dass bis zum Versuchsende SOD im Überschuss vorhanden war.

\subsection{Versuchsdurchführung}

Nachdem alle vorgegebenen Werte für Temperatur, Perfusatfluss und Beatmung erreicht waren, lief das System rezirkulierend in einem Gleichgewichtszustand (Steady State). In der Zwischenzeit wurde die Spin-Probe Lösung angesetzt (s. 2.3.1) und die ESRMessungen vorbereitet. Dies beinhaltete zunächst die Einstellung der Messparameter und die Messung einer Leerprobe. Dazu wurde ein Messdurchlauf ohne Probe, d. h. gegen Raumluft durchgeführt, um die benötigte geringe Hintergrundaktivität sicherzustellen. Dann wurde eine Standardprobe in die Probenaufnahme eingeführt und die Detektoren des Spektroskops auf diese Probe eingestellt. Dieser Schritt war notwendig, da das Gerät für die Kalibrierung der Sensoren auf eine flüssige Probe nach Messung der Leerprobe länger benötigte, als es die Abstände der Messungen während des Versuches zuließen.

Nachdem sich das Perfusionssystem 20 Minuten im Steady State befand, wurde mit der Analyse der ROS-Produktion begonnen. Zuerst wurden $50 \mu 1$ des Perfusats in eine Quarzkapillare (Blaubrand, Brand $\mathrm{GmbH}$ \& Co KG, Wertheim, Deutschland) gefüllt. Gleich nach Abnahme dieser Probe wurde die $5 \mathrm{mM}$ CP-H Lösung in das Reservoir des Perfusionssystem gegeben und das Gesamtperfusatvolumen auf $12 \mathrm{ml}$ aufgefüllt. Somit lag die CP-H Konzentration für die Versuche bei $0,5 \mathrm{mM}$. Die abgenommene Probe ohne $\mathrm{CP}-\mathrm{H}$ wurde nun, nachdem die Detektoren des ESR-Geräts auf diese Probe eingestellt waren, gemessen und das resultierende Spektrum als Hintergrund festgelegt. Für die Auswertung wurde dieses Spektrum als Hintergrundwert von allen in diesem Versuch erhaltenen Spektren subtrahiert. Der Zeitpunk der ersten Probenentnahme wurde als Startpunkt $\left(\mathrm{t}_{0}\right)$ des Versuchs definiert. Zwei Minuten nach CP-H Zugabe erfolgte die erste Abnahme und Messung der CP-H Proben. Die Probennahme zur Messung der ROSFreisetzung in den Mauslungen wurde in Intervallen von je zwei Minuten über einen Zeitraum von zwei Stunden wiederholt (s. dazu auch Abbildung 2-2). Die Detektoren des ESR-Spektroskops wurden für jede Messung auf die zu messende Probe kalibriert. Nach Ablauf von zwei Stunden wurden NADP(H)-Oxidasen durch Zugabe von PMA (SigmaAldrich Chemie $\mathrm{GmbH}$ ) stimuliert. Vor der PMA-Gabe wurde die Probennahme für fünf Minuten ausgesetzt, damit sich die Mauslungen stabilisieren konnten. Dann wurde PMA als Bolus direkt in die Pulmonalarterie injiziert, woraus eine PMA-Konzentration im Perfusat von $10 \mu \mathrm{M}$ resultierte. Die Messung der Radikal-Freisetzung wurde zwei Minuten nach PMA-Gabe wieder aufgenommen und über die nächsten 20 Minuten in Intervallen von je zwei Minuten fortgesetzt.

\subsubsection{Messung der normoxischen Superoxid-Freisetzung}

Die normoxische ROS-Freisetzung aus Mauslungen wurde in normoxisch gehaltenen Mäusen untersucht. Die Tiere wurden über den gesamten Versuchszeitraum mit 
normoxischem Gasgemisch (Air Liquide) beatmet (Abbildung 2-2). Die Zusammensetzung der Ventilationsgase ist in Tabelle 2-3 aufgeführt.

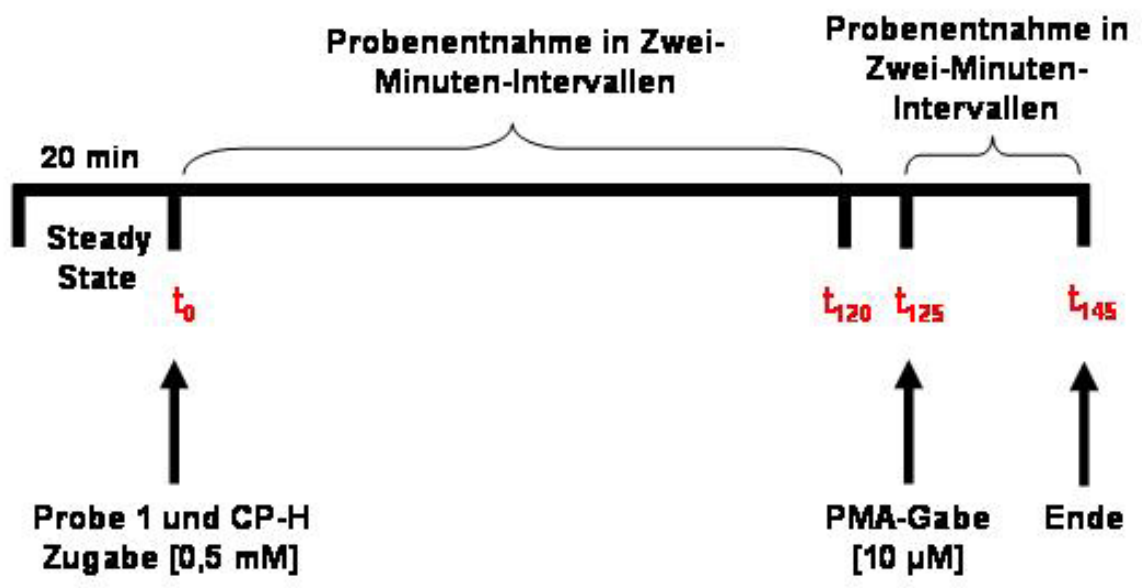

\section{Abbildung 2-2: Versuchsablauf Normoxie}

\subsubsection{Messung der akut-hypoxischen Superoxid-Freisetzung}

Akut hypoxische Bedingungen wurden während der Versuche durch Umstellen auf hypoxisches Atemgas (Air Liquide) mit 1\% Sauerstoff erhalten. Die in diesen Versuchen eingesetzten Mäuse waren normoxisch gehaltene. In den Experimenten wurden die Lungen alternierend für jeweils 15 Minuten hypoxisch und normoxisch ventiliert (Abbildung 2-3

Abbildung 2-3: Versuchsablauf akute Hypoxie).

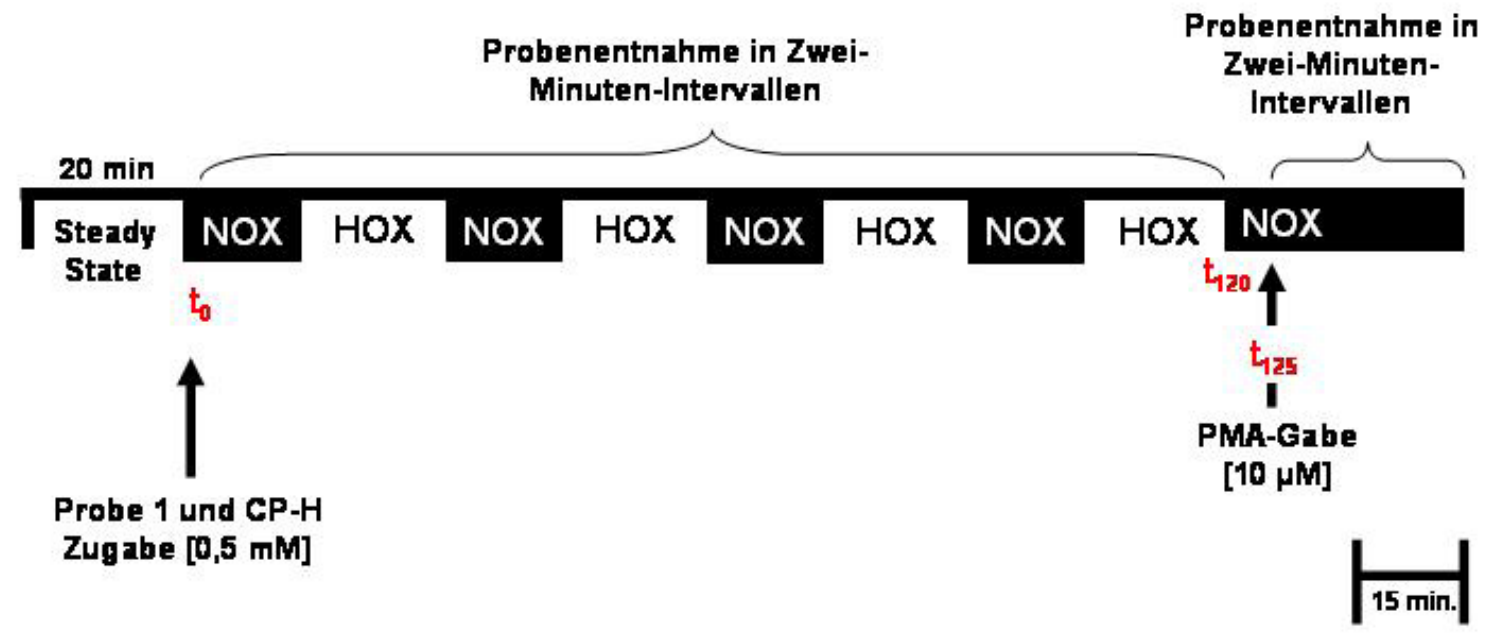

\section{Abbildung 2-3: Versuchsablauf akute Hypoxie}

Der Steady State wurde unter normoxischer Beatmung mit 21\% $\mathrm{O}_{2}$ erreicht. In den hypoxischen Phasen erfolgte die Ventilation mit $1 \% \mathrm{O}_{2}$. Die ROS-Freisetzung wurde in Ventilationsphasen von jeweils $15 \mathrm{~min}$. Dauer gemessen. $\mathrm{NOX}=$ normoxische Beatmung $\left(21 \% \mathrm{O}_{2}\right) ; \mathrm{HOX}=$ hypoxische Beatmung $\left(1 \% \mathrm{O}_{2}\right)$. 


\subsubsection{Messung der Superoxid-Freisetzung nach chronischer Hypoxie}

Die Untersuchung der Superoxid-Freisetzung nach chronisch hypoxischer Exposition wurde an Mäusen untersucht, die 21 Tage in einer normobaren Atmosphäre verminderten Sauerstoffpartialdruckes gehalten wurden. Die Tiere wurden in ihren Käfigen in geschlossenen Boxen (Willi Fischer OHG, Frankfurt/Main, Deutschland) gehalten, die über ein Pumpensystem (KNF Neuberger, Freiburg, Deutschland) mit Atemluft versorgt wurden. Die Sauerstoffkonzentration der Atemluft wurde über Sauerstoffcontroller (Model 4010, Labotech GmbH, Deisendorf, Deutschland) auf 10\% eingestellt, der prozentuale Anteil der anderen in der Luft vorkommenden Atemgase entsprach den normalen Bedingungen. Um den Gasverbrauch möglichst gering $\mathrm{zu}$ halten und das $\mathrm{CO}_{2}$ im rezirkulierenden System zu absorbieren, wurde die Luft in den Hypoxiekäfigen über Atemkalk (Drägersorb 800 Plus, Dräger Medical AG \& CO KGaA, Lübeck, Deutschland) gefiltert. Einmal täglich wurden die Tiere für ca. 10 Minuten aus den Hypoxieboxen genommen, um die Käfige zu säubern und Wasser sowie Futter aufzufüllen

Nach drei Wochen wurde das für den Versuch vorgesehene Tier aus der hypoxischen Atmosphäre entnommen und in einem gasdichten Plastik-Behälter, in dem ebenfalls ein $\mathrm{FiO}_{2}$ von 0.10 eingestellt war, zum Arbeitsplatz transportiert. Dort wurde die Maus in hypoxischer Atmosphäre intubiert und für die weitere Präparationsdauer hypoxisch mit $10 \% \mathrm{O}_{2}$ beatmet. Die hypoxische Beatmung war über den gesamten Versuchsverlauf konstant (Abbildung 2-4).

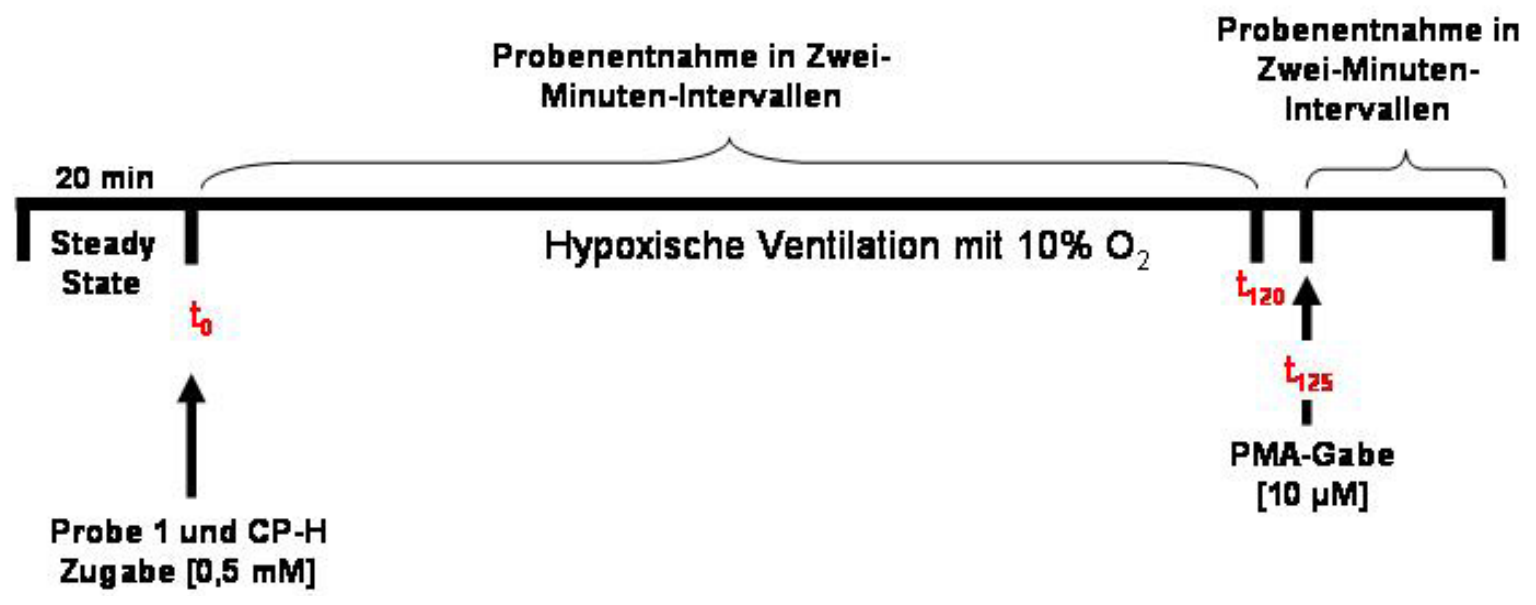

\section{Abbildung 2-4: Versuchsablauf chronische Hypoxie}

Nach chronisch hypoxischer Exposition $\left(21 \mathrm{Tage}, \mathrm{FiO}_{2}=0.10\right)$ wurden die Tiere unter hypoxischer Atmosphäre transportiert und präpariert. Die Beatmung erfolgte über den gesamten Versuchsverlauf mit $10 \% \mathrm{O}_{2}$. PMA wurde ebenfalls bei hypoxischer Beatmung zugegeben.

\subsubsection{Quantifizierung der Superoxidproduktion}

Zur Quantifizierung der Superoxidproduktion aus isoliert perfundierten Mauslungen wurden für alle vorgenannten Versuche Parallelversuche mit dem Enzym Superoxiddismutase (SOD) eingesetzt (s. Abschnitt 2.5). Dazu wurden nach dem Steady State $150 \mathrm{U} / \mathrm{ml}$ SOD in das rezirkulierende System mit einem Gesamtperfusatvolumen von $12 \mathrm{ml}$ gegeben. Die SOD-Gabe erfolgte direkt nach Abnahme der ersten Probe $\left(\mathrm{t}_{0}\right)$. Zwei Minuten nach Zugabe von SOD wurde eine erste SOD-Probe zur Analyse mittels ESR entnommen und sofort nachdem diese Probe genommen war, wurde der Spin-Probe CP-H in bekannter Konzentration zugegeben. Danach erfolgte die Versuchsdurchführung wie 
unter 2.6 beschrieben, allerdings wurde nach Ablauf einer Stunde nochmals SOD $[150 \mathrm{U} / \mathrm{ml}]$ zugegeben, um sicherzustellen, dass das Enzym im Überschuss vorhanden war. Abbildung 2-5 zeigt den Versuchsverlauf exemplarisch für die normoxischen Versuche.

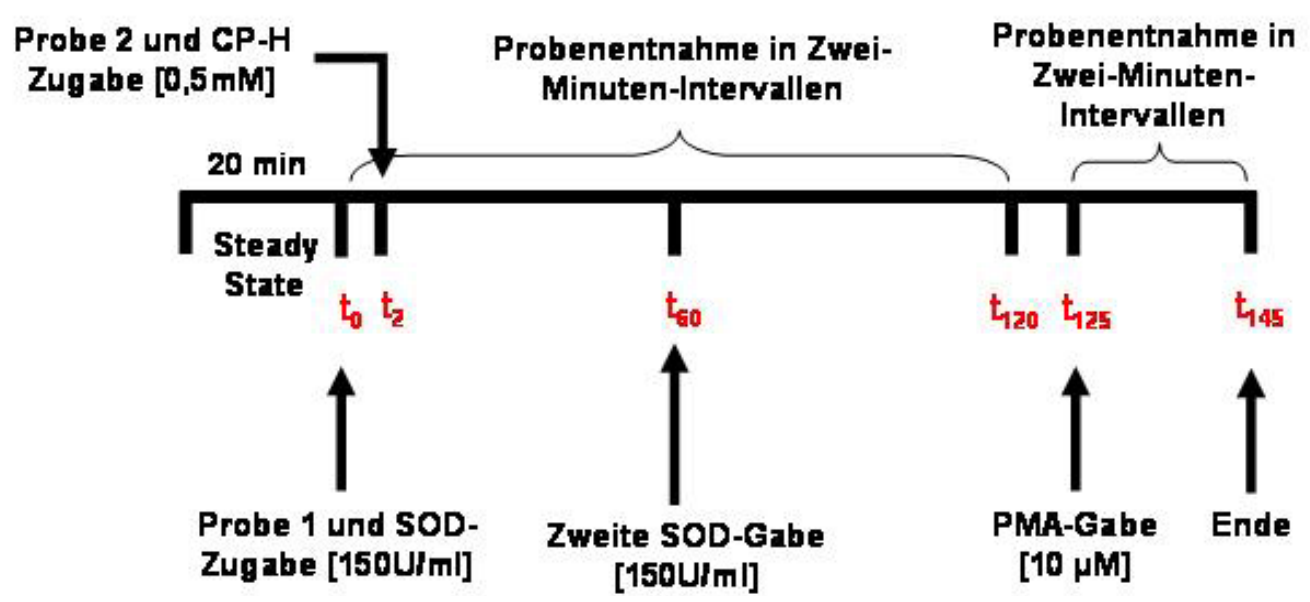

\section{Abbildung 2-5: Versuchsablauf für die Quantifizierung der ${ }^{\bullet} \mathrm{O}_{2}^{-}$-Produktion}

Zur Quantifizierung der ${ }^{\bullet} \mathrm{O}_{2}{ }^{-}$-Produktion wurden dem Perfusat 150U/ml SOD zugesetzt. Die Zugabe erfolgte zu Anfang und nach Ablauf eine Stunde, um sicherzustellen, dass SOD im Überschuss vorhanden war.

\subsection{Statistische Auswertung}

Die Statistik wurde für alle Versuche mit der Statistiksoftware MedCalc (MedCalc Software, Version 7.0.0.2, Mariakerke, Belgien) ausgewertet. Für die Erstellung von Graphiken wurde Microsoft Excel (Microsoft Corp. Deutschland, Unterschleißheim, Deutschland) benutzt.

Alle erhaltenen Daten wurden zunächst mit dem Kolmogorov-Smirnov Test auf eine Normalverteilung nach Gauss untersucht. Das Ergebnis dieses Tests entsprach einer Normalverteilung, wenn der durch den Test errechnete P-Wert über 0,05 lag. Bei einem P-Wert kleiner 0,05 wurde der Test als nicht-normalverteilt zurückgewiesen. Dies war dann der Fall, wenn die Werte der betrachteten Fälle nicht durch das arithmetische Mittel und die Standardabweichung beschrieben werden konnten. Für den Vergleich dieser nichtnormalverteilten Proben wurde der Wilcoxon-Test angewendet. Trat eine Normalverteilung der Werte einer Probe auf, wurden die Daten mittels des Student's-TTests analysiert. Neben diesen Tests wurde eine Varianzanalyse (ANOVA) durchgeführt. Aus diesen Tests ergab sich die Irrtumswahrscheinlichkeit „p“. Der Wert der Irrtumswahrscheinlichkeit „,p“ gibt Aufschluss darüber, ob sich zwei Proben signifikant voneinander unterscheiden. In dieser Arbeit wurden Unterschiede mit einem $p$-Wert $\leq 0,05$ als signifikant betrachtet. 


\section{Ergebnisse}

Zunächst werden die Gewichte aller für die Versuche eingesetzten Tiere dargestellt. Darauf folgt die Auswertung der gemessenen Hämatokritwerte. Anschließend werden in diesem Kapitel die aus den Versuchen erhaltenen physiologischen Daten, also die pulmonalarteriellen Drücke aufgezeigt und abschließend erfolgt die Darstellung der Superoxid-Freisetzung aus den ESR-Messungen.

\subsection{Gewicht}

Die Tiere für die Versuche an der isoliert perfundierten und ventilierten Mauslunge wurden vor Versuchsbeginn gewogen. In Tabelle 3-1 sind die Tiergewichte, eingeteilt nach Stamm und Versuch, zusammengefasst. Insgesamt wurden die Daten aus 143 Mäusen erhoben, die weiterhin in drei verschiedene experimentelle Ansätze unterteilt waren, nämlich Normoxie $(\mathrm{n}=66)$, akute $(\mathrm{n}=49)$ und chronische Hypoxie $(\mathrm{n}=28)$. Zur Quantifizierung der Superoxid-Freisetzung wurde in Parallelansätzen Superoxiddismutase (SOD) zugegeben. Da die in den SOD-Versuchen eingesetzten Tiere den gleichen Bedingungen ausgesetzt waren wie die Tiere, die Versuchen ohne SOD unterzogen wurden und sich darüber hinaus keine signifikanten Unterschiede zwischen den beiden Gruppen ergaben, werden die Mausgewichte nicht nach den Versuchen mit oder ohne SOD aufgeschlüsselt. Alle erhobenen Daten folgten der Gauss'schen Normalverteilung.

Neben den Wildtypmäusen des Stammes C57B1/6J wurden auch genetisch veränderte Mäuse eingesetzt. Diese Mäuse hatten entweder einen Knock-Out der gp91 $1^{\text {phox }}$ Untereinheit von NADP(H)-Oxidasen, im Folgenden als gp91 ${ }^{-/-}$bezeichnet, oder einen Knock-Out der $47^{\text {phox }}$-Untereinheit von NADP(H)-Oxidasen, die in diesem Kapitel als $\mathrm{p} 47^{-/-}$bezeichnet sind. Zudem wurden Mäuse eingesetzt, die die membranständige Untereinheit $\mathrm{p} 22^{\text {phox }}$ von NADP(H)-Oxidasen überexprimieren. Diese Tiere werden als p $22^{+/ T}$ bezeichnet. Neben diesen vier Mausstämmen wurden durch Transplantation von Knochenmark chimäre Mäuse hergestellt (s. 2.1.2). Die Darstellung der aus diesen Tieren erhaltenen Daten folgt in Tabelle 3-2.

\section{Tabelle 3-1. Gewichte von Wildtypen und genetisch veränderten Mäusen}

Aufstellung der Mausgewichte in Gramm [g] \pm SEM nach Stamm und Exposition. Außer den chronisch hypoxischen Tieren wurden alle Mäuse bei Raumluft gehalten. Die chronisch hypoxischen Mäuse wurden einmal täglich zur Säuberung der Käfige aus den Hypoxiekäfigen genommen. $\left({ }^{*} \mathrm{p}<0,05\right.$ gegen die normoxische Gruppe)

\begin{tabular}{|l|c|c|c|c|}
\hline Exposition/Stamm & $\mathrm{C} 57 \mathrm{Bl} / 6 \mathrm{~J}$ & $\mathrm{gp} 91^{-/-}$ & $\mathrm{p} 47^{-/-}$ & $\mathrm{p} 22^{+/ \mathrm{T}}$ \\
\hline \hline Normoxie & $25,0 \pm 0,6$ & $27,2 \pm 1,0$ & $29,1 \pm 1,4$ & $30,2 \pm 3,5$ \\
& $(\mathrm{n}=18)$ & $(\mathrm{n}=20)$ & $(\mathrm{n}=22)$ & $(\mathrm{n}=6)$ \\
\hline Akute Hypoxie & $31,6 \pm 2,6$ & $34,9 \pm 2,3^{*}$ & $30,5 \pm 1,5$ & $28,4 \pm 1,3$ \\
& $(\mathrm{n}=10)$ & $(\mathrm{n}=12)$ & $(\mathrm{n}=16)$ & $(\mathrm{n}=11)$ \\
\hline Chronische Hypoxie & $25,8 \pm 0,4$ & $28,1 \pm 0,7$ & $31,8 \pm 3,2$ & $28,3 \pm 0,9$ \\
& $(\mathrm{n}=14)$ & $(\mathrm{n}=5)$ & $(\mathrm{n}=5)$ & $(\mathrm{n}=6)$ \\
\hline
\end{tabular}

Die nachfolgende Tabelle 3-2 listet die Gewichte der chimären Mäuse auf. Die Tiere sind nach ihrem ursprünglichen Genotyp als Wildtyp (WT) oder gp91 ${ }^{\text {phox }}$-Knock-Out (gp91 $1^{-/-}$) bezeichnet. Zudem wird im zweiten Teil der Bezeichnung der Genotyp des transplantierten 
Knochenmarks angegeben. So entstehen die folgenden vier Gruppen, von denen zwei als Kontrollen für die Transplantationen dienten: Wildtypen mit transplantiertem Knochenmark aus Wildtypen (WT/WT), und gp91 ${ }^{\text {phox }}$-defiziente Mäuse, die Knochenmark aus gp91 $1^{-/-}$Mäusen erhielten $\left(\mathrm{gp} 91^{-/ /} / \mathrm{gp} 91^{-/-}\right)$. Die Versuchsgruppen waren Mäuse des Wildtyps, die Knochenmark aus gp91 ${ }^{-/-}$Spendern erhielten (WT/gp91 $1^{-/}$) umgekehrt Mäuse mit gp91 ${ }^{\text {phox }}$-Defizienz, denen Knochenmark aus Wildtypen injiziert wurde (gp91 $\left.1^{-/} / \mathrm{WT}\right)$. (s. auch 2.1.2). Insgesamt wurde das Gewicht von 27 chimären Mäusen bestimmt.

\section{Tabelle 3-2: Gewichte der chimären Mäuse}

Aufstellung der Mausgewichte in Gramm [g] \pm SEM nach Stamm und Exposition. Alle Tiere wurden bei Raumluft gehalten. Es ergaben sich keine signifikanten Unterschiede.

\begin{tabular}{|c|c|c|c|c|}
\hline Exposition/Tierbezeichnung & WT/WT & $\mathrm{gp} 91^{-/-} / \mathrm{gp} 91^{-/-}$ & $\mathrm{WT} / \mathrm{gp} 91^{-/-}$ & $\mathrm{Gp} 91^{-/ /} / \mathrm{WT}$ \\
\hline Normoxie & $\begin{array}{c}30,9 \pm 2,5 \\
(n=4)\end{array}$ & $\begin{array}{c}38,5 \pm 2,0 \\
(\mathrm{n}=4)\end{array}$ & $\begin{array}{c}30,0 \pm 0,9 \\
(\mathrm{n}=11)\end{array}$ & $\begin{array}{c}39,7 \pm 2,1 \\
(\mathrm{n}=8)\end{array}$ \\
\hline Akute Hypoxie & $\begin{array}{c}27,4 \pm 0,6 \\
(\mathrm{n}=10)\end{array}$ & $\begin{array}{c}30,7 \pm 1,7 \\
(\mathrm{n}=4)\end{array}$ & $\begin{array}{c}27,6 \pm 0,7 \\
(\mathrm{n}=8)\end{array}$ & $\begin{array}{c}33,1 \pm 0,8 \\
(\mathrm{n}=9)\end{array}$ \\
\hline
\end{tabular}

Für die Versuche wurden männliche Tiere eingesetzt. Obwohl für die gp91 ${ }^{\text {phox }}$-Knock-OutMäuse signifikante Abweichungen bezüglich des Körpergewichts errechnet wurden, zeigte sich keine Korrelation $\mathrm{zu}$ den in den Versuchen erhaltenen Daten für den pulmonalarteriellen Druck oder die spektroskopische Radikalmessungen mit ESR. Signifikante Abweichungen im Gewicht dieser Mäuse sind damit zu erklären, dass diese Tiere schon etwas schwerer geliefert wurden als ihre Artgenossen des Wildtyps. Trotzdem ist das Gewicht nur von untergeordneter Bedeutung für die durchgeführten Versuche und beeinflusst die gewonnenen Ergebnisse nicht.

\subsection{Hämatokrit}

Während der Präparation für die Versuche an der isoliert perfundierten und ventilierten Mauslunge wurden pro Maus $40 \mu \mathrm{l}$ Blut aus dem rechten Ventrikel des Herzens entnommen und für eine spätere Bestimmung des Hämatokrits in Kapillaren abgefüllt. In Tabelle 3-3 und Tabelle 3-4 sind die nach Zentrifugation erhaltenen Werte, eingeteilt nach Stamm und Versuch, zusammengefasst. Es wurden, genau wie für die Gewichtsbestimmung, insgesamt drei verschiedene experimentelle Ansätze verfolgt, nämlich Normoxie, akute und chronische Hypoxie. Die Anzahl der Versuchstiere entspricht der unter 3.1 genannten Summe, ebenso die Aufteilung in den jeweiligen Versuchsgruppen. Bezüglich der Tiere, die in den SOD-Versuchen eingesetzt wurden, gelten ebenfalls die im vorigen Abschnitt erwähnten Bedingungen. Alle Daten für den Hämatokrit waren normalverteilt. 
Tabelle 3-3. Hämatokrit von Wildtyp und genetisch veränderten Mäusen

Aufstellung des Hämatokrits in Prozent [\%] \pm SEM nach Stamm und Exposition. Außer den chronisch hypoxischen Tieren wurden alle Mäuse bei Raumluft gehalten. Die Mäuse in chronischer Hypoxie wurden einmal täglich zur Säuberung der Käfige aus den Hypoxieboxen genommen. $\left({ }^{\dagger \dagger}=\mathrm{p}<0,0001\right.$ gegen die jeweilige normoxische Gruppe)

\begin{tabular}{|l|c|c|c|c|}
\hline Exposition/Stamm & $\mathrm{C} 57 \mathrm{Bl} / 6 \mathrm{~J}$ & $\mathrm{gp} 91^{-/-}$ & $\mathrm{p} 47^{-/-}$ & $\mathrm{p} 22^{+/ \mathrm{T}}$ \\
\hline \hline Normoxie & $37,2 \pm 0,6$ & $36,1 \pm 0,6$ & $35,6 \pm 0,9$ & $35,8 \pm 0,9$ \\
& $(\mathrm{n}=18)$ & $(\mathrm{n}=20)$ & $(\mathrm{n}=22)$ & $(\mathrm{n}=6)$ \\
\hline Akute Hypoxie & $34,0 \pm 1,8$ & $36,4 \pm 0,8$ & $35,9 \pm 1,0$ & $36,7 \pm 1,1$ \\
& $(\mathrm{n}=10)$ & $(\mathrm{n}=12)$ & $(\mathrm{n}=16)$ & $(\mathrm{n}=11)$ \\
\hline Chronische Hypoxie & $\begin{array}{c}67,1 \pm 1,1^{\dagger \dagger} \\
(\mathrm{n}=14)\end{array}$ & $\begin{array}{c}79,0 \pm 3,8^{\dagger \dagger} \\
(\mathrm{n}=4)\end{array}$ & $\begin{array}{c}74,0 \pm 2,2^{\dagger \dagger} \\
(\mathrm{n}=6)\end{array}$ & $\begin{array}{c}72,3 \pm 1,5^{\dagger \dagger} \\
(\mathrm{n}=6)\end{array}$ \\
\hline
\end{tabular}

Die nachfolgende Tabelle listet die Werte für den Hämatokrit der chimären Mäuse auf. Die Bezeichnung dieser Tiere folgt dem in Abschnitt 2.1.2 dargestellten Schema.

\section{Tabelle 3-4: Hämatokrit der chimären Mäuse}

Alle Tiere wurden unter normoxischen Bedingungen gehalten. Es ergaben sich keine signifikanten Unterschiede.

\begin{tabular}{|c|c|c|c|c|}
\hline Exposition/Tierbezeichnung & WT/WT & gp91//gp91 $1^{-/-}$ & WT/gp91 $1^{-/-}$ & gp91//-WT \\
\hline Normoxie & $\begin{array}{c}36,3 \pm 1,3 \\
(\mathrm{n}=4)\end{array}$ & $\begin{array}{c}34,0 \pm 1,5 \\
(\mathrm{n}=4)\end{array}$ & $\begin{array}{c}32,6 \pm 1,2 \\
(\mathrm{n}=11)\end{array}$ & $\begin{array}{c}35,5 \pm 0,5 \\
(\mathrm{n}=8)\end{array}$ \\
\hline Akute Hypoxie & $\begin{array}{c}38,4 \pm 0,5 \\
(\mathrm{n}=10)\end{array}$ & $\begin{array}{c}41,1 \pm 0,5 \\
(\mathrm{n}=4)\end{array}$ & $\begin{array}{c}37,0 \pm 0,7 \\
(\mathrm{n}=8)\end{array}$ & $\begin{array}{c}38,0 \pm 0,6 \\
(\mathrm{n}=9)\end{array}$ \\
\hline
\end{tabular}

Die Mäuse, die unter chronisch hypoxischen Bedingungen gehalten wurden, zeigten signifikant erhöhte Werte für den Hämatokrit im Vergleich zu den Tieren, die in normoxischer Atmosphäre lebten. Dies war zu erwarten, da es unter Hypoxie zu einer verstärkten Erythropoese kommt, um den relativen Sauerstoffmangel über die Vermehrung der sauerstoffbindenden Zellen, also der Erythrozyten, auszugleichen. Die Tiere, die einer experimentellen akuten Hypoxie ausgesetzt waren, hatten keinen erhöhten Hämatokrit. Dies erklärt sich daraus, dass diese Mäuse normoxisch gehalten wurden und nur die isolierten Lungen in den Versuchen Verwendung fanden.

\subsection{Genotypisierung der chimären Mäuse}

Die Genotypisierung der durch Knochenmarkstransplantation generierten chimären Tiere erfolgte mit der Polymerase-Kettenreaktion (polymerase chain reaction, PCR). Als Ausgangsmaterial dienten Blut- und Endothelzellen, die aus den jeweiligen Empfängermäusen isoliert wurden. Typisiert wurde jedes Tier, das einer Transplantation unterzogen wurde, in den Versuchen zur Radikalfreisetzung wurden allerdings nur die Mäuse eingesetzt, die gemäß der Typisierung auch einen chimären Genotyp aufwiesen. Abbildung 3-1 stellt exemplarisch ein Bild der gelelektrophoretisch aufgetrennten, bereits amplifizierten DNA dar. Das Gel wurde in der ersten Spur mit einem Größenmarker beladen, der für die Identifizierung der amplifizierten DNA-Bereiche aufgrund deren 
molekularer Größe herangezogen wurde. Die nachfolgenden Spuren zeigen als Kontrolle die amplifizierten DNA-Abschnitte der gp91 ${ }^{\text {phox }}$-Untereinheit von NADP(H)-Oxidasen aus einem Wildtyp (Spur zwei und drei) und einer gp91 ${ }^{\text {phox }}$-defizienten Maus (Spur vier und fünf). Für beide Tiere ist die aus Granulozyten und Endothelzellen gewonnene genomische DNA getrennt dargestellt. Als nächstes wurde die DNA aus einem Wildtypen, der Knochenmark aus einer Wildtypmaus erhielt, aufgetragen. Die Typisierung dieser Tiere wurde zur Kontrolle für den Erfolg der Transplantationen durchgeführt. Zudem wurden die Mäuse benötigt, um in den Versuchen zur Radikalfreisetzung eine Kontrolle über die Auswirkung von Bestrahlung und anschließender Knochenmarkstransplantation zu bekommen. Auch für dieses Tier wurden die aus der PCR gewonnenen DNA-Stücke getrennt nach granulozytärem oder endothelialem Ursprung aufgetragen.

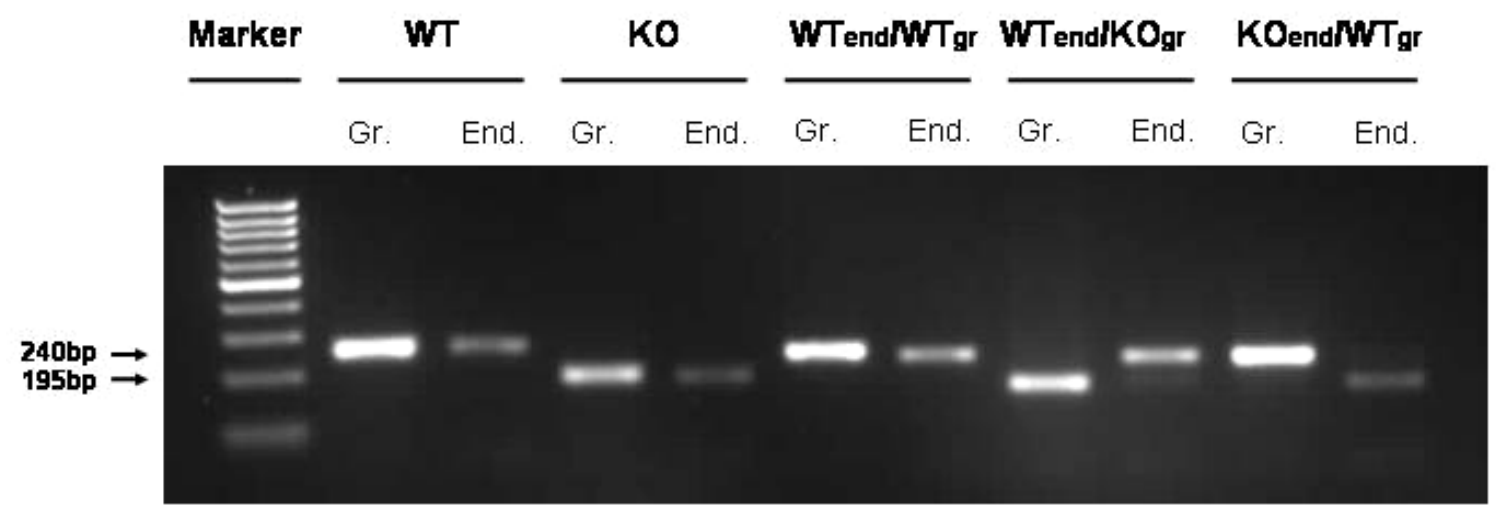

\section{Abbildung 3-1: Elektrophoretische Auftrennung der amplifizierten DNA}

Exemplarische Darstellung der elektrophoretischen Auftrennung nach Amplifizierung genomischer DNA aus Endothelzellen (End) und Granulozyten (Gr) von Wildtypen (WT), gp91 ${ }^{\text {phox }}$-defizienten (KO) und chimären Mäusen $\left(\mathrm{WT}_{\text {end }} / \mathrm{WT}_{\mathrm{gr}} ; \mathrm{WT}_{\text {end }} / \mathrm{KO}_{\mathrm{gr}}\right.$ und $\mathrm{KO}_{\text {end }} / \mathrm{WT}_{\mathrm{gr}}$ ). Von jedem Tier sind die aus der PCR hervorgegangenen DNA-Amplifikationen aus Granulozyten und Endothelzellen getrennt aufgetragen. Die erste Spur zeigt die Größen des aufgetragenen molekularen Standardmarkers. Mit Pfeilen sind links in der Abbildung die Größen der Banden für die intakte NADP(H)-Oxidase (240 bp) und die gp91 ${ }^{\text {phox }}$-defiziente NADP(H)-Oxidase (195 bp) gegeben.

Die abschließenden vier Spuren des Gels wurden mit endothelialer bzw. granulozytärer DNA eines Tieres aus den beiden Versuchsgruppen beladen. Die Spuren acht und neun zeigen DNA einer Maus des Wildtyps, die Knochenmark einer gp91 ${ }^{\text {phox }}$-defizienten Maus injiziert bekam. Deutlich ist zu sehen, dass die amplifizierte DNA aus den Granulozyten kleiner ist als diejenige, die aus den Endothelzellen des Tieres gewonnen wurde. Dieses Ergebnis war zu erwarten, da die Körperzellen, und damit auch die Zellen des Endothels, einen Wildtyp-Genotyp aufweisen. Die Granulozyten sind nach erfolgreicher Knochenmarkstransplantation in diesem Tier hingegen negativ für die gp91 ${ }^{\text {phox }}$ Untereinheit der NADP(H)-Oxidase. Die Spuren zehn und elf zeigen die elektrophoretische Auftrennung genomischer DNA aus Endothelzellen und Granulozyten einer Maus, die vom Stamm her defizient für die gp91 ${ }^{\text {phox }}$-Untereinheit ist, diese also auch nicht in ihren Körperzellen exprimiert. Nach Transplantation von Knochenmark einer Wildtypmaus bildet das Tier Granulozyten, die gp91 ${ }^{\text {phox }}$ positiv sind und genotypisch solchen des Wildtyps entsprechen (Spur zehn). Die Zellen des Endothels hingegen sind nach wie vor negativ für die gp91 ${ }^{\text {phox }}$-Untereinheit von NADP(H)-Oxidasen (Spur elf). Auch dieses Ergebnis entspricht den Erwartungen. 


\subsection{Pulmonalarterieller Druck}

Der pulmonalarterielle Druck (PAP) ist ein direkter Indikator für pulmonale Hypertonie $(\mathrm{PH})$ und das vaskuläre Remodeling. Unter akuter Hypoxie wird durch den Vorgang der hypoxischen pulmonalen Vasokonstriktion (HPV) präkapillärer Gefäße der Blutfluss in der Lunge den regionalen Ventilationsverhältnissen angepasst und das Blut in gut ventilierte Bereiche der Lunge geleitet. Infolgedessen erhöht sich der PAP bei konstantem Fluss innerhalb von Sekunden und kehrt in den folgenden ca. 10 Minuten wieder auf einen niedrigeren Wert zurück, allerdings ohne den Basiswert zu erreichen. Dauert die hypoxische Phase länger an, erhöht sich der PAP nach der ersten initialen Antwort langsam und stetig. Insgesamt gesehen wird unter Hypoxie also eine biphasische Antwort ausgelöst: die erste Phase ist gekennzeichnet durch einen rapiden Druckanstieg, der nach etwa zehn Minuten wieder auf Normalniveau zurückkehrt und eine sich daran anschließende zweite Phase bei verlängerter hypoxischer Beatmung, die sich durch einen langsamen, kontinuierlichen Anstieg des PAP auszeichnet. Nach chronisch hypoxischer Exposition haben die Mäuse nicht nur einen erhöhten Hämatokrit, sondern auch einen erhöhten PAP. Verantwortlich dafür ist das Remodeling der Gefäßwand, durch das das Lumen der Blutgefäße verengt ist.

In diesem Abschnitt werden die pulmonalarteriellen Drücke der Mäuse bei normoxischer und akut hypoxischer Beatmung veranschaulicht. Zudem werden die PAPs der Tiere nach chronischer Hypoxie dargestellt.

\subsubsection{Pulmonalarterieller Druck in Normoxie}

Zuerst werden die normoxischen Basiswerte für die Wildtypen und transgenen Mäuse dargestellt. Pro Abbildung werden jeweils die Tiere ohne und mit Superoxiddismutase im Perfusat zusammengefasst. Neben der Quantifizierung der Superoxid-Freisetzung durch SOD wurden die NADP(H)-Oxidasen der Mauslungen am Ende des Versuches mit PMA stimuliert. Gemeinhin ist anzumerken, dass die in den Versuchen gemessenen pulmonalarteriellen Drücke verglichen mit Ergebnissen aktueller Literatur höher sind. Wie eigene Vorversuche zeigten, ist der Unterschied auf das verwendete Perfusat zurückzuführen, das speziell für die ESR-Messungen angesetzt wurde und höher viskös ist als das Perfusat, welches in anderen Experimenten verwendet wurde. Dennoch sind die hier gezeigten Ergebnisse mit den bereits publizierten Daten vergleichbar und stehen mit diesen in Einklang.

\subsubsection{Wildtypen}

Die Lungen von Wildtypmäusen hatten einen gemittelten PAP von 11,6 $\pm 0,6 \mathrm{~mm} \mathrm{Hg}$ für die Gruppe ohne SOD im Perfusat ( $\mathrm{n}=7$; Abbildung 3-2). Wurde dem Perfusat SOD zugesetzt, betrug der PAP 12,9 $\pm 0,8 \mathrm{~mm} \mathrm{Hg}(\mathrm{n}=7)$. Die Stimulation von NADP(H)Oxidasen mit PMA führte zu einem raschen Druckanstieg, der ca. 30 Sekunden nach der Bolusgabe von PMA einsetzte und letztlich zur Bildung eines Ödems in den Lungen führte. Aus diesem Grund wurden die Lungen nicht von Anfang an mit PMA perfundiert. Der PMA-induzierte Druckanstieg hatte in beiden Gruppen, d. h. in Versuchen mit und ohne SOD, den gleichen zeitlichen Verlauf. Obwohl die maximalen PAP-Werte für die mit SOD perfundierten Lungen $\left(\mathrm{PAP}_{\max }=28,4 \pm 1,5 \mathrm{~mm} \mathrm{Hg}\right.$ ) im Vergleich $\mathrm{zu}$ den Lungen ohne SOD $\left(\mathrm{PAP}_{\max }=24,2 \pm 1,9 \mathrm{~mm} \mathrm{Hg}\right) \mathrm{zu}$ Versuchsende tendenziell höher lagen, ergaben sich daraus keine Unterschiede. Dasselbe gilt für den berechneten Druckanstieg 
pro Minute $(\triangle \mathrm{PAP} / \mathrm{min})$. Dieser Wert lag für die Lungen mit $\mathrm{SOD}$ bei $0,8 \pm 0,1 \mathrm{~mm} \mathrm{Hg}$ und für die Lungen ohne SOD bei $0,7 \pm 0,1 \mathrm{~mm} \mathrm{Hg}$.

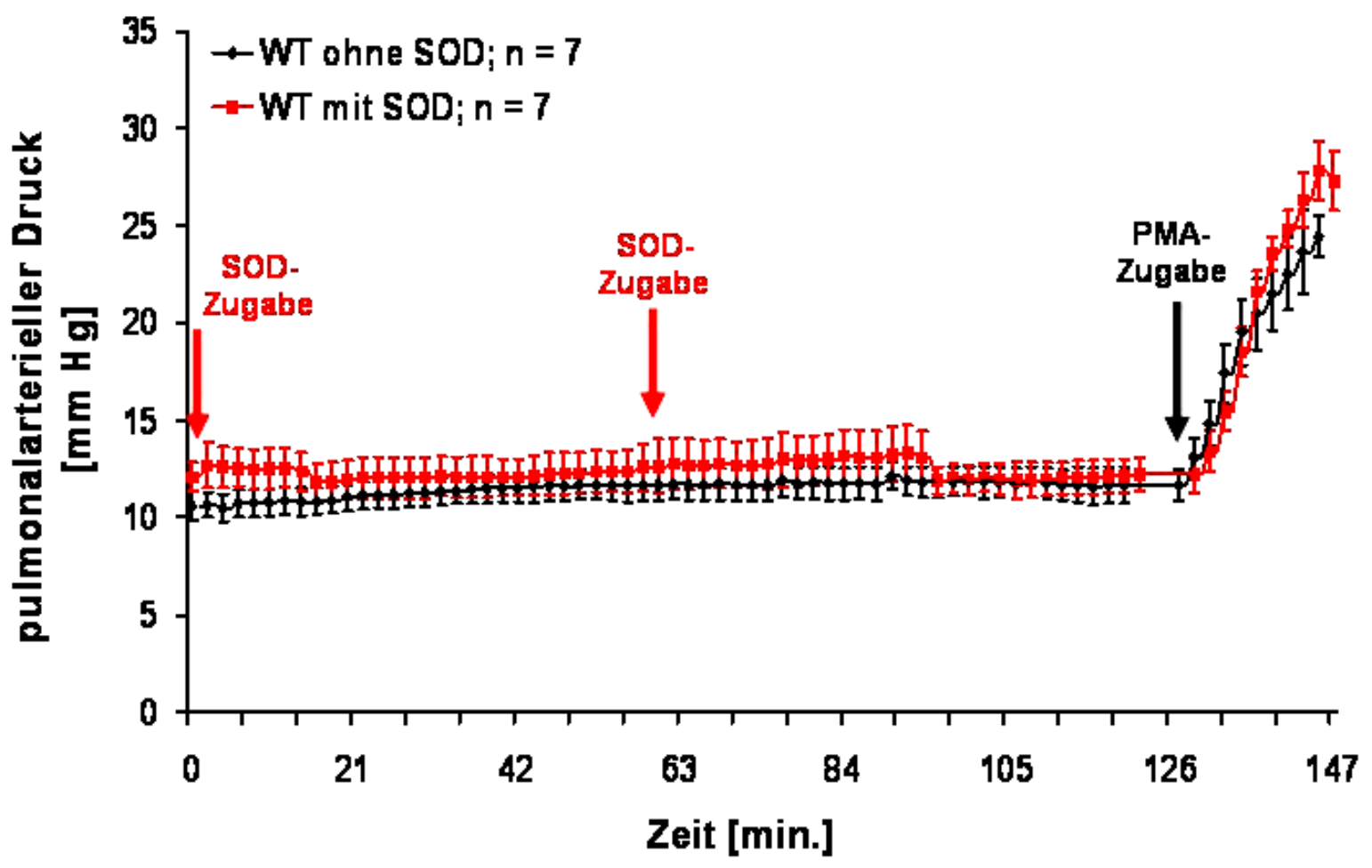

\section{Abbildung 3-2: Pulmonalarterieller Druck in Mauslungen des Wildtyps (C57Bl/6J)}

Die Graphik zeigt den PAP [mm Hg] in den Lungen des Wildtyps bei normoxischer Beatmung. SOD [150 U/ml] wurde zweimal gegeben (rote Pfeile). Die PMA-Gabe [10 $\mu \mathrm{M}$ Endkonzentration im Perfusat] erfolgte für beide Gruppen nach fünfminütigem Aussetzen der Probenentnahme zur Analyse mit ESR. WT = Wildtyp, SOD = Superoxiddismutase, PMA = Phorbol-Myristat-Acetat.

\subsubsection{2 gp91 ${ }^{\text {phox }}$-defiziente Mäuse}

Für die Lungen der Mäuse mit einem Knock-Out der gp91 ${ }^{\text {phox }}$-Untereinheit von NADP(H)Oxidasen ergab sich in den Versuchen ohne SOD ein gemittelter PAP von 12,7 $\pm 0,7 \mathrm{~mm}$ $\mathrm{Hg}$ (Abbildung 3-3; $\mathrm{n}=8$ ). Die Perfusion mit SOD führte zu keiner Veränderung des pulmonalarteriellen Drucks $(12,7 \pm 0,9 \mathrm{~mm} \mathrm{Hg} ; \mathrm{n}=8)$. Nach Stimulation von NADP(H)Oxidasen durch PMA wurde ein maximaler Druck von 25,8 $\pm 1,5 \mathrm{~mm} \mathrm{Hg}$ in den Lungen, die ohne SOD perfundiert wurden, und in den Mauslungen mit SOD im Perfusat ein maximaler PAP von 27,3 $\pm 1,9 \mathrm{~mm} \mathrm{Hg}$ registriert. Die Berechnung des Druckanstieges pro Minute nach PMA-Stimulation ergab im Vergleich der Gruppe ohne SOD $(\triangle \mathrm{PAP}=0,5 \pm$ $0,1 \mathrm{~mm} \mathrm{Hg} / \mathrm{min})$ gegen die Gruppe mit $\mathrm{SOD}(\triangle \mathrm{PAP}=0,7 \pm 0,1 \mathrm{~mm} \mathrm{Hg} / \mathrm{min})$ ebenfalls kein signifikantes Ergebnis. 


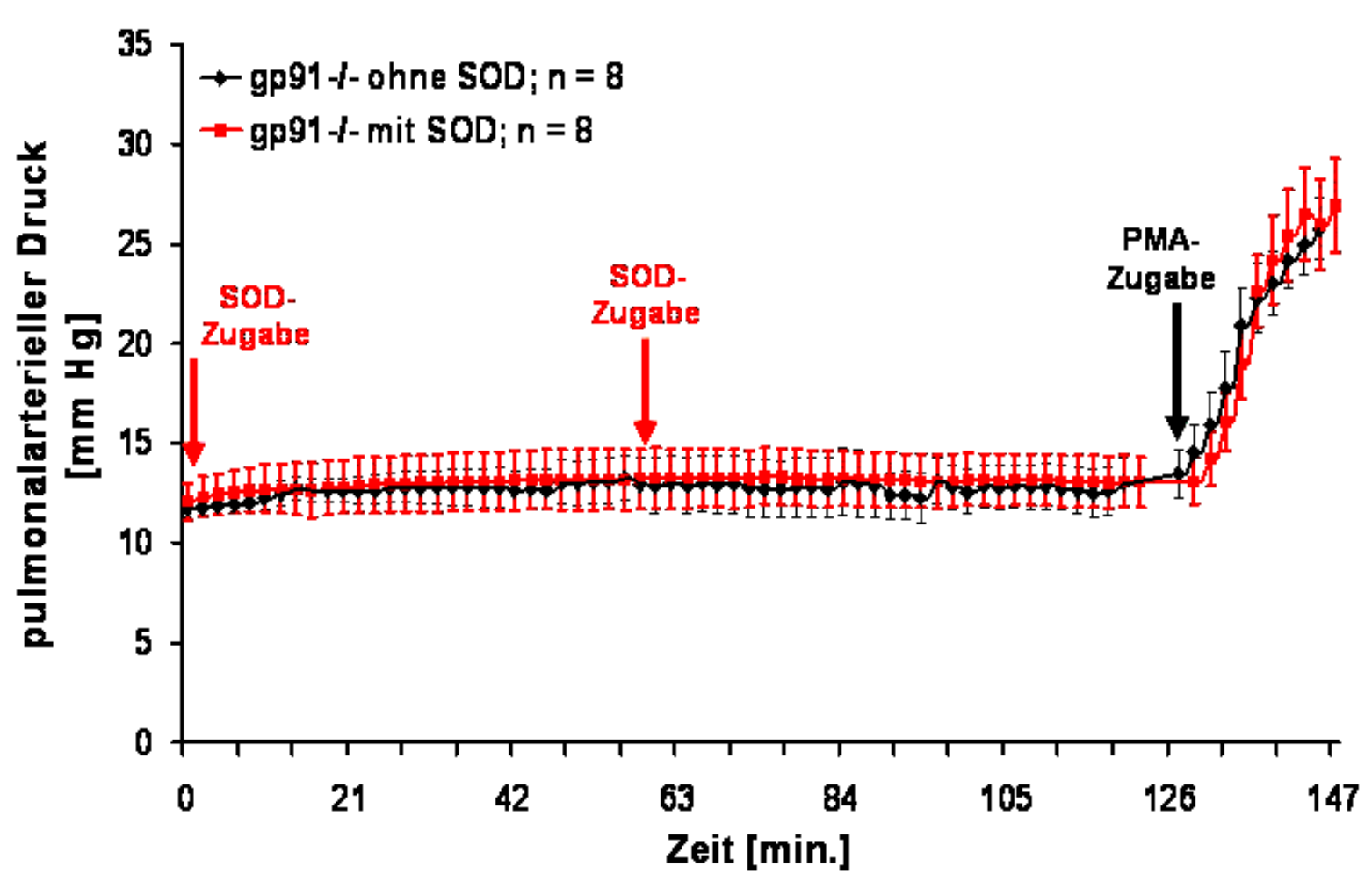

Abbildung 3-3: Pulmonalarterieller Druck in gp91 ${ }^{\text {phox }}$-defizienten Mauslungen

Die Graphik zeigt den PAP [mm Hg] in gp91 ${ }^{\text {phox }}$-defizienten Mäusen bei normoxischer Beatmung. SOD [150 U/ml] wurde zweimal gegeben (rote Pfeile). Die PMA-Gabe [10 $\mu$ M Endkonzentration im Perfusat] erfolgte für beide Gruppen nach fünfminütigem Aussetzen der Probenentnahme zur Analyse mit ESR. gp91 ${ }^{-/}=$gp91 ${ }^{\text {phox }}-$ Knock-Out, SOD $=$ Superoxiddismutase, PMA = PhorbolMyristat-Acetat.

\subsubsection{3 p47 ${ }^{\text {phox }}$-defiziente Mäuse}

Der pulmonalarterielle Druck in Mauslungen, die eine Gendefizienz für die $\mathrm{p} 47^{\text {phox }}$ Untereinheit von NADP(H)-Oxidasen aufweisen, war in den untersuchten Gruppen ohne und mit Superoxiddismutase fast identisch. In den Lungen, die ohne SOD perfundiert wurden, lag der gemittelte Basisdruck in der Pulmonalarterie bei $12,1 \pm 0,6 \mathrm{~mm} \mathrm{Hg}$ $(\mathrm{n}=7)$. Bei Perfusion mit SOD wurde der mittlere pulmonalarterielle Druck mit $12,6 \pm 1,1 \mathrm{~mm} \mathrm{Hg}$ gemessen (Abbildung 3-4; $\mathrm{n}=7$ ). Die Stimulation von NADP(H)Oxidasen in den Lungen dieser Mäuse durch einen PMA-Bolus hatte einen Druckanstieg von $0,5 \pm 0,1 \mathrm{~mm} \mathrm{Hg}$ pro Minute zur Folge wenn kein SOD im Perfusat vorhanden war. Nach 20 Minuten ergab sich ein maximaler Druck von 21,0 $\pm 2,7 \mathrm{~mm} \mathrm{Hg}$ in diesen Lungen. Demgegenüber stand ein maximaler PAP von 24,5 $\pm 2,2 \mathrm{~mm} \mathrm{Hg}$ bei der Perfusion mit SOD und nach PMA-Stimulation. Der $\triangle \mathrm{PAP} / \mathrm{min}$ ergab sich zu 0,7 $\pm 0,1 \mathrm{~mm} \mathrm{Hg}$. 


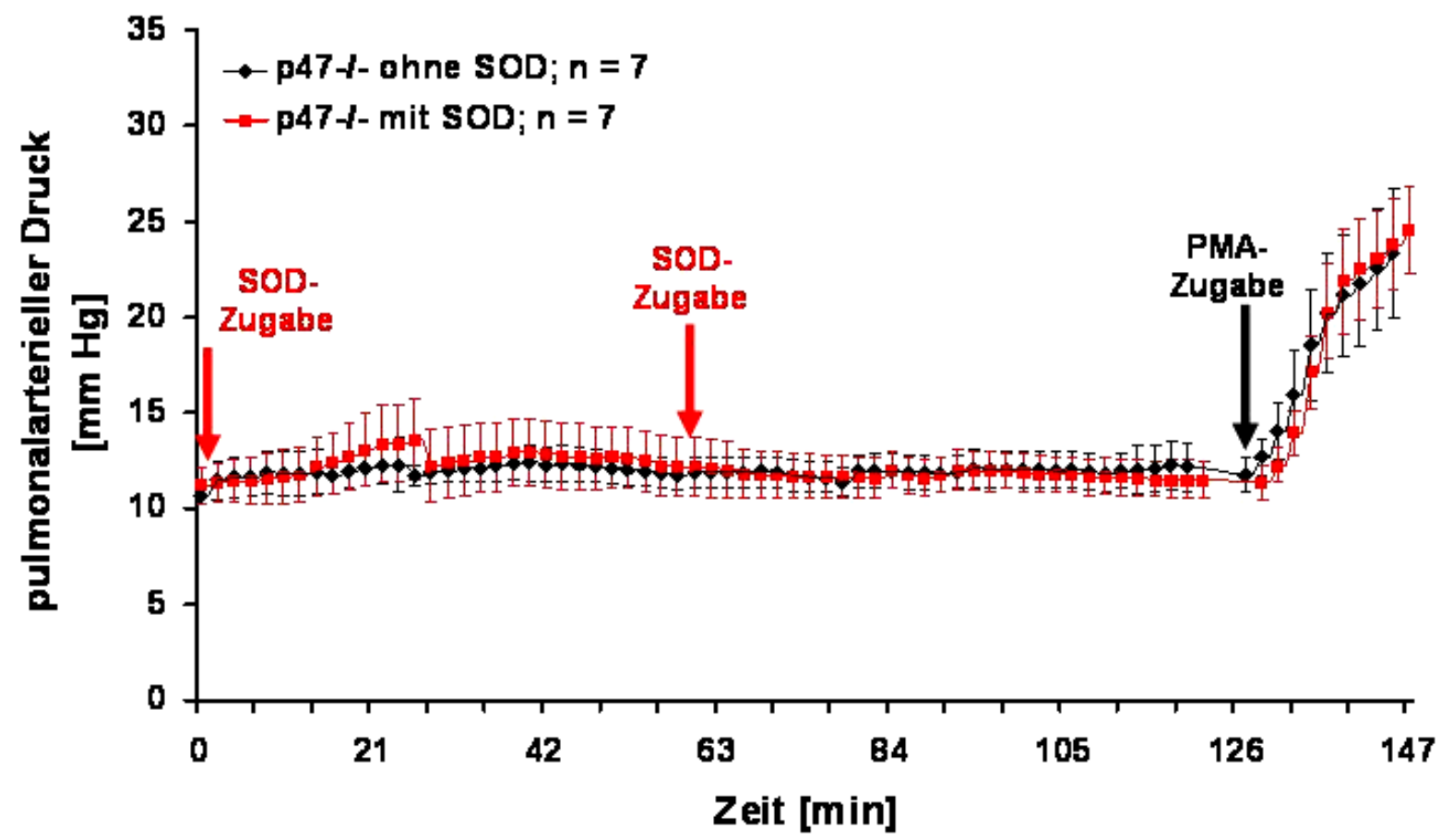

Abbildung 3-4: Pulmonalarterieller Druck in p47 ${ }^{\text {phox }}$-defizienten Mauslungen

Darstellung des PAPs [mm Hg] von p47 $7^{\text {phox }}$-defizienten Mauslungen bei normoxischer Beatmung. SOD $[150 \mathrm{U} / \mathrm{ml}]$ wurde zweimal gegeben (rote Pfeile). Die PMA-Gabe [10 $\mu \mathrm{M}$ Endkonzentration im Perfusat] erfolgte für beide Gruppen nach fünfminütigem Aussetzen der Probenentnahme zur Analyse mit ESR. p4 $47^{-/}=$p $47^{\text {phox }}-$ Knock-Out, SOD $=$ Superoxiddismutase, PMA $=$ PhorbolMyristat-Acetat.

\subsubsection{4 p22 $^{\text {phox }}$-überexprimierende Mäuse}

Der dritte genveränderte Mausstamm, der in den Versuchen eingesetzt wurde, überexprimiert die Untereinheit $\mathrm{p} 22^{\text {phox }}$ von NADP(H)-Oxidasen. Die Mauslungen diesen Stammes zeigten unter normoxischer Beatmung eine signifikante $(p<0,005)$ Erhöhung des pulmonalarteriellen Druckes bei der Perfusion mit SOD (Abbildung 3-5). In diesen Versuchen wurde ein mittlerer PAP von $15,8 \pm 1,4 \mathrm{~mm} \mathrm{Hg}$ gemessen $(\mathrm{n}=3)$, im Gegensatz dazu wurde bei Perfusion ohne SOD $(\mathrm{n}=3)$ ein PAP von 10,6 $\pm 0,3 \mathrm{~mm} \mathrm{Hg}$ registriert. Ausgehend von einem höheren Basisdruck lagen auch die maximalen Werte des PAP nach Stimulation mit PMA in den mit SOD perfundierten Lungen höher als in den Lungen ohne SOD im Perfusat, allerdings war dieser Unterschied nicht signifikant, was wahrscheinlich auf die geringe Anzahl der Versuchstiere zurückzuführen ist. Unter Perfusion mit SOD stieg der pulmonalarterielle Druck auf einen maximalen Wert von $31,1 \pm 2,6 \mathrm{~mm} \mathrm{Hg}$, wohingegen bei Perfusion ohne SOD ein maximaler PAP von 23,4 $\pm 3,4 \mathrm{~mm} \mathrm{Hg}$ erreicht wurde. Trotz dieser Differenz unterscheidet sich der pro Minute gemessene Druckanstieg in beiden Versuchsgruppen nicht. In den Versuchen mit SODPerfusion wurde ein $\triangle \mathrm{PAP}$ von $0,7 \pm 0,1 \mathrm{~mm} \mathrm{Hg} / \mathrm{min}$ gemessen und die Lungen ohne SOD hatten einen $\triangle \mathrm{PAP}$ von $0,6 \pm 0,2 \mathrm{~mm} \mathrm{Hg} / \mathrm{min}$ nach Stimulation mit PMA. 


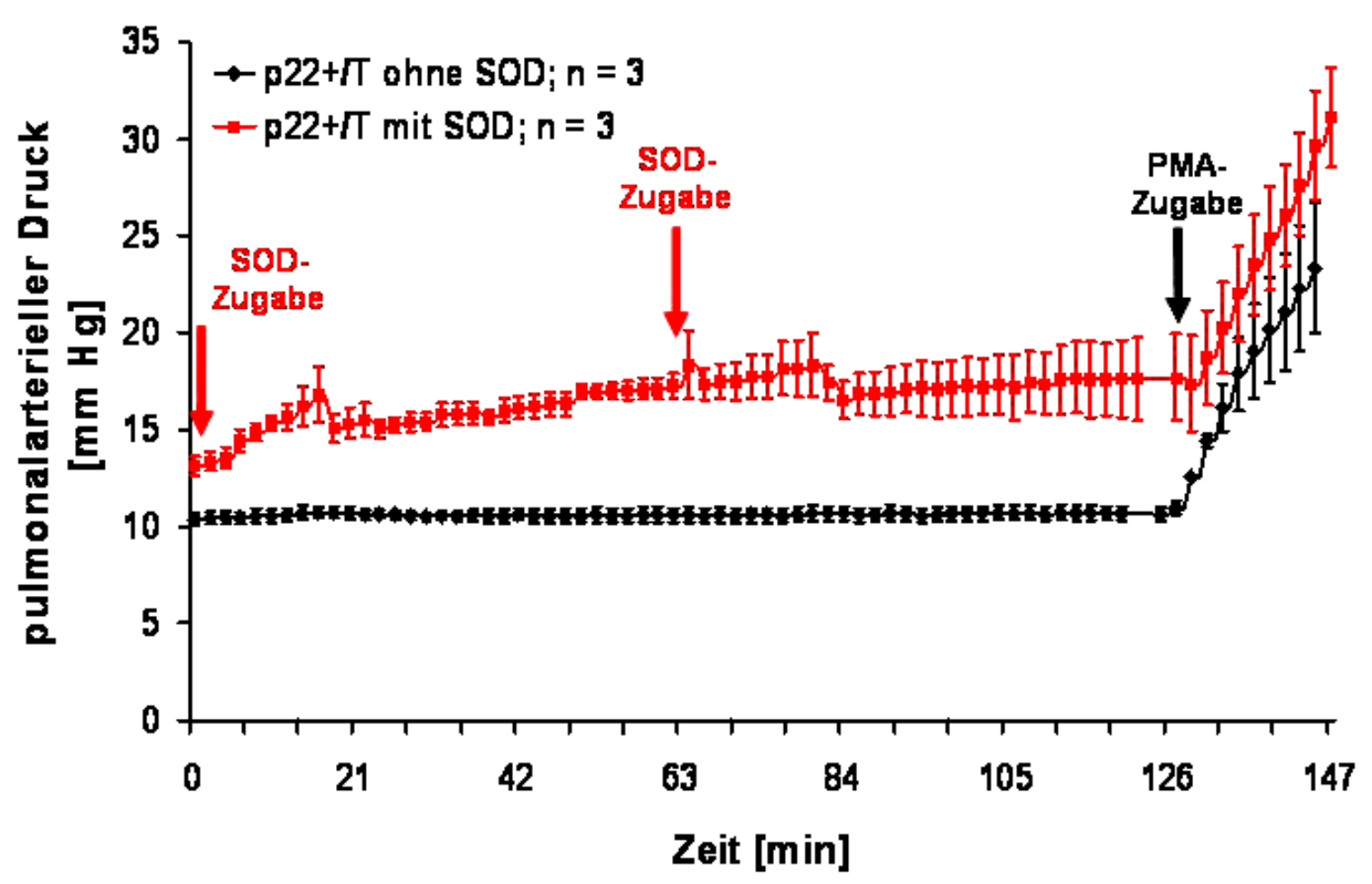

\section{Abbildung 3-5: Pulmonalarterieller Druck in p22 ${ }^{\text {phox }}$-überexprimierenden Mauslungen}

Die Graphik zeigt den PAP [mm Hg] bei normoxischer Beatmung. SOD [150 U/ml] wurde zweimal gegeben (rote Pfeile). Die PMA-Gabe [10 $\mu \mathrm{M}$ Endkonzentration im Perfusat] erfolgte für beide Gruppen nach fünfminütigem Aussetzen der Probenentnahme zur Analyse mit ESR. p22 $2^{+/ \mathrm{T}}=$ p22 $2^{\text {phox }}$-überexprimierend, SOD $=$ Superoxiddismutase, PMA $=$ Phorbol-Myristat-Acetat.

\subsubsection{Chimäre Mäuse}

Auch bei den chimären Mäusen wurde der basale pulmonalarterielle Druck unter normoxischen Bedingungen gemessen. Insgesamt wurden vier verschiedene Typen von Chimären hergestellt, von denen in diesem Kapitel allerdings nur zwei Gruppen behandelt werden: Zum einen die Wildtypen des Stammes C57Bl/6J, die Knochenmark aus gp91 ${ }^{\text {phox }}$ defizienten Mäusen erhalten haben (WT/gp91 ${ }^{-/}$) und zum anderen Mäuse mit einer Deletion der gp91 ${ }^{\text {phox }}$-Untereinheit, welchen Knochenmark aus Wildtypmäusen (gp91 $\left.1^{-/} / \mathrm{WT}\right)$ transplantiert wurden. Die jeweiligen Kontrollen, also die Mäuse, die Knochenmark aus Spendertieren des gleichen Stammes erhielten, werden hier nicht dargestellt, da sich der PAP in diesen Tieren nicht von dem der betreffenden Tiere ohne Knochenmarkstransplantation unterschied.

a) $\mathrm{WT} / \mathrm{gp} 91^{-/-}$

Der gemittelte pulmonalarterielle Druck in den Wildtypen mit transplantiertem Knochenmark aus gp91 ${ }^{\text {phox }}$-defizienten Mäusen betrug 14,7 $\pm 1,4 \mathrm{~mm} \mathrm{Hg}$ wenn die Perfusion ohne SOD-Zugabe $(\mathrm{n}=4)$ stattfand. Wurde dem Perfusat SOD zugegeben, konnte keine Änderung des PAP registriert werden $(14,7 \pm 1,0 \mathrm{~mm} \mathrm{Hg} ; \mathrm{n}=5)$. Nach Stimulation von NADP $(\mathrm{H})$-Oxidasen durch PMA stieg der PAP bei Perfusion ohne SOD auf einen maximalen Wert von 20,6 $\pm 1,1 \mathrm{~mm} \mathrm{Hg}$. Dieser Wert unterschied sich nicht von dem maximalen PAP bei der Perfusion mit SOD, der unter diesen Bedingungen 21,9 $\pm 0,8 \mathrm{~mm} \mathrm{Hg}$ betrug (Abbildung 3-6). Bei Betrachtung des Druckanstiegs pro Minute konnte ebenfalls kein Unterschied ermittelt werden. Bei Perfusion ohne SOD stieg der 
Druck um 0,4 $\pm 0,04 \mathrm{~mm} \mathrm{Hg} / \mathrm{min}$, wurde dem Perfusat SOD beigemischt, betrug der $\triangle \mathrm{PAP}$ $0,3 \pm 0,04 \mathrm{~mm} \mathrm{Hg} / \mathrm{min}$.

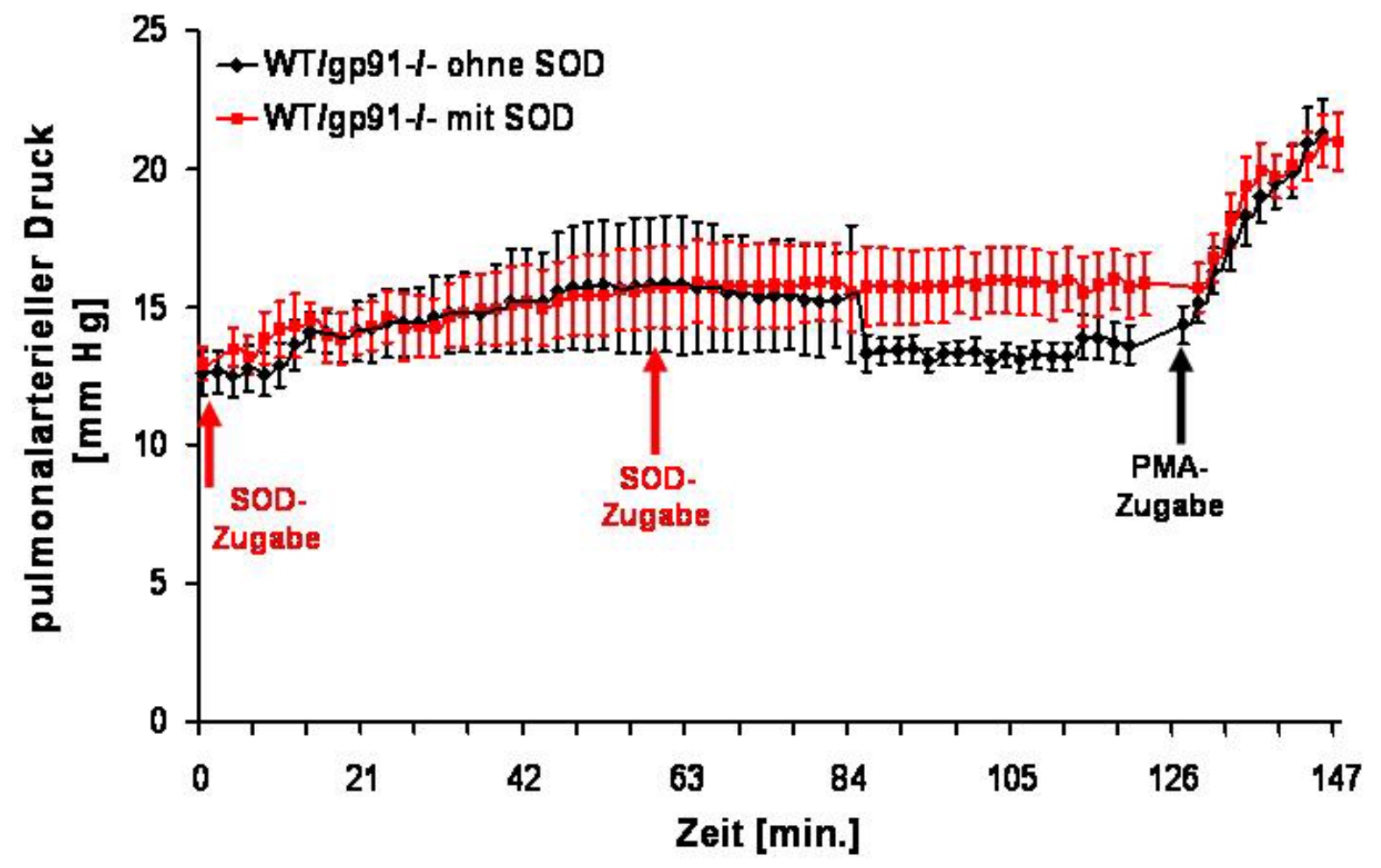

\section{Abbildung 3-6: Pulmonalarterieller Druck in Wildtyplungen mit gp91 $^{-/-}$ Granulozyten}

Die Graphik zeigt den PAP [mm Hg] in Mäusen des Wildtyps, denen Knochenmark aus gp91 ${ }^{\text {phox }}$ defizienten Tieren transplantiert wurde, bei normoxischer Beatmung. SOD [150 U/ml] wurde zweimal gegeben (rote Pfeile). Die PMA-Gabe, in einer Endkonzentration im Perfusat von $10 \mu \mathrm{M}$ resultierend, erfolgte für beide Gruppen nach fünfminütigem Aussetzen der Probenentnahme zur Analyse mit ESR. WT/gp91 $1^{-/-}=$Wildtyp Empfänger und $\mathrm{gp} 91^{-/-}$Spender, $\mathrm{SOD}=$ Superoxiddismutase, PMA = Phorbol-Myristat-Acetat.

b) $\mathrm{gp} 91^{-/-} / \mathrm{WT}$

Der pulmonalarterielle Druck in den gp91 ${ }^{\text {phox }}$-Knock-Out Empfängertieren, die Knochenmark aus Wildtyp-Spendern bekamen, wurde während der Perfusion ohne SOD mit 13,6 $\pm 0,8 \mathrm{~mm} \mathrm{Hg}$ registriert $(\mathrm{n}=4)$. Nach Zugabe von Superoxiddismutase wurde ein leichter Anstieg des gemittelten PAP auf 15,3 $\pm 1,2 \mathrm{~mm} \mathrm{Hg}$ gemessen $(\mathrm{n}=4)$, allerdings war die Druckdifferenz zwischen den beiden Gruppen nicht signifikant (Abbildung 3-7). In den Lungen mit SOD im Perfusat wurde ein niedrigerer maximaler Druck nach Stimulation mit PMA $(23,8 \pm 1,5 \mathrm{~mm} \mathrm{Hg})$ ermittelt als in den Lungen ohne SOD $(25,2 \pm 1,0 \mathrm{~mm} \mathrm{Hg})$. Der Druckanstieg pro Minute in den mit SOD perfundierten Lungen betrug $0,4 \pm 0,1 \mathrm{~mm} \mathrm{Hg}$ und in den Mauslungen ohne Superoxiddismutase im Perfusat $0,6 \pm 0,1 \mathrm{~mm} \mathrm{Hg}$. 


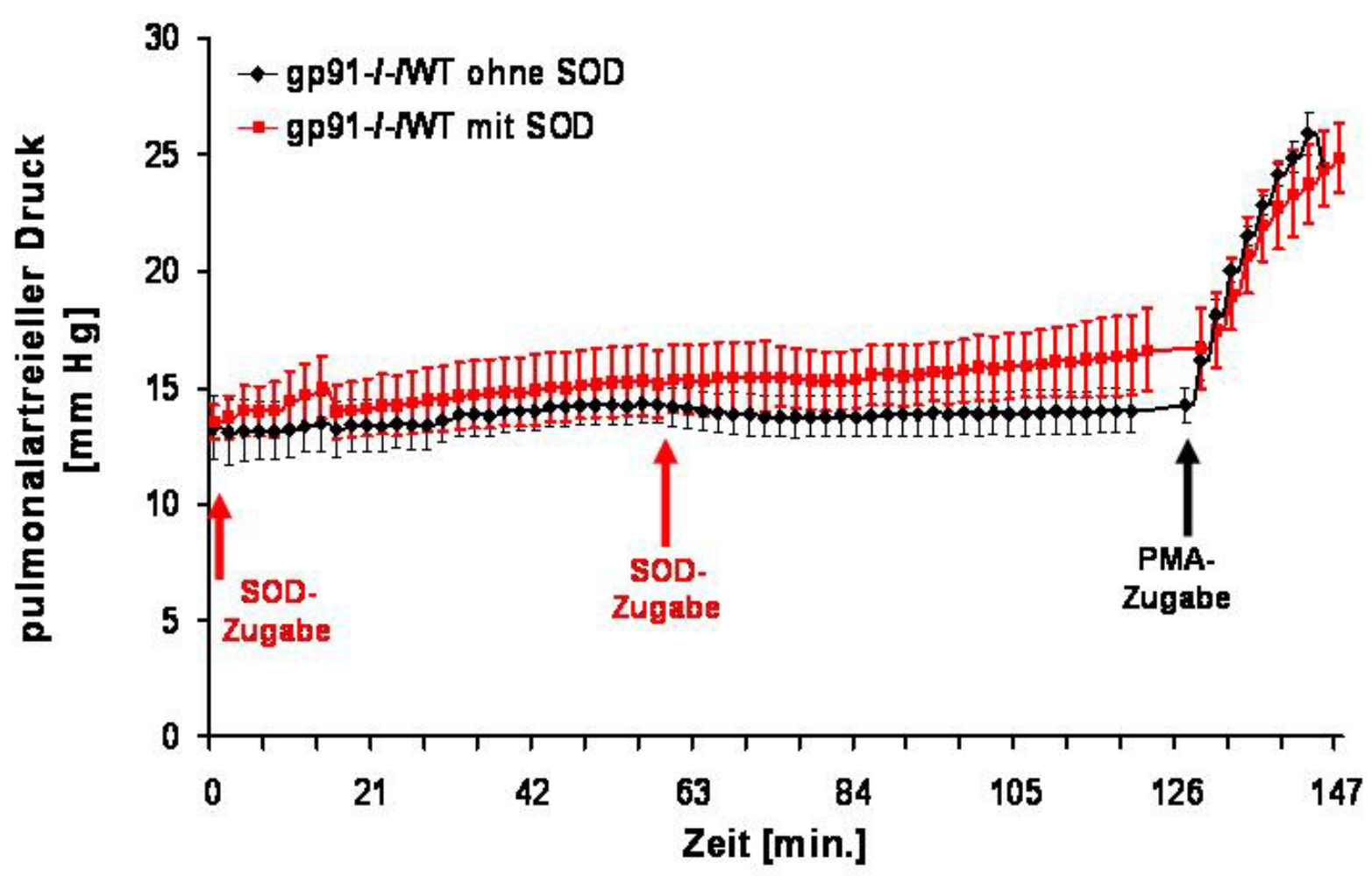

\section{Abbildung 3-7: Pulmonalarterieller Druck in gp91 ${ }^{-/-}$Mauslungen mit Wildtyp- Granulozyten}

Die Graphik zeigt den PAP $[\mathrm{mm} \mathrm{Hg}]$ in gp91 ${ }^{\text {phox }}$-defizienten Mäusen nach Transplantation von Knochenmark aus Wildtypen bei normoxischer Beatmung. SOD [150 U/ml] wurde zweimal gegeben (rote Pfeile). Die PMA-Gabe [10 $\mu \mathrm{M}$ Endkonzentration im Perfusat] erfolgte für beide Gruppen nach fünfminütigem Aussetzen der Probenentnahme zur Analyse mit ESR. gp91///WT $=$ gp91 ${ }^{-/-}$. Empfänger und Wildtyp-Spender, SOD = Superoxiddismutase, PMA = Phorbol-Myristat-Acetat.

\subsubsection{Zusammenfassung}

Um die Verhältnisse der gemessenen pulmonalarteriellen Drücke zu veranschaulichen, werden die Werte in Tabelle 3-5 nochmals zusammengefasst.

\section{Tabelle 3-5: Übersicht der gemessenen Werte für den pulmonalarteriellen Druck}

Die Tabelle zeigt die mittleren Werte für den PAP $[\mathrm{mm} \mathrm{Hg}] \pm \mathrm{SEM}$ in den Lungen der untersuchten Mäusen mit und ohne SOD im Perfusat sowie vor und nach Stimulation von NADP(H)-Oxidasen mit PMA. gp91 $1^{-/-}=$Tiere mit gp91 ${ }^{\text {phox }}$-Defizienz; p47 $7^{-/-}=$Tiere mit p47 ${ }^{\text {phox }}$-Defizienz; p22 $2^{+/ T}=$ Mäuse, welche die p22 ${ }^{\text {phox }}$-Untereinheit von NADP(H)-Oxidasen überexprimieren; WT/gp91 ${ }^{-/}=$ Tiere des Wildtyps C57Bl/6J mit Knochenmark aus gp91 ${ }^{\text {phox }}$-defizienten Tieren; gp91 $1^{-/} / \mathrm{WT}=$ Mäuse mit gp91 ${ }^{\text {phox }}$-Defizienz nach Transplantation von Knochenmark des Wildtyps. $\left(^{*} 0,01 \leq \mathrm{p}<\right.$ 0,05 gegenüber PAP vor PMA-Gabe; ${ }^{*} \mathrm{p}<0,005$ vs. Perfusion ohne SOD)

\begin{tabular}{|c|c|c|c|c|c|c|}
\hline & $\mathrm{C} 57 \mathrm{B1} / 6 \mathrm{~J}$ & ${\mathrm{gp} 91^{-/-}}$ & $\mathrm{p} 47^{-/-}$ & $\mathrm{p} 22^{+/ \mathrm{T}}$ & $\mathrm{WT}^{-\mathrm{gp} 91^{-/-}}$ & ${\mathrm{gp} 91^{-/-} / \mathrm{WT}}$ \\
\hline \hline ohne SOD & $11,6 \pm 0,6$ & $12,7 \pm 0,7$ & $12,1 \pm 0,6$ & $10,6 \pm 0,3$ & $14,7 \pm 1,4^{*}$ & $13,6 \pm 0,8^{*}$ \\
\hline $\begin{array}{c}\text { ohne SOD, } \\
\text { nach PMA }\end{array}$ & $24,2 \pm 1,9^{*}$ & $22,8 \pm, 8^{*}$ & $21,0 \pm, 7^{*}$ & $23,4 \pm 3,4^{*}$ & $20,6 \pm 1,1^{*}$ & $25,2 \pm 1,0^{*}$ \\
\hline mit SOD & $12,9 \pm 0,8$ & $12,7 \pm 0,9$ & $12,6 \pm 1,1$ & $15,8 \pm 1,4^{\#}$ & $14,7 \pm 1,0$ & $15,3 \pm 1,2$ \\
\hline $\begin{array}{c}\text { mit SOD, } \\
\text { nach PMA }\end{array}$ & $28,4 \pm 1,5^{*}$ & $27,3 \pm 1,9^{*}$ & $24,5 \pm 2,2^{*}$ & $31,3 \pm 2,6^{*}$ & $21,9 \pm 0,8^{*}$ & $23,8 \pm 1,5^{*}$ \\
\hline
\end{tabular}


Nach Stimulation von NADP(H)-Oxidasen durch PMA stieg der pulmonalarterielle Druck in allen untersuchten Lungen signifikant an. Die nach der Stimulation maximal erreichten Druckwerte unterschieden sich nicht signifikant voneinander. Für die Gruppen, die mit SOD perfundiert wurden, zeigten die pulmonalarteriellen Drücke keine signifikanten Abweichungen unter Basisbedingungen.

\subsubsection{Pulmonalarterieller Druck in akuter Hypoxie}

Akute alveoläre Hypoxie in der Lunge führt $\mathrm{zu}$ einem schnellen Anstieg des pulmonalarteriellen Druckes. Der Anstieg des PAP als Antwort auf den plötzlich gesunkenen Sauerstoffpartialdruck im Atemgas beruht auf einer Kontraktion der präkapillären Gefäße in der Lunge (HPV). Dadurch wird unter lokal hypoxischen Bedingungen das Blut in die besser ventilierten Bereiche der Lunge umgeleitet und somit eine verbesserte Oxygenierung des Blutes gewährleistet. In diesem Abschnitt werden die Druckanstiege in der Pulmonalarterie als Antwort auf die akut hypoxische Ventilation mit $1 \% \mathrm{O}_{2}$ im Atemgas veranschaulicht.

Die Versuche wurden wiederum mit Lungen von Wildtypmäusen des Stammes C57B1/6J und mit Lungen aus Mäusen mit Knock-Outs oder Überexpression verschiedener NADP $(\mathrm{H})$-Oxidase Untereinheiten durchgeführt. Wie im vorigen Abschnitt beschrieben, waren das Mäuse mit einer Deletion der gp91 ${ }^{\text {phox }}$ - oder $\mathrm{p} 47^{\text {phox }}$-Untereinheit sowie Tiere mit einer Überexpression der p22 $2^{\text {phox }}$-Untereinheit von NADP(H)-Oxidasen. Zudem wurde de HPV in chimären Mäusen untersucht. Eine Gruppe der verwendeten Tiere wurde ohne Superoxiddismutase perfundiert und in einer zweiten, dazu korrespondierenden Gruppe, wurde zur Quantifizierung der Superoxid-Freisetzung SOD in das Perfusat gegeben. Akute Hypoxie wurde durch Beatmung mit einem Gasgemisch mit 1\% $\mathrm{O}_{2}$ erreicht. Die normoxische bzw. hypoxische Ventilationsphase betrug in allen Gruppen jeweils $15 \mathrm{~min}$. Die Darstellung der Ergebnisse erfolgt für jede Gruppe als Druckunterschied zwischen normoxischer und akut hypoxischer Phase ( $\triangle \mathrm{PAP})$.

\subsubsection{Wildtypen}

Für diese Versuche wurden insgesamt 10 Mäuse, aufgeteilt in zwei Gruppen zu je fünf Tieren, eingesetzt. Die Lungen der einen Gruppe dienten als Kontrolle und wurden ohne SOD perfundiert, wohingegen in der zweiten Gruppe zur Quantifizierung der Superoxidfreisetzung mit Superoxiddismutase perfundiert wurde. In den Lungen, die ohne SOD perfundiert wurden, ergab sich in der ersten hypoxisch ventilierten Phase eine Druckdifferenz $(\triangle \mathrm{PAP})$ von 2,1 $\pm 0,4 \mathrm{~mm} \mathrm{Hg}$. Nach dieser ersten Antwort wurde in der folgenden hypoxischen Phase ein $\triangle \mathrm{PAP}$ von $1,9 \pm 0,7 \mathrm{~mm} \mathrm{Hg}$ registriert. Diese Werte sind nahezu identisch zu den Druckdifferenzen, die bei der Perfusion mit SOD gemessen wurden. Unter diesen Umständen betrug der $\triangle \mathrm{PAP}$ in der ersten hypoxischen Phase 2,1 $\pm 0,4 \mathrm{~mm} \mathrm{Hg}$ und in der zweiten 1,9 $\pm 0,6 \mathrm{~mm} \mathrm{Hg}$ (Abbildung 3-8). Die registrierten Anstiege im PAP wichen signifikant vom PAP unter normoxischen Basisbedingungen $a b$. 


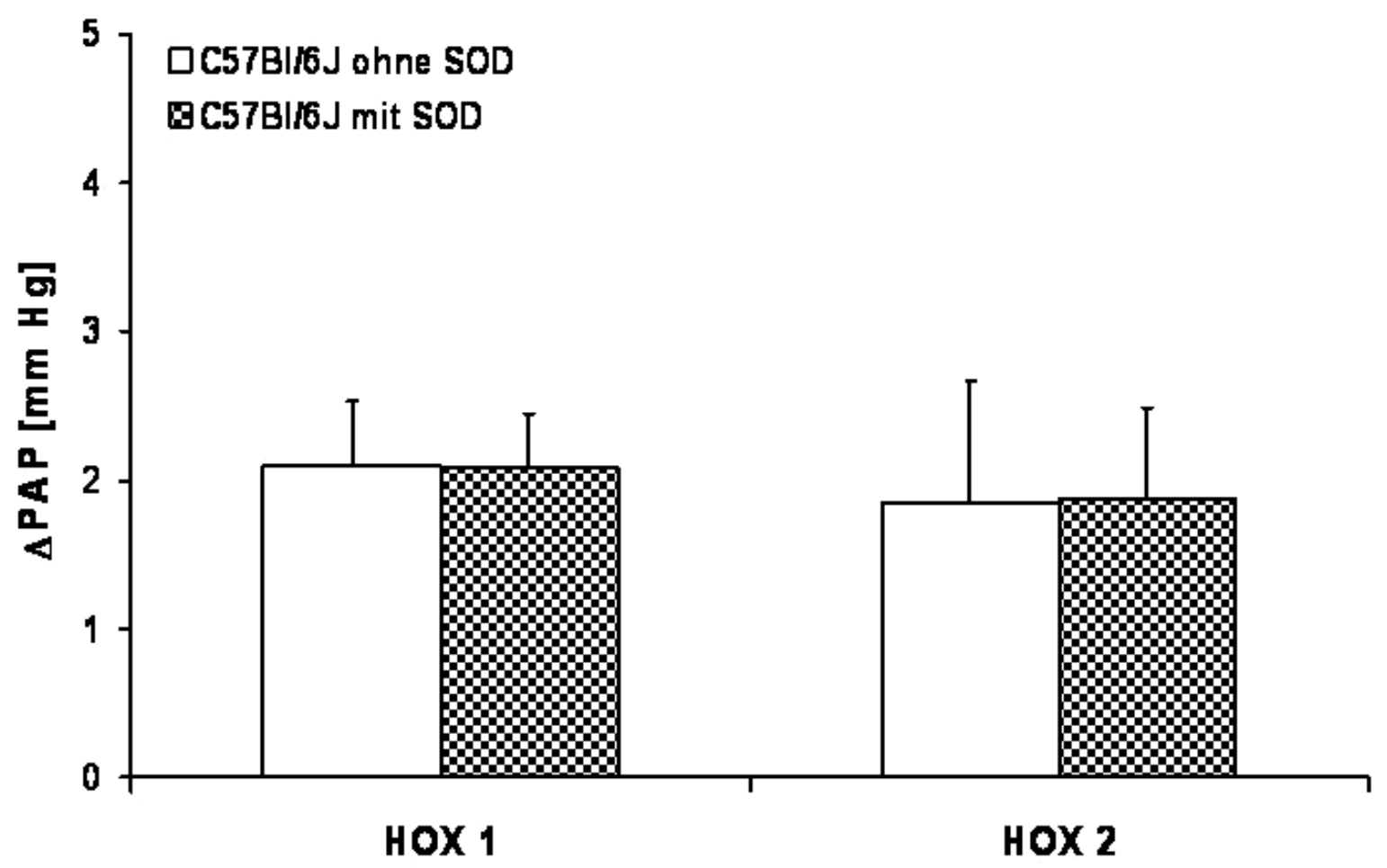

\section{Abbildung 3-8: Hypoxische pulmonale Vasokonstriktion in Lungen des Wildtyps}

Die Graphik zeigt den mittleren Druckanstieg ( $\triangle \mathrm{PAP})$ bei akut hypoxischer Beatmung $(\mathrm{HOX})$ in Lungen des Wildtyps ( $\mathrm{n}=5$ pro Gruppe) im Vergleich $\mathrm{zu}$ normoxischen Basisbedingungen in $\mathrm{mm} \mathrm{Hg}$. In den Versuchen mit SOD-Perfusion erfolgte eine einmalige SOD-Gabe zu Anfang des Versuchs, woraus eine Konzentration von $150 \mathrm{U} / \mathrm{ml}$ resultierte. WT= Wildtyp, SOD = Superoxiddismutase.

\subsubsection{2 gp91 ${ }^{\text {phox }}$-defiziente Mäuse}

Bei den Tieren mit einer Defizienz für die gp9 $1^{\text {phox }}$-Untereinheit von NADP(H)-Oxidasen wurde in der ersten Phase hypoxischer Ventilation ein Anstieg des pulmonalarteriellen Druckes um 3,5 $\pm 1,0 \mathrm{~mm} \mathrm{Hg}$ verzeichnet. In der zweiten hypoxischen Ventilationsphase erhöhte sich der PAP um 2,5 $\pm 1,9 \mathrm{~mm} \mathrm{Hg}(\mathrm{n}=5)$. Wurden die Lungen mit Superoxiddismutase perfundiert $(\mathrm{n}=5)$, konnte ein ca. dreifach erhöhter PAP in den akut hypoxischen Perioden registriert werden. Nach erstmaligem Umschalten auf das hypoxische Atemgas wurde in diesen Lungen ein $\triangle \mathrm{PAP}$ von 7,3 $\pm 1,2 \mathrm{~mm} \mathrm{Hg}$ gemessen, in der zweiten Phase stieg der PAP, verglichen mit dem normoxischen Ausgangswert, um $8,7 \pm 2,1 \mathrm{~mm} \mathrm{Hg}$ (Abbildung 3-9). 


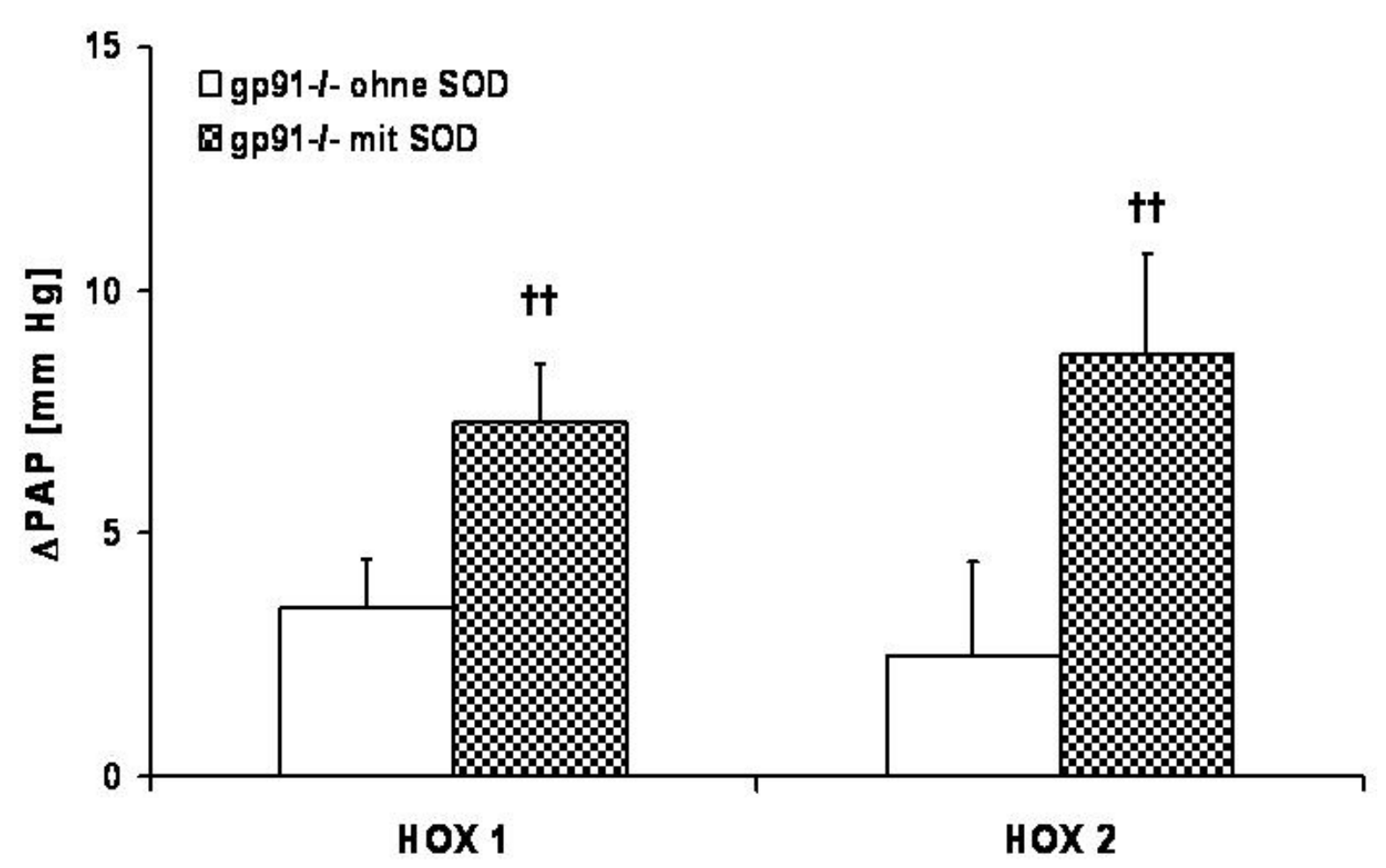

\section{Abbildung 3-9: Hypoxische pulmonale Vasokonstriktion in gp91 $^{\text {phox }}$-defizienten Mauslungen}

Die Graphik zeigt den Anstieg des pulmonalarteriellen Drucks bei akut hypoxischer Beatmung in gp91 ${ }^{\text {phox }}$-defizienten Mäusen. Als Maß für die HPV ist der mittlere Druckanstieg ( $\triangle$ PAP) im Vergleich zu normoxischen Basisbedingungen in $\mathrm{mm} \mathrm{Hg}$ gegeben. In den Versuchen mit SODPerfusion erfolgte eine einmalige SOD-Gabe zu Anfang des Versuchs, die in einer SOD Konzentration von $150 \mathrm{U} / \mathrm{ml}$ resultierte. gp91 ${ }^{-/}=$gp91 ${ }^{\text {phox }}$-defiziente Tiere, SOD = Superoxiddismutase; $\uparrow \dagger=\mathrm{p}<0,005$ gegenüber $\triangle \mathrm{PAP}$ ohne SOD; $\mathrm{n}=5$ pro Gruppe.

\subsubsection{3 p47 ${ }^{\text {phox }}$-defiziente Mäuse}

In den Lungen der $\mathrm{p} 47^{\text {phox }}$-KO-Tiere, die ohne SOD perfundiert wurden $(n=6)$, betrug der $\triangle \mathrm{PAP}$ in der ersten hypoxischen Phase 1,9 $\pm 0,4 \mathrm{~mm} \mathrm{Hg}$, in der zweiten stieg der PAP um $1,5 \pm 0,4 \mathrm{~mm} \mathrm{Hg}$. Die Mauslungen, die mit SOD perfundiert wurden $(\mathrm{n}=6)$, zeigten in der ersten Phase hypoxischer Ventilation einen $\triangle \mathrm{PAP}$ von $1,9 \pm 0,2 \mathrm{~mm} \mathrm{Hg}$, in der zweiten Phase stieg der PAP aufgrund der akuten HPV um 1,6 $\pm 0,3 \mathrm{~mm} \mathrm{Hg}$ an (Abbildung 3-10). Der Anstieg des PAP war signifikant gegenüber den normoxischen Basiswerten. 


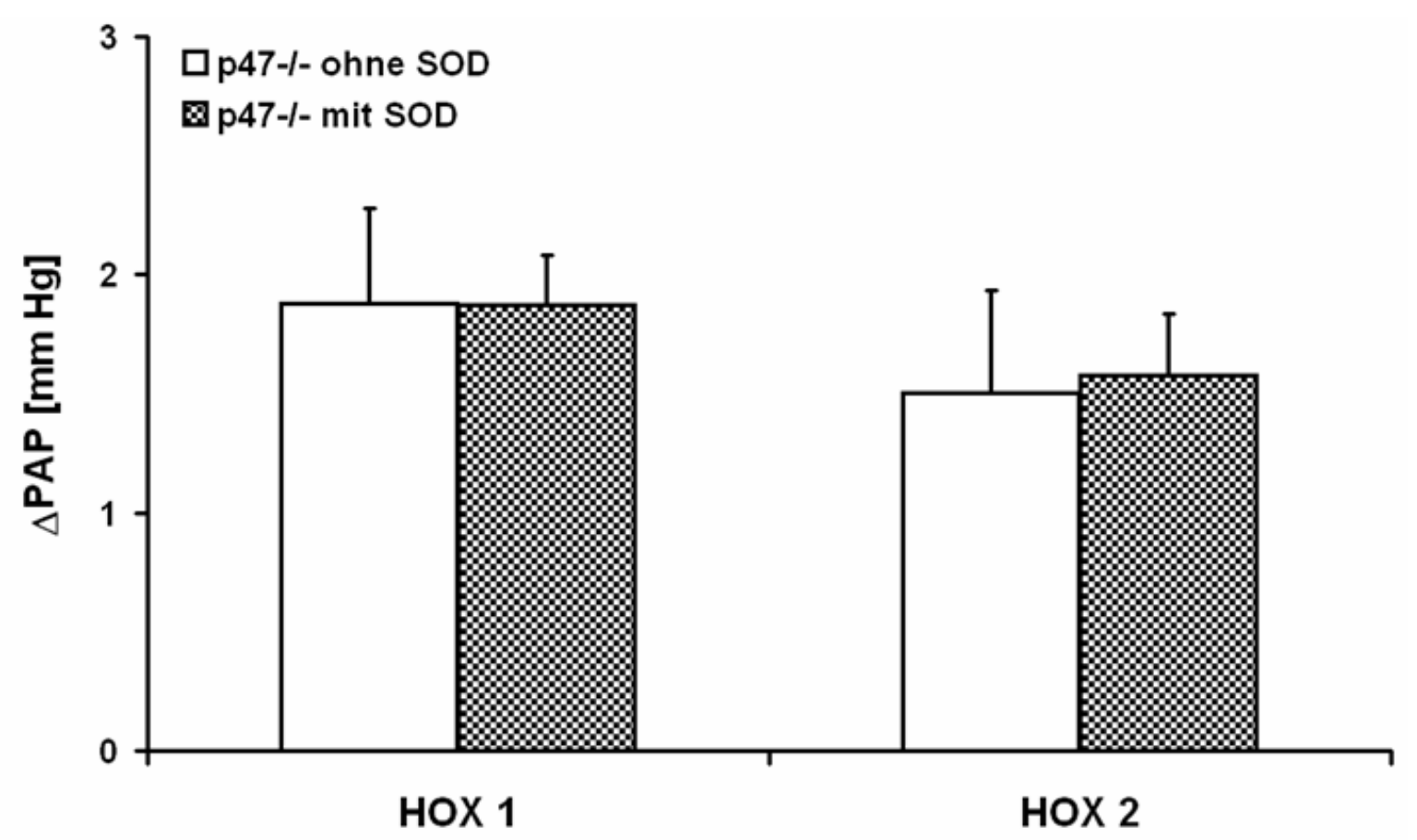

\section{Abbildung 3-10: Hypoxische pulmonale Vasokonstriktion in $\mathbf{p 4}^{\text {phox }}$-defizienten Mauslungen}

Darstellung des $\triangle$ PAP [mm Hg] in Mauslungen mit einer Deletion der p47 ${ }^{\text {phox }}$-Untereinheit bei akut hypoxischer Beatmung im Vergleich zu normoxischen Basisbedingungen. In den Versuchen mit SOD-Perfusion erfolgte eine einmalige SOD-Gabe zu Anfang des Versuchs, die in einer SOD Konzentration von $150 \mathrm{U} / \mathrm{ml}$ resultierte. $\mathrm{p} 47^{-/-}=\mathrm{p} 47^{\text {phox }}$-defiziente Tiere, $\mathrm{SOD}=$ Superoxiddismutase; $\mathrm{n}=6$ pro Gruppe.

\subsubsection{4 p22 ${ }^{\text {phox }}$-überexprimierende Mäuse}

Die Überexpression der p22 $2^{\text {phox }}$-Untereinheit führte in den Lungen der Mäuse zu einer geringeren, allerdings nicht signifikant niedrigeren, HPV im Vergleich zu den Wildtypen. So wurde in den Lungen ohne Beimischung von SOD ins Perfusat bei der ersten hypoxischen Ventilationsphase ein $\triangle \mathrm{PAP}$ von 1,7 $\pm 0,3 \mathrm{~mm} \mathrm{Hg}$ gemessen, in der zweiten Phase wurde ein $\triangle \mathrm{PAP} 0,8 \pm 0,3 \mathrm{~mm} \mathrm{Hg}(\mathrm{n}=5)$ registriert. Die Perfusion mit $\mathrm{SOD}(\mathrm{n}=5)$ hatte keine Auswirkungen auf die HPV. Die Mäuse dieser Gruppe zeigten einen Druckanstieg von 1,6 $\pm 0,3 \mathrm{~mm} \mathrm{Hg}$ bei der ersten hypoxischen Ventilation und von $0,9 \pm 0,2 \mathrm{~mm} \mathrm{Hg}$ in der zweiten hypoxischen Phase (Abbildung 3-11). Diese Werte unterscheiden sich signifikant vom normoxischen Basiswert. 


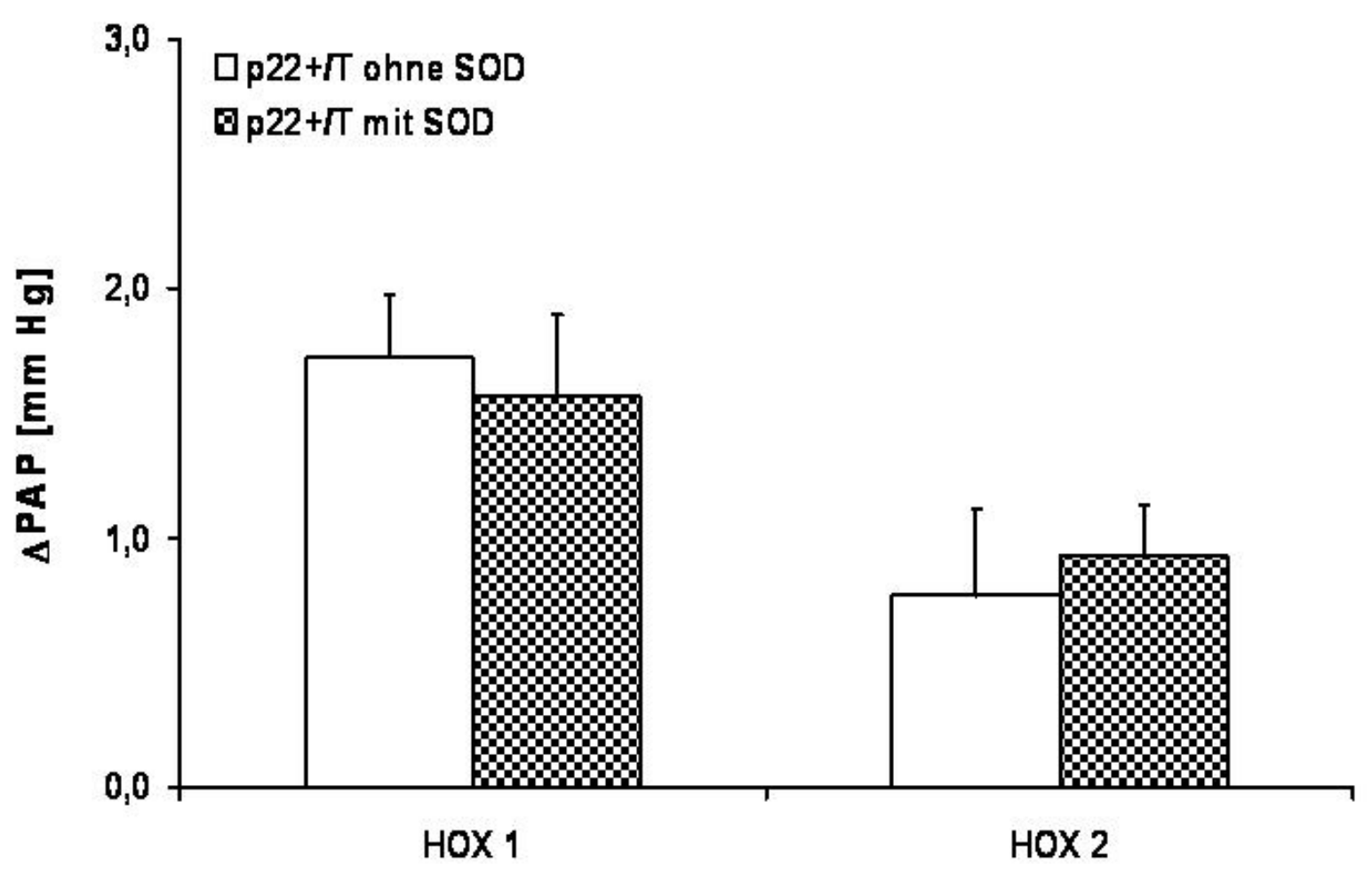

\section{Abbildung 3-11: Hypoxische pulmonale Vasokonstriktion in p22 ${ }^{\text {phox }}$ - überexprimierenden Mauslungen}

Die Graphik veranschaulicht den $\triangle$ PAP [mm Hg] als Ausdruck der akuten HPV im Vergleich zu normoxischen Basisbedingungen in Mauslungen, in denen die $\mathrm{p} 22^{\text {phox }}$-untereinheit überexprimiert ist. In den Versuchen mit SOD-Perfusion erfolgte eine einmalige SOD-Gabe zu Anfang des Versuchs, die in einer SOD Konzentration von $150 \mathrm{U} / \mathrm{ml}$ resultierte. $\mathrm{p} 22^{-+/ \mathrm{T}}=\mathrm{p} 22^{\text {phox }}$ überexprimierende Tiere, $\mathrm{SOD}=$ Superoxiddismutase; $\mathrm{n}=5$ pro Gruppe.

\subsubsection{Chimäre Mäuse}

In diesem Abschnitt werden die pulmonalarteriellen Drücke der chimären Tiere dargestellt. Von den insgesamt vier Typen chimärer Mäuse werden an dieser Stelle allerdings nur die beiden Versuchsgruppen besprochen. Die zugehörigen Kontrollen aus Wildtyptieren nach der Transplantation von Knochenmark aus Wildtypen und gp91 ${ }^{\text {phox }}$-defizienten Mäuse nach Transplantation von Knochenmark des gleichen Stammes, werden an dieser Stelle nicht dargestellt. Die vaskuläre Reaktion der Kontrolltiere auf die akut hypoxische Ventilation unterschied sich nicht von den entsprechenden Tieren ohne Knochenmarkstransplantation.

a) WT/gp91 $1^{\text {phox-/- }}$

Bei den Mäusen des Wildtyps, die durch eine Transplantation Knochenmarkszellen aus gp91 ${ }^{\text {phox }}$-defizienten Tieren erhielten, zeigte sich in den beiden Phasen hypoxischer Ventilation ein signifikanter Anstieg des pulmonalarteriellen Drucks gegenüber dem normoxischen Basisdruck $(\mathrm{p}<0,005)$, ohne dass ein signifikanter Unterschied zwischen der ersten und zweiten hypoxisch ventilierten Phase festgestellt wurde. Es ergab sich zudem keine Differenz der vaskulären Reaktion auf Hypoxie zwischen den Lungen, die mit SOD perfundiert wurden und den Lungen, die ohne SOD-Zugabe perfundiert wurden (Abbildung 3-12). 


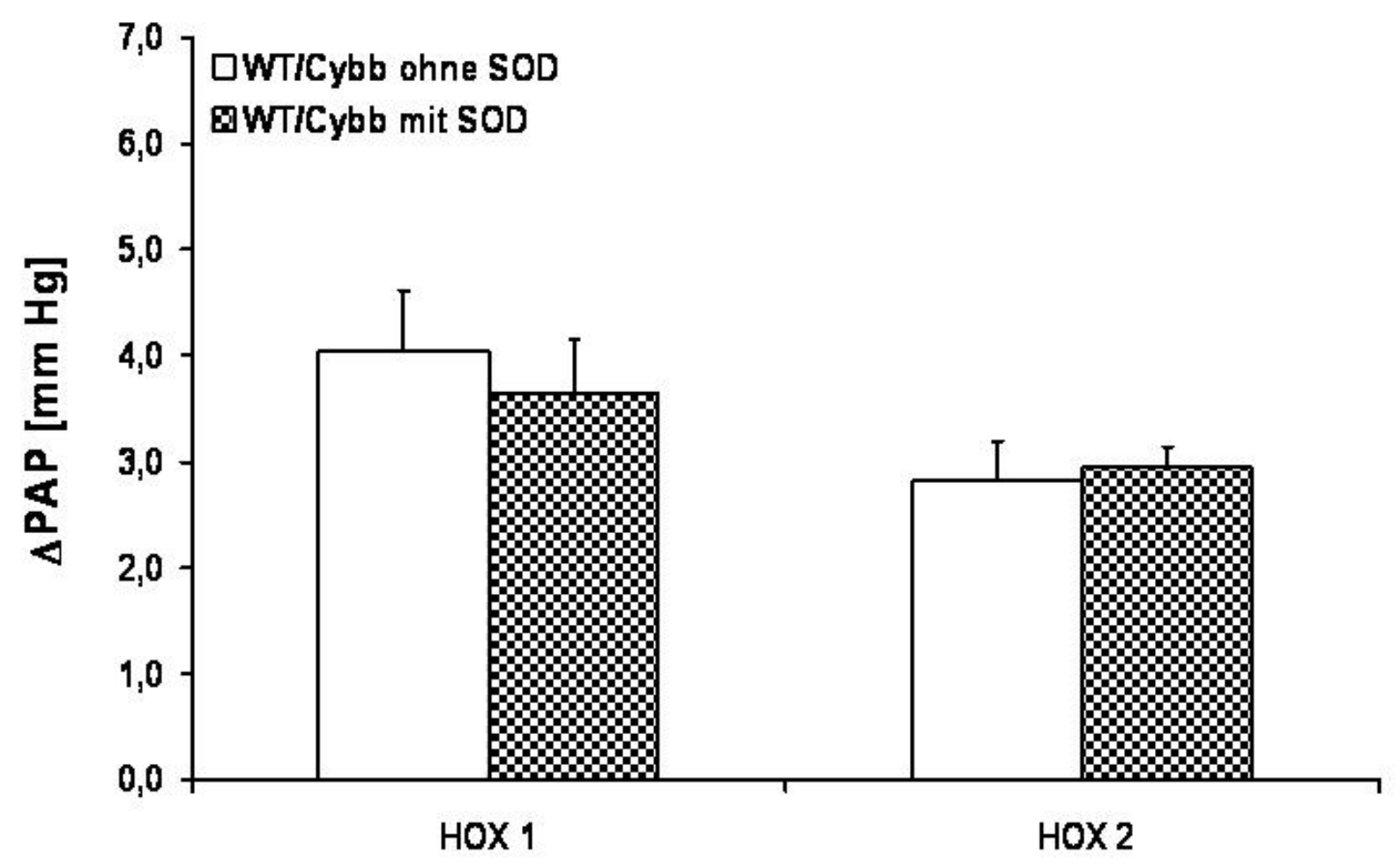

\section{Abbildung 3-12: Hypoxische pulmonale Vasokonstriktion in Mäusen des Wildtyps nach Transplantation von Knochenmark aus gp91 ${ }^{\text {phox }}$-defizienten Tieren}

Die Abbildung zeigt den gemittelten maximalen Druckanstieg ( $\triangle \mathrm{PAP})$ in Lungen aus Wildtypmäusen nach Knochenmarkstransplantation aus gp91 ${ }^{\text {phox }}$-defizienten Tieren bei akut hypoxischer Ventilation. In den zwei durchgeführten hypoxischen Phasen stieg der Druck in der Pulmonalarterie jeweils signifikant über den Basisdruck bei normoxischer Beatmung $(\mathrm{p}<0.005)$. Die gemessenen Druckwerte für die Lungen, die unter Zugabe von SOD perfundiert wurden, zeigten keinen Unterschied zu den Lungen, bei denen die Perfusion ohne SOD-Zugabe stattfand. WT/Cybb $=$ Wildtypen mit Knochenmark aus gp91 ${ }^{\text {phox }}$-defizienten Mäusen, SOD = Superoxiddismutase, HOX $=$ Phase mit hypoxischer Ventilation $\left(1 \% \mathrm{O}_{2}\right) ; \mathrm{n}=3-5$

b) gp91 $1^{\text {phox }-/-} / \mathrm{WT}$

In den Tiere mit einem Knock-Out der gp91 ${ }^{\text {phox }}$-Untereinheit von NADP(H)-Oxidasen, die durch Transplantation Knochenmarkszellen aus Wildtypen erhielten, wurde ein signifikanter Anstieg des pulmonalarteriellen Druckes in den Phasen akut hypoxischer Ventilation registriert (Abbildung 3-13). Für diesen Vergleich wurde ein p-Wert von 0,005 ermittelt. Der statistische Vergleich für die HPV in den Lungen ohne SOD-Perfusion zu den Lungen, die unter Zugaben von SOD perfundiert wurden, zeigte wiederum keine Signifikanz. 


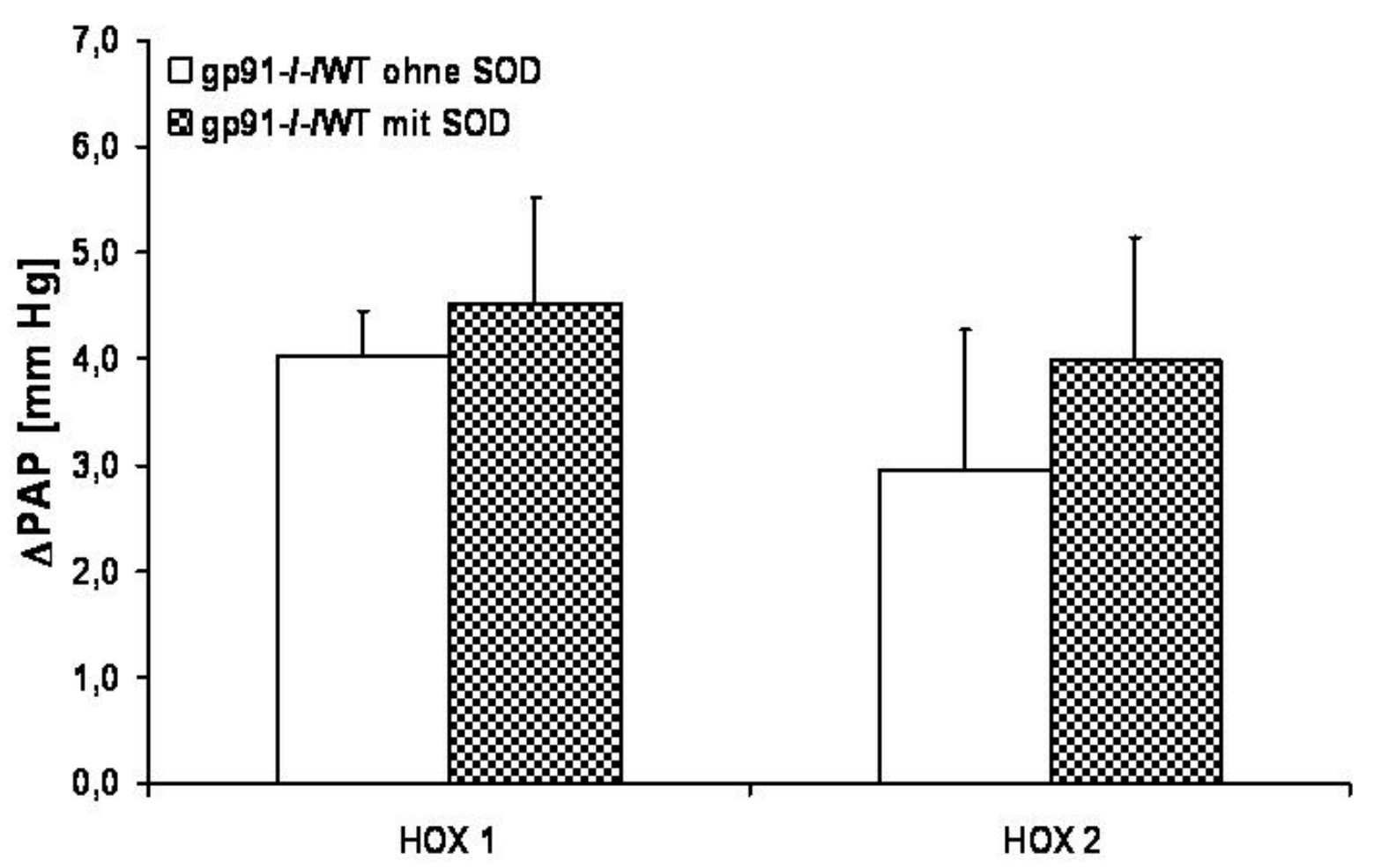

\section{Abbildung 3-13: Hypoxische pulmonale Vasokonstriktion in gp91 $^{\text {phox }}$-defizienten Mäusen nach Transplantation von Knochenmark aus Wildtypen}

Die Abbildung zeigt den gemittelten maximalen Druckanstieg ( $\triangle \mathrm{PAP})$ in Lungen aus gp91 ${ }^{\text {phox }}$ Knock-Out Mäusen nach Knochenmarkstransplantation aus Tieren des Wildtyps bei akut hypoxischer Ventilation. In den zwei durchgeführten hypoxischen Phasen stieg der Druck in der Pulmonalarterie jeweils signifikant über den Basisdruck bei normoxischer Beatmung $(\mathrm{p}<0.005)$. Die gemessenen Druckwerte für die Lungen, die unter Zugabe von SOD perfundiert wurden, zeigten keinen Unterschied zu den Lungen, bei denen die Perfusion ohne SOD-Zugabe stattfand. gp91 ${ }^{-/} / \mathrm{WT}$ $=$ gp9 $1^{\text {phox }}$-defiziente Mäuse mit Knochenmark aus Wildtypen, $\mathrm{SOD}=$ Superoxiddismutase, HOX = Phase mit hypoxischer Ventilation $\left(1 \% \mathrm{O}_{2}\right) ; \mathrm{n}=3$ - 5

\subsubsection{Zusammenfassung}

Die statistische Auswertung ergab für alle untersuchten Gruppen einen signifikanten Anstieg des pulmonalarteriellen Druckes in Phasen hypoxischer Ventilation gegenüber den normoxisch ventilierten Phasen. Die Ausprägung der HPV während der beiden Hypoxien war nicht signifikant unterschiedlich, so dass davon ausgegangen werden kann, dass die untersuchten Lungen eine über den Versuchszeitraum gleichmäßige HPV zeigten. Auch die Vergleiche der jeweils ersten oder zweiten hypoxischen Ventilation zwischen den perfundierten Lungen mit SOD-Zusatz und den Lungen ohne SOD-Perfusion ergaben keine signifikanten Veränderungen (Tabelle 3-6). Ein Einfluss des Enzyms Superoxiddismutase auf die Gefäßreagibilität kann somit ausgeschlossen werden.

Die HPV blieb auch bei Perfusion mit Superoxiddismutase in allen untersuchten Mauslungen signifikant, ohne dass ein Unterschied zwischen der ersten oder zweiten Hypoxie bestand. Einzig die Lungen von gp91 ${ }^{\text {phox }}$-defizienten Mäusen zeigten im Vergleich mit den Lungen der anderen untersuchten Tiere eine signifikant höhere HPV, und zwar sowohl in der ersten als auch in der zweiten hypoxisch ventilierten Phase. Zudem zeigten diese Lungen eine signifikant stärkere HPV bei Perfusion mit SOD im Vergleich zur HPV in den Lungen, die ohne SOD perfundiert wurden $(p<0,005)$. 


\section{Tabelle 3-6: Übersicht des $\triangle$ PAPs als Ausdruck der HPV}

Die Tabelle zeigt den $\triangle$ PAP $[\mathrm{mm} \mathrm{Hg}]$ in den Lungen der untersuchten Mäuse mit und ohne Superoxiddismutase im Perfusat. $\left({ }^{\dagger \dagger}=\mathrm{p}<0,005\right.$ gegenüber HOX ohne SOD).

\begin{tabular}{|l|c|c|c|c|c|c|}
\hline & $\mathrm{C} 57 \mathrm{Bl} / 6 \mathrm{~J}$ & $\mathrm{gp} 91^{-/-}$ & $\mathrm{p} 47^{-/-}$ & $\mathrm{p} 22^{+/ \mathrm{T}}$ & $\mathrm{WT} / \mathrm{gp} 91^{-/-}$ & $\mathrm{gp} 91^{-/ /} / \mathrm{WT}$ \\
\hline \hline $\begin{array}{l}\text { 1. HOX, } \\
\text { ohne SOD }\end{array}$ & $2,1 \pm 0,4$ & $3,5 \pm 1,0$ & $1,9 \pm 0,4$ & $1,7 \pm 0,3$ & $4,0 \pm 0,6$ & $4,0 \pm 0,4$ \\
\hline $\begin{array}{l}\text { 2. HOX, } \\
\text { ohne SOD }\end{array}$ & $1,9 \pm 0,8$ & $2,5 \pm 1,9$ & $1,5 \pm 0,4$ & $0,8 \pm 0,3$ & $2,8 \pm 0,4$ & $2,9 \pm 1,3$ \\
\hline $\begin{array}{l}\text { 1. HOX } \\
\text { mit SOD }\end{array}$ & $2,1 \pm 0,4$ & $7,3 \pm 1,2^{\dagger \dagger}$ & $1,9 \pm 0,2$ & $1,6 \pm 0,3^{*}$ & $3,6 \pm 0,5$ & $4,5 \pm 1,0$ \\
\hline $\begin{array}{l}\text { 2. HOX, } \\
\text { mit SOD }\end{array}$ & $1,9 \pm 0,6^{*}$ & $8,7 \pm 2,1^{\dagger \dagger}$ & $1,6 \pm 0,3$ & $0,9 \pm 0,2$ & $2,9 \pm 0,2$ & $4,0 \pm 1,2$ \\
\hline
\end{tabular}

\subsubsection{Pulmonalarterieller Druck nach chronischer Hypoxie}

Das Remodeling der Gefäßmedia unter chronisch hypoxischen Bedingungen ist gleichbedeutend mit einer Verengung des Gefäßlumens, was wiederum bedeutet, dass das Blut einem erhöhten Strömungswiderstand im Gefäß ausgesetzt ist. Als Folge dessen muss nicht nur das rechte Herz vermehrt Arbeit leisten, es kommt auch zu einem Anstieg des pulmonalarteriellen Druckes. In den in diesem Abschnitt behandelten Versuchen zur chronischen Hypoxie wurden die Mäuse für mindestens 21 Tage in einer normobaren Atmosphäre verminderten Sauerstoffpartialdruckes gehalten. Der $\mathrm{O}_{2}$-Anteil der Luft betrug 10\%, die Anteile der anderen Atemgase entsprachen normalen Verhältnissen.

Wiederum wurden Wildtypmäuse des Stammes C57B1/6J als Kontrollen für die genetisch veränderten Tiere herangezogen. Die genetische Veränderung bezog sich, wie in den vorigen Versuchen auch, entweder auf eine Deletion der gp91 ${ }^{\text {phox }}$ oder $\mathrm{p} 47^{\text {phox }}$ Untereinheit oder auf die Überexpression der $\mathrm{p} 22^{\text {phox }}$-Untereinheit von NADP(H)Oxidasen. In den Versuchen mit Superoxiddismutase wurde das Enzym zweimal appliziert, die Endkonzentration im Perfusat betrug jeweils $150 \mathrm{U} / \mathrm{ml}$. In den letzten 20 Minuten der Versuche wurden NADP(H)-Oxidasen mit PMA stimuliert. Der Stimulus wurde als Bolus gegeben und resultierte in einer Endkonzentration von $10 \mu \mathrm{M}$.

\subsubsection{Wildtypen}

Der gemittelte pulmonalarterielle Druck betrug in den Wildtypmäusen $16,8 \pm 2,0 \mathrm{~mm} \mathrm{Hg}$ $(n=5)$. Die Simulation von NADP $(\mathrm{H})$-Oxidasen führte zu einem drastischen Anstieg des PAP, bei dem ein maximaler Wert von 32,7 $\pm 0,9 \mathrm{~mm} \mathrm{Hg}$ erreicht wurde. Die Perfusion mit SOD hatte keine Auswirkungen auf den PAP unter Basisbedingungen (16,6 \pm 1,3 mm $\mathrm{Hg} ; \mathrm{n}=5$ ), und auch nach PMA-Stimulation erreichte der PAP einen zu den Werten, die bei der Perfusion ohne SOD erzielt wurden, vergleichbaren Maximalwert von 32,6 \pm 1,7 $\mathrm{mm} \mathrm{Hg}$ (Abbildung 3-14). Diese beinahe identischen Maximalwerte drücken sich auch in der Steigung des PAP pro Minute nach der Stimulation aus. In den Lungen, die ohne SOD perfundiert wurden, stieg der PAP um 0,9 $\pm 0,0 \mathrm{~mm} \mathrm{Hg}$ in der Minute an, in den Lungen mit SOD im Perfusat betrug der pulmonalarterielle Druckanstieg $0,8 \pm 0,1 \mathrm{~mm} \mathrm{Hg}$ pro Minute. 


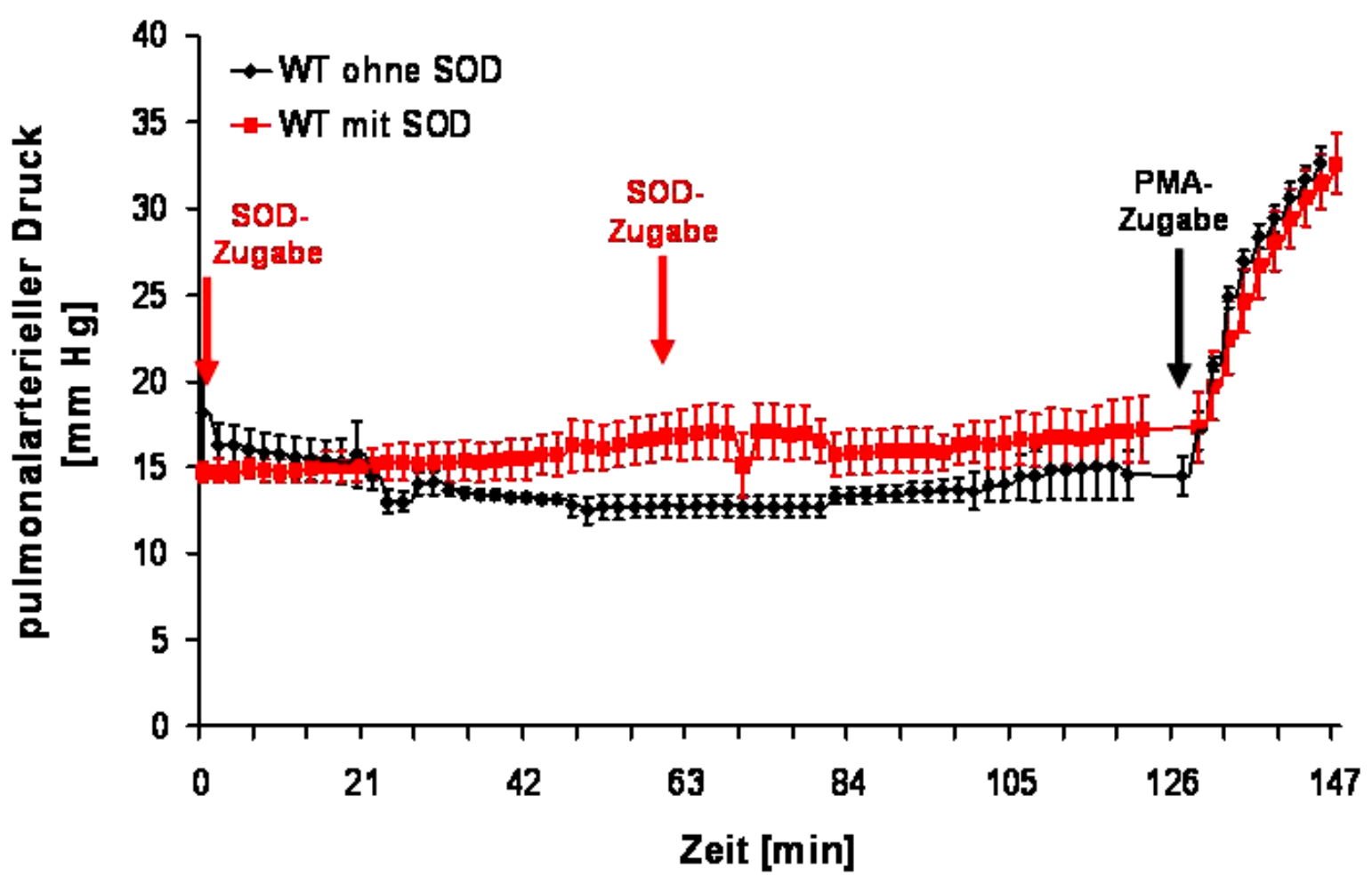

\section{Abbildung 3-14: Pulmonalarterieller Druck in Wildtypen nach chronisch hypoxischer Exposition}

Die Graphik veranschaulicht den PAP des Wildtyps nach chronischer Hypoxie im zeitlichen Verlauf. In rot sind die Versuche mit SOD-Perfusion dargestellt. SOD wurde zweimal während des Versuchs gegeben, die Konzentration resultierte jeweils in $150 \mathrm{U} / \mathrm{ml}$. In schwarz ist der PAP ohne SODPerfusion dargestellt. Am Ende der Versuche wurde in beiden Gruppen PMA zur Stimulation von NADP(H)-Oxidasen gegeben. Die Endkonzentration von PMA im Perfusat war $10 \mu \mathrm{M}$. WT = Wildtyp, SOD = Superoxiddismutase, PMA = Phorbol-Myristat-Acetat; $\mathrm{n}=5$ pro Gruppe.

\subsubsection{2 gp91 ${ }^{\text {phox }}$-defiziente Mäuse}

Die Mäuse mit einer Deletion der gp91 ${ }^{\text {phox }}$-Untereinheit von NADP(H)-Oxidasen zeigten nach chronisch hypoxischer Exposition einen mittleren pulmonalarteriellen Druck von $14,8 \pm 1,9 \mathrm{~mm} \mathrm{Hg}(\mathrm{n}=5)$. Die Stimulation von NADP $(\mathrm{H})$-Oxidasen mit PMA führte zu einem rapiden Anstieg des PAPs, der einen durchschnittlichen Maximalwert von 22,0 $\pm 0,6 \mathrm{~mm} \mathrm{Hg}$ erreichte. Dies entspricht einem Druckanstieg nach PMA-Stimulation von $0,5 \pm 0,0 \mathrm{~mm} \mathrm{Hg} / \mathrm{min}$. Wurden die Lungen der Tiere mit SOD perfundiert, konnte unter Basisbedingungen ein PAP von 18,0 $\pm 0,6 \mathrm{~mm} \mathrm{Hg}$ registriert werden $(\mathrm{n}=4)$. Obwohl der Unterschied zwischen den basalen Drücken der Lunge mit SOD-Perfusion im Vergleich zu den PAP-Werten der Lungen ohne SOD-Perfusion relativ groß ist, zeigte die statistische Auswertung für den Vergleich der ermittelten Werte keine Signifikanz. Nach PMA-Stimulation stieg der PAP in den mit SOD perfundierten Lungen auf einen Maximalwert von 26,6 \pm 0,3 mm Hg (Abbildung 3-15). Dieser Wert unterscheidet sich signifikant von den nach PMA-Stimulation in den Lungen ohne SOD erreichten pulmonalarteriellen Drücken $(\mathrm{p}=0,0002)$. An dem berechneten Druckanstieg pro Minute wird allerdings deutlich, dass der signifikant erhöhte PAP nach PMA-Stimulation weitgehend auf den leicht erhöhten Basisdruck in den Lungen, die mit SOD perfundiert wurden, zurückzuführen ist, denn der berechnete Druckanstieg pro Minute von 
$0,5 \pm 0,1 \mathrm{~mm} \mathrm{Hg} / \mathrm{min}$ unterscheidet sich nicht signifikant von dem $\triangle \mathrm{PAP}$ der Lungen, die ohne SOD perfundiert wurden.

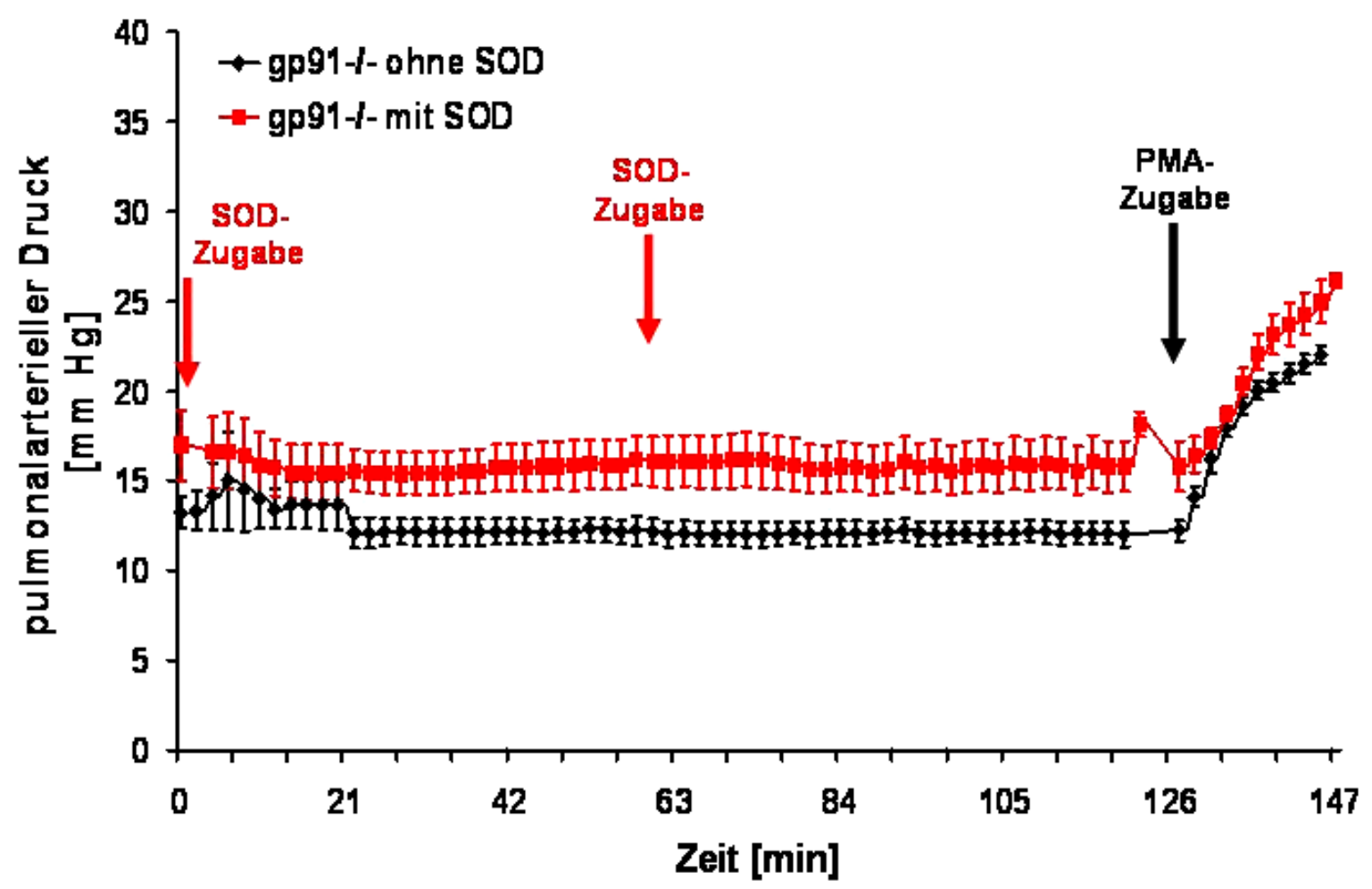

\section{Abbildung 3-15: Pulmonalarterieller Druck in gp91 $^{\text {phox }}$-defizienten Mäusen nach chronischer Hypoxie:}

Graphische Darstellung des PAP in gp91 ${ }^{\text {phox }}$-Knock-Out Mäusen nach chronisch hypoxischer Exposition. In rot sind die Versuche dargestellt, bei denen die Perfusion mit SOD durchgeführt wurde. SOD wurde zweimal während des Versuchs gegeben, die Konzentration resultierte jeweils in $150 \mathrm{U} / \mathrm{ml}$. In schwarz ist der PAP ohne SOD-Perfusion dargestellt. Am Ende der Versuche wurde in beiden Gruppen PMA zur Stimulation von NADP(H)-Oxidasen gegeben. Die Endkonzentration von PMA im Perfusat war $10 \mu \mathrm{M}$. gp91 $1^{-/}=$gp91 $1^{\text {phox }}$-defiziente Tiere, SOD $=$ Superoxiddismutase, PMA

$=$ Phorbol-Myristat-Acetat; $\mathrm{n}=4-5$.

\subsubsection{3 p47 ${ }^{\text {phox }}$-defiziente Mäuse}

In den Mauslungen, die einen Knock-Out für die $\mathrm{p} 47^{\text {phox }}$-Untereinheit von NADP(H)Oxidasen aufwiesen, betrug der PAP nach chronisch hypoxischer Exposition $12,7 \pm 0,4 \mathrm{~mm} \mathrm{Hg}(\mathrm{n}=3)$. Die Simulation von NADP(H)-Oxidasen mit PMA führte zu einem Druckanstieg in der Pulmonalarterie, der einen maximalen Wert von $18,9 \pm 0,9 \mathrm{~mm} \mathrm{Hg}$ erreichte. Das entspricht einem Druckanstieg von 0,4 $\pm 0,0 \mathrm{~mm} \mathrm{Hg}$ pro Minute. Wurden die Lungen mit SOD perfundiert, konnte ein gemittelter PAP von $12,8 \pm 0,4 \mathrm{~mm} \mathrm{Hg}$ gemessen werden $(\mathrm{n}=3)$, der nach der Simulation mit PMA auf ein Maximum von 25,5 $\pm 3,0 \mathrm{~mm} \mathrm{Hg}$ anstieg (Abbildung 3-16). Das entspricht einer signifikanten Erhöhung des PAP von 0,7 $\pm 0,1 \mathrm{~mm} \mathrm{Hg} / \mathrm{min}$. 


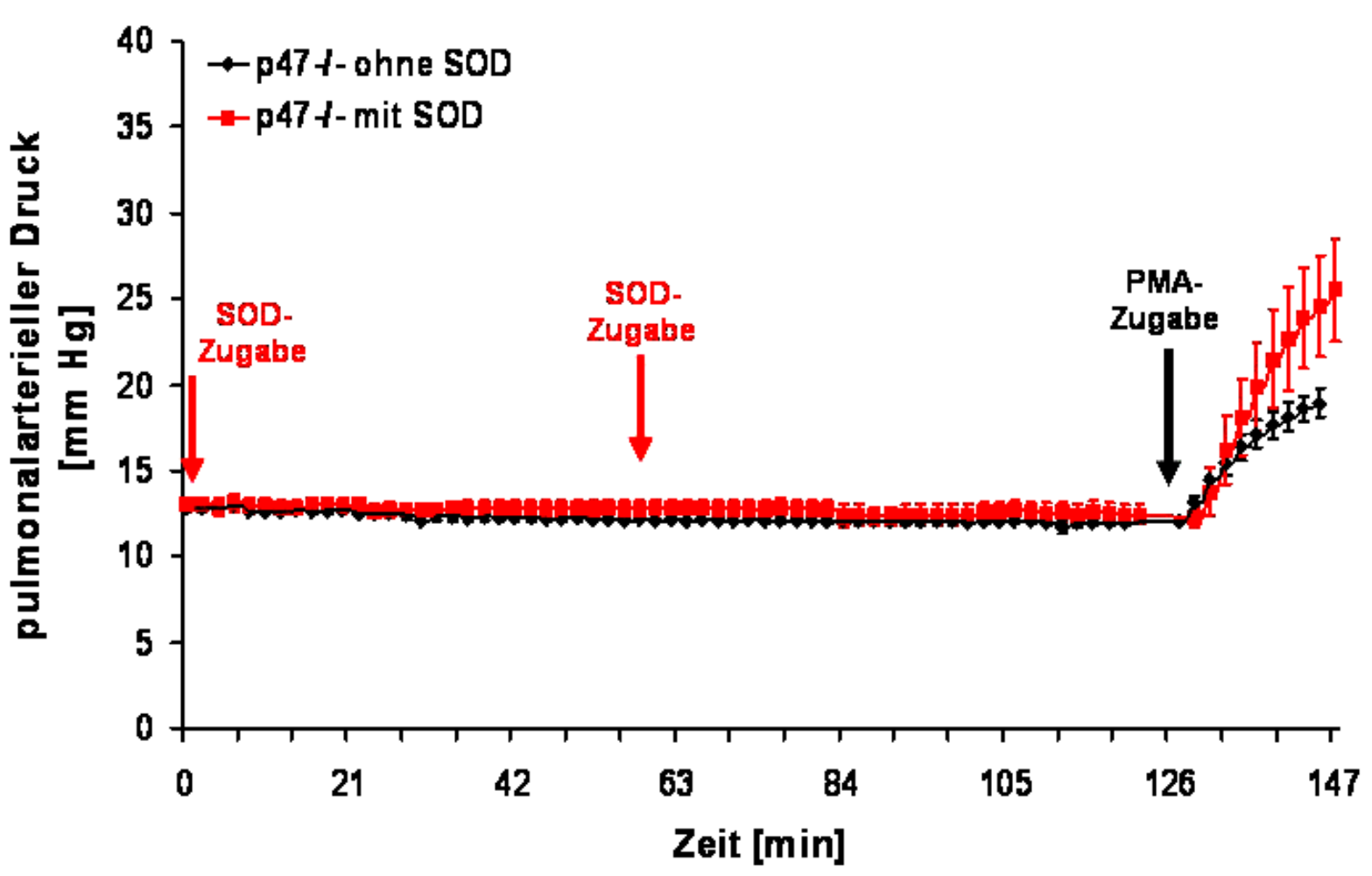

\begin{abstract}
Abbildung 3-16: Pulmonalarterieller Druck in $p 47^{\text {phox }}$-defizienten Mauslungen nach chronisch hypoxischer Exposition

Die Graphik stellt den zeitlichen Verlauf des PAP in Lungen von $\mathrm{p} 47^{\text {phox }}$-Knock-Out Mäusen dar. Die Versuche, die unter SOD-Perfusion durchgeführt wurden, sind in rot gezeigt. SOD [je $150 \mathrm{U} / \mathrm{ml}$ ] wurde zweimal während der Versuche gegeben. In schwarz ist der PAP ohne SOD-Perfusion dargestellt. Am Ende der Versuche wurde in beiden Gruppen PMA zur Stimulation von NADP(H)Oxidasen gegeben. Die Endkonzentration von PMA im Perfusat war $10 \mu \mathrm{M}$. p $47^{-/_{-}}=$p $47^{\text {phox }}$ defiziente Mäuse, $\mathrm{SOD}=$ Superoxiddismutase, $\mathrm{PMA}=$ Phorbol-Myristat-Acetat $\mathrm{n}=3$ pro Gruppe .
\end{abstract}

\title{
3.4.3.4 p22 ${ }^{\text {phox }}$-überexprimierende Mäuse
}

In den Mäusen dieser Gruppe wurde ein mittlerer pulmonalarterieller Druck von $16,4 \pm 1,5 \mathrm{~mm} \mathrm{Hg}$ gemessen, wenn nicht mit SOD perfundiert wurde $(\mathrm{n}=3)$. Bei der Perfusion mit SOD, stellte sich ein PAP von $16,3 \pm 0,5 \mathrm{~mm} \mathrm{Hg}$ ein $(\mathrm{n}=3)$. Die Stimulation von NADP(H)-Oxidasen mittels PMA führte in den $\mathrm{p} 22^{\text {phox }}$-überexprimierenden Lungen zu einem rapiden Anstieg des pulmonalarteriellen Drucks, der für die Tiere ohne SODZusatz einen Maximalwert von 30,2 $\pm 2,3 \mathrm{~mm} \mathrm{Hg}$ erreichte, was einem $\triangle \mathrm{PAP}$ von $0,7 \pm 0,0 \mathrm{~mm} \mathrm{Hg} /$ Minute entspricht. In den Lungen, die mit SOD perfundiert wurden, konnte nach PMA-Stimulation ein maximaler PAP von $26,2 \pm 1,1 \mathrm{~mm} \mathrm{Hg}$ gemessen werden. Hier wurde ein $\triangle \mathrm{PAP}$ von $0,5 \pm 0,1 \mathrm{~mm} \mathrm{Hg}$ errechnet (Abbildung 3-17). 


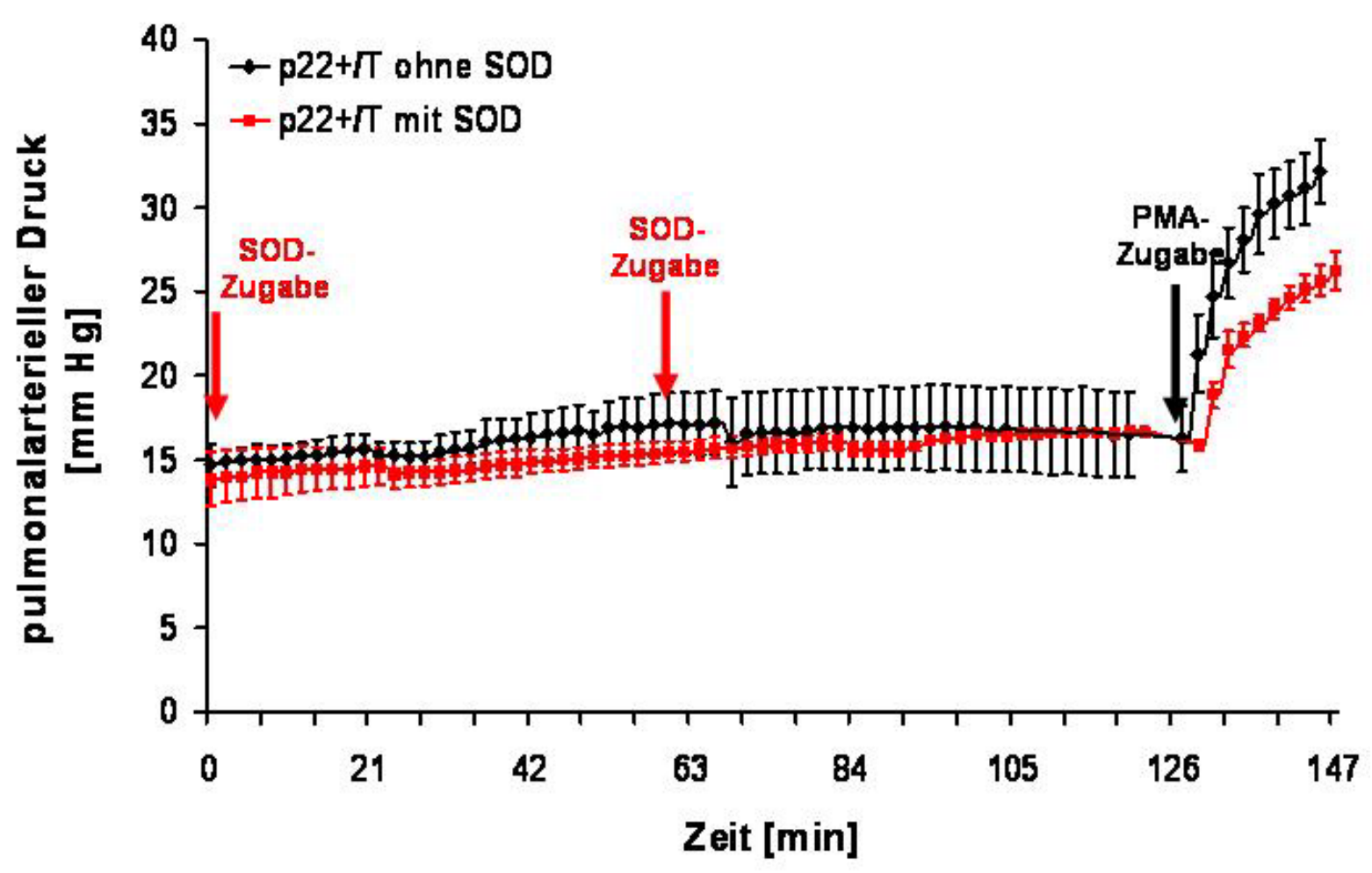

\section{Abbildung 3-17: Pulmonalarterieller Druck in p22 $^{\text {phox }}$-überexprimierenden Mauslungen nach chronisch hypoxischer Exposition}

Die Graphik stellt den PAP nach 21 Tagen hypoxischer Exposition in Lungen von p22 ${ }^{\text {phox }}$ überexprimierenden Mäusen dar. Die Versuche, die unter SOD-Perfusion durchgeführt wurden, sind in rot gezeigt. SOD [je $150 \mathrm{U} / \mathrm{ml}$ ] wurde zweimal während der Versuche gegeben. In schwarz ist der PAP ohne SOD-Zugabe dargestellt. Am Ende der Versuche wurde in beiden Gruppen PMA zur Stimulation von NADP(H)-Oxidasen gegeben. Die Endkonzentration von PMA im Perfusat war $10 \mu \mathrm{M} . \mathrm{p} 22^{+/ T}=$ p $22^{\text {phox }}$-überexprimierende Mäuse, SOD = Superoxiddismutase, PMA = PhorbolMyristat-Acetat; $n=3$ pro Gruppe.

\subsubsection{Zusammenfassung}

Die pulmonalarteriellen Drücke, die nach 21 Tagen Hypoxie in den isoliert perfundierten Mauslungen gemessen wurden, sind in Tabelle 3-7 nochmals zusammengefasst. Da unter chronischer Hypoxie ein Remodeling der Gefäßmedia auftritt, sollte der PAP in den chronisch hypoxischen Tieren höher sein als in den betreffenden normoxisch gehaltenen Kontrollmäusen.

Bei Betrachtung der Ergebnisse aus der Perfusion ohne SOD ergaben die statistischen Tests bezüglich der Differenzen keine signifikanten Unterschiede im Falle der p4 $7^{\text {phox }}$ Knock-Out-Mäuse. Dieses Ergebnis erklärt sich aus der geringen Anzahl erfolgreich durchgeführter Versuche $(\mathrm{n}=3)$, denn bei einer großen Anzahl von Lungen entwickelten sich im Versuchsverlauf Ödeme und die Versuche fanden deswegen keinen Eingang in die Auswertung. Dass Mäuse mit einer Deletion der $\mathrm{p} 47^{\text {phox }}$-Untereinheit von NADP(H)Oxidasen nach chronisch hypoxischer Exposition eine pulmonale Hypertonie ausbilden, wurde in anderen Versuchen mehrfach bestätigt. Auch die gp91 ${ }^{\text {phox }}$-defizienten Mauslungen hatten nach 21 Tagen in Hypoxie keinen signifikant erhöhten pulmonalarteriellen Druck im Vergleich zu den normoxischen Kontrollen der gleichen Stämme. Auch dies erklärt sich aus der geringen Anzahl erfolgreich beendeter Versuche 
$(\mathrm{n}=4)$. Ebenso wie für die Mäuse mit einer Deletion der $\mathrm{p} 47^{\text {phox }}$-Untereinheit von NADP(H)-Oxidasen konnte für die gp91 ${ }^{\text {phox }}$-Knock-Out Mäuse die Ausbildung einer pulmonalen Hypertonie nach chronisch hypoxischer Exposition belegt werden. Anderes ergab sich hingegen für die Lungen aus Wildtypen und $\mathrm{p} 22^{\text {phox }}$-überexprimierenden Mäusen. Beide Tiergruppen hatten im Vergleich $\mathrm{zu}$ den normoxischen Mäusen einen signifikant erhöhten PAP nach chronisch hypoxischer Exposition

\section{Tabelle 3-7: Übersicht der PAPs nach chronisch hypoxischer Exposition}

Die Tabelle zeigt nochmals zusammenfassend die Werte für die registrierten pulmonalarteriellen Drücke für die normoxischen und chronisch hypoxischen Tiere. Alle Messwerte sind angegeben als Mittelwert \pm SEM. C57Bl/6J = Wildtyp, gp91 $1^{-/-}$bzw. p47 $7^{-/-}$Mäuse mit defizienter gp91 ${ }^{\text {phox }}$ bzw. $\mathrm{p} 47^{\text {phox }}$-Untereinheit; $\mathrm{p} 22^{+/ \mathrm{T}}=$ Mäuse mit überexprimierter $\mathrm{p} 22^{\text {phox }}$-Untereinheit von NADP(H)Oxidasen, $\mathrm{NOX}=$ Normoxie, $\mathrm{HOX}=$ chronische Hypoxie. ${ }^{*} \mathrm{p}<0,05$ gegen entsprechende Normoxie.

\begin{tabular}{|l|c|c|c|c|}
\hline & $\begin{array}{c}\mathrm{C} 57 \mathrm{BL} / 6 \mathrm{~J} \\
{[\mathrm{~mm} \mathrm{Hg}]}\end{array}$ & $\begin{array}{c}\mathrm{gp} 91^{-/-} \\
{[\mathrm{mm} \mathrm{Hg}]}\end{array}$ & $\begin{array}{c}\mathrm{p} 47^{-/-} \\
{[\mathrm{mm} \mathrm{Hg}]}\end{array}$ & $\begin{array}{c}\mathrm{p} 22^{+/ \mathrm{T}} \\
{[\mathrm{mm} \mathrm{Hg}]}\end{array}$ \\
\hline \hline $\begin{array}{l}\text { NOX ohne } \\
\text { SOD }\end{array}$ & $11,6 \pm 0,6$ & $12,7 \pm 0,7$ & $12,1 \pm 0,6$ & $10,6 \pm 0,3$ \\
\hline $\begin{array}{l}\text { HOX ohne } \\
\text { SOD }\end{array}$ & $16,8 \pm 2,0^{*}$ & $14,8 \pm 1,9$ & $12,7 \pm 0,4$ & $16,4 \pm 1,5^{*}$ \\
\hline NOX mit SOD & $12,9 \pm 0,8$ & $12,7 \pm 0,9$ & $12,6 \pm 1,1$ & $15,8 \pm 1,4$ \\
\hline HOX mit SOD & $16,6 \pm 1,3^{*}$ & $18,0 \pm 0,6^{*}$ & $12,8 \pm 0,4$ & $16,3 \pm 0,5$ \\
\hline $\begin{array}{l}\text { NOX nach } \\
\text { PMA }\end{array}$ & $24,2 \pm 1,9$ & $22,8 \pm 3,2$ & $21,0 \pm 2,7$ & $23,4 \pm 3,4$ \\
\hline $\begin{array}{l}\text { HOX nach } \\
\text { PMA }\end{array}$ & $32,7 \pm 0,9^{*}$ & $22,0 \pm 0,6$ & $18,9 \pm 0,9$ & $30,2 \pm 2,3^{*}$ \\
\hline $\begin{array}{l}\text { NOX mit SOD } \\
\text { nach PMA }\end{array}$ & $28,4 \pm 1,5$ & $27,3 \pm 1,9$ & $24,5 \pm 2,2$ & $31,1 \pm 2,6$ \\
\hline $\begin{array}{l}\text { HOX mit SOD } \\
\text { nach PMA }\end{array}$ & $32,6 \pm 1,7^{*}$ & $26,6 \pm 0,3$ & $25,5 \pm 3,0$ & $26,2 \pm 1,1$ \\
\hline
\end{tabular}

Wurde dem Perfusat SOD beigemischt, ergab sich ein signifikanter Unterschied für den pulmonalarteriellen Druck in den Lungen aus den Wildtypen und den gp91 ${ }^{\text {phox }}$-deletierten Tieren $(p<0,05)$. Die Tests für die anderen Mäuse ergaben keine Signifikanzen für die Differenz der PAPs. Dennoch sind Tendenzen zu einer Erhöhung des pulmonalarteriellen Drucks zumindest in den Lungen aus den gp91 ${ }^{\text {phox }}$-defizienten Tieren zu erkennen.

Die Stimulation von NADP(H)-Oxidasen mittels PMA führte nur in den Lungen des Wildtyps zu signifikant erhöhten PAP-Werten beim Vergleich der normoxischen mit den hypoxischen Mäusen $(\mathrm{p}<0,05)$, wenn die Perfusion ohne SOD durchgeführt wurde. Alle anderen untersuchten Stämme in dieser Gruppe zeigten keine Abweichung des nach PMAStimulation erreichten maximalen Drucks. Bei der Perfusion mit SOD wurden nach PMAZugabe keine signifikanten Unterschiede mehr für die Maximalwerte des PAPs in den Gruppen festgestellt. 


\subsection{Intravasale Superoxid-Freisetzung}

Die Superoxid-Freisetzung aus den Lungen wurde mittels Elektronenspinresonanz Spektroskopie (ESR) gemessen. Dazu wurde dem Perfusat ein Spin-Probe beigemischt, der mit freien Radikalen reagiert und ein stabiles langlebiges Spin-Addukt bildet, das leicht nachgewiesen werden kann. Da in dieser Arbeit nicht nur die ROS-Produktion festgestellt sondern ebenfalls quantifiziert werden soll, wurden in parallelen Experimenten Mauslungen mit Superoxiddismutase perfundiert. Dieses Enzym katalysiert mit hoher Substratspezifität für das Superoxidanion die Umsetzung von ${ }^{\circ} \mathrm{O}_{2}{ }^{-}$in $\mathrm{H}_{2} \mathrm{O}_{2}$. Letzteres Molekül kann nicht mit dem eingesetzten Spin-Probe reagieren, womit zum einen ein spezifischer Nachweis und zum anderen eine Methode zur Quantifizierung der ${ }^{\circ} \mathrm{O}_{2}^{-}-$ Produktion vorliegt.

Die Darstellung der Ergebnisse erfolgt in Balkendiagrammen, die die jeweiligen Steigungen im ESR-Signal zeigen. Zum besseren Verständnis sind in Abbildung 3-18 die ESR-Signal-Intensitäten für die Superoxid-Freisetzung aus Wildtyplungen unter normoxischen Bedingungen gezeigt.

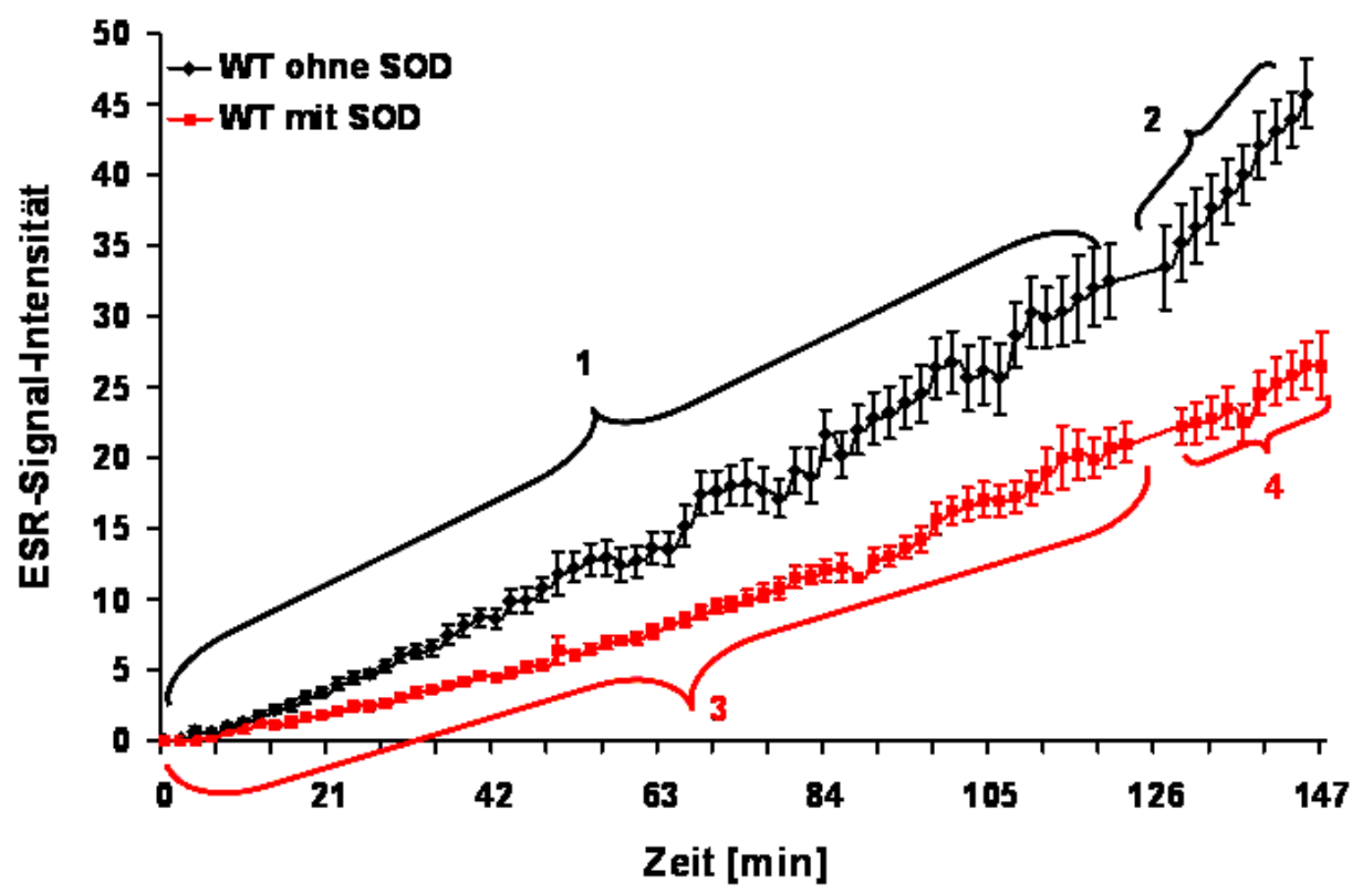

\section{Abbildung 3-18: Darstellung des ESR-Signals im zeitlichen Versuchsverlauf}

Die Abbildung zeigt den linearen Anstieg der ESR-Signalintensität unter normoxischen Bedingungen für die Lungen aus Wildtypen. In schwarz sind die Versuche ohne SOD-Perfusion und in rot die Versuche mit SOD-Perfusion dargestellt. Weitere Erklärungen im Text.

Für jeden Versuchsabschnitt ergab sich eine bestimmte Steigung. Diese sind in dem Diagramm jeweils mit Zahlen markiert. So ergaben sich Steigungen für die basale ROSFreisetzung mit und ohne SOD $(1,3)$ sowie Werte für die Steigung im ESR-Signal nach Stimulation mit PMA $(2,4)$. Die einzelnen Steigungen werden im Folgenden zueinander in Relation gesetzt. Die Fläche zwischen den Kurven, die gleichbedeutend mit unterschiedlichen Steigungen ist, ist dabei ein Maß für die Superoxidproduktion der Lungen. 


\subsubsection{Superoxid-Freisetzung unter Normoxie}

Unter normoxischen Basalbedingungen wurde eine signifikante Superoxid-Freisetzung nur in Lungen von Wildtypen und p22 ${ }^{\text {phox }}$-überexprimierenden Mäusen nachgewiesen. Die Lungen, die einen Knock-Out für $\mathrm{NADP}(\mathrm{H})$-Oxidase Untereinheiten hatten, wie die untersuchten gp91 ${ }^{\text {phox }}$ und $\mathrm{p} 47^{\text {phox }}$-defizienten Mäuse zeigten bei normoxischer Beatmung keine ${ }^{\bullet} \mathrm{O}_{2}{ }^{-}$- Freisetzung aus der Lunge. Auch nach Stimulation der NADP(H)-Oxidasen konnte nur in Wildtypen und $\mathrm{p} 22^{\text {phox }}$-überexprimierenden Mauslungen ein signifikanter Anteil an freiem Superoxid festgestellt werden. Die Tiere, die einen Knock-Out hatten, setzten selbst nach der Stimulation kein Superoxid frei (Abbildung 3-19).

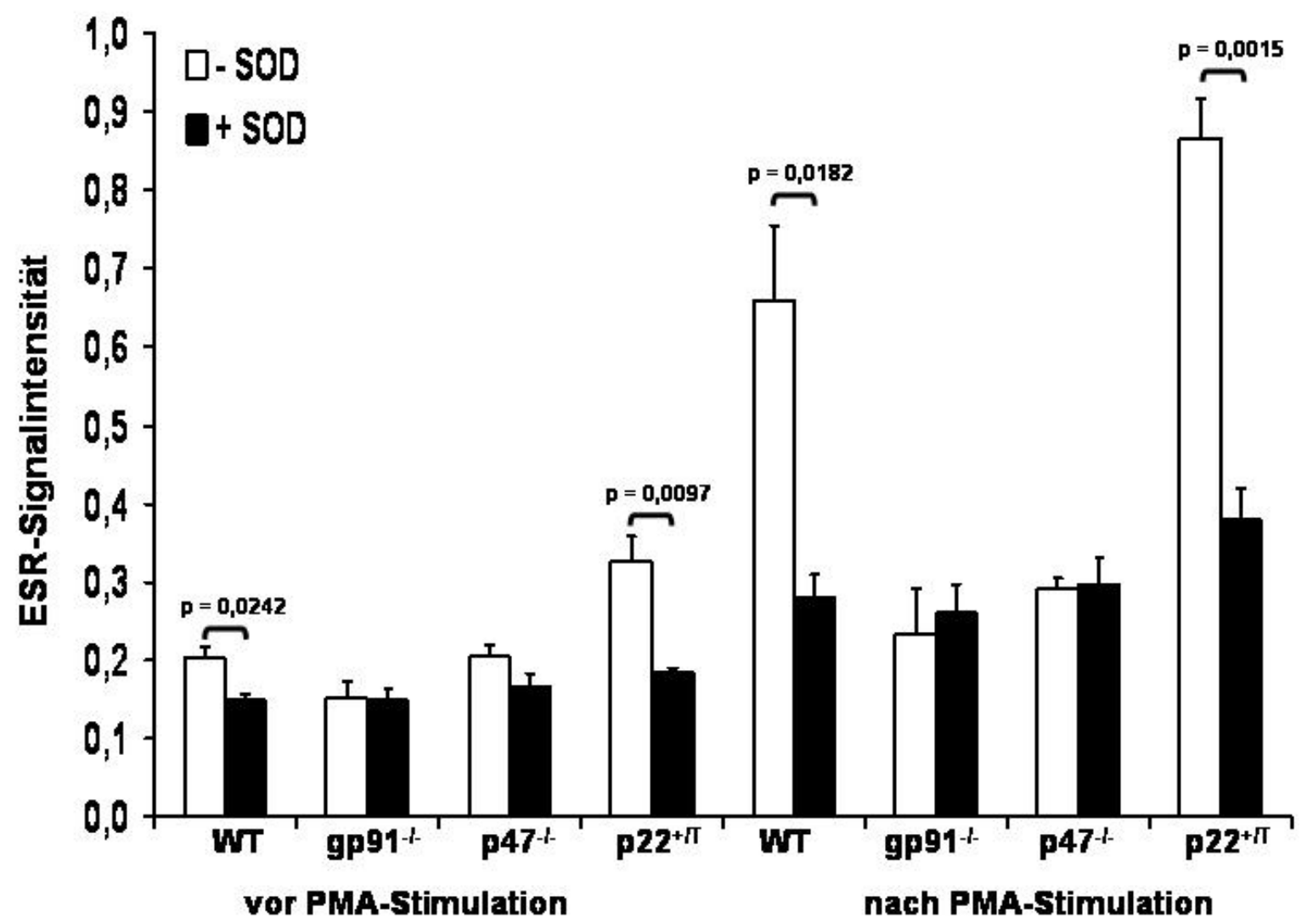

\section{Abbildung 3-19: Normoxische Superoxid-Freisetzung in Mauslungen}

Die Graphik fasst die bei normoxischer Ventilation gemessene Superoxid-Freisetzung in Lungen des Wildtyps und Lungen aus genveränderten Mäusen vor und nach PMA-Stimulation zusammen. Die weißen Balken repräsentieren die ${ }^{\bullet} \mathrm{O}_{2}{ }^{-}$-Produktion ohne Superoxiddismutase im Perfusat und die schwarzen Balken stehen für die nach SOD-Beimischung gemessenen Werte. WT = Wildtyp; gp9 ${ }^{-/-}$ und $\mathrm{p} 47^{-/-}=$Mäuse mit Knock-Outs der gp91 ${ }^{\text {phox }}$ bzw. p47 $7^{\text {phox }}$-Untereinheit von NADP(H)Oxidasen; $\mathrm{p} 22^{+/ \mathrm{T}}=$ Mauslungen mit überexprimierter $\mathrm{p} 22^{\text {phox }}$-Untereinheit; $\mathrm{n}=5-7$.

\subsubsection{Superoxid-Freisetzung in chimären Mäusen unter Normoxie}

Um die Quelle der normoxischen Superoxidproduktion zu identifizieren, wurden chimäre Mäuse eingesetzt. Wie aus den vorangegangenen Ergebnissen hervorgeht, setzen Mäuse des Wildtyps unter normoxischen Basisbedingungen ROS nach intravasal frei. Im Gegensatz dazu stehen die aus gp91 ${ }^{\text {phox }}$-defizienten Mäusen gewonnenen Daten, die keine 
ROS-Produktion aus diesen Lungen zeigen. Um zwischen der Superoxid-Freisetzung aus phagozytären und nicht-phagozytären NADP(H)-Oxidasen $\mathrm{zu}$ unterscheiden, wurden Knochenmarkstransplantationen zwischen Mäusen des Wildtyps und der gp91 ${ }^{\text {phox }}$-KnockOut-Variante durchgeführt. So entstanden insgesamt vier Chimären, die sich bezüglich der Expression funktioneller NADP(H)-Oxidasen unterscheiden (s. 2.1.2).

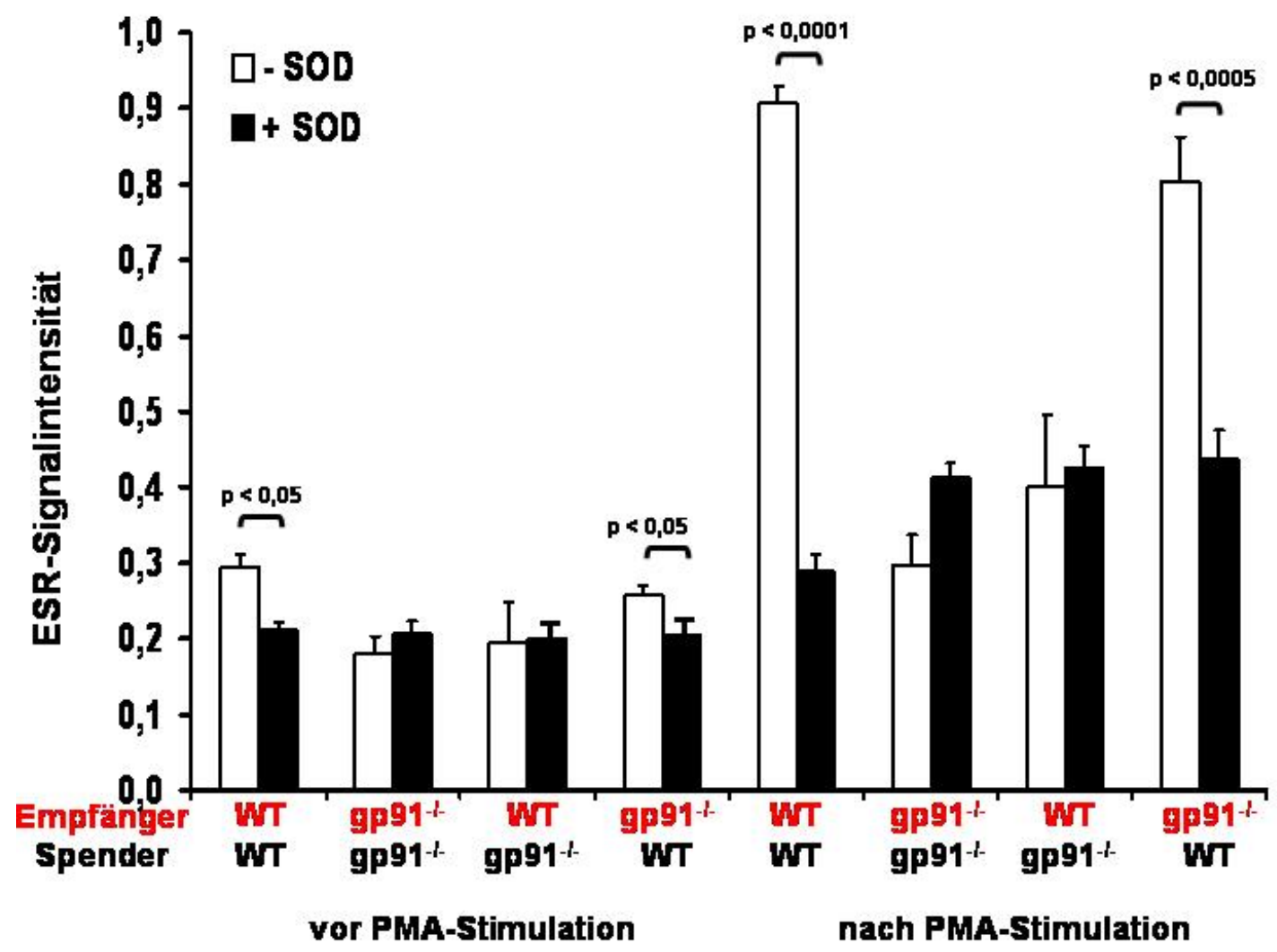

\section{Abbildung 3-20: Superoxid-Freisetzung aus Lungen chimärer Mäuse}

Die Graphik stellt die ${ }^{\circ} \mathrm{O}_{2}{ }^{-}$-Freisetzung aus Lungen chimärer Mäuse dar. In rot sind die jeweiligen Empfänger der Knochenmarksspende aus den in schwarz dargestellten Spendertieren bezeichnet.

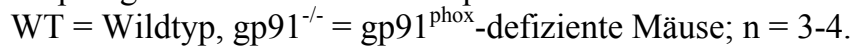

Aus Abbildung 3-20 geht hervor, dass die durchgeführte Transplantation keinen Effekt auf die normoxische Superoxidproduktion hatte. Sowohl die Kontrollen für die Wildtypen (WT/WT) als auch diejenigen für die gp91 ${ }^{\text {phox }}$-Knock-Out Mäuse (gp91 $\left.1^{-/} / \mathrm{gp} 91^{-/-}\right)$zeigten $\mathrm{zu}$ den entsprechenden Tieren ohne Transplantation vergleichbare Werte für die ${ }^{\circ} \mathrm{O}_{2}{ }^{-}$ Produktion. Weiterhin lässt sich aus der Graphik ersehen, dass die Tiere, die Knochenmark aus gp91 $1^{-/}$-Mäusen bekamen, kein ROS freisetzten. Auch nach der Stimulation mit PMA ergab sich kein signifikanter Unterschied zwischen den mit SOD und ohne SOD perfundierten Lungen. Andererseits setzten die Lungen der gp91 ${ }^{-/-}$Mäuse Superoxid frei, wenn ihnen Knochenmark aus Wildtypen transplantiert wurde. Nach der Stimulation von NADP(H)-Oxidasen konnte $\mathrm{n}$ diesen Lungen ein weiterer Anstieg in $\mathrm{der}^{\circ} \mathrm{O}_{2}{ }^{-}$-Freisetzung beobachtet werden. Mit diesem Versuchsansatz konnte somit geklärt werden, dass das im Perfusat gemessene Superoxid aus Granulozyten, also von phagozytären NADP(H)Oxidasen, stammt. 


\subsubsection{Superoxidfreisetzung in akuter Hypoxie}

Zur Untersuchung der ${ }^{\circ} \mathrm{O}_{2}^{-}$-Freisetzung in akuter Hypoxie wurden die bereits erwähnten Mäuse des Wildtyps $(\mathrm{C} 57 \mathrm{Bl} / 6 \mathrm{~J})$ sowie Mäuse mit den bekannten genetischen Veränderungen in den NADP(H)-Oxidasen Untereinheiten gp91 ${ }^{\text {phox }}, \mathrm{p} 47^{\text {phox }}$ und $\mathrm{p} 22^{\text {phox }}$ eingesetzt. In den Versuchen wurden jeweils zwei Phasen normoxischer und hypoxischer Ventilation durchlaufen, die je 15 Minuten andauerten. Da sich die ${ }^{\circ} \mathrm{O}_{2}{ }^{-}$-Freisetzung in der ersten Phase normoxischer respektive hypoxischer Ventilation nicht von der in der zweiten korrespondierenden unterschied, werden die Steigungen der ESR-Signalintensitäten aus beiden Phasen zu einem Mittelwert zusammengefasst (Abbildung 3-21).

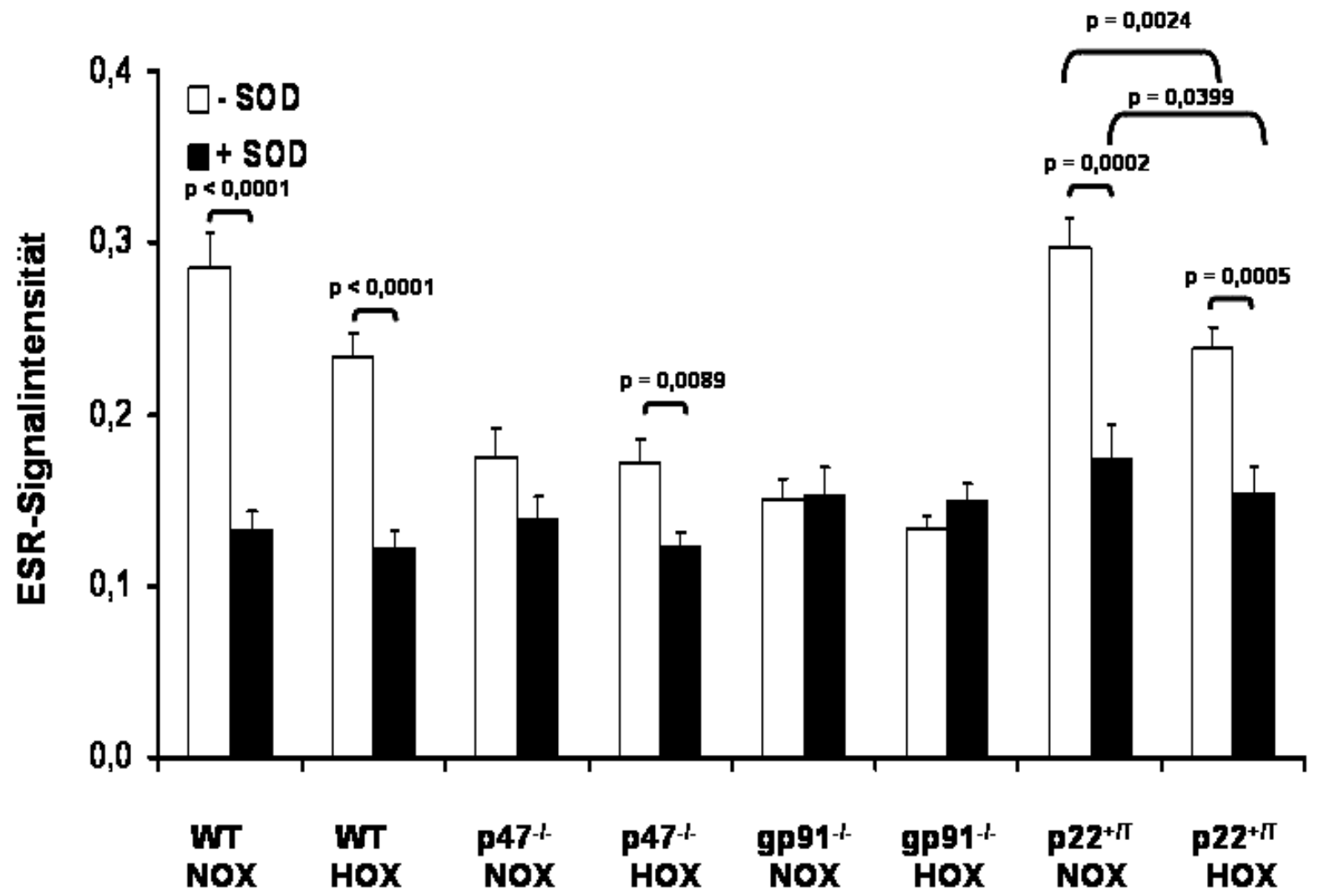

\section{Abbildung 3-21: Superoxid-Freisetzung aus Mauslungen in akuter Hypoxie}

Die Graphik fasst die Unterschiede in der ${ }^{\circ} \mathrm{O}_{2}{ }^{-}$-Freisetzung aus Mauslungen zusammen. Dabei werden die Phasen normoxischer Beatmung denjenigen mit hypoxischer Ventilation gegenüber gestellt. Zur Quantifizierung des Superoxidanions wurden in Parallelexperimenten Lungen mit Superoxiddismutase perfundiert. NOX = normoxische Ventilation; HOX = hypoxische Ventilation; $\mathrm{WT}=$ Wildtyp, p47 $7^{-/ /}$und gp $91^{-/-}=$Knock-Out der p4 $7^{\text {phox }}$ bzw. gp91 ${ }^{\text {phox }}$-Untereinheit; p $22^{+/ \mathrm{T}}=$ Überexpression der $\mathrm{p} 22^{\text {phox }}$-Untereinheit; $\mathrm{n}=4-5$.

Wie aus der obigen Abbildung hervorgeht, setzten Lungen des Wildtyps unter normoxischen und hypoxischen Bedingungen ${ }^{\circ} \mathrm{O}_{2}{ }^{-}$frei. Es wurden keine signifikanten Änderungen der Superoxidproduktion zwischen der Phase mit normoxischer Beatmung und der Phase mit hypoxischer Beatmung festgestellt, unabhängig davon, ob die Lungen mit oder ohne SOD perfundiert wurden. Mauslungen mit einer Deletion der $\mathrm{p} 47^{\text {phox }}$ Untereinheit setzten nur bei hypoxischer Ventilation ein signifikantes Maß des Superoxidanions frei. Bei normoxischer Beatmung ergab sich kein signifikanter Unterschied für die ${ }^{\circ} \mathrm{O}_{2}{ }^{-}$-Quantifizierung. Wurden die Steigung der normoxischen mit der 
der hypoxischen Ventilationsphase verglichen, ergab sich keine signifikante Differenz. Dies ist gleichermaßen gültig für die Perfusion ohne und mit SOD. In den Lungen, die einen Knock-Out der gp91 ${ }^{\text {phox }}$-Untereinheit aufweisen, ist weder bei normoxischer noch hypoxischer Ventilation ein signifikanter Anteil von Superoxid im Perfusat nachzuweisen. Anders hingegen reagierten die Lungen der Mäuse, die die $\mathrm{p} 22^{\text {phox }}$-Untereinhiet von NADP(H)-Oxidasen überexprimieren. Diese Lungen produzieren unter den Versuchsbedingungen, also bei normoxischer und hypoxischer Ventilation, einen signifikanten Anteil des Superoxidanions. Weiterhin ist in diesen Lungen eine geringere - $\mathrm{O}_{2}{ }^{-}$-Produktion in den hypoxischen Phasen zu verzeichnen, wenn die Lungen ohne SOD perfundiert wurden. Zudem unterscheiden sich die erhaltenen Steigungen in den Lungen, bei denen SOD ins Perfusat gemischt wurde, ebenfalls für die normoxischen und hypoxischen Perioden.

\subsubsection{Superoxid-Freisetzung chimärer Mäuse in akuter Hypoxie}

Im vorherigen Abschnitt wurde anhand von chimären Mäusen demonstriert, dass die normoxische Superoxid-Produktion phagozytären Ursprungs ist. Daraus ergab sich die Frage, ob sich bei akuter alveolärer Hypoxie ebenfalls Phagozyten für die ROSFreisetzung nach intravasal verantwortlich zeigen. Um diese Frage zu beantworten, wurden Lungen chimärer Mäuse experimentell repetitiven hypoxischen Manövern ausgesetzt und aus dem Perfusat mittels ESR-Spektroskopie die freigesetzte Menge von Superoxid bestimmt. Die Phasen normoxischer und hypoxischer Ventilation hatten jeweils eine Dauer von 15 Minuten, in denen die Probennahme für die ESR-Messungen in zweiminütigen Intervallen erfolgte. Somit konnten in einer Ventilationsphase sieben Messungen erfolgen, von denen die erste immer eine Minute nach Beginn der normoxischen bzw. hypoxischen Beatmung stattfand.

Die Lungen der untersuchten chimären Tiere setzten während der hypoxischen Manöver kein Superoxid frei (Abbildung 3-22). Auch bei den eingesetzten Kontrolltieren, deren Knochenmark aus Knochenmarkszellen von Tieren des gleichen genetischen Hintergrundes rekonstituiert wurde, wurde in den Phasen hypoxischer Ventilation keine ROS-Freisetzung registriert. Während der normoxischen Ventilation setzten die Lungen ebenfalls kein Superoxid frei. Dies steht im Gegensatz zu den bisher gezeigten Ergebnissen, wonach Tiere des Wildtyps Superoxid nach intravasal freisetzen. Auch die in Abschnitt 3.5.2 dargestellten Resultate zeigen, dass gp91 ${ }^{\text {phox }}$-defiziente Mäuse, welchen Knochenmark aus Wildtypen transplantiert wurde, unter normoxischen Bedingungen ROS produzieren. Diese Abweichung lässt sich daraus erklären, dass die Phasen normoxischer Beatmung in den hier dargestellten Versuchen zur akut hypoxischen Superoxid-Produktion im Vergleich zu den Versuchen mit rein normoxischer Ventilation mit 15 Minuten sehr viel kürzer waren. 


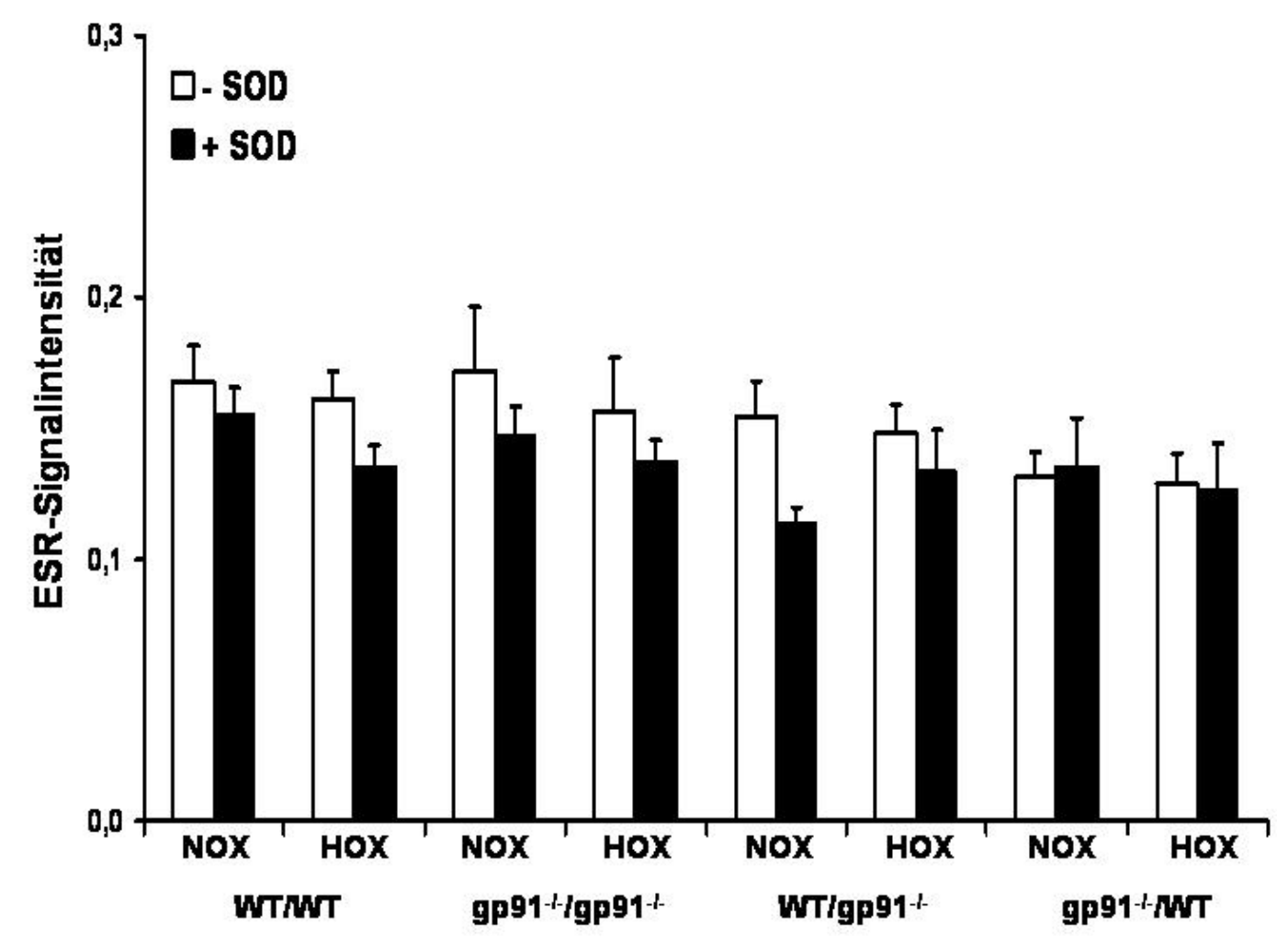

\section{Abbildung 3-22: Superoxid-Freisetzung aus Lungen chimärer Mäuse in akuter Hypoxie}

Die untersuchten Lungen $(n=4$ - 6) setzten unter akut hypoxischen Versuchsbedingungen kein

Superoxid frei. Die Probenentnahme erfolgte in Zwei-Minuten-Intervallen. WT/WT = Wildtypen mit Knochenmark aus Wildtypen; gp $91^{-/ /} / \mathrm{gp} 91^{-/-}=$Mäuse mit einer Deletion der gp $91^{\text {phox }}$-Untereinheit von NADP(H)-Oxidasen mit Knochenmark aus gp91 ${ }^{\text {phox }}$-Knock-Out-Tieren; WT/gp91 ${ }^{-/-}=$Mäuse des Wildtyps nach Transplantation von Knochenmark aus gp91 ${ }^{\text {phox }}$-defizienten Mäusen; gp91 ${ }^{-/} / \mathrm{WT}$ $=$ Tiere mit einer Deletion der gp9 ${ }^{\text {phox }}$-Untereinheit von NADP(H)-Oxidasen nach Transplantation von Knochenmarks aus Wildtyp-Mäusen; $\mathrm{NOX}=$ Normoxie, $\mathrm{HOX}=$ Hypoxie; $\mathrm{SOD}=$ Superoxiddismutase.

\subsubsection{Superoxid-Freisetzung nach chronischer Hypoxie}

Um die Auswirkungen chronischer Hypoxie auf die Superoxidfreisetzung in den Mauslungen zu untersuchen, wurden die Tiere für mindestens 21 Tage unter hypoxischen Bedingungen gehalten $\left(\mathrm{FiO}_{2}=0.10\right)$. Die Versuche wurden ebenfalls unter hypoxischer Ventilation mit einem Gasgemisch, das $10 \% \mathrm{O}_{2}$ enthielt, durchgeführt und es wurde darauf geachtet, dass die Hypoxiekette nicht unterbrochen wurde, damit es durch eine eventuell auftretende Reoxygenierung nicht zu einer Veränderung in der ROS-Produktion kommt. 


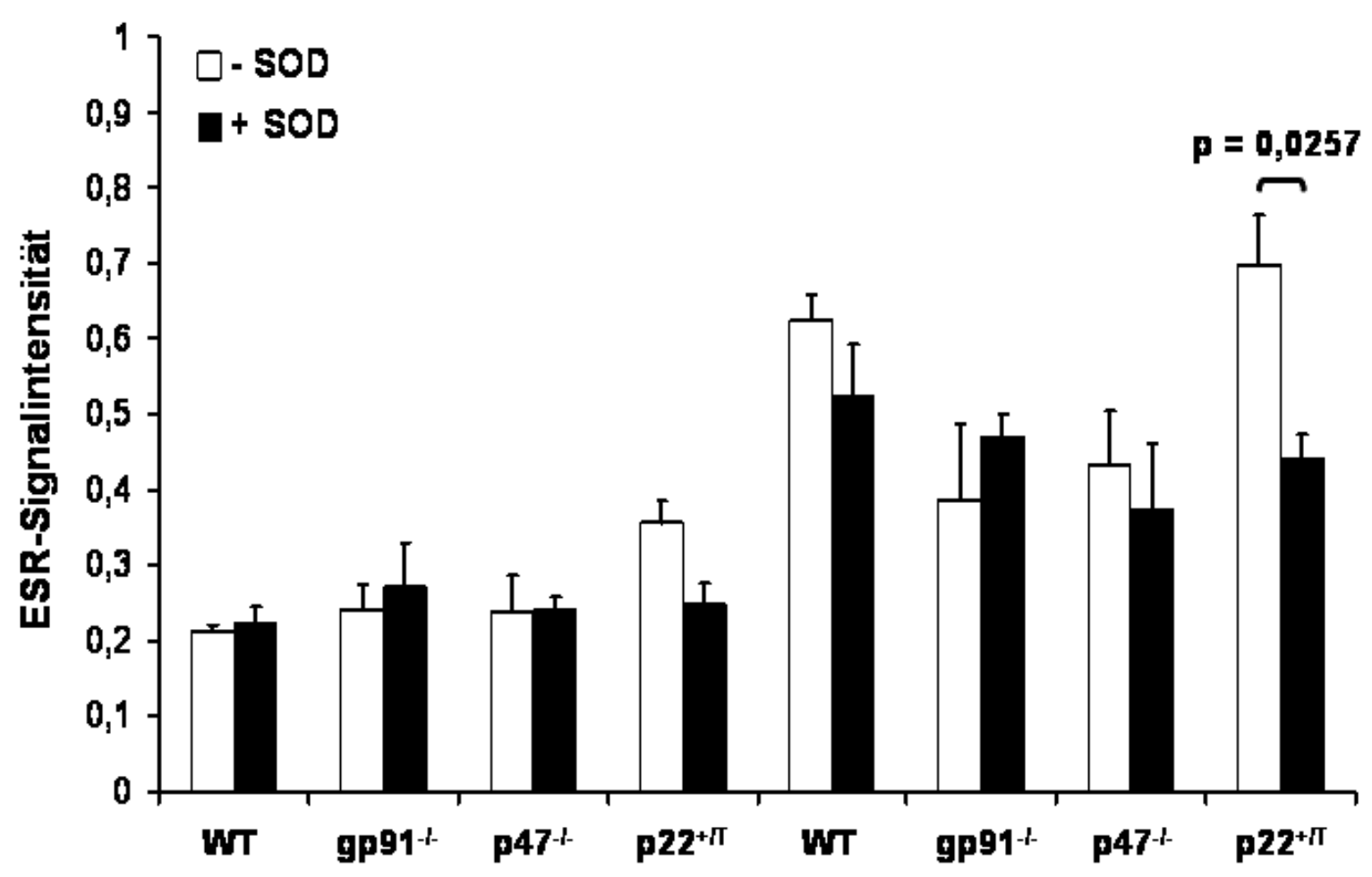

vor PMA-Stimulation

nach PMA-Stimulation

\section{Abbildung 3-23: Superoxid-Freisetzung aus Mauslungen nach 21 Tagen Hypoxie}

$\mathrm{Außer}$ in $\mathrm{p} 22^{\text {phox }}$-überexprimierenden Lungen konnte kein signifikanter Anstieg der Superoxidproduktion nach chronisch hypoxischer Exposition ermittelt werden. WT = Wildtyp; gp91-/- und p47-/- = Mäuse mit einem Knock-Out der gp91 ${ }^{\text {phox }}$ bzw. p $47^{\text {phox }}-$ Untereinheit; p22 $2^{+/ T}=$ Mäuse, die die p22 ${ }^{\text {phox }}$-Untereinheit überexprimieren; $\mathrm{n}=3-7$.

Wie aus Abbildung 3-23 hervorgeht, setzten die untersuchten Mauslungen nach chronisch hypoxischer Exposition kein Superoxid frei. Einzig die Lungen aus p22 ${ }^{\text {phox }}$ überexprimierenden Tieren zeigten bereits ohne Stimulation von NADP(H)-Oxidasen eine Tendenz zur Superoxidfreisetzung. Allerdings konnte aufgrund der geringen Anzahl an Versuchen $(n=3)$ keine Signifikanz festgestellt werden $(p=0,0519)$. Erst nach der Stimulation mit PMA konnte ein signifikanter Anstieg der ROS-Produktion in diesen Lungen nachgewiesen werden. 


\section{Diskussion}

Reaktive Sauerstoffspezies erfüllen im Organismus unterschiedlichste Aufgaben und sind somit für den Körper von großer Bedeutung. Aber nicht nur Menschen und andere Mammalia setzen ROS als Mediatoren zur Regulation von zellulären Prozessen ein. Foreman und Mitarbeiter zeigten im Jahr 2003, dass ein Einstrom von $\mathrm{Ca}^{2+}$-Ionen aus extrazellulären Speichern zum Zellwachstum von Wurzeln und Wurzelhärchen bei Pflanzen beiträgt. Sie konnten zeigen, dass der Einstrom des Kalziums über einen ROSgesteuerten $\mathrm{Ca}^{2+}$-Kanal verläuft und identifizierten NADP(H)-Oxidasen als Quellen der reaktiven Sauerstoffspezies (Foreman et al., 2003).

Im Menschen reguliert die zu den ROS zählende Verbindung $\mathrm{H}_{2} \mathrm{O}_{2}$ das Wachstum vaskulärer Zellen durch die Aktivierung von Protein-Tyrosin-Kinase (PTK) und extrazellulärer Signal-regulierter Kinase (ERK), die die Phosphorylierung von Effektorproteinen steuern (Frank et al., 2000). Die Gruppe um Sim et al. zeigte, dass ROS ebenfalls für die Apoptose von Neutrophilen durch die Aktivierung des ERK-Weges verantwortlich sind (Sim et al., 2005). In beiden Fällen konnten NADP(H)-Oxidasen als Quellen der ROS-Produktion nachgewiesen werden.

Neben NADP(H)-Oxidasen gibt es zahlreiche andere Systeme und Organellen, die ROS produzieren und so das zelluläre Redox-Potential beeinflussen können. Unter anderem sind dies das Xanthin/Xanthin-Oxidase-System (Dudley et al., 2005; Griguer et al., 2006) und die Mitochondrien (Comellas et al., 2006; Liu et al., 2002; Waypa et al., 2001).

In dieser Arbeit wurde die Rolle von NADP(H)-Oxidasen als mögliche Quellen der normoxischen und hypoxischen Superoxidfreisetzung untersucht. Die von diesem System produzierten ROS sollen am Zustandekommen der akuten HPV ebenso beteiligt sein wie an dem vaskulären Remodeling, das unter chronisch hypoxischer Exposition stattfindet. Diese Annahme wird durch Publikationen unserer eigenen als auch anderer Arbeitsgruppen gestützt, in denen zum einen durch verschiedene pharmakologische Interventionen die akute HPV abgeschwächt wird oder nicht mehr auftritt und zum anderen die Rolle von durch NADP(H)-Oxidasen produzierten ROS durch den Einsatz von Knock-Out-Tieren, die defizient für verschiedene Untereinheiten dieses Systems sind, untersucht wurde (Ellmark et al., 2005; Fresquet et al., 2006; Grimminger et al., 1995b; Liu et al., 2005; Liu et al., 2006; Roy et al., 2000; Weissmann et al., 2006d).

Ausgehend von der Hypothese, dass unter Hypoxie vermehrt ROS durch NADP(H)Oxidasen freigesetzt werden und die Radikale zur Entstehung der HPV und PH beitragen, wurde in einem Modell der isoliert perfundierten und ventilierten Mauslunge die ROSFreisetzung unter Normoxie, akuter und chronischer Hypoxie untersucht. Die Analyse der ROS-Produktion aus den Mauslungen wurde mit Elektronenspinresonanz Spektroskopie durchgeführt. Um die Bedeutung von NADP(H)-Oxidasen für diese Prozesse zu klären, wurden genetisch veränderte Mäuse mit Knock-Outs der membranständigen Untereinheit gp91 ${ }^{\text {phox }}$ oder der zytosolischen Untereinheit $\mathrm{p} 47^{\text {phox }}$ eingesetzt. Zudem wurden Mäuse, die die membranständige Untereinheit $\mathrm{p} 22^{\text {phox }}$ von NADP $(\mathrm{H})$-Oxidasen überexprimieren, verwendet. Um zwischen der ROS-Produktion aus phagozytären und nicht-phagozytären NADP(H)-Oxidasen unterscheiden zu können, wurde die Superoxid-Freisetzung ebenfalls aus chimären Mäusen quantifiziert. 


\subsection{Methoden}

Das Methodenspektrum dieser Arbeit setzt sich hauptsächlich aus zwei verschiedenen Systemen zusammen. Die physiologischen Auswirkungen hypoxischer Exposition auf die Lungenstrombahn wurden an der isoliert perfundierten Mauslunge untersucht. Die Freisetzung reaktiver Sauerstoffspezies aus den Lungen wurde mit Elektronenspinresonanz Spektroskopie unter Verwendung des Spin-Probes CP-H quantifiziert.

\subsubsection{Isoliert perfundierte und ventilierte Mauslunge}

Basierend auf einer rezirkulierenden Perfusion ermöglicht dieses System, die physiologische Antwort der Lungengefäße auf Änderungen des Sauerstoffpartialdruckes im Atemgas direkt $\mathrm{zu}$ untersuchen. Zur Perfusion wurde ein physiologischer KrebsHenseleit-Puffer (KHB) eingesetzt, der sämtliche zur Aufrechterhaltung des zellulären Stoffwechsels benötigten Ionen enthielt. Zudem wurde dem Puffer Glukose und Hydroxyethylstärke zugesetzt, die die normalerweise im Blut vorkommenden Makromoleküle ersetzten und das Perfusat somit isoosmotisch zum Blut wurde. Weißmann et al. untersuchten den Effekt unterschiedlicher Perfusionsmedien auf den pulmonalarteriellen Druck in isoliert perfundierten Mauslungen und konnten zeigen, dass die Verwendung von Krebs-Henseleit-Lösung $\mathrm{zu}$ den am besten reproduzierbaren Ergebnissen betreffend der Änderungen des PAPs unter Normoxie und akuter Hypoxie führte (Weissmann et al., 2004). Für die vorliegende Arbeit wurden die isolierten Lungen entsprechend dieser Veröffentlichung in eine wasserumspülte Kammer eingebracht, so dass während der Versuche die Temperatur in den Lungen kontrolliert und konstant gehalten und andere exogene Störfaktoren ausgeschlossen werden konnten. In Versuchen mit isoliert perfundierten Kaninchenlungen zeigten Weißmann und Mitarbeiter, dass die Perfusion mit KHB unter Zusatz von Erythrozyten zu einer erhöhten HPV in diesen Lungen führt (Weissmann et al., 1995). Obwohl diesbezüglich bislang keine Untersuchungen in Mauslungen veröffentlicht wurden, wurden die Mauslungen nicht unter Zusatz von Erythrozyten perfundiert, da diese Zellen durch das Eisenatom des Hämproteins zu einem erhöhten Hintergrundsignal bei der ESR-Analyse führen würde.

Ein Problem dieser Methodik könnte sich aus dem rezirkulierenden Modus der Perfusion ergeben. Zellen, Stoffwechselprodukte und Mediatoren können aus der Lunge in das Perfusat übergehen und dort durch die Rezirkulation und die fehlenden intrinsischen Abbaumechanismen akkumulieren. Natürlich können die körpereigenen Systeme, die normalerweise für den Abbau von nicht benötigten Substanzen verantwortlich sind, in der isoliert perfundierten Lunge nicht eingebracht werden. Diesbezüglich zeigten Weißmann et al. durch Verwendung von Oxygenatoren, dass sich dieser Umstand nicht auf die zu messenden Parameter und die erhaltenen Ergebnisse auswirkt (Weissmann et al., 2005). Zudem wurde in den für diese Arbeit durchgeführten Versuchen dem Umstand der Akkumulation entgegengewirkt, indem die Lungen unter Erhöhung der Perfusionsgeschwindigkeit und der Temperatur bis zum Erreichen der für die Versuche festgesetzten Maximalwerte gespült wurden. Während dieser ca. 20 Minuten dauernden Zeitspanne wurde das Perfusat nach dem Durchgang der Lungengefäße in ein Abfallgefäß geleitet und verworfen. Herausgespülte Zellen, Proteine und nicht-zelluläre Moleküle gingen deshalb nicht in den Versuchsablauf ein. Trotzdem bleiben einige Zellen in den Gefäßen haften und die über den Versuchsverlauf ins Perfusat übergehenden Stoffe verbleiben in der Perfusionslösung. Die Zellpopulation, die in den Lungengefäßen zurückbleibt, setzt sich überwiegend aus Leukozyten zusammen, die aufgrund der starken Adhäsion an der Wand der Gefäße nicht abgelöst werden. Wie mehrere Arbeitsgruppen in 
unterschiedlichen Systemen zeigen konnten, sind die dadurch ausgelösten Effekte aber zu vernachlässigen (Michelakis et al., 2004; Post et al., 1992; Waypa and Schumacker, 2006).

Das Versuchssystem der isoliert perfundierten und ventilierten Lunge erlaubt es, Reaktionen auf Organebene nachzuvollziehen. Das Organ ist zwar auch aus dem Körper gelöst und steht somit nicht mehr im Kontext des Gesamtorganismus, aber die auf die Lunge als Organ bezogenen Regulationsmechanismen bleiben intakt. Dies ist ein entscheidender Vorteil gegenüber der Untersuchung einzelner Zellen oder Zellverbände, die aus der Lunge in Kultur genommen und mehrmals passagiert wurden, denn sie stellen ein artifizielleres System dar als es bei der isoliert perfundierten Lunge der Fall ist. Viele Untersuchungen bezüglich den der HPV zugrunde liegenden Mechanismen, insbesondere die Erforschung der Rolle der ROS, wurden aus Zellkulturen gewonnen und widersprechen sich teilweise, je nachdem welche Zelltypen verwendet wurden (Archer et al., 2004; Brunelle et al., 2005; Chamseddine and Miller, 2003; Jeffery and Morrell, 2002; Moudgil et al., 2005; Rose et al., 2002; Waypa et al., 2006). Der Vorteil der isoliert perfundierten Lunge ist aber gleichzeitig auch ein Nachteil, denn es kann mit diesem System nicht nachvollzogen werden, welche Zelltypen z.B. als Sauerstoffsensoren für Hypoxie oder als ROS-Produzenten in Frage kommen. Für diese Arbeit wurden deswegen Mäuse mit einer Defizienz für bestimmte Untereinheiten von NADP $(\mathrm{H})$-Oxidasen sowie chimäre Tiere in den Versuchen eingesetzt. Besonders der Einsatz der Chimären lässt Rückschlüsse auf die ROS-produzierenden, NADP(H)-Oxidase exprimierenden Zellen und zellulären Kompartimente zu.

\subsubsection{Elektronenspinresonanz Spektroskopie}

Mittels ESR-Spektroskopie lassen sich auf relativ einfache Weise entweder direkt oder indirekt Radikale nachweisen. Für den direkten Nachweis werden Moleküle in der Gasphase oder in Lösung direkt in das Spektroskop eingebracht um Art und Konzentration der ROS zu bestimmen. Diese Methode ist schwierig und allein aus technischen Gründen meist nicht durchführbar. Das begründet sich in der sehr kurzen Halbwertszeit, die z. B. für das Superoxidanion weniger als eine Millisekunde beträgt. Zudem ist dieses Radikal in sehr geringer Konzentration vorhanden $(\sim 1 \mathrm{nM})$ und zeigt bei Raumtemperatur kein ESRSpektrum (Dikalov, 2005). Bei der indirekten Methode werden nicht die Radikale selbst analysiert, vielmehr wird eine Reaktion zwischengeschaltet, aus der ein stabiles und langlebiges Produkt entsteht, das mittels ESR analysiert werden kann. Für diese Arbeit wurde letztgenannte Methode eingesetzt. Dazu wurde als Spin-Probe das zyklische Hydroxylamin 1-Hydroxy-3-carboxy-2,2,5,5-tetramethylpyrrolidin. $\mathrm{HCl}(\mathrm{CP}-\mathrm{H})$ verwendet, das spezifisch mit Superoxid und Peroxynitrit reagiert und das stabile Spin-Addukt CP ${ }^{\bullet}$ bildet (Dikalov et al., 1997c; Dikalov et al., 1997d; Weissmann et al., 2005). Das SpinAddukt ist ein Nitroxid-Derivat, das seine Stabilität $u$. a. durch die Abwesenheit eines $\beta$ Protons erhält. $\beta$-Protonen sind eine der Hauptangriffspunkte im oxidativen Verfall von radikalischen Addukten (Dikalov et al., 1997c). Die Stabilität des Spin-Adduktes kann zudem durch das Ansetzen der Lösung auf Eis, den Einsatz von Metallchelatoren wie DTPA oder DETC, die Begasung der Puffer mit Stickstoff und durch die Verwendung frischer Lösungen zusätzlich erhöht werden. Diese Punkte wurden für alle in dieser Arbeit eingesetzten Lösungen berücksichtigt.

In vielen Studien zur Radikal-Freisetzung und Analyse mit ESR-Spektroskopie werden Spin-Traps, wie z. B. 5,5-Dimethyl-1-pyroline-N-oxide (DMPO) verwendet (Barbacanne et al., 2000; Dikalov et al., 2005; Souchard et al., 1998; Zwicker et al., 1998). Diese Moleküle haben zahlreiche Nachteile gegenüber den Spin-Probes. Die 
Reaktionsgeschwindigkeit der Spin-Traps ist viel geringer als die der Spin-Probes, so dass Antioxidantien einen Großteil der zu detektierenden Radikale bereits in andere Moleküle umgewandelt haben, die dann kein ESR-Spektrum mehr ergeben. Zum Beispiel beträgt die Reaktionskonstante von DMPO mit Superoxid $35 \mathrm{M}^{-1} \mathrm{~s}^{-1}$ wohingegen die Reaktionskonstante von Superoxid mit CP-H bei 3,2 x $10^{3} \mathrm{M}^{-1} \mathrm{~s}^{-1}$ liegt (Dikalov, 2005). Aus den Reaktionen von Spin-Traps mit Radikalen können sich zudem Hydroxyl-RadikalAddukte bilden, die weiterhin zu Hydroxylaminen reduziert werden. Hydroxylamine ergeben wiederum kein ESR-Spektrum, und somit geht ein Grossteil der Information verloren (Dikalov et al., 1997a, b, c; Dikalov et al., 1997d).

Andererseits birgt auch die Verwendung von Spin-Probes gewisse Nachteile in sich. Das aus der Reaktion des Spin-Probes mit einem Radikal entstehende Nitroxid-Radikal hat kein spezifisches Spektrum im ESR. Zudem können sich Spin-Addukte durch unspezifische Oxidation ergeben, die zu einem falsch-positiven Signal führen (Dikalov, 2005; Dikalov et al., 1997c). Dieser relativen Unspezifität kann aber durch den Einsatz von Superoxiddismutase oder durch Inhibitoren für radikalproduzierende Systeme, wie NADP(H)-Oxidasen, Xanthin-Oxidasen oder Mitochondrien, entgegengewirkt werden (Dikalov, 2005; Dikalov et al., 2003; Kuzkaya et al., 2003; Sorescu et al., 2001).

In dieser Arbeit wurde der Spin-Probe CP-H für die Bestimmung der Superoxidproduktion eingesetzt. Um die ${ }^{\bullet} \mathrm{O}_{2}{ }^{-}$-Produktion zu quantifizieren und die Spezifität für den Nachweis dieses Radikals sicherzustellen, wurden in parallelen Experimenten Mauslungen mit Superoxiddismutase perfundiert. Die Autooxidation des Spin-Probes konnte verringert werden, indem alle für die Perfusion eingesetzten Lösungen mit hochreinem Wasser angesetzt und zweiwertige Metallionen mit einem Chelator gebunden wurden. Der Ansatz der CP-H-Lösung erfolgte auf Eis und sie wurde erst kurz vor dem Gebrauch hergestellt. Zudem wurde die Lösung mit Stickstoff begast, um den in der Flüssigkeit gelösten Sauerstoff zu verdrängen. Die Bestimmung der Autooxidation des Spin-Probes fand in zusätzlichen Experimenten statt. Dazu wurde die Spin-Probe-Lösung unter normalen Versuchsbedingungen durch das Perfusionssystem geleitet und mit ESR-Spektroskopie analysiert, allerdings ohne dass eine Lunge in das System eingebracht wurde. Die so erhaltenen Werte wurden für die Auswertung von den Werten der Versuche zur Superoxidfreisetzung aus Mauslungen subtrahiert.

Durch die Kombination von ESR-Spektroskopie und Spin-Probes wurde in der vorliegenden Arbeit zum ersten Mal ein Nachweis für die ROS-Produktion und ROSFreisetzung im intakten Organ erbracht, der vollkommen unabhängig von RedoxFarbstoffen, wie z. B. Lucigenin, Dihydroethidium (DHE) oder 2',7'-dichlorofluorescindiacetat (DCFH) ist. Waypa et al. setzten für ihre Untersuchung zur mitochondrialen ROSProduktion den Redox-sensitiven Farbstoff DCFH ein. Über diese Methode konnte die Gruppe in isolierten Zellen eine ROS-Produktion in Mitochondrien nachweisen. Bei den Untersuchungen zur Implikation mitochondrialer ROS in den Vorgang der HPV, der anhand der isoliert perfundierten Rattenlunge erbracht wurde, verwendete die Gruppe Inhibitoren für den mitochondrialen Elektronentransport (Waypa et al., 2001). Murphy und Mitarbeiter zeigten in einer in vivo Studie im Jahr 1991, dass mittels ESR-Spektroskopie die im Körper freigesetzten ROS nachgewiesen werden können (Murphy et al., 1991). In dieser Studie wurden Plasmaproben aus Kaninchen, die kurzzeitig Zigarettenrauch inhalierten, untersucht. Als Spin-Trap wurde Phenyl-N-t-Butyl-Nitrone (PBN) verwendet, das den Tieren vor der Rauchinhalation systemisch appliziert wurde. Auch andere Arbeitsgruppen konnten durch den Einsatz von ESR-Spektroskopie eine Radikalproduktion in vivo nachweisen (Awasthi et al., 1997; Hartell et al., 1994; Kadiiska et al., 1993; Kadiiska and Mason, 2002). Allen diesen Arbeiten ist gemein, dass die Quelle der ROS-Freisetzung im Tier aufgrund der systemischen Applikation des Spin-Traps nicht 
durch die ESR-Spektroskopie identifiziert werden konnte. Im Gegensatz dazu stehen Studien mit kultivierten Zellen. In isolierten und kultivierten Zellen des respiratorischen Systems, wie z. B. Endothelzellen oder glatten Muskelzellen, wurde von vielen Arbeitsgruppen die Generierung von reaktiven Sauerstoffspezies durch die Verwendung von ESR-Spektroskopie belegt (Barbacanne et al., 2000; Sorescu et al., 2001; Souchard et al., 1998), allerdings konnte in diesen Studien aufgrund der physiologischen Limitierung auf Zellebene nicht auf die Situation im intakten Organ geschlossen werden.

\subsection{Physiologie}

\subsubsection{Gewicht und Hämatokrit}

Für das Gewicht der normoxischen Mäuse fanden sich einige signifikante Unterschiede, insbesondere bei den gp91 ${ }^{\text {phox }}$-defizienten Tiere, die meist schwerer waren als die Kontrollen und andere Knock-Out-Mäuse. Dennoch ist nicht davon auszugehen, dass das Gewicht einen entscheidenden Einfluss auf die in den Messungen erhobenen Daten hat. Allerdings liegen keine Untersuchungen darüber vor, inwieweit das Gewicht der Tiere die physiologischen und pathophysiologischen Vorgänge in der Lunge beeinflusst. Für diese Arbeit wurden nur Mäuse eingesetzt, die vom C57B1/6-Stamm abstammten. Trotz der festgestellten Unterschiede im Gewicht der Tiere, konnte keine Relation $\mathrm{zu}$ den Versuchsergebnissen festgestellt werden. Ein Gewichtsverlust der Mäuse unter chronischer Hypoxie, wie es aufgrund der erhöhten Metabolismusrate zu erwarten wäre, konnte in keiner der untersuchten Gruppen nachgewiesen werden. Das erhöhte Gewicht der chimären Mäuse, besonders der Empfänger mit einem systemischen Knock-Out der gp91 ${ }^{\text {phox }}$-Untereinheit von NADP(H)-Oxidasen, erklärt sich daraus, dass diese Tiere von Anfang an schwerer waren als die jeweiligen Wildtypen und erst später Eingang in die Versuche fanden. Aber auch in diesen Fällen hatte das größere Gewicht keine Auswirkung auf die erhobenen Daten, da sich die durchgeführten Untersuchungen auf die Rolle von NADP(H)-Oxidasen beschränkten, deren Expression und Funktion in keiner Relation zum Gewicht der Tiere steht.

Der Hämatokrit aller untersuchten Mäuse unterschied sich für die normoxisch gehaltenen Tiere nicht signifikant. Akute Hypoxie wurde in den Versuchen durch Ventilation mit hypoxischem Gasgemisch erreicht, und da die Mäuse vor Versuchsdurchführung normoxisch gehalten wurden, ergaben sich auch in dieser Gruppe keine signifikanten Abweichungen für den Hämatokrit. Einzig nach chronisch hypoxischer Exposition zeigten die Mäuse einen signifikant erhöhten Hämatokrit gegenüber den normoxisch gehaltenen Tieren. Durch Hypoxie kommt es zu einer verstärkten Erythropoese, die durch die hypoxische Stimulation des Erythropoetin (EPO)-Gens in der Niere gesteuert wird, was diese Beobachtung erklärt. Die genveränderten Mäuse, also die Tiere mit einer Deletion bzw. Überexprimierung von NADP $(\mathrm{H})$-Oxidase Untereinheiten, zeigten nach chronisch hypoxischer Exposition ebenfalls einen erhöhten Hämatokritwert. Dieser unterschied sich signifikant von dem der in chronischer Hypoxie gehaltenen Wildtypen. Bei der Kontrolle des EPO-Gens spielen ROS, v. a. $\mathrm{H}_{2} \mathrm{O}_{2}$, eine wichtige Rolle (Chandel et al., 2000; Goyal et al., 2004; Zou and Cowley, 2003). Zwar sind die dieser Regulation zugrunde liegenden Mechanismen noch nicht vollständig geklärt, aber einige Untersuchungen zeigen, dass der Hypoxie-induzierbare Faktor 1 (HIF-1) eine wichtige Komponente für die Kontrolle der EPO-Expression ist (Fisher, 1997; Semenza, 1994; Zhu et al., 2002). HIF-1 setzt sich aus 
zwei Untereinheiten zusammen, HIF-1 $\alpha$ und HIF-1 $\beta$, die unter Hypoxie als Komplex an eine regulatorische Gensequenz im EPO-Gen binden und dadurch die Expression von Erythropoetin positiv beeinflussen. Chandel und Mitarbeiter zeigten, dass mitochondriale ROS eine wichtige Funktion bei der Stabilisierung des HIF-1 $\alpha$-Kompexes unter Hypoxie haben (Chandel et al., 2000). In der vorliegenden Arbeit konnte gezeigt werden, dass die Lungen der Knock-Out-Tiere keine Produktion von Superoxid nach chronisch hypoxischer Exposition aufweisen. Allerdings könnte in den Nieren dieser Tiere eine erhöhte ROSBildung durch die mitochondriale Elektronentransportkette vorliegen, so dass die fehlende Radikal-Produktion über die nicht-funktionellen NADP(H)-Oxidasen kompensiert wird. Ein weiterer denkbarer Mechanismus ist, dass die Funktionalität der NADP(H)-Oxidasen durch eine Isoform der deletierten Untereinheiten wieder hergestellt wird (Cheng et al., 2001; Maranchie and Zhan, 2005).

\subsubsection{Normoxische ROS-Produktion und PAP}

Liu und Mitarbeiter zeigten mit der Lucigenin-Methode, dass aus Mäusen isolierte pulmonalarterielle Ringe bzw. intrapulmonale Arterien unter normoxischen Bedingungen intrazelluläre Chemilumineszenz aufweisen (Liu et al., 2005; Liu et al., 2006). Allerdings wurde in diesen Publikationen keine Quantifizierung der Lumineszenz über Superoxiddismutase durchgeführt, so dass fraglich ist, ob es sich bei dieser Beobachtung wirklich um ein intrazelluläres ROS-Signal handelt oder lediglich die Autofluoreszenz des Lucigenins gemessen wurde. In Abbildung 3-19 dieser Arbeit wurde erstmalig gezeigt, dass Mauslungen bereits unter kontinuierlicher normoxischer Beatmung Sauerstoffradikale nach intravasal freisetzen. Die normoxische Radikalproduktion scheint einzigartig für die Mauslunge, denn Weißmann und Mitarbeiter haben gezeigt, dass z. B. in Kaninchenlungen unter vergleichbaren Versuchsbedingungen kein Superoxid zu detektieren ist (Weissmann et al., 2005). Diese Beobachtung könnte allerdings darauf zurückzuführen sein, dass Kaninchenlungen in sehr hohem Maß NO bilden, welches unter den vorgegebenen Versuchsbedingungen mit freigesetztem Superoxid reagieren könnte und somit die normoxische ${ }^{\circ} \mathrm{O}_{2}^{-}$-Bildung der Lungen maskiert. Da Weißmann und Mitarbeiter aber ebenfalls CP-H zur ROS-Detektion mittels ESR-Spektroskopie einsetzten, und der SpinProbe mit dem aus der Reaktion von Superoxid mit NO entstehenden ${ }^{\circ} \mathrm{ONOO}^{-}$interagiert, kann bezüglich der ROS-Produktion in Kaninchenlungen keine klare Aussage getroffen werden. Fraglich bleibt weiterhin, weshalb Mauslungen unter Normoxie generell Superoxid produzieren und das Molekül nach intravasal abgeben. Eine physiologische Rolle für diese in der vorliegenden Arbeit beobachtete ROS-Freisetzung ist bisher nicht beschrieben und konnte bislang nicht erklärt werden. Auch in Anbetracht der Tatsache, dass sich der vaskuläre Tonus unter Perfusion mit SOD weder in den Wildtypen noch in den Knock-Out-Mäusen, die kein ${ }^{\bullet} \mathrm{O}_{2}{ }^{-}$produzierten, nicht verändert, ist eine physiologische Rolle der aufgezeigten ROS-Produktion fraglich. Andererseits werden die vom Endothel gebildeten ROS nicht nur nach intravasal, sondern möglicherweise auch zur Gefäßmedia hin abgegeben. Michelakis und Mitarbeiter fassten in einem 2004 erschienenen Review mögliche Funktionen dieser ROS-Population zusammen (Michelakis et al., 2004). Die Gruppe stützt sich dabei auf die sog. Redox-Theorie, wonach eine ROS-Produktion aus Mitochondrien in Abhängigkeit vom Sauerstoffpartialdruck im umgebenden Gewebe erfolgt. Unter normoxischen Bedingungen hält die latente Bildung eines Redox-Mediators, z. B. $\mathrm{H}_{2} \mathrm{O}_{2}$, spannungsabhängige und sauerstoffempfindliche Kaliumkanäle durch andauernde Oxidation geöffnet und dadurch den vaskulären Tonus konstant. Dieser Anteil der ROS-Produktion konnte allerdings aufgrund der in der vorliegenden Arbeit untersuchten Fragestellung nicht detektiert werden. 
Durch den Einsatz von genetisch veränderten Tieren, die entweder eine Deletion der gp91 ${ }^{\text {phox }}$ - bzw. p4 $7^{\text {phox }}$-Untereinheit von NADP(H)-Oxidasen aufweisen oder die p $22^{\text {phox }}$ Unterheinheit überexprimieren, konnten als Quelle der Radikalproduktion NADP(H)Oxidasen identifiziert werden. Wichtig für die ROS-Bildung ist dabei v. a. die gp91 ${ }^{\text {phox }}$ Untereinheit, denn in Mäusen mit einem Knock-Out für diese Untereinheit wurde keine Radikalproduktion festgestellt, wohingegen Mäuse mit deletierter $\mathrm{p} 47^{\text {phox }}$-Untereinheit zumindest eine Tendenz zur normoxischen ROS-Produktion zeigten, auch wenn sich keine Signifikanzen zwischen den Lungen mit SOD im Perfusat und denjenigen ohne SODPerfusion ergaben (Abbildung 3-19). Diese Daten bestätigen die von Liu et al. erhaltenen Ergebnisse, die belegen, dass eine gp91 ${ }^{\text {phox }}$-enthaltende NADP(H)-Oxidase für die intrazelluläre Superoxidproduktion unter Normoxie verantwortlich ist (Liu et al., 2003; Liu et al., 2006). Des Weiteren werden diese Erkenntnisse von Weißmann und Mitarbeitern durch Versuche am Gesamtorgan gestützt. Diese Arbeitsgruppe zeigte in isoliert perfundierten Kaninchenlungen, dass die normoxische Superoxidproduktion durch Inhibitoren für NADP(H)-Oxidasen reduziert wird und bewies anhand von gp91 ${ }^{\text {phox }}$ Knock-out Mäusen, dass diese Untereinheit essentiell für die ROS-Produktion ist (Weissmann et al., 2005; Weissmann et al., 2006d).

Weiterhin zeigt Abbildung 3-19, dass die normoxische Superoxidproduktion in den Wildtypen durch Zugabe von Phorbol-Myristat-Acetat, einem Stimulator für NADP(H)Oxidasen, erhöht wird. Mit der erhöhten Superoxidproduktion geht eine Erhöhung des pulmonalarteriellen Druckes einher (Abbildung 3-2). Dies steht in Einklang mit Daten anderer Arbeitsgruppen, die nach Stimulation von NADP(H)-Oxidasen mit PMA nicht nur erhöhte pulmonalarterielle Drücke, sondern insbesondere einen Anstieg der ROSProduktion nachweisen konnten (Cheng et al., 2004; Souchard et al., 1998). Der Druckanstieg und die erhöhte ROS-Produktion rühren von der durch PMA induzierten Aktivierung von Proteinkinasen des Typs C (PK-C) her. Dieser und auch andere mögliche Signalwege, die zu einer HPV führen und über intrazelluläre Proteinkinasen gesteuert werden, wurden von mehreren Arbeitsgruppen beschrieben (Ward et al., 2004a; Zhou et al., 2002). Weiterhin sind verschiedene Isoformen von PK-C an der Aktivierung des NADP(H)-Oxidase Komplexes durch Phosphorylierung der $\mathrm{p} 47^{\text {phox }}$-Untereinheit beteiligt (Kitada et al., 2003; Maeda et al., 2003; Talior et al., 2005). Demnach ist die durch PMA ausgelöste Vasokonstriktion mechanistisch mit der durch akute Hypoxie ausgelösten vergleichbar. Dennoch stellt sich die Frage, wieso es in den gp91 ${ }^{\text {phox }}$ und insbesondere in den $\mathrm{p} 47^{\text {phox }}$-KO-Mäusen, die beide keine funktionelle NADP $(\mathrm{H})$-Oxidase besitzen, $\mathrm{zu}$ einer Vasokonstriktion kommt (Abbildung 3-3 und Abbildung 3-4). Gerade die p47 $7^{\text {phox }}$ Untereinheit von NADP(H)-Oxidasen ist ein Schlüsselprotein bei der Aktivierung des Komplexes. Sie wird durch PK-C phosphoryliert, was wiederum das Signal zur Komplexierung mit den anderen zytosolischen Untereinheiten ist. Der zytosolische Komplex translokiert dann zur Zellmembran und bildet dort mit den membranständigen Untereinheiten gp91 ${ }^{\text {phox }}$ und $\mathrm{p} 22^{\text {phox }}$ zusammen mit der GTPase Rac die funktionelle Einheit der NADP(H)-Oxidasen (Babior, 2002a; Decoursey and Ligeti, 2005; Lassegue and Clempus, 2003; Sumimoto et al., 2005). Eine mögliche Erklärung für den beobachteten Druckanstieg in den KO-Mäusen ist die Expression von Isoformen für die erwähnten Proteine. So kann Nox-O, die Isoform von $\mathrm{p} 47^{\text {phox }}$, deren Funktion in den Knock-Out Tieren übernehmen, ebenso wie die Isoformen Nox-1 bis Nox-5 die Funktionen der deletierten gp91 ${ }^{\text {phox }}$-Untereinheit erfüllen können (Banfi et al., 2003; Bengtsson et al., 2003; Cheng and Lambeth, 2004, 2005; Cheng et al., 2004; Takeya et al., 2006; Vaziri and Ni, 2005). Zudem zeigen diese Ergebnisse, dass die durch PMA induzierte Vasokonstriktion nicht von NADP $(\mathrm{H})$-Oxidasen phagozytärer Zellen abhängig ist, sondern vielmehr durch Zellen der Gefäßwand, wie z. B. Endothel- oder glatten Muskelzellen, und dort durch eine intrazelluläre ROS-Produktion gesteuert wird. 
Im Gegensatz zu den Ergebnissen der bereits zitierten Arbeiten von Liu et al. (Liu et al., 2003; Liu et al., 2006; Liu et al., 2004), wurde in der vorliegenden Arbeit mittels chimärer Mäuse belegt, dass der überwiegende Anteil der unter Normoxie freigesetzten Sauerstoffradikale im System der isoliert perfundierten Lunge aus phagozytären NADP(H)-Oxidasen stammt (Abbildung 3-20). Somit erklärt sich auch die Diskrepanz zwischen PMA-induziertem Anstieg des PAP bei gleichzeitiger Abwesenheit der Radikalproduktion in Mäusen mit einer Deletion bestimmter Untereinheiten des NADP(H) konvertierenden Komplexes. In diesem Ergebnis wird ein Nachteil der Untersuchung der ROS-Produktion anhand der isoliert perfundierten Lunge deutlich. Mit diesem System kann nicht geklärt werden, ob unter den vorgegebenen Bedingungen auch weitere Quellen, vornehmlich intrazelluläre, wie von Liu et al. beschrieben, für die ROS-Freisetzung in Frage kommen. Dies liegt zum einen daran, dass ${ }^{\circ} \mathrm{O}_{2}{ }^{-}$kaum membranpermeabel ist und deswegen nur in geringem Maß von den produzierenden Zellen in das Gefäßbett der Lunge abgegeben werden kann. Zum anderen ist der eingesetzte Spin-Probe CP-H ebenfalls nur sehr begrenzt zellpermeabel (Dikalov et al., 1998), so dass auch die Möglichkeiten zur Detektion intrazellulärer ${ }^{\circ} \mathrm{O}_{2}{ }^{-}$-Produktion limitiert sind. Abhilfe würde der Einsatz von membranpermeablen Spin-Probes schaffen, wobei sich bei Anwendung des isoliert perfundierten Lungensystems wiederum die Frage stellt, wie viel von dem Spin-Probe in die Zelle aufgenommen wird und auch wieder aus der Zelle ins Perfusat gelangt, aus dem die Proben entnommen werden. Dennoch reflektiert das eingesetzte System am Besten die Bedingungen, wie sie auch im Tier unter physiologischen Konditionen vorkommen. Zudem bietet die für die Arbeit eingesetzte Kombination aus ESR-Spektroskopie und SpinProbes zum ersten Mal die Möglichkeit, die ROS-Produktion auf physiologischer Ebene im intakten Organ nachzuvollziehen. Alle bisherigen Arbeiten, die die Rolle von ROS und deren Funktion für die akute HPV bzw. das Remodeling nach chronischer Hypoxie untersuchten, stützten sich auf Ansätze mit redox-sensitiven Farbstoffen (Daiber et al., 2004; Keller et al., 2004; Waypa et al., 2001), die meist an isolierten Zellen eingesetzt wurden, oder auf Inhibitorstudien, mit denen zelluläre ROS-produzierende Systeme gehemmt wurden (Li and Trush, 1998; Weir et al., 1994). Aufgrund der sehr großen Bandbreite von Zellen, die zum einen als ROS-Produzenten diskutiert werden und gleichzeitig ROS unter Hypoxie freisetzen und der Vielfalt von eingesetzten Methoden, die für die Untersuchung der ROS-Freisetzung herangezogen werden, ist es nicht verwunderlich, dass die herausragende Rolle reaktiver Sauerstoffspezies nach wie vor nicht genau beschrieben wurde. Die hier angewandte Methode der ESR-Spektroskopie bietet den Vorteil, die ROS-Produktion direkt im Organ nachvollziehen zu können und sie nicht auf einige wenige Zelltypen reduzieren zu müssen.

Die normoxischen Basiswerte für den PAP spiegeln die normal in den Tieren vorkommenden Verhältnisse wider (Abbildung 3-2 bis Abbildung 3-5). Schwenke und Mitarbeiter berichteten einen mittleren PAP in lebenden Mäusen von ca. $15 \mathrm{~mm} \mathrm{Hg}$. Die Gruppe implantierte zur Ermittlung des pulmonalarteriellen Druckes Transmitter in die Pulmonalarterie und zeichnete den PAP über einen längeren Zeitraum auf (Schwenke et al., 2006). Die von Schwenke ermittelten Druckverhältnisse in der Pulmonalarterie entsprechen ebenfalls den in unserem Labor durch Katheterisierung des rechten Ventrikels erhaltenen Werten (Dumitrascu et al., 2006). Im artifiziellen System der isoliert perfundierten Lunge wurde in allen untersuchten Tieren ein normoxischer Basiswert von ca. $12 \mathrm{~mm} \mathrm{Hg}$ gemessen. Die Differenzen zu den beschriebenen Werten erklären sich zum einen durch die Verwendung von Perfusat statt Blut in den Versuchen, zum anderen daraus, dass das Herz-Zeit-Volumen in vivo viel höher liegt als bei der isoliert perfundierten Lunge. Allerdings sind die Werte abhängig von der Perfusionsgeschwindigkeit, dem verwendeten Perfusat sowie der Temperatur. Da diese Parameter für alle Versuche konstant gehalten wurden, ist ihr Einfluss zu vernachlässigen. 
Einzig die chimären Mäuse hatten nach normoxischer Exposition einen signifikant erhöhten PAP im Vergleich zu den Wildtypen und den p22 $2^{\text {phox }}$-überexprimierenden Tieren (Abbildung 3-6 und Abbildung 3-7). Die Chimären wurden durch die Transplantation von Knochenmark nach Bestrahlung erzeugt. Damit die Auswirkungen der Bestrahlung und der Transplantation kontrolliert werden konnte, wurde auch eine Übertragung von Knochenmark auf Mäuse des gleichen genetischen Hintergrundes wie desjenigen der Spender vorgenommen. Die Tiere des Wildtyps, die Wildtyp-Knochenmark erhielten und die gp91 ${ }^{\text {phox }}$-Knock-Out Mäuse, denen gp91 ${ }^{-/-}$Knochenmark injiziert wurde, zeigten in den Versuchen ebenfalls einen erhöhten PAP. Diese Daten sind im Ergebnisteil nicht dargestellt. An dieser Beobachtung zeigt sich, dass entweder die Bestrahlung oder die Transplantation $\mathrm{zu}$ einer Erhöhung des PAP in diesen Mäusen führt. Anhand des Verhaltens der Tiere und ebenfalls aufgrund der Ergebnisse aus den ESR-Messungen zeigte sich aber, dass sich der erhöhte PAP nicht negativ auf die Physiologie der Tiere auswirkt und auch die Superoxidfreisetzung wird dadurch nicht beeinflusst. Vergleichbare Beobachtungen in unbehandelten Tieren aus der Literatur liegen derzeit nicht vor.

Bei der Perfusion der Lungen mit Superoxiddismutase zeigten sich keine Unterschiede im basalen Gefäßtonus sowie der PMA-induzierten Vasokonstriktion (Abbildung 3-2 bis Abbildung 3-5), ein weiterer Hinweis auf eine intrazelluläre Superoxidproduktion. Lediglich die Mäuse, die die p22 $2^{\text {phox }}$-Untereinheit von NADP(H)-Oxidasen überexprimieren, hatten unter diesen Bedingungen einen signifikant erhöhten PAP (Abbildung 3-5). Wahrscheinlich liegt dies daran, dass die NADP(H)-Oxidasen dieser Lungen konstant Superoxid produzieren und es aufgrund der hohen SOD-Konzentration zu einer erhöhten Umsetzung von ${ }^{\circ} \mathrm{O}_{2}^{-} \mathrm{zu} \mathrm{H}_{2} \mathrm{O}_{2}$ kommt. Wasserstoffperoxid wiederum ist vasoreaktiv und führt zur Konstriktion der Gefäße (Jones and Morice, 2000; Sham, 2002).

\subsubsection{Akut hypoxische ROS-Produktion und HPV}

Für die Analyse der ROS-Freisetzung in akuter Hypoxie wurden die Mauslungen abwechselnd für jeweils 15 Minuten normoxisch und hypoxisch beatmet. Pro Versuch erfolgten zwei Phasen hypoxischer Ventilation, unterbrochen von einer Periode mit normoxischer Beatmung. Aufgrund des Versuchsschemas wurde PMA während der normoxischen Ventilationsperiode appliziert und nur in initialen Experimenten durchgeführt. In den Vorversuchen stellte sich heraus, dass die während dieser Phase registrierten Werte für den PAP als auch die Daten der ROS-Messungen keine Unterschiede $\mathrm{zu}$ den nach PMA-Stimulation erhaltenen Ergebnissen der unter rein normoxischen Bedingungen durchgeführten Versuche zeigten. Deswegen wurde in den Versuchen zur akut hypoxischen Vasokonstriktion auf die Stimulation von NADP(H)Oxidasen durch Zugabe von PMA verzichtet.

Alle untersuchten Mauslungen zeigten ohne Ausnahme den charakteristischen und in seiner Höhe signifikanten Druckanstieg, die hypoxische pulmonale Vasokonstriktion, wobei es keine Unterschiede der Vasokonstriktion zwischen der ersten und zweiten hypoxisch ventilierten Phase gab (Tabelle 3-6). Diese konstante Antwort auf repetitive hypoxische Manöver wurde in verschiedenen Modellen der isolierten Lunge vielfach beschrieben (Grimminger et al., 1995b; Robertson et al., 2000; von Euler and Liljestrand, 1946; Waypa et al., 2001; Weigand et al., 2005; Weissmann et al., 1995).

Eines der Ziele dieser Arbeit war zu klären, ob Mauslungen unter Hypoxie reaktive Sauerstoffspezies produzieren. Aus Abbildung 3-21 geht hervor, dass Lungen aus Wildtypen unter akut hypoxischen Bedingungen ROS produzieren und diese nach intravasal abgeben. Der Vergleich zwischen normoxisch ventilierten Phasen zu denen mit 
hypoxischer Beatmung erbrachte keinen signifikanten Unterschied für die registrierte Superoxidfreisetzung in den untersuchten Lungen. In Mauslungen, die die p22 $2^{\text {phox }}$ Untereinheit von NADP(H)-Oxidasen überexprimieren zeigte sich allerdings, dass unter akut hypoxischen Bedingungen die ROS-Produktion im Vergleich zu den normoxischen Phasen signifikant sinkt. Trotzdem konnte auch in diesen Lungen ein signifikanter Anteil Superoxid im intravasalen Kompartiment nachgewiesen werden (Abbildung 3-21). Beide Gruppen zeigten aber keine Veränderung der HPV, wenn die Lungen mit SOD perfundiert wurden (Tabelle 3-6), was ein Hinweis darauf ist, dass die nach intravasal freigesetzten ROS für die Mechanistik der akuten HPV keine Rolle spielen. Möglicherweise ist aber die endotheliale ROS-Produktion in Richtung der Gefäßmedia für die akute HPV wichtig. Dieser Anteil von Radikalen konnte mit dem zugrunde liegenden System allerdings nicht nachgewiesen werden. Die Erkenntnis zur Funktion intravasal abgegebener ROS wird zudem dadurch gestützt, dass Mauslungen aus gp91 ${ }^{\text {phox }}$-defizienten Tieren keine Superoxidproduktion zeigen, und zwar weder unter Normoxie noch unter akuter Hypoxie, diese Tiere aber dennoch eine dem Wildtyp vergleichbare HPV zeigen (Abbildung 3-21 und Tabelle 3-6). Trotzdem führt die Perfusion der gp9 ${ }^{\text {phox }}$-defizienten Lungen mit SOD zu einer sehr starken Antwort auf die hypoxische Ventilation. Dies könnte darauf zurückzuführen sein, dass die Superoxid-Freisetzung aus nicht-phagozytären NADP(H)Oxidasen, die in Tieren mit diesem Knock-Out funktionell sind, beeinträchtigt wird und sich dadurch das intrazelluläre Redox-Gleichgewicht verschiebt, welches für die Aufrechterhaltung des vaskulären Tonus notwendig ist. Ein weiterer Hinweis, der die aufgezeigte Hypothese stützt, ergibt sich aus den von $\mathrm{p} 47^{\mathrm{phox}}$-defizienten Mäusen erhaltenen Ergebnissen. In der normoxisch ventilierten Phase zeigen diese Mauslungen keine ROS-Produktion, allerdings steigt die Superoxidfreisetzung in akuter Hypoxie signifikant an. $\mathrm{Da}$ in dieser Arbeit gezeigt werden konnte, dass die normoxische Superoxidproduktion überwiegend aus phagozytären NADP(H)-Oxidasen stammt (Abbildung 3-20), ist davon auszugehen, dass der Anstieg der ${ }^{\circ} \mathrm{O}_{2}{ }^{-}$-Freisetzung in akuter Hypoxie aus Mauslungen mit einer Defizienz für die $\mathrm{p} 47^{\text {phox }}$-Untereinheit von intrazellulären, nicht-phagozytären NADP $(\mathrm{H})$-Oxidasen abzuleiten ist (Weissmann et al., 2006d). Die vermehrte Produktion von Superoxid aus nicht-phagozytären NADP(H)Oxidasen in den Mauslungen wird in den Wildtypen und $\mathrm{p} 22^{\text {phox }}$-überexprimierenden Mäusen von der ${ }^{\circ} \mathrm{O}_{2}{ }^{-}$-Freisetzung aus funktionellen phagozytären NADP(H)-Oxidasen überdeckt, so dass sie bislang nicht detektiert werden konnte. Für diese These spricht auch der beobachtete pulmonalarterielle Basisdruck, der in den Knock-Out-Mäusen im Vergleich zum Wildtyp nicht verändert ist (Tabelle 3-5 sowie Weissmann et al., 2006b).

Durch die Perfusion von Lungen aus chimären Mäusen unter akut hypoxischen Bedingungen konnte zudem gezeigt werden, dass phagozytäre NADP(H)-Oxidasen nicht für die ROS-Produktion in Frage kommen (Abbildung 3-22), was die o. g. Hypothese stützt. In Mäusen mit systemischem Knock-Out der gp91 ${ }^{\text {phox }}$-Untereinheit von NADP(H)Oxidasen wurde keine ${ }^{\bullet} \mathrm{O}_{2}{ }^{-}$-Freisetzung registriert. Erhielten diese Tiere Knochenmark aus Wildtypen, wodurch die phagozytären Zellen eine funktionelle NADP(H)-Oxidase exprimieren, konnte in den Phasen hypoxischer Ventilation dennoch keine ${ }^{\bullet} \mathrm{O}_{2}{ }^{-}$-Produktion nachgewiesen werden. Gleiches gilt für die Tiere des Wildtyps, die nach Transplantation von Knochenmark aus gp91 ${ }^{\text {phox }}$-defizienten Mäusen nicht mehr zur ROS-Bildung aus phagozytären NADP(H)-Oxidasen in der Lage sind. In diesen Tieren fällt jedoch auf, dass sich in den Phasen normoxischer Ventilation ein Trend $\mathrm{zu}$ einer signifikanten ${ }^{\circ} \mathrm{O}_{2}{ }^{-}$Freisetzung einstellt (Abbildung 3-22). Dies steht im Gegensatz zum vorgenannten, unter normoxischen Bedingungen aufgezeigten Ergebnis. In Abbildung 3-20 wurde gezeigt, dass die normoxische Superoxidproduktion eindeutig phagozytären NADP(H)-Oxidasen zuzuordnen ist, da nur die Chimären mit systemischem Knock-Out der gp91 ${ }^{\text {phox }}$ 
Untereinheit nach Transplantation von Knochenmark aus Wildtypen ${ }^{\circ} \mathrm{O}_{2}{ }^{-}$produzieren. Eine Erklärung für den beobachteten Trend zur normoxischen ROS-Freisetzung in den WT/gp91 ${ }^{\text {phox }}$-Chimären ergibt sich wiederum aus endothelialen NADP(H)-Oxidasen, die unter alveolärer Hypoxie ROS freisetzen, diese aber erst nach einer zeitlichen Verzögerung, hervorgerufen und limitiert durch Diffusion, intravasal detektiert werden können. Aufgrund der kurzen Dauer der hypoxischen Ventilation konnten diese reaktiven Sauerstoffverbindungen nicht während der Hypoxie registriert werden, sondern erst in den normoxischen Phasen, wodurch es $\mathrm{zu}$ dem beschriebenen Anstieg der Superoxidkonzentration im Perfusat kommt. Dies könnte wiederum eine zusätzliche Erklärung für den beobachteten Druckunterschied in den Pulmonalarterien von gp91 ${ }^{\text {phox }}$ defizienten Mäusen bei Perfusion mit SOD sein. Die aus endothelialen Quellen stammenden ROS gelangen langsam, möglicherweise durch Diffusion, in das Gefäßbett der Lunge. Dort ist SOD in hoher Konzentration vorhanden und Superoxid wird schnell in $\mathrm{H}_{2} \mathrm{O}_{2}$ umgewandelt, welches dann durch die vasokonstriktive Eigenschaft $\mathrm{zu}$ dem beobachteten erhöhten PAP führt.

In Bezug auf die akute HPV wurde aufgezeigt, dass es keine Unterschiede in der Stärke der Vasokonstriktion bei den untersuchten Maustypen gibt (Tabelle 3-6). Demnach ist die Antwort auf akute alveoläre Hypoxie unabhängig von phagozytären NADP(H)-Oxidasen, was durch den Einsatz von chimären Mäusen belegt wurde. Dieses Ergebnis steht in Kontrast zu Beobachtungen anderer Arbeitsgruppen, die entweder durch den Einsatz von Inhibitoren von NADP(H)-Oxidasen (Grimminger et al., 1995b; Thompson et al., 1998; Weissmann et al., 2000), wie z.B. Diphenyliodonium (DPI), oder durch Verwendung von KO-Mäusen (Archer et al., 1999; Liu et al., 2003; Liu et al., 2006) zu gegenteiligen Erkenntnissen kamen. Liu et al. beschrieben in Experimenten mit isolierten pulmonalarteriellen Ringen, dass die Antwort auf Hypoxie ausbleibt, wenn die gp91 ${ }^{\text {phox }}$ Untereinheit von NADP(H)-Oxidasen ausgeknockt ist (Liu et al., 2005). Die Gruppe um Weißmann et al. wies eine geringere Antwort auf akute alveoläre Hypoxie in $\mathrm{p} 47^{\text {phox }}$ Knock-Out-Mäusen nach, wohingegen die Tiere mit einer Deletion der gp91 ${ }^{\text {phox }}$ Untereinheit von NADP(H)-Oxidasen keinen Unterschied zum Wildtyp zeigten (Weissmann et al., 2006d). Zwar konnte in der vorliegenden Arbeit bezüglich der Abhängigkeit der HPV von der $\mathrm{p} 47^{\text {phox }}$-Untereinheit keine klare Aussage getroffen werden, dennoch zeigte sich in diesen Tieren eine Tendenz zu einer verringerten HPV.

Weiterhin beschrieben Archer und Mitarbeiter eine verringerte ${ }^{\circ} \mathrm{O}_{2}{ }^{-}$-Produktion in gp91 ${ }^{\text {phox }}$-Knock-out-Mäusen, zeigten aber gleichzeitig, dass die vaskuläre Reaktion dieser Tiere auf alveoläre Hypoxie identisch zu der in Wildtypmäusen beobachteten ist (Archer et al., 1999). Die Diskrepanz zwischen den in dieser Arbeit gezeigten Ergebnissen und den von Weißmann et al. bzw. Archer et al. vorgelegten Daten ist wahrscheinlich auf die verwendeten Systeme zurückzuführen, denn die Beobachtungen beider Gruppen wurden in frei hängenden Lungen erzielt, wohingegen die in der vorliegenden Arbeit gezeigten Daten aus Tieren stammen, deren Lunge im geöffneten Thorax verblieb. Zudem ist auch ein Einfluss des Spin-Probes, mit dem die Lungen für diese Arbeit perfundiert wurden, nicht auszuschließen.

\subsubsection{ROS-Produktion und PAP nach chronischer Hypoxie}

Unter chronischer Hypoxie findet ein Remodeling der medialen Schicht der Blutgefäße statt, das zur Verdickung der Gefäßwand führt und dadurch den pulmonalarteriellen Druck ansteigen lässt (Jeffery and Morrell, 2002; Stenmark et al., 2006; Stenmark et al., 2002). Die in Tabelle 3-7 dargestellten Werte des pulmonalarteriellen Drucks zeigen, dass die 
untersuchten Mäuse des Wildtyps nach chronisch hypoxischer Exposition einen signifikant erhöhten Basis-PAP aufweisen, was auf das Remodeling der Gefäßwand zurückzuführen ist (Jeffery and Morrell, 2002; Liu et al., 2006). In den Mäusen, die eine Defizienz für die gp $9^{\text {phox }}$ oder $\mathrm{p} 47^{\text {phox }}-$ Untereinheit von NADP(H)-Oxidasen haben, konnte allerdings kein erhöhter PAP nach chronischer Hypoxie festgestellt werden. Liu et al. zeigten im Jahr 2006, dass gp91 ${ }^{\text {phox }}$-Knock-Out-Mäuse kein vaskuläres Remodeling haben und auch sonst keine der typischerweise auftretenden Veränderungen nach chronischer Hypoxie aufweisen. Zudem konnte die Gruppe in der gleichen Arbeit demonstrieren, dass die KOMäuse, im Gegensatz zu den Wildtypen, keine Superoxidproduktion nach chronisch hypoxischer Exposition zeigten (Liu et al., 2006). Es ist daher anzunehmen, dass NADP(H)-Oxidasen eine wichtige Funktion für die pathologische Entwicklung einer Mediahypertrophie übernehmen. Andererseits zeigten Weißmann und Mitarbeiter, dass Tiere mit einem systemischen Knock-Out von NADP(H)-Oxidase Untereinheiten nach chronischer Hypoxie einen durch vaskuläres Remodeling hervorgerufenen erhöhten PAP aufweisen (unpublizierte Daten). Die Diskrepanz zwischen diesen Daten und den in dieser Arbeit vorgestellten Ergebnissen ist höchstwahrscheinlich auf die geringe Anzahl der erfolgreich beendeten Versuche für die vorliegende Arbeit zurückzuführen, denn ein Großteil der Lungen aus gp91 ${ }^{\text {phox }}$-defizienten Mäusen, die in den Versuchen zur chronisch hypoxischen ROS-Produktion eingesetzt wurden, zeigten in der isoliert perfundierten Lunge einen immens hohen pulmonalarteriellen Druck, der innerhalb kurzer Zeit zu einer Ödembildung im Organ und damit zum Abbruch des Versuches führte. In der vorliegenden Arbeit wurde ebenfalls gezeigt, dass Mäuse mit einem Knock-Out der gp91 ${ }^{\text {phox }}$ Untereinheit von NADP(H)-Oxidasen nach chronischer Hypoxie kein Superoxid produzieren (Abbildung 3-23). Allerdings setzen auch Lungen des Wildtyps unter diesen Bedingungen kein ${ }^{\circ} \mathrm{O}_{2}^{-}$frei, was die u. a. von Liu et al. postulierte Rolle von aus NADP(H)-Oxidasen stammendem Superoxid im Remodelingprozess fraglich erscheinen lässt. Denkbar hingegen ist, dass die ROS-Freisetzung intrazellulär aus nicht-phagozytären NADP(H)-Oxidasen erfolgt, wie dies Liu et al. in zwei Veröffentlichungen zeigten (Liu et al., 2005; Liu et al., 2006). Beide Publikationen beweisen eine gp91-abhängige intrazelluläre ROS-Produktion, die in isolierten Ringen der Pulmonalarterie demonstriert wurde. Der intrazelluläre Anteil der Superoxidproduktion ist anhand des im Falle der vorliegenden Arbeit verwendeten Systems der isoliert perfundierten Lunge nicht nachweisbar, aber wie bereits unter akut hypoxischen Bedingungen festgestellt wurde, ist eine intrazelluläre ROS-Produktion durchaus möglich. So konnten Goyal et al. eine intrazelluläre NADP(H)-Oxidase Isoform charakterisieren, Nox-1, die unter Hypoxie vermehrt transkribiert wird und in erhöhtem Maß ROS produziert (Goyal et al., 2004).

Neben dem gp91 ${ }^{\text {phox }}$-Protein spielt auch die $\mathrm{p} 47^{\text {phox }}$-Untereinheit für das vaskuläre Remodeling eine große Rolle, denn Mäuse mit einem Knock-Out von $p 47^{\text {phox }}$ zeigen ebenfalls keinen erhöhten PAP nach chronischer Hypoxie (Tabelle 3-7). Da in diesen Tieren auch keine Superoxidproduktion festgestellt werden konnte (Abbildung 3-23), ist es sehr wahrscheinlich, dass ROS aus NADP(H)-Oxidasen am Remodeling beteiligt sind. Zu dieser Schlussfolgerung kommen auch andere Arbeitsgruppen, die die Funktion von NADP(H)-Oxidasen und speziell die von $\mathrm{p} 47^{\text {phox }}$ untersuchten (Castier et al., 2005; Manoury et al., 2005). Diese Untersuchungen beziehen sich zwar nicht auf ein hypoxieinduziertes Remodeling, dennoch konnten beide Studien nachweisen, dass die ROSProduktion unter den Versuchsbedingungen in $\mathrm{p} 47^{\text {phox }}$-Knock-Out Mäusen verringert ist und die Tiere kein Remodeling zeigten. Castier et al. beobachteten zudem, dass der Mechanismus nicht von der gp91 ${ }^{\text {phox }}$-Untereinheit abhängig ist, denn Tiere mit einer Defizienz von gp91 ${ }^{\text {phox }}$ zeigten dem Wildtyp vergleichbare Ergebnisse für das Stressinduzierte Remodeling (Castier et al., 2005). Andererseits könnte das vaskuläre Remodeling durchaus von NADP(H)-Oxidasen unabhängig sein, wie Weißmann et al. in 
bisher unveröffentlichten Daten zeigen. Die Ergebnisse dieser Gruppe belegen, dass p4 $7^{\text {phox }}$-Knock-Out Mäuse nach chronisch hypoxischer Exposition ein dem Wildtyp vergleichbares Remodeling aufweisen.

In $\mathrm{p} 22^{\text {phox }}$-überexprimierenden Mäusen wurde ebenfalls ein signifikant erhöhter Basis-PAP nach chronischer Hypoxie registriert (Tabelle 3-7), allerdings nur in den Lungen, die nicht mit SOD perfundiert wurden. Bei der normoxischen SOD-Perfusion stieg der PAP in den Lungen stark an, so dass sich im Vergleich zum PAP nach chronisch hypoxischer Exposition keine Signifikanz fand. Die Lungen der p22 ${ }^{\text {phox }}$-überexprimierenden Tiere zeigten unter hypoxischen Basisbedingungen Tendenzen, die auf eine Superoxidproduktion hinweisen, allerdings konnte aufgrund der kleinen Gruppengröße keine signifikante ${ }^{\circ} \mathrm{O}_{2}{ }^{-}$-Produktion festgestellt werden (Abbildung 3-23). Erst nach der Stimulation von NADP $(\mathrm{H})$-Oxidasen durch PMA ergab sich in Lungen diesen Maustyps eine signifikante ${ }^{\circ} \mathrm{O}_{2}{ }^{-}$-Freisetzung. Zudem konnte nur in diesen Lungen nach PMAStimulation eine ROS-Produktion nachgewiesen werden, die Lungen aus Wildtypen und den Knock-Out-Mäusen zeigten nach der PMA-Gabe keine signifikante ROS-Freisetzung. Dennoch ist anzumerken, dass die Intensität der analysierten ESR-Signale nach PMAStimulation in den Wildtypen anstiegen (Abbildung 3-23). Der Anstieg der ESR-SignalIntensitäten ist wahrscheinlich auf die Bildung von Peroxynitrit zurückzuführen, das aus der Reaktion von NO mit Superoxid entsteht. ${ }^{\bullet} \mathrm{O}_{2}{ }^{-}$reagiert sehr schnell mit NO, die Umsetzung wird praktisch nur durch die Diffusion limitiert (Dikalov, 2005). Die Reaktion von Superoxid mit Superoxiddismutase verläuft dagegen langsamer und somit erklärt sich der Anstieg der Signalintensität aus einer erhöhten ${ }^{\circ} \mathrm{O}_{2}{ }^{-}$-Produktion, das aber durch eine ebenfalls erhöhte NO-Produktion schneller in ${ }^{\circ} \mathrm{ONOO}^{-}$umgewandelt wird, als es durch $\mathrm{SOD}$ in $\mathrm{H}_{2} \mathrm{O}_{2}$ umgesetzt werden kann. Weiterführende Experimente sind nötig, damit diese Theorie bestätigt werden kann. Aus der Literatur sind bislang sehr widersprüchliche Ergebnisse bezüglich der NO-Freisetzung in Hypoxie zu erhalten. So wiesen Grimminger et al. an der isoliert perfundierten Kaninchenlunge eine verminderte NO-Konzentration im Exhalat nach, wohingegen sich die Konzentration von NO und NO-Verbindungen im Perfusat nicht veränderte (Grimminger et al., 1995a). Archer und Mitarbeiter zeigten in einer Studie, die allerdings nicht an Lungen oder Lungengewebe durchgeführt wurde, dass die Expression von iNOS nicht durch Hypoxie beeinflusst wird, es aber durch Hypoxie zu einer vermehrten Bildung von Peroxynitrit kommt (Archer et al., 1995). In pulmonalarteriellen Endothelzellen beschrieben Hampl und Mitarbeiter eine vermehrte NO-Produktion bei akuter Hypoxie, die durch Stimulation mit Bradykinin weiter erhöht werden kann (Hampl et al., 1995). Ebenso beschrieben Yamamoto et al. einen Anstieg der NO-Produktion in Glomuszellen, die aus dem Carotidenkörper isoliert wurden (Yamamoto et al., 2006).

\subsubsection{Phorbol-Myristat-Acetat stimulierte ROS-Produktion und PAP}

Durch PMA-Stimulation werden in lebenden Zellen Proteinkinasen des Typs C $\alpha$ und C $\delta$ aktiviert, welche die Untereinheiten $\mathrm{p} 47^{\text {phox }}$ und $\mathrm{p} 67^{\text {phox }}$ des NADP(H)-Oxidase Komplexes phosphorylieren (Babior, 2004; Lassegue and Clempus, 2003). Durch diesen Prozess wird die Zusammenlagerung der verschiedenen Proteine induziert und es bildet sich die funktionelle NADP $(\mathrm{H})$-Oxidase, welche hauptverantwortlich für den oxidativen Burst aus neutrophilen Granulozyten ist und die entscheidende Reaktion für die Abwehr invasiver Pathogene darstellt. NADP(H)-Oxidasen kommen aber nicht nur in phagozytierenden Zellen vor, sondern werden als Homologe auch in nicht-phagozytierenden Zellen exprimiert (Bengtsson et al., 2003; Sumimoto et al., 2005). Diese Zellen, z. B. glatte 
Muskelzellen, Endothelzellen oder Fibroblasten, produzieren überwiegend intrazelluläre ROS, die wahrscheinlich in Regulationsprozesse in der Zelle und im Zellverband involviert sind (Gamaley and Klyubin, 1999; Laloi et al., 2004; Lee et al., 2003; Sauer et al., 2001).

In Mäusen des Wildtyps und in $\mathrm{p} 22^{\text {phox }}$-überexprimierenden Tieren wurde gezeigt, dass die Stimulation von NADP(H)-Oxidasen mit PMA $\mathrm{zu}$ einem rapiden Anstieg des pulmonalarteriellen Druckes führt und der Druckanstieg mit einer erhöhten ROSProduktion und Freisetzung einhergeht (Abbildung 3-2, Abbildung 3-5, Abbildung 3-19). Aber auch in Mäusen, die durch genetische Veränderung keine funktionelle phagozytäre NADP(H)-Oxidase exprimierten, wurde durch die PMA-Gabe ein Anstieg des PAP erzielt, ohne dass dabei ROS freigesetzt wurden. Durch die Experimente mit chimären Mäusen konnte bewiesen werden, dass die normoxische ROS-Produktion aus phagozytären Zellen erfolgt und nicht-phagozytäre NADP(H)-Oxidasen anscheinend nicht beteiligt sind (Abbildung 3-20). Trotzdem ist denkbar, dass nicht-phagozytäre NADP(H)-Oxidasen erstens intrazellulär ROS produzieren oder zweitens ROS nicht nach intravasal, sondern in Richtung der Gefäßmedia freisetzen und diese Population dann zur Konstriktion der Gefäße beitragen. In den Tieren mit defizienten NADP(H)-Oxidase Untereinheiten könnte deren Funktion durch Isoformen, wie Nox-3, Nox-4 oder NoxO-1, übernommen werden. $\mathrm{Zu}$ beachten ist zudem, dass sich Granulozyten direkt in der Blutbahn befinden und stark an den Gefäßwänden adhärieren, also in der isoliert perfundierten Lunge nur schwer auszuwaschen sind. Durch die Stimulation mit PMA, welches direkt in das rezirkulierende Perfusionsmedium gegeben wurde, werden die NADP(H)-Oxidasen von Granulozyten aktiviert und die ROS-Produktion induziert. Im zeitlichen Verlauf ist diese Reaktion aufgrund der exponierten Lage der phagozytierenden Zellen früher als die intrazelluläre Antwort nicht-phagozytärer NADP(H)-Oxidasen auf den Stimulus zu erkennen. Für diese Theorie spricht außerdem, dass durch die Zugabe von SOD zwar die PMA-induzierte Superoxidproduktion quantifiziert werden kann, dies aber keine Auswirkungen auf die ausgelöste Vasokonstriktion hat.

\subsubsection{Entkopplung endothelialer NO-Synthasen}

Neben NADP(H)-Oxidasen, dem Xanthin-Oxidase-System und Mitochondrien können ROS auch aus endothelialen NO-Synthasen (eNOS) entstehen. Die endotheliale Produktion von NO, dem potentesten Vasorelaxans, ist die Hauptkomponente in der Regulation des vaskulären Tonus und wenn die Bioverfügbarkeit von NO sinkt, wird die endothelabhängige Vasorelaxation eingeschränkt. Die NO-Produktion kann dabei auf verschiedene Weise beeinflusst werden. Zum einen durch Regulation der Expression von eNOS und zum anderen durch Degradierung von benötigtem Substrat oder wichtigen Kofaktoren. Die NO-Produktion erfolgt durch Oxidation aus L-Arginin und involviert die Reduktion molekularen Sauerstoffs. Steht die Aminosäure nicht in ausreichendem Maß zur Verfügung, z. B. durch die erhöhte Degradierung durch das Enzym Arginase, wird die eNOS „entkoppelt“ und es entsteht Superoxid. Neben diesem Prozess spielt auch Tetrahydrobiopterin $\left(\mathrm{BH}_{4}\right)$ als Kofaktor eine wichtige Rolle bei der NO-Produktion, denn er koppelt die Reduktion des Sauerstoffs an die Oxidation des L-Arginins. Fehlt der Kofaktor, wird die eNOS gleichfalls entkoppelt. $\mathrm{BH}_{4}$ wird zudem durch Oxidation degradiert, so dass eine erhöhte ROS-Produktion aus NADP $(\mathrm{H})$-Oxidasen zu verminderten $\mathrm{BH}_{4}$-Konzentrationen führt und somit wiederum weniger $\mathrm{NO}$ produziert wird, was sich schlussendlich negativ auf die endothelabhängige Vasorelaxation auswirkt (Kuzkaya et al., 2003; Landmesser et al., 2003). 
Neben den genannten Mechanismen, die die Produktion von NO beschreiben, wird dessen Verfügbarkeit auch direkt von ROS beeinflusst. Durch die Reaktion von Superoxid mit NO bildet sich ${ }^{\circ} \mathrm{ONOO}^{-}$und die Konzentration von NO sinkt. Diese Reaktion wird nicht von SOD beeinflusst, da die Umsetzung von Superoxid zu $\mathrm{H}_{2} \mathrm{O}_{2}$ durch SOD langsamer verläuft als die Interaktion von ${ }^{\circ} \mathrm{O}_{2}{ }^{-}$mit NO (Dikalov et al., 1997d). Ein denkbares Szenario wäre also, dass es unter Hypoxie zu einer vermehrten ROS-Produktion kommt, die zur Vasokonstriktion führt. Gleichzeitig wird als Gegenregulation durch endotheliale NOS vermehrt NO gebildet. Die ROS-Freisetzung würde dann zum einen durch die Oxidierung von $\mathrm{BH}_{4}$ zur Entkopplung von eNOS führen und so die ROS-Konzentration weiter erhöhen. Gleichzeitig würde das vorhandene NO durch Interaktion mit Superoxid zu Peroxynitrit umgewandelt werden und wäre so nicht mehr vasoaktiv. Infolge dieser Vorgänge käme es zu einer verstärkten Vasokonstriktion.

\subsection{Ausblick}

Die Produktion von ROS ist auch für andere pathophysiologische pulmonale Veränderungen von Bedeutung. Bei chronisch obstruktiven Lungenerkrankungen (engl.: chronic obstructive pulmonary disease, COPD) spielt eine erhöhte ROS-Freisetzung eine Rolle, ebenso bei Schäden, die nach Ischämie und Reperfusion (I/R) auftreten.

\subsubsection{ROS-Produktion in chronisch obstruktiven Lungenerkrankungen}

COPD ist eine Krankheit, deren Entstehung auf die Inhalation von Partikeln zurückgeführt wird. Als eine der Hauptursachen für die Erkrankung wird Zigarettenrauch diskutiert, aber auch zivilisatorische Umwelteinflüsse, wie Dieselpartikel oder Stäube, können bei der Entwicklung der Krankheit eine wesentliche Rolle spielen. Das Anfangsstadium von COPD ist durch eine chronische Inflammation der Atemwege charakterisiert, hervorgerufen durch die dauerhafte Exposition mit schädlichen Partikeln. Zudem wird das Flimmerepithel der Lunge durch den irreversiblen Verlust der Zilien bleibend geschädigt, so dass der in der Lunge produzierte Schleim, in dem Fremdpartikel gebunden werden, nicht mehr abtransportiert werden kann. Weiterhin kommt es zu einer Metaplasie von Becherzellen, die vermehrt Schleim sezernieren. In den Atemwegen von COPD-Patienten bilden sich Schleimpfropfen, die den pulmonalen Gasaustausch stören und durch die Inflammation werden die Bronchien durch zähflüssigen Schleim verklebt, was den Gasaustausch zusätzlich erschwert (Hogg, 2001). Im weiteren Krankheitsverlauf kommt es zur Bildung von Emphysemen, die durch den Verlust von Alveolen und einer dadurch hervorgerufenen Erweiterung des pulmonalen Luftraums gekennzeichnet sind, was gleichbedeutend mit der Einbusse von respiratorisch aktivem Epithel ist (Hogg, 2001).

Das Anfangsstadium dieser Erkrankung ist, wie bereits erwähnt, eine durch Partikel hervorgerufene chronische Entzündung der Atemwege. Inflammationen sind klassisch durch den Einstrom von neutrophilen Granulozyten charakterisiert, die zum einen proinflammatorische Mediatoren freisetzen und zum anderen durch die Produktion von ROS die Entzündung eindämmen (Kinnula, 2005; Rahman and Adcock, 2006). Viele Arbeitsgruppen untersuchen aktuell die zugrunde liegenden Mechanismen, welche die Entwicklung von COPD und Emphysemen beeinflussen, allgemein wird aber davon ausgegangen, dass eine erhöhte ROS-Freisetzung durch Neutrophile zur Zerstörung der Lungenarchitektur führt (Bowler et al., 2004; Orosz et al., 2007; Wang et al., 2003). 


\subsubsection{ROS-Produktion nach Ischämie und Reperfusion (I/R)}

Verletzungen nach Ischämie-Reperfusion (I/R) sind eine der wichtigsten Komplikationen nach Lungentransplantationen oder kardiopulmonalen Bypassoperationen. Sie sind charakterisiert durch unspezifische Schäden der Alveolen, Ödembildung in der Lunge und Verringerung des Sauerstoffgehaltes im Blut (Hypoxämie) innerhalb 72 Stunden nach erfolgter Organtransplantation (de Perro et al., 2003). Obwohl speziell die Vorversorgung zu transplantierender Organe in den letzten Jahren stark verbessert wurde, bleiben Schäden durch I/R eine der Hauptursachen für die hohe Sterblichkeit nach Transplantationen. Zudem wurden Schädigungen durch $\mathrm{I} / \mathrm{R}$ als Quelle früher Abstoßung transplantierter Organe identifiziert. Wird ein Organ ischämisch, d. h. es wird nicht mit Blut versorgt, erhöht sich der ATP-Verbrauch in den Mitochondrien, einhergehend mit einer Veränderung der Zellmembranpermeabilität, Änderungen der intrazellulären Osmolarität, Schädigung der Mitochondrien und des Zytoskeletts bis hin zu Apoptose von Zellen und Nekrose des Organs. Beginnende Reperfusion verschlimmert den Schädigungszustand, was auf die Interaktion von Neutrophilen und nicht-funktionalen Endothelzellen zurückzuführen ist. Zudem steigt die Produktion an freien Radikalen in den geschädigten Organbereichen, inflammatorische Zellen wandern in diese Bereiche ein und das Koagulationssystem wird aktiviert (de Perro et al., 2003).

Eine intrazelluläre ROS-Produktion konnte in fast allen Lungenparenchymzellen nachgewiesen werden, wie z. B. in Endothelzellen, Alveolarepithelzellen des Typs II, Clarazellen und ziliären Epithelzellen der Atemwege, aber auch in alveolären Makrophagen. Verantwortlich für die ROS-Produktion in den genannten Zelltypen sind zwei Mechanismen. Der erste beruht auf dem Xanthinoxidase-System, das unter Anoxie aktiviert wird und nach Reoxygenierung durch Umwandlung von Hypoxanthin Superoxid produziert. Der andere Mechanismus beruht auf NADP(H)-Oxidasen, die v. a. in den Zellmembranen von Neutrophilen und Monozyten vorkommen und die Reduktion von Sauerstoff zu Wasserstoffperoxid und Superoxid katalysieren. Bisher wurde gezeigt, dass Tiere mit fehlender gp91 ${ }^{\text {phox }}$-Untereinheit keine Schädigungen nach $\mathrm{I} / \mathrm{R}$ der betroffenen Organe aufweisen (Bell et al., 2005), ein Indikator für die besondere Aufgabe dieser Untereinheit bei der ROS-Produktion.

Die aktuelle Forschung geht momentan davon aus, dass sowohl zu Beginn der ischämischen Phase, also in der Phase, in der z. B. ein zu transplantierendes Organ nicht durchblutet wird, als auch zu Beginn der Reperfusion, d. h. wenn das transplantierte Organ wieder an den Blutkreislauf angebunden ist, ein rapider Anstieg der Radikalproduktion erfolgt (Andresen et al., 2006). Diese hohe, zumeist intrazelluläre Produktion reaktiver Sauerstoffspezies wird als einer der Hauptgründe für die I/R-Schädigungen von Organen angesehen.

\subsection{Fazit}

Ziele dieser Arbeit waren, zum einen die Freisetzung von reaktiven Sauerstoffspezies unter akut und chronisch hypoxischen Bedingungen zu analysieren und zum anderen die Rolle, die diesen Molekülen bei der akut hypoxischen pulmonalen Vasokonstriktion sowie der Entwicklung von pulmonaler Hypertonie zukommt, zu charakterisieren. Als Quellen der hypoxischen Radikalproduktion wurden NADP(H)-Oxidasen phagozytären und nichtphagozytären Ursprungs angenommen und die Radikalfreisetzung in isoliert perfundierten und ventilierten Mauslungen durch Einsatz von ESR-Spektroskopie untersucht. 
Mit der vorliegenden Arbeit wurde erstmals gezeigt, dass die Produktion und Freisetzung von reaktiven Sauerstoffspezies im intakten Organ durch Einsatz der ESR-Spektroskopie ohne Zusatz von Redox-Farbstoffen nachgewiesen und durch Zugabe von SOD quantifiziert werden kann.

Weiterhin wurde nachgewiesen, dass isoliert perfundierte Mauslungen bereits bei normoxischer Ventilation ROS nach intravasal freisetzen. Unter Verwendung von chimären Mäusen, welche nach einer Knochenmarkstransplantation entweder intakte $\mathrm{NADP}(\mathrm{H})$-Oxidasen in phagozytären Zellen oder in Endothelzellen exprimierten, konnte diese normoxische Produktion von reaktiven Sauerstoffspezies phagozytären Zellen zugeordnet werden. In transgenen Mäusen, die Knock-Outs der NADP(H)-Oxidase Untereinheiten gp9 $1^{\text {phox }}$ oder $\mathrm{p} 47^{\text {phox }}$ hatten, wurden keine ROS detektiert. Dies weist auf die essentielle Rolle dieser Proteine für die Funktion der NADP(H)-Oxidasen hin. In Mäusen, welche die $\mathrm{p} 22^{\text {phox }}$-Untereinheit von NADP(H)-Oxidasen überexprimieren, wurde unter Normoxie eine erhöhte ROS-Freisetzung nach intravasal gemessen. Auf den pulmonalarteriellen Druck hat die registrierte Produktion von ROS allerdings keinen Einfluss, da in allen untersuchten Mäusen vergleichbare Werte für den PAP gemessen wurden. Auch die durch PMA induzierte Vasokonstriktion, die in Tieren mit funktionalen phagozytären NADP(H)-Oxidasen mit einem Anstieg der ROS-Freisetzung verbunden war, zeigte keinen Unterschied in ihrer Ausprägung im Vergleich zu den Mäusen, die eine Defizienz für bestimme NADP(H)-Oxidase Untereinheiten hatten. Dies erklärt sich wahrscheinlich durch andere ROS-produzierende Systeme, wie z. B. nicht-phagozytäre NADP(H)-Oxidasen, die ROS in Richtung der Gefäßmedia abgeben oder durch Isoformen, die die fehlenden Nox-Proteine substituieren.

In akuter Hypoxie setzten Mauslungen des Wildtyps und aus p22 $2^{\text {phox }}$-überexprimierenden Tieren ROS nach intravasal frei. Unter diesen Bedingungen konnte ebenfalls eine Superoxidproduktion in $\mathrm{p} 47^{\text {phox }}$-defizienten Lungen nachgewiesen werden, Lungen aus gp91 ${ }^{\text {phox }}$-defizienten Mäusen setzten jedoch keine ROS frei. Dieses Ergebnis belegt, dass die ROS-Produktion unter akuter Hypoxie auf nicht-phagozytäre NADP(H)-Oxidasen zurückzuführen ist. Zudem kann aus Experimenten mit chimären Mäusen geschlossen werden, dass die Freisetzung reaktiver Sauerstoffspezies unter akut hypoxischen Ventilationsverhältnissen in Richtung der Gefäßmedia erfolgt und erst nach einiger Zeit das intravaskuläre Kompartiment erreicht, in dem es aufgrund des Versuchsaufbaus detektiert werden kann. Unter normoxischen Basisbedingungen ist diese ROS-Freisetzung durch die Superoxidproduktion phagozytärer NADP(H)-Oxidasen maskiert. Dieser Schluss wird auch durch den Verlauf des pulmonalarteriellen Druckes gestützt, da in allen untersuchten Lungen eine signifikante Steigerung des PAP in den Phasen akut hypoxischer Ventilation zu beobachten war.

Nach chronisch hypoxischer Exposition der Mäuse konnte lediglich in p22 $2^{\text {phox }}$ überexprimierenden Tieren eine Tendenz zur ROS-Produktion festgestellt werden, die sich allerdings erst nach Stimulation mit PMA in signifikantem Maß manifestierte. In den anderen Versuchsgruppen konnte keine ROS-Freisetzung nachgewiesen werden. Auch die für den PAP erhobenen Daten zeigten, dass die untersuchten Knock-Out Tiere keine pulmonale Hypertonie entwickeln, wobei dieses Ergebnis auf kleinen Versuchsgruppen mit wenigen Tieren basiert, so dass weitere Arbeiten notwendig sind, um diese Beobachtung zu erklären. Auch in der Literatur wird die Ausbildung von pulmonaler Hypertonie v. a. in gp91 ${ }^{\text {phox }}$-defizienten Tieren kontrovers diskutiert.

Schlussendlich konnte auch mit dieser Arbeit die Rolle von ROS für die akut hypoxische Vasokonstriktion und die Ausbildung von pulmonaler Hypertonie nicht vollständig geklärt werden. Dennoch zeigte die Untersuchung, dass phagozytäre NADP(H)-Oxidasen für die normoxische Superoxidproduktion in Mauslungen verantwortlich sind und es in akuter 
Hypoxie zur Aktivierung nicht-phagozytärer NADP(H)-Oxidasen kommt. Damit klärt sich ebenfalls die Frage, ob NADP(H)-Oxidasen unter hypoxischen Bedingungen ROS produzieren können, denn Lungen des Wildtyps, also mit funktionellen NADP(H)Oxidasen, setzten unter akuter Hypoxie Superoxid frei. Erst nachdem eine für die Funktion des NADP(H)-konvertierenden Proteinkomplexes essentielle Untereinheit durch genetische Modifikation ausgeschaltet war, konnte kein ROS mehr detektiert werden. 


\section{Zusammenfassung}

Unter hypoxischen Bedingungen kommt es in der Lunge zu (patho-)physiologischen Veränderungen der pulmonalen Strombahn. Bei akuter alveolärer Hypoxie kontrahieren präkapilläre Gefäße in diesen Regionen, so dass Blut in gut ventilierte Areale der Lunge geleitet wird. Dieser als hypoxische pulmonale Vasokonstriktion (HPV) bezeichnete Mechanismus ist essentiell für die Optimierung des pulmonalen Gasaustausches und verhindert ein Ungleichgewicht zwischen Ventilation und Perfusion. Verlängert sich die hypoxische Exposition und wird zu einem chronischen Zustand, entwickelt sich pulmonale Hypertonie, eine schwere, lebensbedrohliche Krankheit. Sie ist durch den deutlich und dauerhaft erhöhten pulmonalarteriellen Druck charakterisiert, der durch strukturelle Veränderungen der Gefäßwand, dem sog. Remodeling, hervorgerufen wird. Grundlage des Remodelings sind Proliferation und Migration von glatten Muskelzellen und Fibroblasten in der Gefäßmedia, wodurch sich diese Schicht der Gefäßwand verdickt und der Innendurchmesser der Strombahn verengt wird. Dadurch erhöht sich der Widerstand der pulmonalen Gefäße, so dass das Herz erhöhte Arbeit leisten muss und infolge dessen sich eine Hypertrophie des rechten Ventrikels und letztendlich eine Herzinsuffizienz ausbildet.

Reaktive Sauerstoffspezies (ROS) werden von mehreren Arbeitsgruppen als intra- und extrazelluläre Mediatoren für die Veränderungen des pulmonalen Blutflusses angenommen. Als ROS-produzierende Systeme werden verschiedene Enzymsysteme, wie z. B. Xanthin-Oxidasen oder NADP(H)-Oxidasen, als auch Zellorganelle wie Mitochondrien diskutiert. Strittig ist die Frage, ob es unter Hypoxie zu einer vermehrten oder verminderten ROS-Freisetzung kommt. Für diese Arbeit wurden NADP(H)-Oxidasen phagozytären und nicht-phagozytären Ursprungs als Quelle einer erhöhten hypoxischen ROS-Produktion untersucht.

Die Untersuchung erfolgte in isoliert perfundierten und ventilierten Lungen von Wildtypund transgenen Mäusen, die defizient für die gp91 ${ }^{\text {phox }}$ oder $\mathrm{p} 47^{\text {phox }}$-Untereinheit von NADP $(\mathrm{H})$-Oxidasen waren oder die p22 ${ }^{\text {phox }}$-Untereinheit überexprimierten. Zudem wurden durch Knochenmarkstransplantation chimäre Mäuse generiert, um zwischen der ROSFreisetzung aus phagozytären und nicht-phagozytären NADP(H)-Oxidasen differenzieren zu können. Die ROS-Produktion in Normoxie, akuter Hypoxie und nach chronisch hypoxischer Exposition (21 Tage, $\mathrm{FiO}_{2}=0.10$ ) wurde im intakten Organ mit Elektronenspinresonanz Spektroskopie gemessen und in separaten Experimenten durch Zugabe von Superoxiddismutase quantifiziert. NADP(H)-Oxidasen wurden durch die Zugabe von Phorbol-Myristat-Acetat stimuliert. Neben der ROS-Freisetzung wurde in den Versuchen ebenfalls der pulmonalarterielle Druck aufgezeichnet, so dass die Vasokonstriktion als Antwort auf akute Hypoxie oder ein durch Remodeling nach chronisch hypoxischer Exposition erhöhter PAP direkt mit der ROS-Freisetzung korreliert werden konnte.

Diese Arbeit zeigt, dass Mauslungen aus Wildtypen bereits unter normoxischen Basisbedingungen reaktive Sauerstoffspezies produzieren und nach intravasal abgeben. Den Haupanteil der nachgewiesenen ROS bildet das Superoxid-Anion, das durch die Perfusion mit Superoxiddismutase quantifiziert werden konnte. Nach PMA-Stimulation erhöhte sich die ${ }^{\bullet} \mathrm{O}_{2}{ }^{-}$-Freisetzung. Die aufgezeigte normoxische Superoxidproduktion ist maßgeblich von den NADP(H)-Oxidase Untereinheiten gp9 ${ }^{\text {phox }}$ und $\mathrm{p} 47^{\text {phox }}$ abhängig, da in Tieren mit einer Defizienz für eine dieser Untereinheiten weder unter Basisbedingungen noch nach PMA-Stimulation eine ROS-Produktion nachgewiesen werden konnte. Überexpression der $\mathrm{p} 22^{\text {phox }}$-Untereinheit führte $\mathrm{zu}$ einer erhöhten basalen und PMAstimulierten Radikalproduktion. Durch Experimente mit chimären Mäusen konnte die Superoxidproduktion eindeutig phagozytären NADP $(\mathrm{H})$-Oxidasen zugeordnet werden. Der 
PAP wird durch das Fehlen der normoxischen phagozytären ROS-Produktion nicht beeinflusst, ebenso wie der durch PMA induzierte Anstieg des pulmonalarteriellen Druckes. Diese Beobachtung erklärt sich wahrscheinlich durch das Vorhandensein einer intrazellulären, nicht-phagozytären superoxidbildenden NADP(H)-Oxidase. Da in dem verwendeten Untersuchungssystem die intrazelluläre ROS-Produktion nicht nachvollzogen werden konnte, ist dieser Mechanismus durchaus denkbar.

In Phasen akut hypoxischer Ventilation setzten Lungen aus Wildtypen und $\mathrm{p} 22^{\text {phox }}$ überexprimierenden Mäusen Superoxid nach intravasal frei. Auch in den Mauslungen mit einer Defizienz für die p47 $7^{\text {phox }}$-Untereinheit von NADP(H)-Oxidasen wurde während den hypoxisch ventilierten Phasen eine signifikant erhöhte ${ }^{\circ} \mathrm{O}_{2}{ }^{-}$-Produktion detektiert, wohingegen Mäuse mit einem Knock-Out der gp91 ${ }^{\text {phox }}$-Untereinheit keine ROSProduktion zeigten. Der beobachtete Trend zur ROS-Freisetzung während der normoxisch ventilierten Phasen nach akuter Hypoxie in chimären Mäusen mit rekonstituierten Knochenmarkszellen aus gp91 ${ }^{\text {phox }}$-defizienten Tieren zeigt, dass bei alveolärer Hypoxie sehr wahrscheinlich nicht-phagozytäre NADP(H)-Oxidasen Superoxid freisetzen. Diese Freisetzung wird in den Lungen der Wildtypen und $\mathrm{p} 22^{\text {phox }}$-überexprimierenden Tiere durch die ROS-Produktion aus phagozytären NADP(H)-Oxidasen maskiert. Diese Annahme wird zudem durch den Verlauf des pulmonalarteriellen Druckes gestützt, der bei allen untersuchten Tieren eine signifikante HPV als Antwort auf alveoläre Hypoxie zeigte.

Nach chronisch hypoxischer Exposition der Versuchstiere setzten die Lungen kein Superoxid frei. Lediglich p22 ${ }^{\text {phox }}$-überexprimierende Mäuse zeigten unter Basalbedingungen eine Tendenz und nach PMA-Stimulation eine signifikant erhöhte ROSProduktion. Um die ${ }^{\bullet} \mathrm{O}_{2}{ }^{-}$-Freisetzung nach chronischer Hypoxie zu charakterisieren sind weitere Experimente notwendig, gleiches gilt für die Untersuchung des vaskulären Remodelings, v. a. in Bezug auf die in den Versuchen eingesetzten Knock-Out Mäuse. Um die Superoxidfreisetzung während und nach chronisch hypoxischer Exposition nachzuweisen, wäre ein in vivo Ansatz denkbar, bei dem Spin-Probes systemisch oder intratracheal appliziert werden und dann über die gesamte Expositionsdauer im Tier verbleiben. Dieser Ansatz war für die vorliegende Arbeit allerdings nur schwer durchführbar, da die zu dieser Zeit erhältlichen Spin-Traps aufgrund der hohen Toxizität und Unverträglichkeit nicht in einem lebenden Tier einzusetzen waren. 


\section{Abstract}

Hypoxia induces (patho)physiological changes in the lung. Physiological matching of perfusion to ventilation occurs in acute hypoxia by constriction of precapillary vessels. Pathophysiological changes result in media hypertrophy (remodeling) by proliferation and migration of smooth muscle cells and fibroblasts driven by chronic hypoxia. For both processes, reactive oxygen species (ROS) are thought to play a pivotal role as signalling molecules. The aim of this study was to elucidate the role of ROS under acute and chronic hypoxia and non-phagocytic NADPH-oxidases (NOX) as possible source of lung superoxide $\left({ }^{\bullet} \mathrm{O}_{2}^{-}\right)$release.

We investigated ${ }^{\bullet} \mathrm{O}_{2}{ }^{-}$release in isolated perfused and ventilated mouse lungs using electron spin resonance spectroscopy with the spin probe hydroxy-carboxy-tetramethylpyrrolidine. Specificity for ${ }^{\circ} \mathrm{O}_{2}^{-}$was assured in parallel experiments in the presence of superoxide dismutase. NOX were activated by phorbol-myristate-acetate. The impact of chronic hypoxia on ROS production in mouse lungs was investigated in mice kept for 21 days under hypoxia $\left(\mathrm{FiO}_{2}=0.10\right)$. We also investigated ${ }^{\circ} \mathrm{O}_{2}{ }^{-}$- release in mice lacking the $\mathrm{p} 47$ or gp91 or overexpressing the p22 subunit of NOX. The source of ${ }^{\circ} \mathrm{O}_{2}{ }^{-}$was identified in chimeric mice.

Normoxically ventilated mouse lungs released ${ }^{\circ} \mathrm{O}_{2}{ }^{-}$under baseline conditions into the intravascular compartment. Mice show no ${ }^{\bullet} \mathrm{O}_{2}{ }^{-}$-release under baseline conditions after chronic hypoxia. Depletion of the p47 or gp91 subunit of NOX decreases ${ }^{\bullet} \mathrm{O}_{2}{ }^{-}$-release, but overexpression of the $\mathrm{p} 22$ subunit increases ${ }^{\circ} \mathrm{O}_{2}{ }^{-}$production in mouse lungs.

Mouse lungs release ${ }^{\bullet} \mathrm{O}_{2}^{-}$under normoxic conditions. This release is only partially dependent on the p47, but highly dependent on gp91 and p22 subunit of NADP(H)oxidases. Trials with chimeras specify leukocytes being the primary source of normoxic $\mathrm{O}_{2}{ }^{-}$-production. 


\section{Anhang}

\subsection{Eidesstattliche Erklärung}

Hiermit erkläre ich, dass diese Doktorarbeit selbständig verfasst wurde und von mir keine anderen als die angegebenen Quellen und Hilfsmittel verwendet wurden.

Ort, Datum

Rolf Schäfer 


\subsection{Danksagung}

Mein Dank gilt:

Prof. Dr. med. Werner Seeger: Für die freundliche Aufnahme in das Lungenzentrum der Universität Gießen (University of Giessen Lung Center, UGLC), die Bereitstellung der Labors und der technischen Ausstattung.

Prof. Dr. rer. nat. Wolfgang Clauss: Für die freundliche und unkomplizierte Betreuung der Arbeit im Fachbereich 08 - Biologie und Chemie - der Justus-Liebig-Universität Gießen.

Prof. Dr. rer. nat. Norbert Weißmann: Für die Überlassung des bearbeiteten Themas, die exzellente, kompetente Betreuung, das allzeit „offene Ohr“, Kritik, Anregung und Unterstützung. Vielen Dank für das offene und freundschaftliche Arbeitsverhältnis!

Prof. Dr. med. Hossein Ardeschir Ghofrani und Prof. Dr. rer. nat. Ralph Schermuly: Für Betreuung, Kritik, Anregung und das kollegiale Arbeitsverhältnis.

Dr. rer. nat. Markus Roth: Für Gespräche, Anregung und Ideen, das offene und freundschaftliche Verhältnis und die gute Arbeitsatmosphäre.

Dr. med. Oliver Eickelberg: Für Kritik, Anregung und aufgeregte/aufregende Diskussionen sowie die Lehre(n) im Rahmen des MBML.

Rory Edward Morty, PhD: Für die zeitintensiven Klausurvorbereitungen und Diskussionen, Gespräche und das offene, freundschaftliche Verhältnis.

Dr. Steven M. Holland and Dr. Li Ding, Laboratory of Clinical Infectious Diseases, NIH, Bethesda, MD: Für die Bereiststellung der p47 ${ }^{\text {phox }}$-Knock-Out Mäuse

Dr. David G. Harrison, Emory University, School of Medicine, Atlanta, GA: Für die Bereitstellung der $\mathrm{p} 22^{\text {phox }}$-überexprimierenden Mäuse

„Meinen Labormädels“:

Karin Quanz: Für die exzellente Einarbeitung, Hilfe, Betreuung, Kritik und Anregung sowie das überaus freundschaftliche Verhältnis, die sehr gute Zusammenarbeit und sehr angenehme Arbeitsatmosphäre.

Anke Voigt: Für Hilfe, das sehr freundschaftliche Verhältnis und die sehr gute Zusammenarbeit und angenehme Arbeitsatmosphäre.

Ingrid Breitenborn-Müller: Für Fragen, Antworten und Zuhören sowie das freundschaftliche Verhältnis, die sehr gute Zusammenarbeit und sehr angenehme Arbeitsatmosphäre.

Monika Kreutzer: Für Abwechslung, Pausen, Kaffee und „Dampf ablassen“, das freundschaftliche und freundliche Verhältnis und die angenehme Atmosphäre.

Allen Doktoranden, Diplomanden und technischen Mitarbeitern der Labors Seeger/Grimminger: Für Hilfe und die angenehme Arbeitsatmosphäre

Dem MBML-Jahrgang 2005

Nicht zuletzt bedanke ich mich bei meiner Familie, die mir immer mit Rat und Tat zur Seite stand und mir Kraft und Zuversicht gab. Besonderer Dank gilt meiner Mutter für das Vertrauen in mich und die finanzielle Unterstützung während meines Studiums.

Weiterhin möchte ich mich bei Tatjana Duch für die umfassende Hilfe und die starken Nerven bedanken. Ferner bedanke ich mich bei Martin Köstler, Patrick Schäfer und Oliver Schmidt für die Ratschläge, Hilfestellungen und Ablenkung zwischendurch. 


\section{Literaturverzeichnis}

Aaronson, P. I., 2006, Hypoxic pulmonary vasoconstriction is/is not mediated by increased production of reactive oxygen species, $J$ Appl Physiol 101(3):1000; author reply 1004-5.

Aaronson, P. I., Robertson, T. P., Knock, G. A., Becker, S., Lewis, T. H., Snetkov, V., and Ward, J. P., 2006, Hypoxic pulmonary vasoconstriction: mechanisms and controversies, J Physiol 570(Pt 1):53-8.

Acker, T., Fandrey, J., and Acker, H., 2006, The good, the bad and the ugly in oxygensensing: ROS, cytochromes and prolyl-hydroxylases, Cardiovasc Res 71(2):195207.

Albert, A. P., and Large, W. A., 2006, Signal transduction pathways and gating mechanisms of native TRP-like cation channels in vascular myocytes, $\mathbf{5 7 0}(\mathrm{Pt}$ $1): 45-51$.

Andresen, H. M., Regueira, H. T., and Leighton, F., 2006, [Oxidative stress in critically ill patients.], Rev Med Chil 134(5):649-56.

Archer, S. L., and Cowan, N. J., 1991, Measurement of endothelial cytosolic calcium concentration and nitric oxide production reveals discrete mechanisms of endothelium-dependent pulmonary vasodilatation, Circ Res 68(6):1569-81.

Archer, S. L., Freude, K. A., and Shultz, P. J., 1995, Effect of graded hypoxia on the induction and function of inducible nitric oxide synthase in rat mesangial cells, Circ Res 77(1):21-8.

Archer, S. L., Huang, J., Henry, T., Peterson, D., and Weir, E. K., 1993, A redox-based O2 sensor in rat pulmonary vasculature, Circ Res 73(6):1100-12.

Archer, S. L., Michelakis, E. D., Thebaud, B., Bonnet, S., Moudgil, R., Wu, X. C., and Weir, E. K., 2006a, A central role for oxygen-sensitive K+ channels and mitochondria in the specialized oxygen-sensing system, Novartis Found Symp 272:157-71; discussion 171-5, 214-7.

Archer, S. L., Michelakis, E. D., Thebaudt, B., Bonnet, S., Moudgil, R., Wu, X. C., and Weir, E. K., 2006b, A central role for oxygen-sensitive K+ channels and mitochondria in the specialized oxygen-sensing system, Novartis Found Symp 272:157-71; discussion 171-5, 214-7.

Archer, S. L., Reeve, H. L., Michelakis, E., Puttagunta, L., Waite, R., Nelson, D. P., Dinauer, M. C., and Weir, E. K., 1999, O2 sensing is preserved in mice lacking the gp91 phox subunit of NADPH oxidase, Proc Natl Acad Sci U S A 96(14):7944-9.

Archer, S. L., Wu, X. C., Thebaud, B., Moudgil, R., Hashimoto, K., and Michelakis, E. D., 2004, O2 sensing in the human ductus arteriosus: redox-sensitive $\mathrm{K}+$ channels are regulated by mitochondria-derived hydrogen peroxide, Biol Chem 385(3-4):205-16.

Arnold, R. S., Shi, J., Murad, E., Whalen, A. M., Sun, C. Q., Polavarapu, R., Parthasarathy, S., Petros, J. A., and Lambeth, J. D., 2001, Hydrogen peroxide mediates the cell growth and transformation caused by the mitogenic oxidase Nox1, Proc Natl Acad Sci U S A 98(10):5550-5.

Atherton, N., 1993, Electron Spin Resonance, J. Wiley, New York. 
Awasthi, D., Church, D. F., Torbati, D., Carey, M. E., and Pryor, W. A., 1997, Oxidative stress following traumatic brain injury in rats, Surg Neurol 47(6):575-81; discussion 581-2.

Babior, B. M., 1999, NADPH oxidase: an update, Blood 93(5):1464-76.

Babior, B. M., 2000, The NADPH oxidase of endothelial cells, IUBMB Life 50(4-5):267-9.

Babior, B. M., 2002a, The activity of leukocyte NADPH oxidase: regulation by p47PHOX cysteine and serine residues, Antioxid Redox Signal 4(1):35-8.

Babior, B. M., 2002b, The leukocyte NADPH oxidase, Isr Med Assoc J 4(11):1023-4.

Babior, B. M., 2004, NADPH oxidase, Curr Opin Immunol 16(1):42-7.

Babior, B. M., Lambeth, J. D., and Nauseef, W., 2002, The neutrophil NADPH oxidase, Arch Biochem Biophys 397(2):342-4.

Banfi, B., Clark, R. A., Steger, K., and Krause, K. H., 2003, Two novel proteins activate superoxide generation by the NADPH oxidase NOX1, J Biol Chem 278(6):3510-3.

Banfi, B., Malgrange, B., Knisz, J., Steger, K., Dubois-Dauphin, M., and Krause, K. H., 2004, NOX3, a superoxide-generating NADPH oxidase of the inner ear, $J$ Biol Chem 279(44):46065-72.

Banfi, B., Molnar, G., Maturana, A., Steger, K., Hegedus, B., Demaurex, N., and Krause, K. H., 2001, A Ca(2+)-activated NADPH oxidase in testis, spleen, and lymph nodes, $J$ Biol Chem 276(40):37594-601.

Barbacanne, M. A., Souchard, J. P., Darblade, B., Iliou, J. P., Nepveu, F., Pipy, B., Bayard, F., and Arnal, J. F., 2000, Detection of superoxide anion released extracellularly by endothelial cells using cytochrome c reduction, ESR, fluorescence and lucigeninenhanced chemiluminescence techniques, Free Radic Biol Med 29(5):388-96.

Bartholome, B., Biekert, E., Hellmann, G., Ley, H., Weigert, W. M., and Weise, E., 1980, Ullmanns Encyklopadie der technischen Chemie, Verlag Chemie, Weinheim.

Bell, R. M., Cave, A. C., Johar, S., Hearse, D. J., Shah, A. M., and Shattock, M. J., 2005, Pivotal role of NOX-2-containing NADPH oxidase in early ischemic preconditioning, Faseb J 19(14):2037-9.

Bengtsson, S. H., Gulluyan, L. M., Dusting, G. J., and Drummond, G. R., 2003, Novel isoforms of NADPH oxidase in vascular physiology and pathophysiology, Clin Exp Pharmacol Physiol 30(11):849-54.

Berasi, S. P., Xiu, M., Yee, A. S., and Paulson, K. E., 2004, HBP1 repression of the p47phox gene: cell cycle regulation via the NADPH oxidase, Mol Cell Biol 24(7):3011-24.

Bokoch, G. M., and Knaus, U. G., 2003, NADPH oxidases: not just for leukocytes anymore!, Trends Biochem Sci 28(9):502-8.

Boldogh, I., Bacsi, A., Choudhury, B. K., Dharajiya, N., Alam, R., Hazra, T. K., Mitra, S., Goldblum, R. M., and Sur, S., 2005, ROS generated by pollen NADPH oxidase provide a signal that augments antigen-induced allergic airway inflammation, $J$ Clin Invest 115(8):2169-79.

Bonnet, S., Michelakis, E. D., Porter, C. J., Andrade-Navarro, M. A., Thebaud, B., Haromy, A., Harry, G., Moudgil, R., McMurtry, M. S., Weir, E. K., and Archer, S. L., 2006, An abnormal mitochondrial-hypoxia inducible factor-1alpha-Kv channel pathway disrupts oxygen sensing and triggers pulmonary arterial hypertension in 
fawn hooded rats: similarities to human pulmonary arterial hypertension, Circulation 113(22):2630-41.

Bowler, R. P., Barnes, P. J., and Crapo, J. D., 2004, The Role of Oxidative Stress in Chronic Obstructive Pulmonary Deisease, COPD: Journal of Chronic Obstructive Pulmonary Disease 1(2):255-277.

Bradford, J., and Dean, H., 1894, The Pulmonary Circulation, J Physiol 16:34-96.

Brar, S. S., Corbin, Z., Kennedy, T. P., Hemendinger, R., Thornton, L., Bommarius, B., Arnold, R. S., Whorton, A. R., Sturrock, A. B., Huecksteadt, T. P., Quinn, M. T., Krenitsky, K., Ardie, K. G., Lambeth, J. D., and Hoidal, J. R., 2003, NOX5 $\mathrm{NAD}(\mathrm{P}) \mathrm{H}$ oxidase regulates growth and apoptosis in DU 145 prostate cancer cells, Am J Physiol Cell Physiol 285(2):C353-69.

Brennan, L. A., Steinhorn, R. H., Wedgwood, S., Mata-Greenwood, E., Roark, E. A., Russell, J. A., and Black, S. M., 2003, Increased superoxide generation is associated with pulmonary hypertension in fetal lambs: a role for NADPH oxidase, Circ Res 92(6):683-91.

Brunelle, J. K., Bell, E. L., Quesada, N. M., Vercauteren, K., Tiranti, V., Zeviani, M., Scarpulla, R. C., and Chandel, N. S., 2005, Oxygen sensing requires mitochondrial ROS but not oxidative phosphorylation, Cell Metab 1(6):409-14.

Castier, Y., Brandes, R. P., Leseche, G., Tedgui, A., and Lehoux, S., 2005, p47phoxdependent NADPH oxidase regulates flow-induced vascular remodeling, Circ Res 97(6):533-40.

Cave, A., Grieve, D., Johar, S., Zhang, M., and Shah, A. M., 2005, NADPH oxidasederived reactive oxygen species in cardiac pathophysiology, Philos Trans $R$ Soc Lond B Biol Sci 360(1464):2327-34.

Chamseddine, A. H., and Miller, F. J., Jr., 2003, Gp91phox contributes to NADPH oxidase activity in aortic fibroblasts but not smooth muscle cells, Am J Physiol Heart Circ Physiol 285(6):H2284-9.

Chandel, N. S., McClintock, D. S., Feliciano, C. E., Wood, T. M., Melendez, J. A., Rodriguez, A. M., and Schumacker, P. T., 2000, Reactive oxygen species generated at mitochondrial complex III stabilize hypoxia-inducible factor-1alpha during hypoxia: a mechanism of O2 sensing, J Biol Chem 275(33):25130-8.

Chandel, N. S., and Schumacker, P. T., 2000, Cellular oxygen sensing by mitochondria: old questions, new insight, $J$ Appl Physiol 88(5):1880-9.

Cheng, G., Cao, Z., Xu, X., van Meir, E. G., and Lambeth, J. D., 2001, Homologs of gp91phox: cloning and tissue expression of Nox3, Nox4, and Nox5, Gene 269(12):131-40.

Cheng, G., and Lambeth, J. D., 2004, NOXO1, regulation of lipid binding, localization, and activation of Noxl by the Phox homology (PX) domain, J Biol Chem 279(6):4737-42.

Cheng, G., and Lambeth, J. D., 2005, Alternative mRNA splice forms of NOXO1: differential tissue expression and regulation of Nox1 and Nox3, Gene 356:118-26.

Cheng, G., Ritsick, D., and Lambeth, J. D., 2004, Nox3 regulation by NOXO1, p47phox, and p67phox, J Biol Chem 279(33):34250-5. 
Christman, M. F., Morgan, R. W., Jacobson, F. S., and Ames, B. N., 1985, Positive control of a regulon for defenses against oxidative stress and some heat-shock proteins in Salmonella typhimurium, Cell 41(3):753-62.

Clapham, D. E., 2003, TRP channels as cellular sensors, 426(6966):517-524.

Clapham, D. E., Runnels, L. W., and Strubing, C., 2001, The TRP ion channel family, 2(6):387-396.

Comellas, A. P., Dada, L. A., Lecuona, E., Pesce, L. M., Chandel, N. S., Quesada, N., Budinger, G. R., Strous, G. J., Ciechanover, A., and Sznajder, J. I., 2006, Hypoxiamediated degradation of $\mathrm{Na}, \mathrm{K}-\mathrm{ATPase}$ via mitochondrial reactive oxygen species and the ubiquitin-conjugating system, Circ Res 98(10):1314-22.

Commoner, B., Townsend, J., and Pake, G. E., 1954, Free radicals in biological materials, Nature 174(4432):689-91.

Cornfield, D. N., Reeve, H. L., Tolarova, S., Weir, E. K., and Archer, S., 1996, Oxygen causes fetal pulmonary vasodilation through activation of a calcium-dependent potassium channel, Proc Natl Acad Sci U S A 93(15):8089-94.

Cucoranu, I., Clempus, R., Dikalova, A., Phelan, P. J., Ariyan, S., Dikalov, S., and Sorescu, D., 2005, NAD(P)H oxidase 4 mediates transforming growth factor-beta1induced differentiation of cardiac fibroblasts into myofibroblasts, Circ Res 97(9):900-7.

Daiber, A., August, M., Baldus, S., Wendt, M., Oelze, M., Sydow, K., Kleschyov, A. L., and Munzel, T., 2004, Measurement of NAD(P)H oxidase-derived superoxide with the luminol analogue L-012, Free Radic Biol Med 36(1):101-11.

de Perro, M., Liu, M., Waddell, T. K., and Keshavjee, S., 2003, Ischemia-reperfusioninduced Lung injury, Am J Respir Crit Care Med 167:490-511.

Decoursey, T. E., and Ligeti, E., 2005, Regulation and termination of NADPH oxidase activity, Cell Mol Life Sci 62(19-20):2173-93.

Dikalov, S., 2005, Detection of Superoxide with Cyclic Hydroxylamines, in: SFRBM Virtual Free radical School, SFRBM, Austin.

Dikalov, S., Grigor'ev, I. A., Voinov, M., and Bassenge, E., 1998, Detection of superoxide radicals and peroxynitrite by 1-hydroxy-4-phosphonooxy-2,2,6,6-

tetramethylpiperidine: quantification of extracellular superoxide radicals formation, Biochem Biophys Res Commun 248(2):211-5.

Dikalov, S., Jiang, J., and Mason, R. P., 2005, Characterization of the high-resolution ESR spectra of superoxide radical adducts of 5-(diethoxyphosphoryl)-5-methyl-1pyrroline N-oxide (DEPMPO) and 5,5-dimethyl-1-pyrroline N-oxide (DMPO). Analysis of conformational exchange, Free Radic Res 39(8):825-36.

Dikalov, S., Skatchkov, M., and Bassenge, E., 1997a, Quantification of peroxynitrite, superoxide, and peroxyl radicals by a new spin trap hydroxylamine 1-hydroxy2,2,6,6-tetramethyl-4-oxo-piperidine, Biochem Biophys Res Commun 230(1):54-7.

Dikalov, S., Skatchkov, M., and Bassenge, E., 1997b, Spin Trapping of Superoxide Radicals and Peroxynitrite by 1-Hydroxy-3-carboxy-pyrrolidine and 1-Hydroxy2,2,6,6,-tetramethyl-4-oxo-piperidine and the Stability of Corresponding Nitroxyl Radicals Towards Biological Reductans, Biochem Biophys Res Commun 231:701704. 
Dikalov, S., Skatchkov, M., and Bassenge, E., 1997c, Spin trapping of superoxide radicals and peroxynitrite by 1-hydroxy-3-carboxy-pyrrolidine and 1-hydroxy-2,2,6, 6tetramethyl-4-oxo-piperidine and the stability of corresponding nitroxyl radicals towards biological reductants, Biochem Biophys Res Commun 231(3):701-4.

Dikalov, S., Skatchkov, M., Fink, B., and Bassenge, E., 1997d, Quantification of superoxide radicals and peroxynitrite in vascular cells using oxidation of sterically hindered hydroxylamines and electron spin resonance, Nitric Oxide 1(5):423-31.

Dikalov, S., Tordo, P., Motten, A., and Mason, R. P., 2003, Characterization of the high resolution ESR spectra of the methoxyl radical adducts of 5-(diethoxyphosphoryl)5-methyl-1-pyrroline N-oxide (DEPMPO), Free Radic Res 37(7):705-12.

Donko, A., Peterfi, Z., Sum, A., Leto, T., and Geiszt, M., 2005, Dual oxidases, Philos Trans R Soc Lond B Biol Sci 360(1464):2301-8.

Dudley, S. C., Jr., Hoch, N. E., McCann, L. A., Honeycutt, C., Diamandopoulos, L., Fukai, T., Harrison, D. G., Dikalov, S. I., and Langberg, J., 2005, Atrial fibrillation increases production of superoxide by the left atrium and left atrial appendage: role of the NADPH and xanthine oxidases, Circulation 112(9):1266-73.

Dumitrascu, R., Weissmann, N., Ghofrani, H. A., Dony, E., Beuerlein, K., Schmidt, H., Stasch, J. P., Gnoth, M. J., Seeger, W., Grimminger, F., and Schermuly, R. T., 2006, Activation of soluble guanylate cyclase reverses experimental pulmonary hypertension and vascular remodeling, Circulation 113(2):286-95.

El-Benna, J., Dang, P. M., Gougerot-Pocidalo, M. A., and Elbim, C., 2005, Phagocyte NADPH oxidase: a multicomponent enzyme essential for host defenses, Arch Immunol Ther Exp (Warsz) 53(3):199-206.

Ellmark, S. H., Dusting, G. J., Fui, M. N., Guzzo-Pernell, N., and Drummond, G. R., 2005, The contribution of Nox4 to NADPH oxidase activity in mouse vascular smooth muscle, Cardiovasc Res 65(2):495-504.

Fink, B., Dikalov, S., and Bassenge, E., 2000, A new approach for extracellular spin trapping of nitroglycerin-induced superoxide radicals both in vitro and in vivo, Free Radic Biol Med 28(1):121-8.

Fisher, J. W., 1997, Erythropoietin: physiologic and pharmacologic aspects, Proc Soc Exp Biol Med 216(3):358-69.

Fleming, I., Michaelis, U. R., Bredenkotter, D., Fisslthaler, B., Dehghani, F., Brandes, R. P., and Busse, R., 2001, Endothelium-derived hyperpolarizing factor synthase (Cytochrome P450 2C9) is a functionally significant source of reactive oxygen species in coronary arteries, Circ Res 88(1):44-51.

Foreman, J., Demidchik, V., Bothwell, J. H., Mylona, P., Miedema, H., Torres, M. A., Linstead, P., Costa, S., Brownlee, C., Jones, J. D., Davies, J. M., and Dolan, L., 2003, Reactive oxygen species produced by NADPH oxidase regulate plant cell growth, Nature 422(6930):442-6.

Forman, H. J., and Torres, M., 2001, Signaling by the respiratory burst in macrophages, IUBMB Life 51(6):365-71.

Forman, H. J., and Torres, M., 2002, Reactive oxygen species and cell signaling: respiratory burst in macrophage signaling, Am J Respir Crit Care Med 166(12 Pt 2):S4-8. 
Frank, G. D., Eguchi, S., Yamakawa, T., Tanaka, S., Inagami, T., and Motley, E. D., 2000, Involvement of reactive oxygen species in the activation of tyrosine kinase and extracellular signal-regulated kinase by angiotensin II, Endocrinology 141(9):31206.

Fresquet, F., Pourageaud, F., Leblais, V., Brandes, R. P., Savineau, J. P., Marthan, R., and Muller, B., 2006, Role of reactive oxygen species and gp91phox in endothelial dysfunction of pulmonary arteries induced by chronic hypoxia, $\mathrm{Br} J$ Pharmacol 148(5):714-23.

Gamaley, I. A., and Klyubin, I. V., 1999, Roles of reactive oxygen species: signaling and regulation of cellular functions, Int Rev Cytol 188:203-55.

Geiszt, M., 2006, NADPH oxidases: new kids on the block, Cardiovasc Res 71(2):289-99.

Geiszt, M., and Leto, T. L., 2004, The Nox family of NAD(P)H oxidases: host defense and beyond, J Biol Chem 279(50):51715-8.

Goyal, P., Weissmann, N., Grimminger, F., Hegel, C., Bader, L., Rose, F., Fink, L., Ghofrani, H. A., Schermuly, R. T., Schmidt, H. H., Seeger, W., and Hanze, J., 2004, Upregulation of NAD(P)H oxidase 1 in hypoxia activates hypoxia-inducible factor 1 via increase in reactive oxygen species, Free Radic Biol Med 36(10):127988.

Griendling, K. K., Ushio-Fukai, M., Lassegue, B., and Alexander, R. W., 1997, Angiotensin II signaling in vascular smooth muscle. New concepts, Hypertension 29(1 Pt 2):366-73.

Griguer, C. E., Oliva, C. R., Kelley, E. E., Giles, G. I., Lancaster, J. R., Jr., and Gillespie, G. Y., 2006, Xanthine oxidase-dependent regulation of hypoxia-inducible factor in cancer cells, Cancer Res 66(4):2257-63.

Grimminger, F., Spriestersbach, R., Weissmann, N., Walmrath, D., and Seeger, W., 1995a, Nitric oxide generation and hypoxic vasoconstriction in buffer-perfused rabbit lungs, J Appl Physiol 78(4):1509-15.

Grimminger, F., Weissmann, N., Spriestersbach, R., Becker, E., Rosseau, S., and Seeger, W., 1995b, Effects of NADPH oxidase inhibitors on hypoxic vasoconstriction in buffer-perfused rabbit lungs, Am J Physiol 268(5 Pt 1):L747-52.

Gupte, S. A., and Wolin, M. S., 2006, Hypoxia promotes relaxation of bovine coronary arteries through lowering cytosolic NADPH, Am J Physiol Heart Circ Physiol 290(6):H2228-38.

Hampl, V., Cornfield, D. N., Cowan, N. J., and Archer, S. L., 1995, Hypoxia potentiates nitric oxide synthesis and transiently increases cytosolic calcium levels in pulmonary artery endothelial cells, Eur Respir J 8(4):515-22.

Harrison, D., Griendling, K. K., Landmesser, U., Hornig, B., and Drexler, H., 2003, Role of oxidative stress in atherosclerosis, Am J Cardiol 91(3A):7A-11A.

Hartell, M. G., Borzone, G., Clanton, T. L., and Berliner, L. J., 1994, Detection of free radicals in blood by electron spin resonance in a model of respiratory failure in the rat, Free Radic Biol Med 17(5):467-72.

Hogg, J. C., 2001, Chronic obstructive pulmonary disease: an overview of pathology and pathogenesis, 234:4-19. 
Hohler, B., Holzapfel, B., and Kummer, W., 2000, NADPH oxidase subunits and superoxide production in porcine pulmonary artery endothelial cells, Histochem Cell Biol 114(1):29-37.

Hool, L. C., Di Maria, C. A., Viola, H. M., and Arthur, P. G., 2005, Role of NAD(P)H oxidase in the regulation of cardiac L-type $\mathrm{Ca} 2+$ channel function during acute hypoxia, Cardiovasc Res 67(4):624-35.

Humbert, M., Morrell, N. W., Archer, S. L., Stenmark, K. R., MacLean, M. R., Lang, I. M., Christman, B. W., Weir, E. K., Eickelberg, O., Voelkel, N. F., and Rabinovitch, M., 2004, Cellular and molecular pathobiology of pulmonary arterial hypertension, $J$ Am Coll Cardiol 43(12 Suppl S):13S-24S.

Irani, K., 2000, Oxidant signaling in vascular cell growth, death, and survival : a review of the roles of reactive oxygen species in smooth muscle and endothelial cell mitogenic and apoptotic signaling, Circ Res 87(3):179-83.

IUPAC, 2006, IUPAC Compendium of Chemical Terminology, Transformed and rewritten from PDF version (entry http://www.iupac.org/goldbook/S05878.pdf) by: Miloslav Nic, Jiri Jirat, Bedrich Kosata, ICT Prague, Czech Republic.

Jeffery, T. K., and Morrell, N. W., 2002, Molecular and cellular basis of pulmonary vascular remodeling in pulmonary hypertension, Prog Cardiovasc Dis 45(3): 173202.

Jin, N., Packer, C. S., and Rhoades, R. A., 1992, Pulmonary arterial hypoxic contraction: signal transduction, Am J Physiol 263(1 Pt 1):L73-8.

Jones, R. D., Hancock, J. T., and Morice, A. H., 2000, NADPH oxidase: a universal oxygen sensor?, Free Radic Biol Med 29(5):416-24.

Jones, R. D., and Morice, A. H., 2000, Hydrogen peroxide--an intracellular signal in the pulmonary circulation: involvement in hypoxic pulmonary vasoconstriction, Pharmacol Ther 88(2):153-61.

Kadiiska, M. B., Hanna, P. M., and Mason, R. P., 1993, In vivo ESR spin trapping evidence for hydroxyl radical-mediated toxicity of paraquat and copper in rats, Toxicol Appl Pharmacol 123(2):187-92.

Kadiiska, M. B., and Mason, R. P., 2002, In vivo copper-mediated free radical production: an ESR spin-trapping study, Spectrochim Acta A Mol Biomol Spectrosc 58(6):1227-39.

Keller, A., Mohamed, A., Drose, S., Brandt, U., Fleming, I., and Brandes, R. P., 2004, Analysis of dichlorodihydrofluorescein and dihydrocalcein as probes for the detection of intracellular reactive oxygen species, Free Radic Res 38(12):1257-67.

Kelley, E. E., Hock, T., Khoo, N. K., Richardson, G. R., Johnson, K. K., Powell, P. C., Giles, G. I., Agarwal, A., Lancaster, J. R., Jr., and Tarpey, M. M., 2006, Moderate hypoxia induces xanthine oxidoreductase activity in arterial endothelial cells, Free Radic Biol Med 40(6):952-9.

Kimura, H., Sawada, T., Oshima, S., Kozawa, K., Ishioka, T., and Kato, M., 2005, Toxicity and roles of reactive oxygen species, Curr Drug Targets Inflamm Allergy 4(4):489-95.

Kinnula, V. L., 2005, Production and degradation of oxygen metabolites during inflammatory states in the human lung, Curr Drug Targets Inflamm Allergy 4(4):465-70. 
Kitada, M., Koya, D., Sugimoto, T., Isono, M., Araki, S., Kashiwagi, A., and Haneda, M., 2003, Translocation of glomerular p47phox and p67phox by protein kinase C-beta activation is required for oxidative stress in diabetic nephropathy, Diabetes 52(10):2603-14.

Klinke, R., and Silbernagl, S., 2003, Lehrbuch der Physiologie, Georg Thieme Verlag, Stuttgart.

Kummer, W., and Yamamoto, Y., 2002, Cellular distribution of oxygen sensor candidatesoxidases, cytochromes, $\mathrm{K}+$-channels--in the carotid body, Microsc Res Tech 59(3):234-42.

Kuppusamy, P., and Zweier, J. L., 1989, Characterization of free radical generation by xanthine oxidase. Evidence for hydroxyl radical generation, J Biol Chem 264(17):9880-4.

Kuzkaya, N., Weissmann, N., Harrison, D. G., and Dikalov, S., 2003, Interactions of peroxynitrite, tetrahydrobiopterin, ascorbic acid, and thiols: implications for uncoupling endothelial nitric-oxide synthase, J Biol Chem 278(25):22546-54.

Kuzkaya, N., Weissmann, N., Harrison, D. G., and Dikalov, S., 2005, Interactions of peroxynitrite with uric acid in the presence of ascorbate and thiols: implications for uncoupling endothelial nitric oxide synthase, Biochem Pharmacol 70(3):343-54.

Laloi, C., Apel, K., and Danon, A., 2004, Reactive oxygen signalling: the latest news, Curr Opin Plant Biol 7(3):323-8.

Lambeth, J. D., 2002, Nox/Duox family of nicotinamide adenine dinucleotide (phosphate) oxidases, Curr Opin Hematol 9(1):11-7.

Lambeth, J. D., 2004, NOX enzymes and the biology of reactive oxygen, Nat Rev Immunol 4(3):181-9.

Landmesser, U., Dikalov, S., Price, S. R., McCann, L., Fukai, T., Holland, S. M., Mitch, W. E., and Harrison, D. G., 2003, Oxidation of tetrahydrobiopterin leads to uncoupling of endothelial cell nitric oxide synthase in hypertension, $J$ Clin Invest 111(8):1201-9.

Lassegue, B., and Clempus, R. E., 2003, Vascular NAD(P)H oxidases: specific features, expression, and regulation, Am J Physiol Regul Integr Comp Physiol 285(2):R27797.

Lassegue, B., and Griendling, K. K., 2004, Reactive oxygen species in hypertension; An update, Am J Hypertens 17(9):852-60.

Lee, H. S., Son, S. M., Kim, Y. K., Hong, K. W., and Kim, C. D., 2003, NAD(P)H oxidase participates in the signaling events in high glucose-induced proliferation of vascular smooth muscle cells, Life Sci 72(24):2719-30.

Leto, T. L., and Geiszt, M., 2006, Role of Nox family NADPH oxidases in host defense, Antioxid Redox Signal 8(9-10):1549-61.

Li, J. M., and Shah, A. M., 2002, Intracellular localization and preassembly of the NADPH oxidase complex in cultured endothelial cells, J Biol Chem 277(22):19952-60.

Li, N., Yi, F. X., Spurrier, J. L., Bobrowitz, C. A., and Zou, A. P., 2002, Production of superoxide through NADH oxidase in thick ascending limb of Henle's loop in rat kidney, Am J Physiol Renal Physiol 282(6):F1111-9. 
Li, Y., and Trush, M. A., 1998, Diphenyleneiodonium, an NAD(P)H oxidase inhibitor, also potently inhibits mitochondrial reactive oxygen species production, Biochem Biophys Res Commun 253(2):295-9.

Liu, J. Q., Erbynn, E. M., and Folz, R. J., 2005, Chronic hypoxia-enhanced murine pulmonary vasoconstriction: role of superoxide and gp91phox, Chest $\mathbf{1 2 8}(6$ Suppl):594S-596S.

Liu, J. Q., Sham, J. S., Shimoda, L. A., Kuppusamy, P., and Sylvester, J. T., 2003, Hypoxic constriction and reactive oxygen species in porcine distal pulmonary arteries, Am J Physiol Lung Cell Mol Physiol 285(2):L322-33.

Liu, J. Q., Zelko, I. N., Erbynn, E. M., Sham, J. S., and Folz, R. J., 2006, Hypoxic pulmonary hypertension: role of superoxide and NADPH oxidase (gp91phox), Am J Physiol Lung Cell Mol Physiol 290(1):L2-10.

Liu, J. Q., Zelko, I. N., and Folz, R. J., 2004, Reoxygenation-induced constriction in murine coronary arteries: the role of endothelial NADPH oxidase (gp91phox) and intracellular superoxide, J Biol Chem 279(23):24493-7.

Liu, Y., Fiskum, G., and Schubert, D., 2002, Generation of reactive oxygen species by the mitochondrial electron transport chain, J Neurochem 80(5):780-7.

Lopez-Barneo, J., del Toro, R., Levitsky, K. L., Chiara, M. D., and Ortega-Saenz, P., 2004, Regulation of oxygen sensing by ion channels, J Appl Physiol 96(3):1187-95; discussion 1170-2.

Lopez-Barneo, J., Ortega-Saenz, P., Piruat, J. I., and Garcia-Fernandez, M., 2006, Oxygensensing by ion channels and mitochondrial function in carotid body glomus cells, Novartis Found Symp 272:54-64; discussion 64-72, 131-40.

Madden, J. A., Keller, P. A., and Kleinman, J. G., 2000, Changes in smooth muscle cell pH during hypoxic pulmonary vasoconstriction: a possible role for ion transporters, Physiol Res 49(5):561-6.

Maeda, K., Yasunari, K., Sato, E. F., Yoshikawa, J., and Inoue, M., 2003, Activation of protein kinase $\mathrm{C}$ and nicotinamide adenine dinucleotide phosphate oxidase in leukocytes of spontaneously hypertensive rats, Hypertens Res 26(12):999-1006.

Mandegar, M., Fung, Y. C., Huang, W., Remillard, C. V., Rubin, L. J., and Yuan, J. X., 2004, Cellular and molecular mechanisms of pulmonary vascular remodeling: role in the development of pulmonary hypertension, Microvasc Res 68(2):75-103.

Manoury, B., Nenan, S., Leclerc, O., Guenon, I., Boichot, E., Planquois, J. M., Bertrand, C. P., and Lagente, V., 2005, The absence of reactive oxygen species production protects mice against bleomycin-induced pulmonary fibrosis, Respir Res 6(1):11.

Maranchie, J. K., and Zhan, Y., 2005, Nox4 is critical for hypoxia-inducible factor 2-alpha transcriptional activity in von Hippel-Lindau-deficient renal cell carcinoma, Cancer Res 65(20):9190-3.

Martins Chaves, M., Prates Rodrigues, A. L., Pereira dos Reis, A., Gerzstein, N. C., and Nogueira-Machado, J. A., 2002, Correlation between NADPH oxidase and protein kinase $\mathrm{C}$ in the ROS production by human granulocytes related to age, Gerontology 48(6):354-9.

Mayer-Kuckuk, T., 1977, Atomphysik, Teubner-Verlag, Stuttgart.

McNally, J. S., Davis, M. E., Giddens, D. P., Saha, A., Hwang, J., Dikalov, S., Jo, H., and Harrison, D. G., 2003, Role of xanthine oxidoreductase and NAD(P)H oxidase in 
endothelial superoxide production in response to oscillatory shear stress, $A m J$ Physiol Heart Circ Physiol 285(6):H2290-7.

Michelakis, E. D., Archer, S. L., and Weir, E. K., 1995, Acute hypoxic pulmonary vasoconstriction: a model of oxygen sensing, Physiol Res 44(6):361-7.

Michelakis, E. D., Rebeyka, I., Wu, X., Nsair, A., Thebaud, B., Hashimoto, K., Dyck, J. R., Haromy, A., Harry, G., Barr, A., and Archer, S. L., 2002, O2 sensing in the human ductus arteriosus: regulation of voltage-gated $\mathrm{K}+$ channels in smooth muscle cells by a mitochondrial redox sensor, Circ Res 91(6):478-86.

Michelakis, E. D., Thebaud, B., Weir, E. K., and Archer, S. L., 2004, Hypoxic pulmonary vasoconstriction: redox regulation of $\mathrm{O} 2$-sensitive $\mathrm{K}+$ channels by a mitochondrial O2-sensor in resistance artery smooth muscle cells, J Mol Cell Cardiol 37(6):111936.

Mochizuki, T., Furuta, S., Mitsushita, J., Shang, W. H., Ito, M., Yokoo, Y., Yamaura, M., Ishizone, S., Nakayama, J., Konagai, A., Hirose, K., Kiyosawa, K., and Kamata, T., 2006, Inhibition of NADPH oxidase 4 activates apoptosis via the AKT/apoptosis signal-regulating kinase 1 pathway in pancreatic cancer PANC-1 cells, Oncogene.

Moslen, M. T., 1994, Reactive oxygen species in normal physiology, cell injury and phagocytosis, Adv Exp Med Biol 366:17-27.

Moudgil, R., Michelakis, E. D., and Archer, S. L., 2005, Hypoxic pulmonary vasoconstriction, J Appl Physiol 98(1):390-403.

Murphy, P. G., Myers, D. S., Webster, N. R., Jones, J. G., and Davies, M. J., 1991, Direct detection of free radical generation in an in vivo model of acute lung injury, Free Radic Res Commun 15(3):167-76.

Nishiyama, A., Yao, L., Nagai, Y., Miyata, K., Yoshizumi, M., Kagami, S., Kondo, S., Kiyomoto, H., Shokoji, T., Kimura, S., Kohno, M., and Abe, Y., 2004, Possible contributions of reactive oxygen species and mitogen-activated protein kinase to renal injury in aldosterone/salt-induced hypertensive rats, Hypertension 43(4):8418.

Orosz, Z., Csiszar, A., Labinskyy, N., Smith, K., Kaminski, P. M., Ferdinandy, P., Wolin, M. S., Rivera, A., and Ungvari, Z., 2007, Cigarette smoke-induced proinflammatory alterations in the endothelial phenotype: role of $\mathrm{NAD}(\mathrm{P}) \mathrm{H}$ oxidase activation, Am J Physiol Heart Circ Physiol 292:H130 - H139.

Peacock, A. J., 1999, Primary pulmonary hypertension, Thorax 54(12):1107-18.

Porwol, T., Ehleben, W., Brand, V., and Acker, H., 2001, Tissue oxygen sensor function of NADPH oxidase isoforms, an unusual cytochrome aa3 and reactive oxygen species, Respir Physiol 128(3):331-48.

Post, J. M., Hume, J. R., Archer, S. L., and Weir, E. K., 1992, Direct role for potassium channel inhibition in hypoxic pulmonary vasoconstriction, Am J Physiol 262(4 Pt 1):C882-90.

Potashkin, J. A., and Meredith, G. E., 2006, The role of oxidative stress in the dysregulation of gene expression and protein metabolism in neurodegenerative disease, Antioxid Redox Signal 8(1-2):144-51.

Rahman, I., and Adcock, I. M., 2006, Oxidative stress and redox regulation of lung inflammation in COPD, Eur Respir J 28:219 - 242. 
Rhyu, D. Y., Yang, Y., Ha, H., Lee, G. T., Song, J. S., Uh, S. T., and Lee, H. B., 2005, Role of reactive oxygen species in TGF-betal-induced mitogen-activated protein kinase activation and epithelial-mesenchymal transition in renal tubular epithelial cells, J Am Soc Nephrol 16(3):667-75.

Robertson, T. P., Dipp, M., Ward, J. P., Aaronson, P. I., and Evans, A. M., 2000, Inhibition of sustained hypoxic vasoconstriction by Y-27632 in isolated intrapulmonary arteries and perfused lung of the rat, Br J Pharmacol 131(1):5-9.

Rojas, A., Figueroa, H., Morales, M. A., and Re, L., 2006, Facing up the ROS labyrinth-Where to go?, Curr Vasc Pharmacol 4(3):277-89.

Rose, F., Grimminger, F., Appel, J., Heller, M., Pies, V., Weissmann, N., Fink, L., Schmidt, S., Krick, S., Camenisch, G., Gassmann, M., Seeger, W., and Hanze, J., 2002, Hypoxic pulmonary artery fibroblasts trigger proliferation of vascular smooth muscle cells: role of hypoxia-inducible transcription factors, Faseb $J$ 16(12):16601.

Roy, A., Rozanov, C., Mokashi, A., Daudu, P., Al-mehdi, A. B., Shams, H., and Lahiri, S., 2000, Mice lacking in gp91 phox subunit of NAD(P)H oxidase showed glomus cell $[\mathrm{Ca}(2+)](\mathrm{i})$ and respiratory responses to hypoxia, Brain Res 872(1-2):188-93.

Sanders, K. A., Sundar, K. M., He, L., Dinger, B., Fidone, S., and Hoidal, J. R., 2002, Role of components of the phagocytic NADPH oxidase in oxygen sensing, $J \mathrm{Appl}$ Physiol 93(4):1357-64.

Satoh, M., Fujimoto, S., Haruna, Y., Arakawa, S., Horike, H., Komai, N., Sasaki, T., Tsujioka, K., Makino, H., and Kashihara, N., 2005, NAD(P)H oxidase and uncoupled nitric oxide synthase are major sources of glomerular superoxide in rats with experimental diabetic nephropathy, Am J Physiol Renal Physiol 288(6):F1144-52.

Sauer, H., Wartenberg, M., and Hescheler, J., 2001, Reactive oxygen species as intracellular messengers during cell growth and differentiation, Cell Physiol Biochem 11(4):173-86.

Scheffler, K., and Stegmann, H. G., 1970, Elektronenspinresonanz - Grundlagen und Anwendungen in der organischen Chemie, Springer-Verlag, Berlin, Heidelberg, New York.

Schumacker, P. T., 2003, Current paradigms in cellular oxygen sensing, Adv Exp Med Biol 543:57-71.

Schwenke, D. O., Pearson, J. T., Mori, H., and Shirai, M., 2006, Long-term monitoring of pulmonary arterial pressure in conscious, unrestrained mice, J Pharmacol Toxicol Methods 53(3):277-83.

Semenza, G. L., 1994, Regulation of erythropoietin production. New insights into molecular mechanisms of oxygen homeostasis, Hematol Oncol Clin North Am 8(5):863-84.

Seno, T., Inoue, N., Gao, D., Okuda, M., Sumi, Y., Matsui, K., Yamada, S., Hirata, K. I., Kawashima, S., Tawa, R., Imajoh-Ohmi, S., Sakurai, H., and Yokoyama, M., 2001, Involvement of NADH/NADPH oxidase in human platelet ROS production, Thromb Res 103(5):399-409.

Sham, J. S., 2002, Hypoxic pulmonary vasoconstriction: ups and downs of reactive oxygen species, Circ Res 91(8):649-51. 
Shiose, A., Kuroda, J., Tsuruya, K., Hirai, M., Hirakata, H., Naito, S., Hattori, M., Sakaki, Y., and Sumimoto, H., 2001, A novel superoxide-producing NAD(P)H oxidase in kidney, J Biol Chem 276(2):1417-23.

Short, M. D., Fox, S. M., Lam, C. F., Stenmark, K. R., and Das, M., 2006, Protein kinase Czeta attenuates hypoxia-induced proliferation of fibroblasts by regulating MAP kinase phosphatase-1 expression, Mol Biol Cell 17(4):1995-2008.

Sies, H., and de Groot, H., 1992, Role of reactive oxygen species in cell toxicity, Toxicol Lett 64-65 Spec No:547-51.

Sim, S., Yong, T. S., Park, S. J., Im, K. I., Kong, Y., Ryu, J. S., Min, D. Y., and Shin, M. H., 2005, NADPH oxidase-derived reactive oxygen species-mediated activation of ERK $1 / 2$ is required for apoptosis of human neutrophils induced by Entamoeba histolytica, J Immunol 174(7):4279-88.

Soccio, M., Toniato, E., Evangelista, V., Carluccio, M., and De Caterina, R., 2005, Oxidative stress and cardiovascular risk: the role of vascular $\mathrm{NAD}(\mathrm{P}) \mathrm{H}$ oxidase and its genetic variants, Eur J Clin Invest 35(5):305-14.

Sorescu, D., Somers, M. J., Lassegue, B., Grant, S., Harrison, D. G., and Griendling, K. K., 2001, Electron spin resonance characterization of the NAD(P)H oxidase in vascular smooth muscle cells, Free Radic Biol Med 30(6):603-12.

Souchard, J. P., Barbacanne, M. A., Margeat, E., Maret, A., Nepveu, F., and Arnal, J. F., 1998, Electron spin resonance detection of extracellular superoxide anion released by cultured endothelial cells, Free Radic Res 29(5):441-9.

Spiekermann, S., Landmesser, U., Dikalov, S., Bredt, M., Gamez, G., Tatge, H., Reepschlager, N., Hornig, B., Drexler, H., and Harrison, D. G., 2003, Electron spin resonance characterization of vascular xanthine and $\mathrm{NAD}(\mathrm{P}) \mathrm{H}$ oxidase activity in patients with coronary artery disease: relation to endothelium-dependent vasodilation, Circulation 107(10):1383-9.

Spieß, H. W., 1998, Einführung in die ESR-Spektroskopie, Spieß, H.W., Mainz.

Stenmark, K. R., Davie, N., Frid, M., Gerasimovskaya, E., and Das, M., 2006, Role of the adventitia in pulmonary vascular remodeling, Physiology (Bethesda) 21:134-45.

Stenmark, K. R., Gerasimovskaya, E., Nemenoff, R. A., and Das, M., 2002, Hypoxic activation of adventitial fibroblasts: role in vascular remodeling, Chest $\mathbf{1 2 2}(6$ Suppl):326S-334S.

Storz, G., Tartaglia, L. A., and Ames, B. N., 1990, Transcriptional regulator of oxidative stress-inducible genes: direct activation by oxidation, Science 248(4952):189-94.

Suh, Y. A., Arnold, R. S., Lassegue, B., Shi, J., Xu, X., Sorescu, D., Chung, A. B., Griendling, K. K., and Lambeth, J. D., 1999, Cell transformation by the superoxide-generating oxidase Mox1, Nature 401(6748):79-82.

Sumimoto, H., Miyano, K., and Takeya, R., 2005, Molecular composition and regulation of the Nox family NAD(P)H oxidases, Biochem Biophys Res Commun 338(1):67786.

Sylvester, J. T., 2001, Hypoxic pulmonary vasoconstriction: a radical view, Circ Res 88(12):1228-30.

Sylvester, J. T., Gordon, J. B., Malamet, R. L., and Wetzel, R. C., 1985, Prostaglandins and estradiol-induced attenuation of hypoxic pulmonary vasoconstriction, Chest $\mathbf{8 8}(4$ Suppl):252S-254S. 
Sylvester, J. T., and McGowan, C., 1978, The effects of agents that bind to cytochrome P450 on hypoxic pulmonary vasoconstriction, $\operatorname{Circ} \operatorname{Res} 43(3)$ :429-37.

Szanto, I., Rubbia-Brandt, L., Kiss, P., Steger, K., Banfi, B., Kovari, E., Herrmann, F., Hadengue, A., and Krause, K. H., 2005, Expression of NOX1, a superoxidegenerating NADPH oxidase, in colon cancer and inflammatory bowel disease, $J$ Pathol 207(2):164-76.

Takeya, R., Ueno, N., and Sumimoto, H., 2006, Regulation of superoxide-producing NADPH oxidases in nonphagocytic cells, Methods Enzymol 406:456-68.

Talior, I., Tennenbaum, T., Kuroki, T., and Eldar-Finkelman, H., 2005, PKC-deltadependent activation of oxidative stress in adipocytes of obese and insulin-resistant mice: role for NADPH oxidase, Am J Physiol Endocrinol Metab 288(2):E405-11.

Thompson, J. S., Jones, R. D., Rogers, T. K., Hancock, J., and Morice, A. H., 1998, Inhibition of hypoxic pulmonary vasoconstriction in isolated rat pulmonary arteries by diphenyleneiodonium (DPI), Pulm Pharmacol Ther 11(1):71-5.

Touyz, R. M., and Schiffrin, E. L., 2004, Reactive oxygen species in vascular biology: implications in hypertension, Histochem Cell Biol 122(4):339-52.

Vaziri, N. D., and Ni, Z., 2005, Expression of NOX-I, gp91phox, p47phox and P67phox in the aorta segments above and below coarctation, Biochim Biophys Acta 1723(13):321-7.

Vejrazka, M., Micek, R., and Stipek, S., 2005, Apocynin inhibits NADPH oxidase in phagocytes but stimulates ROS production in non-phagocytic cells, Biochim Biophys Acta 1722(2):143-7.

von Euler, U. S., and Liljestrand, G., 1946, Observations on the pulmonary arterial blood pressure in the cat, Acta Physiol Scand 12:310-20.

Wang, Y. H., Bai, C. X., Hong, Q. Y., and Chen, J., 2003, Anti-inflammatory effect of methoxyphenamine compound in rat model of chronic obstructive pulmonary disease, 24(12):1324-1327.

Ward, J. P., Knock, G. A., Snetkov, V. A., and Aaronson, P. I., 2004a, Protein kinases in vascular smooth muscle tone--role in the pulmonary vasculature and hypoxic pulmonary vasoconstriction, Pharmacol Ther 104(3):207-31.

Ward, J. P., Snetkov, V. A., and Aaronson, P. I., 2004b, Calcium, mitochondria and oxygen sensing in the pulmonary circulation, Cell Calcium 36(3-4):209-20.

Waypa, G. B., Chandel, N. S., and Schumacker, P. T., 2001, Model for hypoxic pulmonary vasoconstriction involving mitochondrial oxygen sensing, Circ Res 88(12):125966.

Waypa, G. B., Guzy, R., Mungai, P. T., Mack, M. M., Marks, J. D., Roe, M. W., and Schumacker, P. T., 2006, Increases in Mitochondrial Reactive Oxygen Species Trigger Hypoxia-Induced Calcium Responses in Pulmonary Artery Smooth Muscle Cells, Circ Res.

Waypa, G. B., Marks, J. D., Mack, M. M., Boriboun, C., Mungai, P. T., and Schumacker, P. T., 2002, Mitochondrial reactive oxygen species trigger calcium increases during hypoxia in pulmonary arterial myocytes, Circ Res 91(8):719-26.

Waypa, G. B., and Schumacker, P. T., 2002, O(2) sensing in hypoxic pulmonary vasoconstriction: the mitochondrial door re-opens, Respir Physiol Neurobiol 132(1):81-91. 
Waypa, G. B., and Schumacker, P. T., 2005, Hypoxic pulmonary vasoconstriction: redox events in oxygen sensing, $J$ Appl Physiol 98(1):404-14.

Waypa, G. B., and Schumacker, P. T., 2006, Role for mitochondrial reactive oxygen species in hypoxic pulmonary vasoconstriction, Novartis Found Symp 272:176-92; discussion 192-5, 214-7.

Weigand, L., Foxson, J., Wang, J., Shimoda, L. A., and Sylvester, J. T., 2005, Inhibition of hypoxic pulmonary vasoconstriction by antagonists of store-operated $\mathrm{Ca} 2+$ and nonselective cation channels, Am J Physiol Lung Cell Mol Physiol 289(1):L5-L13.

Weil, J. A., Bolton, J. R., and Wertz, J. E., 1994, Electron paramagnetic resonance: elementary theory and practical applications, John Wiley \& Sons, Inc., New York, Chichester, Brisbane, Toronto, Singapore.

Weir, E. K., and Archer, S. L., 2006, HPV is/is not mediated by increased production of reactive oxygen species, $J$ Appl Physiol.

Weir, E. K., Hong, Z., Porter, V. A., and Reeve, H. L., 2002, Redox signaling in oxygen sensing by vessels, Respir Physiol Neurobiol 132(1):121-30.

Weir, E. K., Wyatt, C. N., Reeve, H. L., Huang, J., Archer, S. L., and Peers, C., 1994, Diphenyleneiodonium inhibits both potassium and calcium currents in isolated pulmonary artery smooth muscle cells, J Appl Physiol 76(6):2611-5.

Weissmann, N., Akkayagil, E., Quanz, K., Schermuly, R. T., Ghofrani, H. A., Fink, L., Hanze, J., Rose, F., Seeger, W., and Grimminger, F., 2004, Basic features of hypoxic pulmonary vasoconstriction in mice, Respir Physiol Neurobiol 139(2):191202.

Weissmann, N., Dietrich, A., Fuchs, B., Kalwa, H., Ay, M., Dumitrascu, R., Olschewski, A., Storch, U., Schnitzler, M., Ghofrani, H. A., Schermuly, R. T., Pinkenburg, O., Seeger, W., Grimminger, F., and Gudermann, T., 2006a, Classical transient receptor potential channel 6 (TRPC6) is essential for hypoxic pulmonary vasoconstriction and alveolar gas exchange, 103(50):19093-19098.

Weissmann, N., Ebert, N., Ahrens, M., Ghofrani, H. A., Schermuly, R. T., Hanze, J., Fink, L., Rose, F., Conzen, J., Seeger, W., and Grimminger, F., 2003a, Effects of mitochondrial inhibitors and uncouplers on hypoxic vasoconstriction in rabbit lungs, Am J Respir Cell Mol Biol 29(6):721-32.

Weissmann, N., Grimminger, F., Olschewski, A., and Seeger, W., 2001a, Hypoxic pulmonary vasoconstriction: a multifactorial response?, Am J Physiol Lung Cell Mol Physiol 281(2):L314-7.

Weissmann, N., Grimminger, F., Walmrath, D., and Seeger, W., 1995, Hypoxic vasoconstriction in buffer-perfused rabbit lungs, Respir Physiol 100(2):159-69.

Weissmann, N., Kuzkaya, N., Fuchs, B., Tiyerili, V., Schafer, R. U., Schutte, H., Ghofrani, H. A., Schermuly, R. T., Schudt, C., Sydykov, A., Egemnazarow, B., Seeger, W., and Grimminger, F., 2005, Detection of reactive oxygen species in isolated, perfused lungs by electron spin resonance spectroscopy, Respir Res 6(1):86.

Weissmann, N., Nollen, M., Gerigk, B., Ardeschir Ghofrani, H., Schermuly, R. T., Gunther, A., Quanz, K., Fink, L., Hanze, J., Rose, F., Seeger, W., and Grimminger, F., 2003b, Downregulation of hypoxic vasoconstriction by chronic hypoxia in rabbits: effects of nitric oxide, Am J Physiol Heart Circ Physiol 284(3):H931-8. 
Weissmann, N., Schermuly, R. T., Ghofrani, H. A., Hanze, J., Goyal, P., Grimminger, F., and Seeger, W., 2006b, Hypoxic pulmonary vasoconstriction--triggered by an increase in reactive oxygen species?, Novartis Found Symp 272:196-208; discussion 208-17.

Weissmann, N., Sommer, N., Schermuly, R. T., Ghofrani, H. A., Seeger, W., and Grimminger, F., 2006c, Oxygen sensors in hypoxic pulmonary vasoconstriction, Cardiovasc Res.

Weissmann, N., Tadic, A., Hanze, J., Rose, F., Winterhalder, S., Nollen, M., Schermuly, R. T., Ghofrani, H. A., Seeger, W., and Grimminger, F., 2000, Hypoxic vasoconstriction in intact lungs: a role for NADPH oxidase-derived $\mathrm{H}(2) \mathrm{O}(2)$ ?, Am J Physiol Lung Cell Mol Physiol 279(4):L683-90.

Weissmann, N., Winterhalder, S., Nollen, M., Voswinckel, R., Quanz, K., Ghofrani, H. A., Schermuly, R. T., Seeger, W., and Grimminger, F., 2001b, NO and reactive oxygen species are involved in biphasic hypoxic vasoconstriction of isolated rabbit lungs, Am J Physiol Lung Cell Mol Physiol 280(4):L638-45.

Weissmann, N., Zeller, S., Schafer, R. U., Turowski, C., Ay, M., Quanz, K., Ghofrani, H. A., Schermuly, R. T., Fink, L., Seeger, W., and Grimminger, F., 2006d, Impact of mitochondria and NADPH oxidases on acute and sustained hypoxic pulmonary vasoconstriction, Am J Respir Cell Mol Biol 34(4):505-13.

Wenger, R. H., 2006, Mitochondria: oxygen sinks rather than sensors?, Med Hypotheses 66(2):380-3.

West, J. B., Dollery, C. T., and Heard, B. E., 1964, Increased vascular resistance in the lower zone of the lung caused by perivascular oedema, Lancet (189):181-3.

West, J. B., Dollery, C. T., and Heard, B. E., 1965, Increased pulmonary vascular resistance in the dependent zone of the isolated dog lung caused by perivascular edema, Circ Res 17:191-206.

Wilborn, A. M., Evers, L. B., and Canada, A. T., 1996, Oxygen toxicity to the developing lung of the mouse: role of reactive oxygen species, Pediatr Res 40(2):225-32.

Wolin, M. S., 2000, Interactions of oxidants with vascular signaling systems, Arterioscler Thromb Vasc Biol 20(6):1430-42.

Wolin, M. S., Ahmad, M., and Gupte, S. A., 2005, Oxidant and redox signaling in vascular oxygen sensing mechanisms: basic concepts, current controversies, and potential importance of cytosolic NADPH, Am J Physiol Lung Cell Mol Physiol 289(2):L159-73.

Yamamoto, Y., Konig, P., Henrich, M., Dedio, J., and Kummer, W., 2006, Hypoxia induces production of nitric oxide and reactive oxygen species in glomus cells of rat carotid body, Cell Tissue Res 325(1):3-11.

Yao, X., and Garland, C. J., 2005, Recent developments in vascular endothelial cell transient receptor potential channels, 97(9):853-863.

Yoshimoto, T., Gochou, N., Fukai, N., Sugiyama, T., Shichiri, M., and Hirata, Y., 2005, Adrenomedullin inhibits angiotensin II-induced oxidative stress and gene expression in rat endothelial cells, Hypertens Res 28(2):165-72.

Yu, Y., Fantozzi, I., Remillard, C. V., Landsberg, J. W., Kunichika, N., Platoshyn, O., Tigno, D. D., Thistlethwaite, P. A., Rubin, L. J., and Yuan, J. X., 2004, Enhanced 
expression of transient receptor potential channels in idiopathic pulmonary arterial hypertension, 101(38): 13861-13866.

Yuan, S. H., Dai, D. Z., Guan, L., Dai, Y., and Ji, M., 2006, Cpu0507, an endothelin receptor antagonist, improves rat hypoxic pulmonary artery hypertension and constriction in vivo and in vitro, Clin Exp Pharmacol Physiol 33(11):1066-72.

Yuan, X. J., Tod, M. L., Rubin, L. J., and Blaustein, M. P., 1990, Contrasting effects of hypoxia on tension in rat pulmonary and mesenteric arteries, Am J Physiol 259(2 Pt 2):H281-9.

Zekry, D., Epperson, T. K., and Krause, K. H., 2003, A role for NOX NADPH oxidases in Alzheimer's disease and other types of dementia?, IUBMB Life 55(6):307-13.

Zhang, J. W., Liu, Y., Li, W., Hao, D. C., and Yang, L., 2006, Inhibitory effect of medroxyprogesterone acetate on human liver cytochrome P450 enzymes, Eur $J$ Clin Pharmacol 62(7):497-502.

Zhou, H., Chen, S., Wang, L., He, Q., and Fan, X., 2002, [Regulation of the expression of pulmonary arterial collagen by protein kinase $\mathrm{C}$ and breviscapine in chronic hypoxic rats], Zhonghua Jie He He Hu Xi Za Zhi 25(6):347-51.

Zhu, H., Jackson, T., and Bunn, H. F., 2002, Detecting and responding to hypoxia, Nephrol Dial Transplant 17 Suppl 1:3-7.

Zou, A. P., and Cowley, A. W., Jr., 2003, Reactive oxygen species and molecular regulation of renal oxygenation, Acta Physiol Scand 179(3):233-41.

Zwicker, K., Dikalov, S., Matuschka, S., Mainka, L., Hofmann, M., Khramtsov, V., and Zimmer, G., 1998, Oxygen radical generation and enzymatic properties of mitochondria in hypoxia/reoxygenation, Arzneimittelforschung 48(6):629-36. 